\title{
RELACIONES INTERNACIONALES (RRII) ENTRE ECONOMÍAS SUBTERRÁNEAS O ILÍCITAS (ESol) NARCOVIOLENTAS EN COLOMBIA Y MÉXICO Y LA INCIDENCIA DE LAS POLÍTICAS ESTATALES DE EEUU 1990-2014
}

Doctoranda: Mg. Diana Patricia Arias Henao Director de tesis: Ph.D. Daniel Cieza

Doctorado en Relaciones Internacionales Universidad Nacional de La Plata - Argentina

\section{TABLA DE CONTENIDO}

\section{CAPÍTULO I: CONSIDERACIONES METODOLÓGICAS}

1.1. Clase del Método Comparativo y sus elementos

1.2. Epistemología de la comparación

1.3. Los enfoques comparativos
a. Enfoque comparativo ideográfico
b. Enfoque comparativo interpretativo
c. Enfoque comparativo difusionista

1.4. Estudios transcontextuales
a. Estudios cros-nacionales
b. Estudios cros-culturales

1.5. Flexibilidad en la creación de conocimiento científico humano.

\section{CAPITULO II: DISCURSOS ANTINARCÓTICOS}

2.1. Narco-mediatización de las Relaciones Internacionales: investigación con variable cultural independiente.

2.2. Desinformación: metástasis del sistema metodológico en Relaciones Internacionales 


\section{CAPÍTULO III: ESTRUCTURA METODOLÓGICA}

3.1. Planteamiento del problema de investigación

3.2. Formulación de objetivos e hipótesis

3.3. Formulación de variables de investigación

\section{CAPÍTULO IV: NARCO-INSUFICIENCIA PARADIGMÁTICA}

4.1. Realismo Político

4.2. Racionalismo Político

4.3. Revolucionarismo Político: violento o pacífico

4.4. Realismo Vs Idealismo

4.5. Ciencias Vs Humanidades

4.6. Globalidad Vs Estatocentrismo

4.7. Conceptualización de la Paz

a. Idealismo

b. Liberalismo

c. Realismo

d. Estructuralismo

e. Teoría crítica y post-estructuralismo

4.8. Una teoría parcial narcoviolenta: adaptación a las escuelas de las Relaciones Internacionales y la Consolidación de narco-paradigmas

\section{CAPÍTULO V: EL HEGEMÓN Y EL SISTEMA MUNDO: ASIMETRÍAS E INFLUENCIAS JURÍDICO- POLITCAS DE LA POSGUERRA FRÍA Y EL FLORECIMIENTO DE NUEVAS AMENAZAS}

5.1 Nacionalismo de la posguerra fría -PF- después del derrumbe de la Unión Soviética

5.2. Condicionamientos de la PF a la política exterior latinoamericana

5.3. Nuevas Guerras: el caso del paramilitarismo de las AUC en Colombia

5.3.1. Factores de reclutamiento paramilitar

5.4. El condicionamiento político externo: impactos de las asimetrías marcadas por la Posguerra

5.5. Subsidiariedad de la Justicia Internacional en el Sistema Mundo

5.6. Misión del SIDH: mecanismo de promoción y protección de los DDHH

5.6.1. Comisión Interamericana de Derechos Humanos CIDH

5.6.2. Corte Interamericana de Derechos Humanos - Cort.IDH 
5.7. Hechos de la Masacre de Mapiripán Julio 15 - 20 de 1997

5.7.1. Mapiripán en el SIDH

5.7.2. Mapiripán después del SIDH

5.8. Soberanía y armonización de ordenamientos jurídicos por control de convencionalidad (CC) Beneficios de la política internacional de la Posguerra.

CAPÍTULO VI: LA LUCHA ARMADA CONTRA EL NARCOTRÁFICO EN COLOMBIA Y MÉXICO: UN ANÁLISIS A LA LUZ DEL ARTÍCULO 3 COMÚN A LOS CONVENIOS DE GINEBRA

6.1. Los narcoviolentos y el artículo 3 común

6.2. Los Convenios de Ginebra y sus Protocolos Adicionales

6.2.1. Contenido de los Convenios de Ginebra

6.2.2. Contenido del artículo 3 Común a los Convenios de Ginebra

6.3. Conflictos Armados no internacionales

6.3.1. Elementos constitutivos del conflicto internacional

6.3.2. Disturbios interiores y tensiones

6.4. Convergencia normativa: Ginebra - Haya

\section{CAPÍTULO VII: COSNTRUCCION DE NARCOIDENTIDADES EN COLOMBIA Y MEXICO}

7.1. Las narco-oportunidades

7.2. Narco-economía violenta

7.3. Narco-contextualización

7.4. La narco-cultura

7.5. Códigos Narco

7.6. Marco teórico para estudiar la narcoviolencia

7.7. La construcción de la narco-nación

7.8. Narco-identidades

7.8.1. Narco-identidad en Colombia

7.8.2. Narco-identidad en México

7.9. Narco-tendencias

7.10. La oferta de las narco-identidades

7.11. El Caribe: el punto de interconexión de la trasnacional del narcotráfico 
CAPÍTULO VIII: NARCOVIOLENCIA COMO EMPRESA SABUTERRÁNEA EN COLOMBIA Y MÉXICO: INCIDENCIAS DE LA POLÍTICA NORTEAMERICANA EN LOS ESTADOS SUPERADOS

8.1. Los Estados Superados

8.2. Debilitamiento del Estado Nación y privatización de la violencia: de Guerras Clásicas a Guerras Promiscuas

8.3. Narco-empresarios violentos que superan sujetos internacionales

8.4. Narco-violencia: un mero tipo de violencia trasnacional

\section{CAPÍTULO XIX: GRUPOS NARCOVIOLENTOS COLOMBO-MEXICANOS}

9.1. Colombia

9.2. México

9.3. Colombia y México

CAPÍTULO X: NARCOCORRUPCIÓN ESTATOCENTRISTA: ESTATOCENTRISMO MACHO Y BORRACHO

10.1. Narco-condicionantes políticos exógenos: las políticas estatales de los EEUU

10.2. Efectos narco-estadounidenses en territorio azteca

10.3. Narco-contextualización azteca

10.4. La matriz extirpada de la escindida ESol narcoviolenta: Golfo-Zetas.

10.5. La Familia de Michoacán

10.6. Impactos sociales antinarcóticos

\section{CAPÍTULO XI: NARCOVIOLENCIA EN COLOMBIA}

11.1. La narco-actividad colombiana desde la escuela contemporánea de las Relaciones Internacionales

\subsection{Los narcotraficantes}

11.3. La Oficina de Envigado: Nueva razón social del cártel de Medellín

11.4. Currículum vitae abreviado de las AUC

11.5. Narco-alianzas legitimadas o Narco-partidos políticos

11.6. Mutabilidad de las estructuras narcotraficantes

11.7. ESol narcoviolenta trasnacional 
CAPÍTULO XII: DESCONTEXTUALIZACIÓN NARCOVIOLENTA: LA NECESIDAD DE LA DESTEORIZACIÓN CLÁSICA

12.1 Narcoviolencia: un diagnostico descontextualizado

12.2. Narco-globalización - narco-glocalización: represión violenta legítima o legalización

CONCLUSIÓN

REFERENCIAS

REFERENCIAS ELECTRÓNICAS 


\section{INTRODUCCIÓN}

La vinculación entre las ESol en las RRII bilaterales entre Colombia y México, obedece a una relación antigua, por lo menos demostrada a partir de la década del 70 , entre el cartel de Sinaloa (México) y el cartel de Medellín (Colombia), y sus respectivos sucesores. Esta relación bilateral no sería posible sin el monopolio narco-violento establecido por los grupos de crimen organizado en Colombia y en México, que traducen su poderío, en especial económico, mediante la consolidación del negocio trasnacional de matriz colombo-mexicana.

Las organizaciones narco-violentas colombianas y mexicanas estructuran su accionar como una red trasnacional en el cometido de su principal objetivo: el envío de droga de Colombia a México, para luego ser introducida a EE.UU. Desde la década del 80, se sistematizó el uso de los carteles mexicanos por parte de los colombianos, como mulas o transportadores de narcóticos, en especial, por el amplio conocimiento que poseían de la frontera México/EE.UU y de las rutas internas de distribución de los EE.UU"1 .

Con el desmantelamiento de los carteles de Medellín y de Cali, los mexicanos lideraron el comercio internacional ilícito a los EEUU, a través de los cientos de micro-carteles colombianos que dieron continuidad a la narcoviolencia desplegada por los grandes capos y otra parte del negocio de las drogas pasó a manos, en la década del 90, de grupos guerrilleros y de extrema derecha como paramilitares, en sus diversos causes ${ }^{2}$, y del Cartel del Norte del Valle posteriormente. En México, a partir de los 90 se re-estructuraron los carteles de la droga.

Las Bandas Criminales - BACRIM, resultado de la supuesta desmovilización de los paramilitares a través de la Ley de Justicia y Paz, que otorgó como pena máxima 8 años de prisión a criminales de lesa humanidad, siguen funcionando en torno a "la disputa por el control del narcotráfico... (las más importantes) Los Urabeños, Los Paisas, Los Machos, Renacer, Ejército Revolucionario Popular Anti-subversivo de Colombia (Erpac) y Los Rastrojos... estas estructuras tienden a recomponerse rápidamente, remplazando a los miembros" (Echandía, 2010: 168).

1 INSTITUTE FOR NATIONAL STRATEGIC STUDIES. La Conexión Mexicana: Poniendo al descubierto los vínculos de los cárteles de la droga en la región Andina". Pg.5. www.ndu.edu. Consultado el 4.6.2012.

2 Sobre el tema de los paramilitares y grupos guerrilleros se puede consultar: ARIAS HENAO, Diana. (2008). Sistema Político Colombiano: el desarrollo de la violencia y la incidencia del condicionante externo. Universidad Nacional de La Plata, Argentina. Instituto de Relaciones Internacionales IRI. Tesis de maestría en RRII. 
Es así como, Colombia y México sienten los efectos de "la industria de las drogas ilegales... la cantidad de divisas ilegales que entran a la economía, las formas que han sido asimiladas en ella, los patrones de inversión de algunos empresarios de las drogas" ${ }^{\prime 3}$, entre los principales.

Dentro de las asimétricas RRII narco-violentas de las ESol trasnacionales de matriz colombomexicana, es posible, identificar como condicionante exógeno a las políticas estatales de los EEUU, que para enfrentar las realidades de los países soberanos, condiciona la estrategia de la militarización como respuesta global al narcotráfico y sus delitos conexos, perfilándose como narco-garante en el mantenimiento de la narco-industria, que mina las condiciones sociales y ambientales de los territorios donde se ejecutan sus condicionamientos empotrados en la variable exclusiva de Seguridad Nacional.

Ahora bien, como principal factor endógeno encontramos a la marginalidad social que sin importar los nacionalismos, requiere de la oferta de la narco-empresa, y la política, la narcofinanciación. El realismo como herramienta paradigmática y puesta en práctica por décadas sigue fracasando pero aplicándose con moral ortodoxa internacional.

Los paradigmas teóricos clásicos ni contemporáneos han logrado consensuar sobre el diagnóstico del fenómeno trasnacional de las drogas, requiriéndose indagar las posibles renovaciones interdisciplinares que impriman un dinamismo conceptual precautorio y que posibilite reales estrategias de transformación y de disminución de la narcoviolencia.

La falta de condiciones dignas dentro de sectores nacionales de diversos Estados, abre la plataforma de reclutamiento por parte de las ESol narco-violentas. Como lo refería Marcos Camacho alias Marcola, jefe del Primer Comando de la Capital de San Pablo - (PCC), quien era un ser invisible y miserable para su Estado. Sostuvo al ser entrevistado: "Ahora estamos ricos con la multinacional de la droga. Y ustedes se están muriendo de miedo. Nosotros somos el inicio tardío de vuestra conciencia social... Nosotros somos hombres-bombas. En las villas miseria hay cien mil hombres-bombas... Ya somos una nueva especie, ya somos otros bichos, diferentes a ustedes. La muerte para ustedes es un drama cristiano en una cama, por un ataque al corazón. La muerte para nosotros es la comida diaria, tirados en una fosa común... Hay una tercera cosa creciendo allí

3 THOUMI, Francisco. Los efectos económicos de la industria de drogas ilegales y las agendas de política en Bolivia, Colombia y Perú. www.colombia internacional.uniandes.edu.co/view.php/202/view.php. Consultado el 5.6.2012. 
afuera, cultivada en el barro, educándose en el más absoluto analfabetismo, diplomándose en las cárceles, como un monstruo Alien escondido en los rincones de la ciudad... La post miseria genera una nueva cultura asesina, ayudada por la tecnología, satélites, celulares, Internet, armas modernas... Nosotros somos una empresa moderna, rica. Si el funcionario vacila, es despedido y colocado en el microondas. Ustedes son el Estado quebrado, dominado por incompetentes. Nosotros tenemos métodos ágiles de gestión. Ustedes son lentos, burocráticos. Nosotros luchamos en terreno propio, ustedes en tierra extraña... Nosotros estamos bien armados. Ustedes tienen calibre 38... Nosotros somos ayudados por la población de las villas miseria, por miedo o por amor. Ustedes son odiados" ${ }^{4}$.

Entonces la herramienta violenta legítima es presentada tras el atuendo de la cooperación militar diseñada por el hegemón, que en materia antinarcótica, continúa liderando los lineamientos internacionales, pese a no tener resultados durante décadas. En concordancia con dicha ideología de combatir las drogas en territorios extranjeros, en 2014 el Informe Mundial de Human Rigth Watch, ratificó que el narcotráfico es un fenómeno global en el cual participan de diversas formas la mayoría de los Estados y otros tantos actores internacionales no estatales, legales e ilegales e instó a despenalizar el consumo personal y la posesión de drogas.

La estrategia de combate contra la rentabilidad de la organizaciones narco-violentas debe atender al tema de "cooperación regional en seguridad y defensa:1) la creciente militarización de la seguridad pública; 2) la privatización de la seguridad y; 3) los actores armados no estatales"(Benítez, 2010: s.p.).

Lo anterior será estudiado mediante una investigación comparativa que busca "explicar y encontrar el sentido de los procesos, su génesis y los factores de su evolución", a través del objeto de estudio, las unidades de análisis y variables planteadas a continuación. Indagando vertientes de conocimiento oficiales y oficiosas, internas e internacionales, deontológicas y ontológicas.

\section{CAPITULO I: CONSIDERACIONES METODOLOGICAS}

\footnotetext{
${ }^{4}$ http://www.forodeseguridad.com/artic/reflex/8063.htm. Consultado el 12.9.2013. Periódico "O Globo", de Brasil, de su Editorial Segundo Cuaderno.
} 
La metodología de la investigación pretende facilitar el camino del investigador, que lo conduce sin dilatarse en el proceso mediante el uso de conceptos definidos como objetivos de investigación y sus mecanismos, o valga la redundancia, los métodos investigativos. En el campo de las ciencias blandas en general, y de las RRII en particular, el debate suele centrarse entre quién crea efectivamente y quién no crea conocimiento científico.

Lamentablemente para muchos investigadores rígidos por así denominarles, no existen reglas claras ni contundentes que permitan concluir asertivamente que un nuevo conocimiento se ha ofrecido al mundo teórico, en especial por la inaplicabilidad total y permanente de los paradigmas de las RRII. Algunos investigadores menos exegéticos logran comprender y asimilar que la construcción original de un sujeto en relación con su específico entorno, es un nuevo conocimiento, debido a que el mismo no es solo uno finito, sino es un conjunto que comprende infinidad de elementos que no cesan de interrelacionarse, generando nuevas formar de saber, de ser, de estar y de tener.

La investigación en RRII, que agrupa los estudios interdisciplinarios de historia, política, economía y derecho internacional, "depende en gran medida de un conjunto de decisiones y acciones que, especialmente en el ámbito de las disciplinas humanísticas, requieren de lo que Polanyi clasificaría como conocimientos personales. La investigación se puede aprender; pero no solamente a través de un curso de aprendizaje, sino por medio de la experiencia" (Piovani, 2001: 97).

A la vez, autores como Smelser y Lipjhart han generalizado dentro de la metodología de la investigación que se surte en campos de las ciencias humanas, blandas o inexactas, al método comparado, como el método predilecto o específico de investigación que conlleva a la demostración de una hipótesis propuesta, permitida tal demostración por la previa enunciación de variables.

La comparación consiste en una confrontación entre estados de dos o más objetos sobre una misma propiedad o propiedades. Por lo tanto, "cualquiera que sea el diseño experimental, recurrir a la comparación resulta inevitable" (Piovani, 2001: 97). 


\subsection{CLASES DEL METODO COMPARATIVO Y SUS ELEMENTOS}

Los elementos del acto de comparación (objetos, propiedades, aspectos temporales) permiten discriminar entre la comparación sincrónica y la comparación diacrónica. La comparación sincrónica no atiende al aspecto temporal debido a que considera como único a los diferentes momentos temporales en el acto de comparación. Por el contrario, la comparación diacrónica en su estadio más sencillo, atiende el acto de comparación en momentos temporales distintos. La comparación diacrónica más avanzada o "compleja es aquella en la que se consideran un objeto, dos propiedades y puntos de tiempo" (Piovani, 2001:99).

Conforme lo expresado, "Swanson critica la expresión investigación comparada en cuanto ella implica que existan investigaciones no comparadas" (Fideli, 1998: 18). De esta manera se vislumbra que, "la pluralidad de formas que puede asumir la comparación y de fines por los cuales se puede comparar ha inducido a algunos estudiosos a afirmar que es imposible realizar alguna actividad cognitiva sin recurrir a la comparación. En consecuencia, toda actividad científica debería considerarse comparada" (Fideli, 1998: 13).

Logrando identificar la ciencia de otra formación de conocimientos. No sería posible, entonces, investigar científicamente sin comparar. Esta posición de los autores, en la práctica, resulta estrecha para la creación de conocimiento en ciencia política. Una investigación no se reduce a la comparación entendida particularmente como "acto singular de conocimiento". (Piovani, 2001:99) Un sector de la doctrina, ha definido la expresión comparada a las investigaciones sociales que la comprenden como un sistema global no singular. Sistemas globales que "emplean datos referidos a sociedades, culturas o naciones diferentes" (Fideli, 1998: 18).

Es inoportuno dar relevancia mayor a elementos investigativos que como la comparación ${ }^{5}$ hacen parte de un sinfín de medios, que son utilizados o no por los investigadores, puesto que la independencia de los casos nos recuerda que cada cual es único e independiente de la posible variedad de estrategias que se empleen para abordarlo, por lo tanto, los investigadores rígidos mal hacen en desechar la construcción original del conocimiento de un investigador empírico, porque

\footnotetext{
${ }^{5}$ La comparación está inserta en cualquier investigación científica.
} 
aunque no comparta su visión, la misma hace parte de la compleja realidad que existe en el mundo.

Valga establecer que la razonabilidad debe preceder los pensamientos en cuanto el entendimiento de no cuestionar las ideas fundamentales, para no proceder a un estudio meramente filosófico. Entonces, el dominio de conocimiento es personal y no se puede pretender conocer el comportamiento humano como definición única y estática, lo cual iría en contravía de la esencia de la vida, que es el contexto humano. Mucho menos el compartimiento de los Estados que componen a la sociedad internacional.

De ésta manera las tensiones paradigmáticas se presentan para quedarse y mutar, puesto que existen elementos que a su vez son válidos para el estudio de un caso e inválidos para otro, un problema similar al que representa la equivalencia en la comparación. La conducta humana, tanto a nivel individual como grupal, se modifica respecto de los aspectos espacio-temporales, en los cuales se desarrolla o existe.

Por eso, las investigaciones científicas en el campo de las RRII no pueden tender a la objetivización absoluta de sus elementos y deben reconocer, como elemento esencial, el condimento personal o conocimiento intrínseco del investigador. En consecuencia, para mantener razonabilidad y equivalencia es necesario determinar claramente la estructura metodológica y definir las estrategias que se utilizarán para delimitar el abordaje empírico ${ }^{6}$ que produce conocimiento original y concluye con el proceso disciplinado del investigador que se desarrolla en el tiempo y, varía conforme, se surta la toma de decisiones prácticas que haga éste y que le determinan el ejercicio de las mismas.

\subsection{EPISTEMOLOGÍA DE LA COMPARACIÓN}

\footnotetext{
${ }^{6}$ Ya desde 1960 Lijphart sostuvo que la "actividad científica busca establecer relaciones empíricas generales entre dos o más variables... manteniendo constantes, todas las otras". Siguiendo esta fórmula primaria la investigación queda restringida a la actuación protagónica y/o antagónica de variables. LIJPHART (1971:70). Consultado en PIOVANI, JUAN IGNACIO (b). Acerca del status de la comparación en la Ciencia Política. Esta ponencia se basó en parcialmente en el artículo "los estudios comparativos: estrategias de investigación empírica en relaciones internacionales. Relaciones Internacionales, Año 10, N. 20. Pg. 2.
} 
Por otra parte, autores como Fideli y Marradi han definido desde el punto de vista epistemológico a la comparación como aquella operación cognitiva a través de la cual se cotejan los estados de uno o más objetos sobre la base de al menos una propiedad de los mismos.

Encontrando como elementos de la comparación epistemológica, los siguientes:

1. Objeto: sujetos, grupos, instituciones;

2. 1 o más propiedades;

3. Estado de los objetos sobre la propiedad, y;

4. Tiempo específico donde se revelaron los estados.

El planteamiento anterior resulta muy amplio para demarcar los linderos investigativos, puesto que el mismo como criterio catalizador, diluye su utilidad en la investigación científica. La comparación es una operación mental existente en todas las estrategias metodológicas de construcción y justificación del conocimiento.

Como lo advertimos, otra vertiente de estudiosos le ha otorgado a la comparación la calidad de método científico, además, en cuanto a la ciencia política y a las RRII se refiere, la comparación parece ocupar el lugar protagónico en las investigaciones que se realizan.

Una u otra concepción reflejan simplemente unas tendencias mayoritarias respecto al abordaje de la conducta humana social, diseñadas para acercarse a un estudio, sin embargo, parece que el método empírico comparativo no puede llegar a estereotiparse en el sentido rígido de ser la solución aritmética exacta que ha venido buscando irracionalmente la historia de la humanidad, para validar el comportamiento cambiante, libre y sui generis, tanto del individuo como de su interacción con sus pares y sus dispares, refiriéndonos al poder como la propiedad que los semejanza o diferencia.

Contemporáneamente "la idea más comúnmente admitida, al menos dentro del mundo occidental, es aquella que ve en la convergencia de las aspiraciones del grupo y de los objetivos del poder, el fundamento de legitimidad de este" (Naranjo, 2003: 123). En occidente: Democracia.

\subsection{LOS ENFOQUES COMPARATIVOS}


Respecto de la tipología expuesta por Marradi relativa a los fines cognitivos de la comparación científica, revisten de importancia los siguientes enfoques comparativos y cuya orientación es de investigación cualitativa, puesto que permite el uso de una gran variedad de estrategias, en cuanto a la relación que se presenta entre los objetos estudiados:

a. Enfoque comparativo ideográfico: coteja configuraciones causales del fenómeno observado para señalar su especificidad y así proceder a comprenderlo, partiendo de las particularidades de cada proceso histórico. Los objetivos primarios que pretende conseguir éste enfoque, buscan explicar la naturaleza del fenómeno que se observa y reconstruirlo comprensivamente, esto es, identificando e indagando en torno a las causas explicativas del mismo.

b. Enfoque comparativo interpretativo: confronta representaciones culturales diversas. Mediante la comparación se analizan las diferencias culturales, tratando así, de comprender las diferentes culturas desde la perspectiva misma de sus actores. Esta tipología de estudios resulta pertinente para los de contenido constitucional puesto que son etnográficos. Un aspecto fundamental, lo contiene el etnocentrismo en RRII que puede ser positivo o negativo, dependiendo de los efectos producidos en la convivencia armónica internacional y de la equivalencia que se emplee efectivamente, es decir, sí es posible eliminar el personalismo al momento de diseñar el camino metodológico, adecuando las emociones del investigador dentro de un esquema neutral que permita la entrada de otras culturas al estudio, sin preferir el aspecto dentro del cual se fundamenta el contexto donde se desarrolla o desearía desarrollarse el investigador.

c. Enfoque comparativo difusionista: pretende establecer cómo lo colectivo se difunde de un contexto determinado a otro(s). Puede entenderse la difusión más claramente pensando en instituciones, tendencias culturales, estructuras de funcionamiento políticas, económicas, financieras, administrativas, servicios de telecomunicaciones, entre otras formas posibles de difusión. Por ejemplo, la mediatización internacional de los métodos de combate a la ESol narcoviolenta. 
Entonces, "la comparación puede ser empleada en la ciencia con diversas finalidades" (Piovani, 2003: 100). Por lo que "finalmente, parece legítimo afirmar que tampoco se pueda desarrollar un estudio de caso sin realizar comparaciones... el estudio de los cambios del caso observado a lo largo del tiempo implicará alguna forma de comparación" (Piovani, 2000: 3).

Igualmente es importante resaltar que tratándose de campos sociales "la comparación se emplea con fines ideográficos o interpretativos" (Piovani, 2001: 101). O difusionistas. Los cuales, para el estudio de las RRII resultan apropiados pero no exclusivos.

\subsection{ESTUDIOS TRANSCONTEXTUALES}

Una comparación tildada de mayor especificidad es la llamada comparación transcontextual que comprende dos tipos de investigaciones que se surten, en gran medida, en el campo de las ciencias sociales. A saber:

a. Estudios cros-nacionales: parten del significado francés de Estado-nación como unidad política administrativa y con prevalencia en la presencia de la figura de la descentralización territorial.

En RRII, generalmente se presentan estudios claros, encasillados dentro de esta tipología específica de comparación, puesto que generalmente tienden a comparar unidades de análisis, resultando estudios cross nacionales descriptivos o explicativos, pero sin contar con elementos técnicos de investigación, tal vez, por la dualidad del campo en que se desarrolla el objeto de estudio: las humanidades.

Así, "la investigación cross-nacional" se enmarca en un tipo genérico que podríamos clasificar como investigación comparada... (resultando) más apropiado reservar el rótulo de investigación comparada sólo para casos como el de los estudios cross-nacionales" (Piovani, 2001: 98).

7 Comparación entre Estados. aclaratorios y explicativos 
b. Estudios cros-culturales: "el énfasis principal de la investigación cross-cultural es la identificación de similitudes y diferencias en conductas o conceptos en distintas culturas" (Olavarrieta, 1990: 58).

Este tipo de investigación resalta lo importante de generalizar equitativamente aspectos universales que aporten al entendimiento del comportamiento humano pero no a su rígida clasificación. De esta manera, "los investigadores cross-cultural deben estar informados de la necesidad de ir más allá de la mera descripción o comparación de resultados, y avanzar a fases de explicación o de teorización respecto a los por qué de éstas diferencias" (Olavarrieta,1990:74).

No obstante, como se ha venido expresando, que a la comparación se le haya tildado por un gran sector de la doctrina como el método específico, útil o distintivo de las ciencias sociales; la comparación como acto cognitivo no encuentra unos linderos bien definidos, lo que conlleva, a que otro sector de la doctrina la considere como inconclusa en términos de utilidad referido a desarrollos investigativos.

\subsection{FLEXIBILIDAD EN LA CREACIÓN DE CONOCIMIENTO CIENTÍFICO HUMANO}

La sociedad internacional contemporánea carga inmersa la peligrosa tendencia que conlleva "toda generalización. Encasillar a una persona en modelos rígidos, en tipos de conductas, es olvidar la mutabilidad de comportamiento del hombre: el deseo, la inclinación o el pensamiento de hoy, no tiene que ser el de mañana. El ser humano tiene la capacidad de autodeterminarse" (Suárez, 2004: 7). Así mismo, se generaliza en la lucha armada contra la narcoviolencia, ha generado el incremento y perdurabilidad de los daños colaterales así como la mutación de los grupos de ESol narco-violentos que rápidamente se adaptan a los escenarios que plantean los Estados y el sistema mundo.

La compleja capacidad de aceptar o no, de elegir consentir o combatir. Sin embargo, "las generalizaciones son un importante punto de partida... en el campo de los estudios transculturales, las generalizaciones se tornan destructivas cuando degeneran en estereotipos. Las 
generalizaciones están abiertas a la revisión y al cambio; los estereotipos son sistemas de creencias cerrados" (Brake, 1995: 44-45).

La generalización en términos culturales permite ver que "cada cultura es diferente y que sus grados y las razones de obediencia al poder político son propias y particulares y no son iguales a otras, o a lo sumo similares" (Suárez, 2004:8). Por esto, es imprudente e inconveniente plantear las mismas estrategias contra el narcotráfico en Estados con culturas diferentes.

Resultando útil "analizar, en una perspectiva histórica y teniendo en cuenta las relaciones de poder/reconocimiento, la manera como los actores construyen sus identidades" (Ulloa, 2001: 9). Por consiguiente, es importante considerar la posibilidad de construcción de narco-identidades trasfronterizas.

En el campo de los negocios, autores también han manifestado importante preocuparse acerca del abordaje objetivo y óptimo que requiere una investigación y de uno de ellos es posible destacar algunos de los aspectos expuestos y asimilarlos dentro de los estudios comparativos. Se ha definido entonces, que el tipo denominado "cross-cultural, se refiere a la investigación de un fenómeno o teoría, comparando al menos dos culturas diferentes" (Olavarrieta, 1990: 55).

En tal sentido, "los términos investigación cross-cultural o cross-national pueden considerarse un tanto más específicos en relación con el término investigación comparativa, pues indican claramente que la variable independiente examinada para explicar diferencias en resultados, es la nación o cultura" (Olavarrieta, 1990: 57). Dejando por sentando que el narcotráfico no es un asunto exclusivo del seguridad sino de marcada dinámica transcultural.

En consecuencia, "la legitimidad puede ser una, pero las razones en que se fundamenta cambian (García, 2000; 24) ${ }^{8}$, de acuerdo con la concepción cultural y antropológica de cada sociedad"(Suárez, 2004: 3). Por ejemplo, desde la cultura oriental se ha criticado "la idea

\footnotetext{
${ }^{8}$ GARCIA, Eloy (2000). ¿Cuál es la razón que lleva a un hombre a acatar la voluntad de otro hombre? No cabe una respuesta de valor universal: la respuesta la da en cada momento la realidad en que el hombre se halla inmerso, la idea de política en el sentido amplio del término que en cada sociedad prevalece, el grado de maduración de su conciencia colectiva, lo que significa que la obediencia nace de la aceptación social. Pero no existe un principio de obediencia al margen de la historia, como tampoco una razón única de obediencia... la legitimidad es una particular forma de obediencia que se afirma cuando el consentimiento de los gobernados hacia el gobernante permite conjurar el recurso al miedo". El estado constitucional ante su momento maquiavélico. Cuadernos civitas, Madrid, Pg.24.
} 
estadounidense de exportar su cultura política a países en desarrollo, en donde pretende importarla rápidamente, sin considerar si hay aceptación o no por parte de los destinatarios" (Chua, 2003:1). Tal y como lo que se refleja en la práctica del Plan Colombia y la Iniciativa Mérida, extirpantes militares de culturas cocaleras, por ejemplo. 


\section{CAPÍTULO II: DISCURSOS ANTINARCÓTICOS}

\subsection{NARCOMEDIATIZACION DE LAS RELACIONES INTERNACIONALES: INVESTIGACION CON VARIABLE CULTURAL INDEPENDIENTE}

Tal y "como señala Fitzgerald el concepto de identidad puede ser un puente entre los estudios de comunicación interpersonal y de masas. Aunque este concepto parece estar más próximo a la comunicación interpersonal, no se puede ignorar la influencia de los mass media en los procesos de identificación" ${ }^{9}$ (Alsina, 2010).

La variable cultural se encuentra a la vanguardia de los estudios contemporáneos en RRII debido a su estrecha relación con la teoría de la dependencia, y en contraste, se presentan condicionantes externos en el plano cultural respectivo: una imposición cultural, un formato social que prevalece sobre uno de menor influencia en la sociedad internacional o al interior de un Estado. Ajustándose a los patrones antinarcóticos predominantes, que de tinte neorrealista, y con todas las armas a su disposición, no han sido capaces de terminar con las amenazas de los grupos ESol narcoviolentos.

Es decir, la teoría de la interdependencia económica sostiene que para que exista un país desarrollado debe existir uno subdesarrollado del cual mantenga su margen de utilidad. En materia cultural, referiría el mantenimiento de una cultura basada en el exterminio paulatino de otra. Y en cuanto al narcotráfico, se traduciría en un linkage narcoviolento.

Ahora bien, durante la década del 60 autores latinoamericanos como García Canclini "entre otros, formularon la teoría de la dependencia y del imperialismo. Estas teorías critican la teoría del desarrollo que, desde los años 50, consideraba a los medios de comunicación instrumentos para el

\footnotetext{
9 "La comunicación transcultural (cross-cultural) es la comparación entre formas de comunicación interpersonal de distintas culturas. En este caso no se trata de analizar las interrelaciones, sino simplemente comparar las diferencias entre las propias formas de comunicación de cada cultura (Brislin,1986)". ALSINA, Miguel Rodrigo. Los Estudios de Comunicación Intercultural Red de La Iniciativa de Comunicación. Donde la comunicación y los medios son parte esencial del desarrollo social y económico de América Latina y el Caribe. Profesor Titular de la Facultad de Ciencias de la Comunicación de la Universidad Autónoma de Barcelona. Revista de Estudios de Comunicación ZER, Universidad del país Vasco. www.comminit.com Consultado el 4 de febrero de 2010.
} 
progreso de los pueblos y por ello propugnaba la libre circulación de todos los productos comunicativos industriales. En los años 60, también se rompe la visión etnocéntrica que consideraba que el problema del desarrollo podía solventarse aplicando mecánicamente el sistema político y económico occidental en el tercer mundo" (Alsina, 2010: 1).

Por lo tanto, conocer el aspecto cultural de cada sociedad con sus diversas vertientes "puede permitir entender los fundamentos de la legitimidad en cada sociedad... igualmente, en las sociedades con diversidad étnica y cultural debe existir un verdadero consenso político que de soporte legítimo al propio Estado" (Suárez, 2004: 9).

Convirtiéndose la comunicación intercultural en la clave metodológica de las RRII contemporáneas. Por lo que la obstaculización intencional de las élites de poder al momento de ejercer el derecho contemporáneo de doble vía a la comunicación, logra que la opinión pública nacional e internacional se polarice peligrosamente.

Lo que impide que surjan individuos facultados y formados para discernir en comunidad. Generando una plataforma mediática que coadyuva a una cultura democrática occidentalizadora, y en ocasiones armada, que se adueña de la conceptualización en el marco de los estudios en RRII. Imposibilitando establecer relaciones entre variables empíricas que requieren "la verificación de los estados del objeto estudiado... lo que no puede lograrse sin recurrir a la comparación" (Piovani, 2001: 102).

\subsection{DESINFORMACIÓN: METÁSTASIS DEL SISTEMA METOdOLÓGICO EN RELACIONES INTERNACIONALES}

Continuando la ejemplificación de los estudios culturales, la desinformación produce el riesgo al investigador de "ver las cosas únicamente desde el ámbito cultural al que pertenece... puede llevar a pensar que sólo las ideas, valores y conductas, allí nacidos, gozan de veracidad y validez... de esa forma, se le da con ligereza, universalidad a los principios democráticos de una sociedad" (Suárez, 2004: 3). 
Los aspectos internos culturales en RRII vislumbran la diversidad cultural existente en cada Estado nacional. En consecuencia, el "reconocimiento y respeto de la diversidad cultural de un Estado fundamenta su legitimidad" (Suárez, 2004: 8). Si lo anterior no ocurre, la polarización de la opinión pública nacional e internacional, se presentará en algún grado. Lo mismo en cuanto a la polarización que ocurre frente al combate o legalización de los narcóticos.

Así, el derecho a la comunicación "afecta tanto a los que emiten como a los que reciben la información, por lo tanto atañe al emisor y al receptor... la información es susceptible de generar conocimiento en las personas, pero también lo es producir la comunicación entre ellas. Igualmente no se puede negar que para generar opinión pública en una sociedad (se requiere) una necesaria información suficiente" (González, 2009).

De esta manera, "estudios de la recepción de White ponen al manifiesto que el uso de los medios de comunicación se inscriben dentro de otras prácticas culturales cotidianas. Ser un espectador no es simplemente ser un tipo de sujeto determinado, sino que es estar en una situación de comunicación determinada que está condicionada por las propias características del sujeto y por su entorno personal y social. Es decir... se pone de manifiesto las interrelaciones entre la comunicación interpersonal y la comunicación mediada... Los estudiosos de la comunicación tienen cada día más claro la sinergia de cualquier proceso comunicativo. Ni la comunicación mediada puede no tener en cuenta la comunicación interpersonal... ni la comunicación interpersonal puede estudiarse sin tenerse en cuenta el contexto cultural y mass mediático" (Alsina, 2010).

Informar y ser informado eficazmente por medios de comunicación oficiales de difusión masiva aparece en las RRII contemporáneas como la "principal base sustantiva del Derecho a la Comunicación y uno de los pilares fundamentales del Derecho Internacional de los Derechos Humanos... signo constitutivo y emblemático del sistema democrático. Por tal motivo, no puede desentenderse de la necesidad de garantizar la producción de sentido democrático en el discurso mediático, contribuyendo a poner límites a los abusos y la manipulación del poder políticoeconómico que tienen por fin lograr la docilidad y la inmovilidad ciudadana" (Duhalde, 2009). Ni tampoco de movilidad dirigida. Resaltemos, que la comunicación mediada es en la cual ocurre una "producción mediatizada del discurso" (Alsina, 2010). 
El método para desarrollar una investigación debe contar entonces con fuentes primarias y secundarias, persiguiendo la comprobación de la hipótesis que se formule mediante el empleo de la herramienta del recorte tempo-espacial respecto al objeto que se pretende estudiar neutralmente.

OBJETO DE ESTUDIO: RRII bilaterales entre ESol de narcotráfico colombo-mexicanas como fenómeno de violencia transnacional y su permeabilidad en las economías legales.

La forma política del sistema internacional no es homogénea por eso se limita la variable política al interior de un Estado Nacional. No existe consenso cultural en la sociedad internacional pero curiosamente si existen pactos de normas de comportamiento comercial internacional.

La bisagra que le hace falta a la sociedad internacional globalizada es la efectividad de una información objetiva y veraz pues destruye la anhelada plataforma democrática u otra organización política predilecta y soberana que busque la paz, mutilando la opción de comprender de una manera neutral la agenda narco-interméstica de los Estados, fomentando la polarización de la opinión pública.

En las investigaciones cross-nacionales y las cross-culturales metodológicamente hablando, debemos enfatizar en la problemática central, que se refleja en la equivalencia entre lo que se observa y lo que se describe.

La actuación de la comparación en el campo de la creación y construcción de conocimiento científico no se limita a un medio sino que se expande dentro de múltiples escenarios que se traducen en medios o recursos. Por lo tanto, la comparación puede aparecer con distintos métodos y enfoques científicos y es posible su articulación y su variabilidad en el tiempo y en diversos contextos.

Si se garantiza la efectividad en los servicios de telecomunicación de difusión, se posibilita el acceso democrático mediante el goce pleno del derecho humano a la información, generándose una sociedad fundamentada en culturas democráticas reales, capaces de ejercer procesos de toma 
de decisiones políticas coherentes con su realidad como individuo y como ser social de participar en igualdad de condiciones en los asuntos de interés colectivo, reforzando la necesidad de identificarse como consumistas de un modelo insostenible, mutando las condiciones de gobernabilidad. Igualmente posibilitaría que los Estados soberanos así estén superados parcialmente por las ESol narcoviolentas, atiendan sus propios factores socioculturales para diagnosticar las herramientas de transformación y evitar que la cooperación se trasforme en intervención o en dominación.

Dejando para la reflexión los entramados retóricos, el modelo de desarrollo actual vulnera y amenaza constantemente con destruir la validez de los estudios en RRII por no ofrecer respuestas al fenómeno narcoviolento y su funcionalidad política manipulada a través de medios de comunicación masivos trasnacionales.

Los estudios internacionales sobre la narcoviolencia como interdisciplina debe contemporáneamente partir de la base metodológica del Sistema Mundo de Wallerstein. Sistema con impronta multipolar y donde claramente la variable política predomina sobre la jurídica, asumido el sistema sobre un rol económico enraizado en el contexto de la globalización como factor de aumento de incertidumbre económica y estratégica.

Reforzando el marco teórico, la teoría del caos y la dialéctica, así como la consideración del elemento humano y sus particularidades en cuanto a la lucha contra las ESol narco-violentas, se refiere.

Un sistema de interacciones y actores no estatales influyentes e influenciados que provoca un análisis polemológico, definido como "el estudio objetivo y científico de las guerras, como fenómeno social susceptible de observación, igual que otro cualquiera, y que por consiguiente debe constituir un capítulo dentro de las ciencias sociales y las relaciones internacionales" (Bouthoul, 1084:66), adaptando el concepto de guerra a la narcoviolencia y sus desarrollos como actores que permean la economía y, por ende, a todos los ámbitos legales. 
Así, la unidireccionalidad de la militarización representa "la inutilidad de la fuerza" (Maghroori, 1982) para resolver los estados de crisis, así como, la inaplicabilidad de los paradigmas clásicos a la amenaza global.

Los intereses estatales y de grupos económicos legales son encubiertos en las estrategias oficiales presentando a los Estados de Colombia y de México, como víctimas o blancos de luchas extremistas entre paramilitares e insurgencia. Desconociendo los orígenes de cada organización, muchas veces, estatales aunque se siga insistiendo oficialmente su ilegitimidad y carácter no estatal.

En consecuencia con lo descrito, se abordará el manejo y consecuencias de la ESol narco-violenta a las realidades de violencia político- institucional y violencia social. La violencia políticoinstitucional es "desplegada por el Estado o grupos para-estatales contra opositores políticos y la violencia social (es) desarrollada por el Estado u organizaciones del crimen organizado, contra población civil” (Arias, 2010:1).

La clasificación de los grupos narco-violentos que dirigen las ESol, que representan otros muchos grupos de crimen organizado, como los paramilitares y narco-paramilitares, parapolíticos identificados y no identificados, miembros del Ejército y mercenarios, entre los principales, ofrece escenarios teóricos contradictorios en cuanto a su pertenecía estatal, pues en teoría los Estados de Colombia y México sostienen que la mayoría son agentes no estatales y de eminente estructura de crimen organizado, pero la realidad demuestra que la mayoría de estos poseen vínculos estatales en diferentes grados, e inclusive, que son varios los que obedecen a la mera funcionalidad de los gobiernos de Colombia y México e incluso de los EEUU.

Igualmente en fallos ${ }^{10}$ de cortes norteamericanas entre otros muchos fallos nacionales, los paramilitares han sido calificados como actores estatales ${ }^{11}$ o los actores estatales han sido condenados como paramilitares.

10 El 14 de abril de 2003 se admitió una demanda presentada por la Fundación Internacional para los Derechos Laborales en nombre del sindicato de mineros y familiares de los asesinados ante una corte laboral en Alabama, EEUU.

11 Demanda por conspiración con paramilitares para asesinatos sindicales en marzo de 2001. 
Estados permisibles ante tal realidad atendiendo factores externos, como el interés de gobiernos poderosos y sus compañías trasnacionales, en particular, el de los EEUU como consumidor principal de drogas provenientes de Colombia y México e inversionista extranjero directo de diferentes clases de bienes y servicios, en especial los de CMP.

Los grupos trasnacionales ESol narco-violentos colombianos y mexicanos o en ocasiones colombomexicanos, han cooptado en diferentes grados bajo la complicidad norteamericana, los territorios y la actividad política, y de seguridad y defensa, de Colombia y México.

Ahora bien, para comprender cada tipo de violencia será necesario asumir por esta a: "la realización de un poder acumulado sobre el término más débil de una relación social asimétrica, que se despliega cuando los símbolos y valores que sostienen el poder se ven amenazados. Se presenta como combate entre fuerzas iguales, pero ésta imagen encubre historias previas y relaciones de poder. Estas relaciones de poder se naturalizan o normalizan”(Arias; Cieza, 2010).

Lo cierto es que todos los grupos armados que ejecutan los dos tipos de violencia descrita en el desarrollo de su empresa ilegal o incorrecta, sean o no calificados como estatales o de crimen organizado, son "capaces de emprender operaciones...tienen objetivos, estrategias, vínculos con actividades criminales, proveedores de fondos, diásporas, códigos de comportamiento" (Muñoz, s.d.e). Generando que "movimientos sociales... creen nuevas formas de resistencia"(Torralba, 2006. P. 1).

En definitiva, la fuerza habita en manos de la autoridad quien la ejerce en el debido respeto y obediencia de sus receptores. El ejercicio del poder incluye procedimientos para su permanencia, búsqueda de consenso y mecanismos para su legitimación (Dualde, 1999: s.p). Según este enfoque la única forma para neutralizar o disminuir la violencia, es que en el marco de las relaciones sociales dadas, emerja un actor capaz de hacer frente a las prácticas violentas. Actores que imprimen más fuerza que los sujetos de derecho, como los carteles al enfrentar la fuerza legítima de Colombia y México, con su recepción de fondos internacionales para fortalecer la estrategia de la militarización. 


\section{CAPÍTULO III: ESTRUCTURA METODOLÓGICA}

\subsection{PLANTEAMIENTO DEL PROBLEMA DE INVESTIGACIÓN}

Colombia y México, sus respectivas agendas y marcos normativos intermésticos en materia de narcoviolencia, comparten el carácter de ser países débiles en el marco de las RRII asimétricas del Sistema Internacional, en especial, atendiendo a las políticas estatales norteamericanas.

Los conflictos intermésticos, es decir, elementos de interés y contenido tanto interno como internacional, son estratégicos para lograr la paz, sea ésta positiva o negativa, en fenómenos violentos o de crisis en lugares concretos del mundo, como el que genera la ESol narco-violenta colombiana y mexicana y colombo-mexicana.

Es decir, la narcoviolencia es un conflicto interméstico: "una forma específica de conflicto interestatal o inter-societal, en el que las formas convencionales de rivalidad - militar, económica y política - se les suma una discrepancia global de normas políticas y sociales, lo que suele prestarles legitimidad"(Halliday, 2000: 209 -210). Problema que podría solucionarse a través de una estrategia de pluralismo socio-jurídico dadas las características de transnacionalización de los grupos ESol narco-violentos.

Ahora bien, para Ángel Tello, la globalización es el marco adecuado para iniciar cualquier análisis de un conflicto moderno y de estirpe estratégica, como lo es el conflicto de las ESol narcoviolentas. Sostiene además que: "el conflicto es un choque de voluntades y no siempre se resuelve a través del empleo de la violencia" (Tello,2004, p.1) así esta sea legítima o legitimada. Reiterando entonces, su consideración, de ser la incertidumbre política la que nutre la incertidumbre estratégica, características del orden internacional globalizado.

Un concepto de contenido político en donde los gobiernos periféricos son condicionados por los centrales y a su vez, los centros disputan la unidireccionalidad del tratamiento militar al combate 
contra el narcotráfico, en especial, en los conflictos (Geertz, 1994: 149 - 150) de Colombia y México. El fenómeno narco debe plantearse como una posibilidad de transformación de políticas, si no bien hemisféricas, al menos regionales o en bloques, por ejemplo, similares al Plan de acción de los Objetivos del Milenio"(Consani; Surasky; s.d.e.).

\subsection{FORMULACIÓN DE OBJETIVOS E HIPÓTESIS}

OBJETIVO GENERAL: Analizar la transnacionalización de las ESol narco-violentas en Colombia y México entre 1990-2014.

\section{OBJETIVOS ESPECÍFICOS}

$\checkmark$ Caracterizar la narcoviolencia originaria en Colombia y México.

$\checkmark$ Identificar los factores internos y externos que condicionan el objeto de estudio y sus consecuencias en cuanto a la permeabilidad de las economías legales por las ESol narco-violentas en Colombia y México.

$\checkmark$ Analizar la relación de cada factor identificado (institucionalidad como valor, corrupción, permeabilidad de la economía lícita con la ESol narco-violenta) con el status de violencia política institucional y social producida por la ESol narco-violenta.

$\checkmark$ Proponer herramientas para aplicar estrategias regionales contra el problema de la ESol narcoviolenta originaria en Colombia y México y con cadenas de producción y distribución trasnacionales.

HIPÓTESIS: Las Soberanías de Colombia y México están condicionadas por las pautas de la política estatal norteamericana sobre la lucha contra las ESol narco-violentas.

Las pautas son los imperativos de las políticas estatales de EEUU, pues la política norteamericana condiciona las soberanías de los Estados de Colombia y México en la lucha contra las ESol narcoviolentas. Aspectos que refieren la continuidad a partir de la dependencia política de la política norteamericana pero a partir del interés diferenciador de dicha política referida a Colombia y México. 
Así, desarrollando este proyecto de investigación, se analizará la vinculación entre las RRII de las ESol en México y Colombia y el mantenimiento e incremento de las consecuencias de la narcoviolencia por las directrices de la política norteamericana con respecto a ambos Estados.

\subsection{FORMULACIÓN DE VARIABLES DE INVESTIGACIÓN}

Independiente: Economía Legal permeada por la ESol narco-violenta colombiana y mexicana y la incidencia en el mercado de consumo de los EE.UU.

Resultando imperante destacar que tal y como se expresó anteriormente existen diversas economías comprometidas mediante la relación bilateral en estudio, sin embargo, los EEUU resultan ser el sujeto destinatario del nuevo sistema ESol descrito y el consumidor principal que mantiene vivo el fenómeno trasnacional. Así como ser el Estado que lidera la estrategia en la lucha de nuestras unidades de análisis desde la visión estatocéntrica como desde la institucionalidad internacional.

Dependientes:

1. Institucionalidad de Colombia y México referente al fenómeno trasnacional de la ESol narco-violenta.

2. Política global contra el fenómeno trasnacional de la ESol narco-violenta.

La falta de institucionalidad (valor) afecta las políticas globales en la lucha contra la narcoviolencia en Colombia y México.

Las redes ESol narco-violentas obtuvieron de utilidad en 2009 " 870 mil millones dólares - 1.5\% del PIB mundial (poniendo) en peligro las economías lícitas y (teniendo) un impacto directo sobre la gobernanza... por la corrupción (y la cooptación política y territorial de Colombia y México). Fenómeno trasnacional con efectos locales... El dinero es lavado a través de los sistemas bancarios... menos del 1 por ciento de las ganancias lavadas son interceptados y confiscados (UNDOC, 2012:s.p). 
El narcotráfico representa una empresa rentable y sus utilidades ilícitas permean un sinfín de crímenes internacionales así como a las economías legales internacionales y las instituciones democráticas.

En 2014, como alternativas de transformación de la política internacional hegemónica de los EEUU, se analizan dos tipos de legalizaciones del fenómeno narco: legalización del consumo y la legalización de la producción.

Lo que requiere una diferenciación entre las sustancias y entre el consumo y el consumo indebido o endémico que causa "toda una serie de problemas sociales, que a su vez lo impulsan, entre los que se destacan la violencia, la delincuencia organizada, la corrupción, el desempleo, la mala salud y la educación deficiente, en una espiral nefasta de daño individual y colectivo"(JIFE,2011: 1). Sin olvidar, que en diversas ocasiones, los actores de la narcoviolencia y de la violencia legítima, usan la droga para ser verdaderos señores de la guerra.

Sin embargo, dichas alternativas generan diversas reacciones insospechadas, por ejemplo "lo que anhelan los productores de coca es algo que no pueden decirlo abiertamente: la preservación del actual estado de cosas, caracterizado por la condena retórica y la prohibición formal - legal" (Mansilla, 2008:5), puesto que esto les asegura un ingreso mucho mayor que como actividad legal, pues paga los riesgos de amenazas y penalización.

De otro lado, la militarización puede generar la victimización de los Estados productores resultando funcionales las estrategias made in usa como Plan Colombia e Iniciativa Mérida, que le reporta a Colombia y México, un flujo constante de miles de millones de dólares para modernizar las Fuerzas Armadas - FFAA- como única opción del combate contra el narcotráfico y sus delitos conexos.

EE.UU en 2011 aportó a Colombia, fondos de asistencia por aproximadamente US\$562 millones, y cerca del 61\% se destinó a ayuda militar y policial"(Informa HRW, 2012: 31 y 32). A México, desde 2008 ha aportado US\$1.600 millones “a través de la Iniciativa Mérida" (Informa HRW, 2012: 31 y 32). 
Lo cierto es que no se ha podido acabar con el fenómeno narcoviolento con la táctica unidireccional de la militarización y sigue siendo el combustible de las diversas estructuras delincuenciales, provenientes de sectores legales e ilegales, nacionales e internacionales.

Un escenario de constante violación de normas imperativas- lus Cogens que en la práctica internacional siguen siendo "relaciones de negociación" (Álvarez, 1999:87). Un sistema de principios democráticos sin eco en la realidad social"12. Demostrado por "injusticias, desigualdades y exclusiones y que tienden a ser propositivas en contextos históricos específicos"(Archila, 2010, p.18).

Los principales factores identificados por la doctrina que indican el statu quo de la ESol narcoviolenta en Colombia y México, se traducen en: ausencia de voluntad política para un diagnóstico multidimensional del fenómeno trasnacional; el énfasis militar ante un fenómeno multisectorial (no solo se seguridad sino de salud pública); más represivo que preventivo; con una institucionalidad involucrada en el establecimiento comercial ilegal que permite la penetración de actividades de lavado de activos; entre otros (Cieza, 2011, p.1).

En definitiva las ESol narcoviolentas de y entre Colombia y México, se repite el problema clave de las RRII: el estatocentrismo, reflejado en la unidireccionalidad de la militarización.

Tampoco resulta suficiente el neorrealismo pues "el prefijo neo sirvió en cierta medida para ocultar la reafirmación de los temas tradicionales - sobre el Estado, el poder, el conflicto- reflejo también de dos importantes cambios con respecto a la agenda anterior: por un lado, se prestaba una atención mucho mayor al papel de lo económico en las relaciones interestatales, no en los términos de los enfoques transnacionales o interdependientes sino como un instrumento, mercantilista y competitivo, del poder estatal; por otro lado, se hizo una revisión teórica, en un intento de elaborar una teoría más rigurosa"(Halliday, 2000, p.57 y 58 ).

En consecuencia, las críticas al paradigma realista, en sus dos versiones, "descansan principalmente en su ignorancia de los procesos transnacionales y de los actores no estatales, que tienen... un papel central en... las relaciones internacionales"(Arenal, 2010:26).

12 www.canalsolidario.com. 
Este debate ofrece un campo que permite vislumbrar la multidimensionalidad del fenómeno de las ESol narco-violentas. Adicionalmente, "supone la negación de que las relaciones internacionales sean por naturaleza esencialmente conflictivas y puedan interpretarse exclusivamente en términos de lucha por el poder. Aunque se reconoce el carácter conflictivo, mejor, <<problemático〉>, se afirma igualmente su carácter cooperativo" (Arenal, 2010:26). Pero no una cooperación condicionante ni de un solo sujeto. Sería preciso concebir una verdadera política regional que adapte cada uno de los particularismos que caracterizan las ESol narco-violentas de Colombia y México.

Resultando innegable la existencia de los actores transnacionales no legales como protagonistas en la Sociedad Internacional "dadas las actividades a las que se dedican, el impacto social y político de las mismas y el volumen del dinero que manejan: ... pueden dividirse en dos: los grupos que desarrollan actividades delictivas tradicionales, como tráfico de armas, drogas, tráfico de seres humanos y falsificaciones... y los grupos terroristas"(Pereira, 2009: 46).

En el fenómeno de las ESol narco-violentas convergen los dos tipos de actores transnacionales no legales aunque su estatalidad es en muchos casos cuestionable. Afectando directamente la economía mundial y siendo generadores de empleos. Creando un Suborden y un Subsistema Internacional de las ESol Narcoviolentas que actúan sobre el orden internacional de la globalización imperante en el sistema internacional, con matriz colombo-mexicana. En el suborden y en el subsistema nos interesará "delimitar la relación y coordinación entre partes (actores) y procesos (factores)... (donde) el factor económico puede considerarse...como el factor decisivo"(García, 2000:183-184).

Las economías colombiana y mexicana se encuentran muy condicionadas "por los negocios delictivos complejos y por la acción discrecional de los EE.UU...se trata sin más de una suerte de apropiación política, de una problemática tradicionalmente subsumida en las agencias de seguridad y policiales... que sin duda son parte del problema"(Sain, 2010: 323 -325).

Lo anterior, sumado a que "más de la mitad de la población colombiana con algún grado de ocupación está involucrada en actividades caracterizadas en su mayoría por su baja productividad, 
su precariedad y por estar fuera de la normatividad económica, laboral y urbanística"13 , y muchas actividades económicas importantes comparten tales características y adicionalmente "no están registradas" ${ }^{14}$. Situación que no es ajena a la realidad mexicana.

Consideramos entonces, utilizar como referencia teórica, el enfoque de la escuela que plantea la interdependencia y no la realista, en especial, por la amplitud del campo, para el estudio de la narco-violencia. Sin embargo, ante la asimetría de los sujetos, no se podría hablar de interdependencia entre Estados sino de otro tipo de sujetos y actores, que la interdependencia no contempla, como otros campos no exclusivamente económicos, por ejemplo, escenarios interculturales.

Resultando necesario adecuar el estudio de la teoría del linkage al linkage narcoviolento: "la existencia de un nexo o vínculos entre la política internacional y la interna, que hace que ambas interactúen y se influyan mutuamente"(García, 2010:90), manteniendo la productividad de las ESol narco-violentas que son subsumidas por las actividades económicas legales.

Privilegiando la garantía de los DDHH enfocando el fenómeno desde el pluralismo visto desde lo estudiado por Boaventura de Sousa Santos, articulado con un fundamento paradigmático constructivista.

Dicha concepción teórica podría plantear la coexistencia de dos o más ordenamientos jurídicos en un mismo ámbito de tiempo y espacio, como una alternativa de solución desde el elemento jurídico de las RRII de ESol, cuestionando igualmente la validez del monopolio de la fuerza estatal y del sistema internacional. No obstante, este pluralismo debe ser atendido desde su concepción socio-jurídica, para ser más omnicomprensiva de las ESol narco-violentas, que permite la codificación de "cualquier conjunto de normas que regulen la conducta humana, y que sea reconocido por sus destinatarios como vinculante"(Santos, 1998:s.p).

\begin{tabular}{|c|c|c|c|c|c|c|c|c|c|}
\hline 13 & VASQUEZ, & Ángela. & Problemas & crítico & colombianos. & Tercera & Parte. & Primera & Edición \\
\hline 14 & VASQUEZ, & Ángela. & Problemas & crítico & colombianos. & Tercera & Parte. & Segunda & Edición \\
\hline
\end{tabular}


Para estos combates legítimos o legitimados por el sistema internacional "surgen gastos reservados de la $\mathrm{CIA}$, la DEA y otros organismos regionales y nacionales que permiten operaciones políticas y acciones encubiertas antiterroristas, así como mecanismos ilegales de control social."(Rossi, 2009, p.118). No obstante, Colombia, México, Centro-América, EE.UU, Europa y todos los sujetos de la esfera internacional podrían estar "perdiendo la guerra contra el narcotráfico y... por ende, la estrategia se debe cambiar radicalmente"(Aguilar, 2009:184).

Así, el "cambio de estrategia apunta a la legalización"(Benítez, 2010:184). O a la descriminalización gradual de los factores y actores narcóticos, expresados.

Los fantasmas latinoamericanos "de la droga y la violencia... (pueden tener) un fin político con fines de control social y también de hegemonía global. Tal (seria) el caso de la política norteamericana en materia de drogas y las políticas internas... la guerra de las drogas opera allí como Caballo de Troya"(Hopenhayn, 2002:17).

En consecuencia encontrará el lector una investigación comparativa desarrollada mediante la triangulación de las variables dependientes y la independiente, esto es, de la institucionalidad en Colombia y México condicionadas por las políticas estatales norteamericanas, referida al fenómeno trasnacional de la ESol narco-violenta y la política global con la economía legal permeada por los narcodineros.

Soportado mediante los índices de violencia como tasa de homicidios dolosos que desencadena el combate y otros indicadores observables y comparables tanto políticos como sociales y principalmente, económicos y culturales entre Colombia y México a través de la ESol narcoviolenta y con especial relevancia en el mercado de consumo de los EEUU.

Se trabajará sobre la base de técnicas cuantitativas y cualitativas ajustadas a los objetivos y unidades de análisis propuestas. 


\section{CAPÍTULO IV: NARCOINSUFICIENCIA PARADIGMATICA}

Tan solo después de la IGM las ciencias sociales presenciaron el surgimiento de las RRII como disciplina que busca enfrentar la realidad internacional, conflictiva y asimétrica, desde un enfoque global. Las diferentes escuelas de las RRII representan los modos de interpretar las realidades internacionales. Ningún paradigma ha logrado encontrar el molde maestro y la disciplina exige contar con la flexibilidad teórica que conlleva la multiplicidad de percepciones que surgen en el escenario internacional, y por su puesto la influencia que ejerce dicho escenario, en los diversos ámbitos nacionales. Los factores internacionales o externos pueden desencadenar en revoluciones internas y transfronterizas, como es el caso de las ESol narcoviolentas.

Pensemos que el "significado de la distribución del poder en la política internacional está constituido en buena medida por la distribución de los intereses, y el contenido de estos intereses, se compone, de manera importante, en las ideas" (Wendt,1999: s.p).

Las ideas filosóficas principales han erigido una serie paradigmas en las RRII. Los tres principales son: el "tradicional, realista o estatocéntrico...; 2. De la dependencias... neomarxista o estructuralista...; 3. El paradigma de la sociedad global, transnacionales 0 de la interdependencia"(Arenal,2010:29). Conocidos como el realismo, el racionalismo u revolucionarismo o funcionalismo, los cuales pueden sintetizarse así (García, 2010:53-55):

\subsection{REALISMO POLÍTICO}

Aristóteles, Tucídides. Maquiavelo, Bodino, Hobbes, Spinoza, Vattel, Hegel: consideran a la naturaleza humana como intrínsecamente egoísta...la guerra algo inevitable, inherente a la condición humana, una necesidad e incluso un factor de progreso de las sociedades humanas particulares y de la especie humana en su conjunto, al eliminarse los más débiles y menos capaces. La política internacional se entiende como una política de fuerza... el fin justifica los medios... siendo los Estados los primeros actores siempre a la defensiva, sin reconocer a ninguna instancia superior a ellos mismos. La diplomacia se concibe como un ejercicio de astucia y habilidad...

\subsection{RACIONALISMO POLÍTICO}

Platón, Cicerón, Dante, Vitoria, Suárez, Grocio, Pufendorf, Wolff, Kant, Wilson: se inclinan hacia una visión del hombre que sin ser del todo optimista en cuanto a sus raíces, sí entiende que las situaciones de violencia y necesidad, inherentes a la vida, 
pueden mejorarse mediante el ejercicio de la razón, la templanza, la sociabilidad y la cultura... la guerra puede, bien paliarse con mecanismos que atemperen su crueldad, bien evitarse con dispositivos diplomáticos y de otro tipo - económico, social, cultural - que desmantelen las causas de origen... la sociabilidad...predilecta del estoicismo... existen dispositivos de consenso... la política internacional está presidida por el Derecho... la unión de los débiles o pequeños... puede alterar a los fuertes.

4.3. REVOLUCIONARISMO POLÍTICO: VIOLENTO O PACÍFICO

Agustín de Hipona, Calvino, De las Casas, Campanella, Rousseau, Penn, Payne, Fourier, Marx, Rosenberg, Chomsky, el subcomandante Marcos... ven en el hombre una criatura situada en un mundo que le trasciende, bien en sentido espiritual, porque creen o afirman creer en Dios, en un Ser Supremo, en una Religión, en una filosofía, etc.; bien en sentido material porque creen o afirman creer en la historia, la Filosofía, el progreso, la raza, la lucha de clases, etc... comparten un pesimismo existencial, antropológico y cultural (pero) los revolucionarios son idealistas en cierta forma, utópicos muchos de ellos, y optimistas respecto de sus propias posibilidades de transformar las cosas, con métodos drásticos, radicales, que excluyen toda tibieza... su horizonte de acción es siempre el genérico futuro... a grandes males grandes remedios... en su tendencia belicosa, el revolucionarismo justifica la guerra y el conflicto... propensión al totalitarismo... fundamentalismo.

Holsti afirmó "que la teoría internacional... el paradigma tradicional y los demás paradigmas han girado y giran alrededor de tres cuestiones claves: 1 . Las causas de la guerra y las condiciones de paz-seguridad -orden...; 2. Los actores esenciales y/o las unidades de análisis; 3. Las imágenes del mundo-sistema-sociedad de los Estados"(Holsti, 1977:7).

El paradigma tradicional derivado del Renacimiento y reforzado por el sistema europeo de Estados y los pensamientos de Maquiavelo y Hobbes, se hizo realidad posterior a la crisis de los 30 del siglo XX y se cristalizó terminado el periodo de la GF, que fundamentó el power politics en sociedades por regla general anárquicas y conflictivas, resultado de " un proceso de concentración y secularización del poder a nivel de entidades políticas y de descentralización a nivel internacional... legitimidad del recurso de la fuerza armada ... y la separación de las esferas de la política interna-... y la internacional"(Arenal, 2010:30).Los realistas a-históricos (Halliday,2000:73) imprimen el mismo pensamiento sin importar las características temporales y espaciales diversos.

Morguenthau visualizó tres tipos de política internacional según su finalidad "conservar el poder, incrementar el poder o demostrar el poder... la política del statu quo, la política imperialista y al política de prestigio"(Arenal,2010:134). 
En definitiva, "la mayor parte de las aportaciones de la teoría sistémica en el campo de las RRII han operado a nivel del propio sistema internacional, pero considerando al Estado como el principal, sino el único, actor de las RRII, es decir, desde una visión estatocéntrica del sistema internacional. Sin embargo... no han faltado autores que han tratado de supera(la)... incluyendo actores no estatales... teorías de la decisión... integración y el neofuncionalismo... del conflicto, el linkage politics, la teoría de la comunicación... del equilibrio, etc, son... complementarias en muchos casos"(Arenal, 2010:208). Como se describe en los dos siguientes paradigmas.

El paradigma de la dependencia es concomitante en su surgimiento con el de la sociedad global pero enfoca su teoría en las condiciones internacionales de desigualdad y dominación. Es "también llamado neomarxista... referencia principalmente a la teoría del imperialismo elaborada por Rosa Luxemburgo y Lenin... su desarrollo se produce principalmente en los países en vías de desarrollo y sobre todo en América Latina... características...: 1. La consideración del mundo como un único sistema económico, dominado por el capitalismo transnacional... la dinámica y los procesos del sistema se caracterizan en términos de conflicto, por un lado y sobre todo, de explotación y dominación, de creación continuada de lazos de dependencia entre el Norte y el Sur. Entre el centro y la periferia"(Arenal, 2010:34-36).

El marxismo ingresó como paradigma de las RRII apoyándose en los estadios generados por el "del subdesarrollo y en muchos sentidos... quedó confinado a esta área"(Halliday, 2000:42).

Por su parte, los denominados neo-funcionalistas "no encuentran una distinción fundamental entre los sistemas políticos nacionales e internacionales y que la política es definida como un proceso... los valores son dispuestos autoritariamente por grupos... perciben a las instituciones supranacionales (como) la mejor vía de satisfacer sus intereses egoístas"(Hodges en Arenal, 2010:255).

El neoinstitucionalismo pretende revalorizar la importancia de las instituciones(Rivas, 2003:37): (legislatura, sistema legal, partidos y/o movimientos políticos, económicas - empresa, religiosas, sociales, ONG, entre otras) radica en que éstas y el Estado mismo, "conforman el principal medio y pivote a través del cual se estructuran no sólo la democracia, el sistema político, sino además y de manera especial, nuestras propias políticas, conductas, reglas, normas, rutinas, códigos y 
naturalmente los procesos de socialización, participación e interacción social y política" (Rivas, 2003:37). Revirtiendo igualmente importancia "a las reglas, procedimientos, organizaciones y demás variables que integran en conjunto al sistema político"(Giddens en Cohen,1996:36-46).

En términos amplios, sistema político "es un conjunto de variables que se encuentran interrelacionadas entre sí, internas o externas... pero que de una manera directa o indirecta inciden en el mismo. La forma de interrelación de las variables será de tal manera, que unas condicionarán a otras"(Dallanegra, 2003:8).

Originalmente el concepto de sistema político viene de Aristóteles pero encontró asiento en el trabajo El Leviatán de Hobbes. Posteriormente Talcott Parsons, hizo un estudio del mismo desde el cual David Easton, se opuso, evaluando al sistema político en su dinámica y no en su estática, como Parsons sostuvo.

Easton lo definió como el conjunto de interacciones que asignan autoritativamente valores a una sociedad que son productos elaborados dentro del propio sistema y con otros sistemas políticos. Dichas interacciones operan de la siguiente forma: generan un flujo entre inputs y outputs: inputs son las demandas y apoyos que el sistema recibe de la sociedad o de determinados entes: outputs son las respuestas que el sistema ofrece a las demandas. Un verdadero proceso de retroalimentación, que Easton ha denominado feedback loop y que funciona como una caja negra.

No obstante, nos interesa para el objeto de estudio establecer una definición contemporánea que si bien no puede ser omnicomprensiva de lo que encierra el sistema político tanto en Colombia como en México, al menos nos delimite, algunos linderos para poder determinar los aspectos que a aquel le competen. Podemos decir en un sentido general, que sistema político es el sistema que opera en el ámbito de la política y el gobierno.

Y en un sentido más estricto, como el conjunto de todas las instituciones, organizaciones políticas, grupos de interés y las relaciones entre estas instituciones y las normas políticas que rigen sus funciones. O como el conjunto restringido de los miembros de un grupo social que ocupa el poder, componiendo la forma, en el que el gobierno toma sus decisiones políticas y organiza su administración. 
Una definición teórica contemporánea del sistema político proveniente del sur, lo define como el "conjunto de interrelaciones políticas objetivas (entre instituciones, Estados, partidos, grupos de presión, grupos de interés, clases sociales, organizaciones internacionales y nacionales, económicas, científicas, medioambientales y culturales) y subjetivas (normas, conciencias, tradiciones, culturas políticas, formación de políticas, toma de decisiones) tendientes a una organización sistémica de la producción y reproducción del poder societario y al ejercicio de su distribución sobre la base del equilibrio. Este sistema se estructura fundamentalmente en sociedad política y sociedad civil, en el cual el Estado desempeña el papel preminente"15.

Podemos afirmar, desde luego, que el Estado representa el espacio institucional a través del cual se ejerce el poder y también el marco reglado para llevar a cabo la política. En palabras más sencillas, el sistema político es el marco de relaciones de poder, institucionalizadas o no, pero que explican los sucesos, las filiaciones o acuerdos políticos y las interacciones que determinan la toma de decisiones que trascienden a la vida pública de la Nación. Y como vimos, su progresión puede explicarse por la violencia política que determinan las relaciones de poder. En definitiva, "violencia que ha caracterizado al régimen político colombiano"(Tokatlian,1995:32), desde mucho antes de la gestación insurgente.

El sistema político no tiene una personalidad específica, existe una relación entre éste y el conflicto armado, según el cual el primero propicia o determina la aparición de factores de violencia (véase por ejemplo el cierre de la política a sólo dos partidos durante el frente nacional y los efectos en el surgimiento de grupos armados que no encontraron otros espacios en la vida política y acudieron a las armas para expresarse, no olvidar que la guerra es el ejercicio de la política por otros medios).

En definitiva, los surgimientos de grupos armados irregulares no constituyen un hecho desligado a la función Estatal y el sistema sobre el cual se erige su estructura, por el contrario, son una consecuencia de ella misma.

15 FUNG, Thalia, CABRERA, Carlos (2002). www.nodo50.org. Sitio visitado 28/10/07. Epigrafe del libro ciencia política: nuevas dimensiones y perspectivas. Edición en la Editorial Félix Varela, La Habana. 
La política colombiana, mexicana e inclusive la norteamericana, es el resultado de una actividad tendiente al ejercicio personalizado del poder (acaso víctimas de ello seremos?), lo cual lleva a que la gente quiera los privilegios que resultan del ejercicio del mismo con codicia, porque quien ejerce la política lo hace a su favor y por ahí derecho en contra de los otros, a quienes debe representar, por supuesto que el que ha probado las mieles del poder, jamás retorna a otros caminos, sólo se pierde en el deseo de ejercer en la burocracia política para tener más y también está dispuesto a llegar a él, en la forma que sea. Es más probable retornar de la adicción a la coca o a la heroína que de la droga de la corrupción.

En los casos de Colombia y México referido al problema narcoviolento, la corrupción y la venta del poder político, representa un factor endógeno que mantiene a las ESol narcoviolentas trasnacionales.

La intervención del dinero proveniente de actividades ilícitas para financiar las campañas electorales y el consiguiente compromiso que los elegidos asumen frente a los financistas, torna común, subastar el poder político al servicio del mejor postor sin importar la procedencia de los dineros que lo compran. Generalmente ha sido la clase adinerada la compradora; pero que desde la década del 80, esa ralea está constituida también con personas que han ascendido en la escala social a partir de narco-conductas encubiertas pero reprochables.

En definitiva, la alta concentración de la riqueza y el cerramiento de caminos accesibles para la obtención de propósitos socialmente deseables (propiedades), cada vez empuja más al ciudadano promedio a dedicar su intención a actividades ilícitas y por esa vía a intervenir con esos dineros en el campo fértil del codiciado poder, que garantice los privilegios de la clase social que históricamente ha dominado, pero que ahora se ve haciendo pactos con el diablo, para alcanzar un resultado favorable en las urnas. Aciago augurio. El Estado, actor del conflicto, el cual a través del ejército -brazo armado legítimo del sistema- enfrenta a los rebeldes para intentar el restablecimiento del orden instituido por las normas del Estado, pero dominando, por su hegemón político, en los casos de Colombia y México, es claramente EEUU.

La idea es que el sistema político democrático refleje la querencia de la sociedad y los propósitos que persigue y defiende, se supone que la sociedad debe elegir a los mandatarios en la medida en 
que representen esos objetivos, la distorsión de esto es que los políticos ofrezcan por grupos el dinero del Estado - mediante la contratación administrativa y la burocracia- para la obtención del favor electoral, lo que se denomina clientelismo. Pero en general, debe existir comunicación entre la sociedad y el sistema político.

El Estado efectivamente es un ente jurídico que representa a la Nación hacia afuera pero que hacia adentro tiene los propósitos señalados por la constitución. El sistema político colombiano, está condicionado desde afuera y desde dentro, desde el extranjero mayormente, porque la capacidad adquisitiva del país genera una subordinación que influye en las decisiones políticas internas, en materia económica y social.

Además, el sistema político no tiene reglas específicas y el Estado se debe sujetar a las previsiones legales, en un marco normativo. Todo esto porque las fuerzas económicas se mueven independientemente de los Estados, como lo hacen, las actividades ilícitas de los marcos constitucionales y legales, nacionales, internacionales y universales.

A partir de los contrastes generados por la ambigüedad conceptual es posible afirmar que no existe cosa juzgada conceptualmente hablando y que una parte de esa confusión es útil a los objetivos norteamericanos. Esto revela lo imperioso de reforzar el campo jurídico, de tal manera que sea tan fuerte que no sea susceptible de cambios en razón a justificaciones y conveniencias políticas.

El neoinstitucionalismo compone en sí "una de las expresiones acabadas de la transdisciplinariedad y, naturalmente de los avances de la economía y la ciencia política" (Rivas, 2003:36-46). El inconveniente en esta estructura lógica de pensamiento es el elemento humano corrupto que paraliza el sistema.

Las RRII "entre los países desarrollados y la periferia son relaciones de dependencia más que de interdependencia"(Peñas, 1997:138). La autotomía política esta medida por la posibilidad del Estado soberano a decidir, a optar libremente, sin ninguna clase de discriminación y respetando la igualdad de los mismos Estados. La soberanía no es una condición del Estado; es una consecuencia de la territorialidad y de la autonomía política. 
Los imparables e impactantes avances tecnológicos amenazan con desarrollarse al ritmo impuesto por las necesidades económicas de una sociedad de consumo que cada día se polariza inmortalizando la desigualdad entre los individuos a nivel planetario. Se avecina un cambio de roles evidente en lo económico donde el Estado se convierte en la Empresa mediante la atribución de sus funciones en manos de sectores privados, o mixtos, en el mejor de los casos, en un teatro transnacionalizado.

Así, "desde el consenso de Washington de 1989, la tendencia es el achicamiento del Estado y su rol, (hacía) las privatizaciones" (Dallanegra, 2003:7). Se jerarquiza el concepto de mercado y se aviva la tensión con los Estados soberanos, que muchas veces cede mediante de la consecución de beneficios particularismos de las élites de poder, entiéndanles, públicas y privadas. Aunque si bien, no podemos hablar de una sustitución de la lógica interestatal por la lógica transnacional, si podemos aludir a una coexistencia entre ambas en el escenario internacional.

La principal característica del concepto trasnacional es "la afirmación de la necesidad de cambiar el clásico paradigma del Estado como centro de la teoría internacional... Keohane y Nye definen las relaciones trasnacionales como contactos, coaliciones e interacciones a través de las fronteras del Estado que no están controladas por los órganos centrales encargados de la política exterior de los gobiernos"(Keohane en Arenal, 2010:300-301).

Keohane, Nye y Hayser se percataron de la inoperabilidad del sistema tradicional de RRII al no incluir dentro del estudio de la realidad a los actores no estatales, proveyendo diagnósticos errados y por ende la clausura de las posibles soluciones a las realidades internacionales. Pensamiento que representa gran utilidad para el análisis sistémico de la narcoviolencia. Por su parte, Falk "desarrolló una teoría de alternativas y oposiciones al poder estatal a nivel internacional que se basada también en necesidades humanas e interacciones trasnacionales, entre actores no estatales"(Halliday, 2000:42).

Rapoport definió sistema como "una totalidad que funciona como tal en virtud de la interdependencia de sus partes... y el método que trata de descubrir cómo esto se produce en el seno de la más amplia variedad de sistemas llamado teoría general de los 
sistemas"(Arenal,2010:205). Kaplan al respecto, estimó que "la teoría de los sistemas permite la integración de variables provenientes de distintas disciplinas"(Kaplan en Arenal, 2010, p.205). Braillard comprendió por sistema al "conjunto de elementos en interacción que constituyen una totalidad y que manifiestan una cierta organización"(Arenal,2010:206).

Aron distingue "entre sistemas homogéneos y heterogéneos... homogéneos... en los cuales los Estados pertenecen al mismo tipo y obedecen al mismo concepto de política... heterogéneos... a aquellos sistemas en los que los Estados están organizados de acuerdo con otros principios y proclaman valores contradictorios"(Arenal, 2010:206).

Hoffman conforme con el pensamiento aroniano revirtió vital importancia a imprimir "una radical diferencia entre el medio interno y el medio internacional... (preconizando igualmente) una teoría empírica... un estudio sistemático de los fenómenos observados, destinado a poner de manifiesto las principales variables, a explicar las conductas, y a dar a conocer las formas características de las relaciones entre las unidades"(Hoffman en Arenal, 2010:169-170).

La transnacionalización política que evidencia la imposición de intereses y los consecuentes efectos de la dominación, reina en escenarios asimétricos y sujetos y actores con las mismas diferencias estructurales, como lo representa el actual escenario internacional. Evidenciando como "las relaciones trasnacionales erosionan el proceso democrático"(Kaiser en Arenal, 2010:306).

Lo que conlleva a los actores y sujetos participantes en el sistema a emplear estrategias definidas por la doctrina como la teoría de los juegos que "establece la forma como las personas racionales actúan en unas situaciones de conflicto algo especiales" (Nicholson en Arenal, 2010:285). Claro está, sin tener muy consensuado a lo que se refiere la racionalidad en las RRII. Porque aquellos que se dicen más racionales son los más violentos y han conseguido el protagonismo e imposición de los planteamientos realistas clásicos.

Igualmente se puede referir en cuanto al alcance del concepto teórico del Linkage cuyo inicio y final se describen como "inputs y outputs y se diferencian según se originen en el Estado o el sistema internacional. Rosenau establece tres tipos de linkage: penetrativo, reactivo y emulativo. 
El... penetrativo tiene lugar cuando los miembros de una unidad actúan en el proceso de otra unidad, y abarca no sólo la penetración política y militar, sino también la económica. El... reactivo se produce cuando los acontecimientos en un sistema político provocan una reacción en otro sistema político, sin que exista participación directa de los miembros de un sistema en el otro. El... emulativo ocurre cuando la reacción que se produce en un sistema, a consecuencia de los acontecimientos que tienen lugar en otro... por ejemplo cuando un golpe de Estado origina otros"(Rosenau en Arenal, 2010: 295-296).

Por su parte la teoría referida a los regímenes internacionales refiere a la interdependencia compleja como aquella que caracteriza a las RRII contemporáneas, que se encuentran "marcadas por el juego conjunto de las relaciones diplomático-estratégicas y de las relaciones económicas internacionales" (Krasner en Arenal, 2010:313).

Los nuevos niveles incrementados de interdependencia en el escenario internacional también producen una significativa reducción en cuanto a la "capacidad de los gobiernos para lograr la autonomía nacional, objetivo central característico del tradicional sistema de Estados"(Morse en Arenal, 2010: 301).

Junto con el proceso globalizador, la agenda internacional de tipo vertical comenzó a horizontalizarse mediante el reconocimiento de nuevas variables, sin descartar a la seguridad, pero mediante un tratamiento menos mono-causal. La globalización del sistema mundo incrementó las infinitas interrelaciones entre sus actores, así como también las ha hecho difusas, esto es, difíciles de percibir en todas sus dimensiones y en sus reales cantidades.

El impacto que produjo el proceso de la globalización en cuanto al tipo ideal de Estado, se concentró en el concepto hegemónico proveniente de la "tradición liberal europea - aterrorizada por las características y los efectos de la fase jacobina de la Revolución francesa - y la revolución norteamericana. De esta manera el proyecto globalizador busca generar un consenso entre la comunidad global sobre la necesidad o pertinencia de adoptar los valores propios del Estado de Derecho y el modelo constitucional vinculado a él; consenso que se realiza al margen de los procesos sociales internos (sean nacionales, locales o comunitarios), que no necesariamente abrazan tales valores por ser, por ejemplo, contrarios a su cosmovisión"(López, 2013:14). 
Según Sassen el proyecto globalizador fue promovido "desde un reducido número de países: EEUU, UK, Alemania, Francia, Luxemburgo y Suiza”(López,2013:17-18).

La globalización produce la afectación al esquema westfaliano de soberanía. Una soberanía operativa "a partir de dos ámbitos. En el interno, como la capacidad de autorregulación y autodeterminación de un Estado y de una sociedad o comunidad nacionales, sustentado en la obediencia legítima de los pobladores frente a la autoridad; $y$, en el externo, como la no intervención de ningún otro actor en los asuntos de un Estado, el reconocimiento de los demás Estados como soberanos y un escenario de igualdad entre ellos... una idea operativa de globalización jurídica... (es visible en) el control de lavado de activos y en el dedicado a los diálogos jurídicos globales... /entre tanto... el fenómeno de la desoberanización que se advierte como base de la globalización constitucional... permite la diferenciación entre los distintos Estados... (operando en 2014) una desoberanización en los eventos que subvierten el principio de autodeterminación (libertad) y que explican el actual andamiaje funcional de los Estados y las sociedades a las que pertenecen (Luhmann,2007:s.p). Tal Subversión ${ }^{16}$ puede ocurrir desde el interior (caso de las dictaduras), por medio del interior (al desconocer el principio de autodeterminación) o desde el exterior (negación del derecho internacional)”(López,2013:9-13).

Convirtiéndose al concepto de la soberanía en uno de tipo "anacrónico que, en el mejor de los casos, es disfuncional y, en el peor, engañoso"(Kahn, 2012:12). Krasner afirmaría en consecuencia que la soberanía del Estado fue erosionada por la globalización (Krasner, 1999: 12-13).

Galtung señaló al derecho internacional como "una fuente de más violencia estructural, toda vez que los convenios y tratados internacionales son el reflejo de situaciones de poder, que sólo aprueban y tienen vigencia cuando los poderosos han logrado que los más débiles acepten sus condiciones"(Galtung, 2003:11).

Por eso la corriente hegemónica norteamericana considera que "la soberanía sigue siendo un elemento crítico de su concepción de la fuente y el significado de la vida política. El soberano popular adquiere su existencia mediante un acto violento propio que le da existencia: la

16 Subversión pues no se trata de un fenómeno destructivo sino complejo dice el autor, permitiendo afectaciones parciales a la soberanía. 
revolución. La Constitución se muestra como el producto de ese sujeto soberano... el soberano popular se entiende como un sujeto colectivo e intemporal en el que todos participan" (Kahn, 2012:185).

Gramsci entendió a la hegemonía como "el poder adicional del que goza un grupo dominante en virtud de su capacidad para impulsar a la sociedad en una dirección que sólo sirve a sus propios intereses y que es entendida por los grupos subordinados como interés general" (García en Pereira, 2009, p. 658).

Por esto Francis Fukuyama consideró “que el curso del fin de la Historia había llegado a su fin... no tanto por una convergencia gradual de los sistemas políticos y económicos en una única síntesis liberal sino por la victoria incontrovertible de ésta"(García, 2010, p.129). Pero su posibilidad de consenso es bastante lejana pues reviste las mismas diferencias culturales que ha enfrentado las ideas sobre las cuales se estructuran los gobiernos nacionales que interactúan en la sociedad internacional.

La concepción sociológica "es más extendida de lo que explícitamente se reconoce y si la encontramos en autores norteamericanos significativos, aparece, sin embargo, más arraigada en sus cultivadores europeos, tal vez porque la propia sociología general, en Europa, dio más ampliamente cabida desde un principio, en su temática, a los fenómenos y procesos sociales internacionales" (Truyol en Arenal, 2010, p. 149). Por lo cual Durkeim identificó a los hechos sociales como "límites impuestos al individuo. En RRIl ésta función la desempeña el concepto de sistema"(Halliday, 2000, p. 131) o debería desempeñar.

Así mismo para Cox "las fuerzas sociales podrían superar estos proyectos hegemónicos buscando una mayor libertad y participación política, económica y social... las élites económicas se organizaron en el plano trasnacional para conservar su poder, mientras que los grupos tradicionalmente desfavorecidos se fragmentaron" (Cox en Richmond, 2012, 218). Pero no es simplemente considerar la posibilidad de la superación de las ESol narcoviolentas sino su imbricación en los sistemas políticos de Colombia y México, y en aquellos Estados donde se radique la ESol, bien por factores de debilidad institucional o por la narco-migración fomentada 
por mediadas de seguridad e inteligencia, principalmente liderada por los EEUU y seguidas por la sociedad internacional.

La dificultad entre separar los ámbitos internos y externos generó el protagonismo de los conflictos de tipo interméstico, los cuales, pueden operar en tres escenarios o niveles: “interestatal, inter-socioeconómico e inter-ideológico"(Halliday, 2000, p. 224).

Es por lo anteriormente descrito que consideramos que el mejor camino paradigmático debe construirse de la amalgama de la línea del postbehaviorismo o pluralismo paradigmático que ofrece interpretaciones y soluciones a los problemas del presente (Arenal, 2010, p. 395).

Ahora bien, en cuanto a los debates (García, 2010, p. 61 -62 y 64) de las RRII podemos sintetizarlos, así:

4.4 REALISMO VS IDEALISMO (1914-1949), es decir, el final de la IGM y el comienzo de la GF) con las crisis de la década de los treinta, el idealismo dio paso al realismo.

"el realismo ve a la Sociedad Internacional como estructura jerarquizada del poder; el idealismo como una organización cosmopolita de equilibrio de poder... parte de las humanidades tradicionales - incluidas las ciencias sociales - como fundamento teórico y metodológico de sus investigaciones.

4.5 CIENCIAS VERUS HUMANIDADES (1949 y 1979)

Opone a universitarios y académicos primordialmente anglófonos de ambas orillas del Atlántico, partidarios unos, de la aplicación del positivismo científico a las Ciencias Sociales (Norteamérica), y, otros, de mantenerse fieles a los métodos tradicionales de las Humanidades (Gran Bretaña). La historia del debate se sitúa es el papel que desempeña la Historia... se trata de una re-elaboración cientificista que modifica el concepto tradicional de estructura internacional, vista como estructura anarquizada interactiva e interdependiente... el poder se mide con arreglo a nuevos parámetros definidos por factores relevantes... la economía y el progreso científico y tecnológico. El Estado sigue ocupando el centro... pero comparte con otros actores... de ahí el interés por las corrientes behavioristas. El sistema internacional es cerrado, en equilibrio y conservador; se adapta al modelo de Easton... fundamentalismos, liberalismo monetario, revolución conservadora.

4.6 GLOBALIDAD VERSUS ESTATOCENTRIMO (1979 y 1989) 1980 - término universal - En Francia se denominó mundialización - defensores del sistema económico dominante.

Se manifiesta el escenario de un Cuarto debate: Anarquía -caos; homogeneidad heterogeneidad; inclusión - exclusión. 


\subsection{CONCEPTUALIZACION DE LA PAZ}

Finalmente, "en la literatura de las RRII y sus disciplinas menores pueden identificarse varias estrategias para conceptuar la paz (Cox en Richmond, 2012, p. 41-43). Las cuales pueden resumirse así:

\section{a. IDEALISMO}

Describe una paz futura y total que incorpora una armonía social, política y económica (de la que no hay ejemplos) representada por el internacionalismo, la federación y el gobierno mundial. Una forma ideal, lo que para los idealistas no significa, sin embargo, que deban abandonarse las tentativas de alcanzar la paz.

$\begin{array}{lllr}\text { b. } & \text { LIBERALISMO, INSTITUCIONALISMO/INTERNACIONALISMO } & \text { LIBERAL, } \\ & \text { NEOLIBERALISMO, IMPERIALISMO LIBERAL Y, RECIENTEMENTE, REALISMO } \\ & \text { LIBERAL } & & \\ \end{array}$

Describen una paz general alcanzable que deriva de las instituciones y organizaciones internacionales que proponen acuerdos y normas universales. Esto proporciona una base para el individualismo y para los derechos y las responsabilidades sociales, políticos y/o económicos, basados en niveles justificativos de justicia y de consenso. Esta forma de paz pueda verse truncada por la injusticia, el terrorismo, el secesionismo o la guerrilla perpetrados por actores marginado que no aceptan las normas y los marcos engendrados en tales acuerdos universales...paz perpetua Kantiana... paz liberal, arraigada en la ONU y la sociedad internacional de posguerra fría.

c. REALISMO

Considera la paz resultante del equilibrio del poder, o la dominación, en las percepciones de amenaza y en la glorificación del interés nacional con relación al poder militar.

\section{d. ESTRUCTURALISMO}

De corte marxista presentan a la paz como algo basado en la justicia social, la igualdad y en un sistema justo de comercio internacional. En el que los Estados y los actores no están organizados jerárquicamente según indicadores de clase económica. En estos términos, la paz es alcanzable, pero probablemente sólo tras un gran vuelvo - quizás revolucionario - en la economía internacional, en las jerarquías y sistemas económicos y de clase que reorganicen los estados y el oren internacional de manera que represente mejor los intereses de los trabajadores y de la sociedad, y no sólo el de las élites pudientes.

\section{e. TEORÍA CRITICA Y POSTESTRCUTURALISMO}

Basados en cierto grado en el legado intelectual de los puntos 1, 2 y 4, describen una paz emancipatoria, polifacética, que al considerar otras formas de justicia, de identidad y de representación permite tener en cuenta a actores marginados (como mujeres, niños y minorías) y los factores medioambientales. 


\subsection{UNA TEORÍA PARCIAL NARCOVIOLENTA: ADAPTACIÓN A LAS ESCUELAS DE LAS RRII Y LA CONSOLIDACIÓN DE NARCOPARADIGMAS}

Evidentemente la teorización de la narcoviolencia no está consensuada. La corriente mayoritaria sostiene que, "la producción, el trafico y el consumo de drogas ilícitas continúan siendo uno de los principales problemas del mundo actual... desde su detección y reconocimiento hace varias décadas por parte de la comunidad de naciones, y a pesar de la voluntad política de luchar frontalmente por su erradicación, el mercado de estas ha aumentado, sus mecanismos de producción son más eficientes entre ellas el terrorismo, se hacen cada vez más fuertes. Por otra parte, este flagelo cuenta con una característica muy singular pues parece mutar constantemente, lo cual le permite sobrevivir y salir fortalecido de las diferentes estrategias que contra él se aplican".

Otros autores sostienen que la narco-oferta no ha disminuido y su economía ilegal sigue creciendo mediante el uso de la violencia, sin embargo, dicho marco narcoviolento ofrece posibilidades de proyectos de vida, sin atender a temas morales.

Es importante para esta investigación partir del precepto del crimen como criatura no necesariamente narcotizada, como lo estableció falsamente el mass media conducido por el hambre de la política.

Presiones externas, más concretamente norteamericanas, crean los conceptos y las problemáticas que golpean Estados débiles dentro de las relaciones internacionales asimétricas, que los hace percibirse unos a otros como amenazas, escondiendo sus propios intereses en dominar la región para acreditar ante la sociedad internacional su poder irrefutable y hegemónico. Es así como, "la internacionalización adopta la forma de intervención" (Borda, 2012, p. 11).

Desde hace varios años y con una frecuencia constante en la sociedad internacional en general y particularmente en América Latina - AL, se refieren los riesgos de la colombianización y ahora mexicanización de los Estados.

Una ecuación teórica ubicaría a los EEUU como numerador y a México y Colombia como comunes denominadores en cuanto a la lucha contra el narcoterrorismo se refiere. El mecanismo militar 
para combatir la narcoviolencia asegura su status quo. El continuo uso de la teoría realista mantiene viva la narcoviolencia que afecta al sistema internacional y es funcional a las élites de poder y grupos socioeconómicos. Distorsionando la realidad narcoviolenta en Colombia y México.

$$
\frac{\text { Estados Unidos }}{\text { Mexico y Colombia }}=\text { Militarización contra el narcoterrorismo }
$$

Respecto a los debates contemporáneos sobre la condición fallida de los Estados es necesario resaltar que todos surgen "del modelo liberal europeo y el producto de la Revolución estadounidense... aquellos que se acerquen al ideal Estado de derecho serán menos fallidos (o dejarán de serlo), lo que garantiza reputación y garantía de supervivencia dentro de los cánones del estado westfaliano"(López, 2013, p.15-16). Pero como vimos anteriormente la globalización rompe los parámetros westfalianos.

También se han asimilado a conceptos tales como Estados Exiguos e inviables y las condiciones de ellos como las del Fallidos pueden encontrarse interconectadas o pueden presentarse de manera individual. Entonces, "un Estado fallido no es exiguo de manera necesaria, aunque la exigüidad favorece a veces que el proyecto estatal no prospere. El fallo del Estado puede deberse a la incapacidad manifiesta de lograr una forma política estable... un Estado inviable no lo es tampoco por su exigüidad sino que entran en juego otros factores como la violencia, la corrupción, el subdesarrollo, las catástrofes naturales, por ejemplo. Un Estado exiguo puede ser el resultado de procesos secesionistas debidos a micro-nacionalismos irredentos; su viabilidad sin embargo, puede lograrse si consigue desempeñar un papel necesario en la escena internacional" (García, 2010, p. 198).

La concepción de Estados Fallidos refleja la condicionalidad de los estándares atribuidos a la economía global lo que "implica también una tremenda interdependencia en las dimensiones securitarias. Así, la relevancia internacional ya no concierne solo a la posesión de recursos de poder (militares, políticos y económicos), tal y como se había asumido en la lógica westfaliana, sino que la debilidad, la fragilidad, se convierten en bazas pertinentes en el juego político mundial 
dada su potencialidad para desestabilizar el sistema internacional y generar anarquía" (Rojas, 2007, p. 73-85).

Dicha inestabilidad ha sido provocada sin lugar a dudas por las ESol narcoviolentas de Colombia y México, no obstante, la inestabilidad parece resultar funcional a intereses legales tanto nacionales como internacionales, los que aseguran a través del discurso doble moralista, el mantenimiento del status quo narco-violento.

Consideramos que la real implicancia de los denominados grupos narcoviolentos colombianos y mexicanos no es el generar Estados Fallidos, Exiguos o inviables, sino se adaptaría al concepto teórico base de ésta tesis doctoral, que son los Estados Superados, es decir, el Estado se encuentra parcialmente en mora en cuanto a la ejecución de sus obligaciones soberanas dentro de sus territorios respectivos. Convirtiéndose así las ESol en agentes superadores de los vacíos dejados, voluntaria o involuntariamente, por los Estados Superados. No obstante existen también Estados Superadores como lo representaría EEUU frente a Colombia y México en cuanto a la lucha antinarcótica se refiere.

La teorización política internacional "nunca ha dejado de estar obsesionada con la persona del soberano... Hay que cortarle la cabeza al rey"(Focault, 2012, p.12). Es decir, la corrupción de los sistemas representaría al Rey o a las inobjetables decisiones soberanas, que utilizarían a los moldes institucionales como narco-instituciones parciales, es decir, ciertos sectores legales y estatales, apoyarían la actividad violenta de las ESol, las cuales se encargan de satisfacer las necesidades de sus poblaciones más marginales.

La narcoviolencia que experimentan Colombia y México y su actividad ilícita trasnacional que desborda otro tipo de actividades ilegales, pueden representar un subsistema regional donde "un Estado o dos o más Estados cercanos e interrelacionados que tienen algún vínculo étnico, lingüístico, cultural, social e histórico común y cuyo sentido de identidad es con frecuencia incrementado por las acciones y actitudes de Estados externos al sistema" (Cantori en Arenal, 2010, p. 228-229). Casi representados en subsistemas narco-militares y narco-ideológicos. 
La periferia de la perifieria se sirve de la narcoviolencia como economía subterránea para dominar y disputar poder legítimo mientras que EEUU homogeniza a los Estados que en la práctica son heterogéneos como Colombia y México.

Estados que adoptan la postura norteamericana por el reconocimiento de su debilidad, carencia de autonomía y limitación de la soberanía en las RRII asimétricas. Garantizando la continuidad diplomática y comercial.

No obstante es improbable "prevenir y preparar una guerra al mismo tiempo" (Einstein en Richmond, 2012, p. 21). Pues los cárteles actúan independientemente de las decisiones estatales y continúan dominando y monopolizando el negocio del narco y sus delitos conexos, mediante la efectiva organización trasnacional de sus operaciones, que muchas veces, cuentan con el beneplácito de sujetos legales, tanto públicos como privados, nacionales y globales.

Para ejemplificar la globalidad de los grupos narcoviolentos podemos mencionar el crimen organizado oriental representado principalmente en las actividades de la Yakuza japonesa y las triadas chinas" (Ávila en López, 2010, p. 113).

El crimen organizado estructura a sus empresas bajo sistemas muy similares a las de "las empresas multinacionales que operan dentro de la economía legítima" (Fernández, 2008, p. 14). Las ESol narcoviolentas son organizaciones criminales "sumamente cualificadas... forman parte de un concepto mas global que se atiene a las necesidades del mercado. La ejecución de los actos delictivos... se lleva a cabo siguiendo el principio de la división del trabajo (Sielaff, 1989, 9. 41)... el crimen organizado es una construcción cultural, jurídica y política" (Fernández, 2008, p. 21).

Esta especie de narco-integración "no sólo significa una mayor interdependencia entre las economías y sociedades que la emprenden. También puede llegar a determinar el tipo de desarrollo que tendrá cada uno de los... participantes, de acuerdo a cuál sea el alcance y profundidad de los esquemas que se adopten" (Palomares, 2009, p. 157).

La clave no es el porcentaje de utilidades o el interés que perciben en sus actividades las ESol narcoviolentas sino que una vez los recursos ingresan en el sistema financiero legal, el sistema 
fracasa, es una farsa. Pero su actividad sigue siendo legitimada por elites socioeconómicas reducidas.

Para las ESol narcoviolentas "el blanqueo se reduce en buena medida a la transferencia de los beneficios de la droga a sus empobrecidos países y regiones de origen, donde no tienen demasiados problemas a la hora de hace uso de su dinero ilícito" (Fernández, 2008, p. 134 -135). En cuanto a lavado de activos "la Unidad de Información y Análisis Financieros (UIAF) colombiana y las normas reglamentarias, al igual que ocurre en otras latitudes, no solo incorpora automáticamente los estándares internacionales... sino que además abre espacios para que el Estado vigile y se inmiscuya en la vida privada de los asociados" (Garay, 2012, p.22).

La sociedad internacional "a través de la OCDE, creó en 1990 el Grupo de Acción Financiera GAFI, contra el lavado de activos y el financiamiento del terrorismo. Tiene una subsede regional a la que pertenece Colombia, GAFISED... A nivel internacional, EEUU también ejerce una cerrada vigilancia sobre Colombia, a través de su Departamento de Estado con la llamada descertificación en materia de lucha contra el narcotráfico. Existe una red de agencias norteamericanas de control que defienden las políticas internas de Colombia en esta materia, tales como FINGEN, OFAC, FINRA, SEC, NNIC, etc" (Romero, 2011, p. 207-208).

No obstante, "los llamados paraísos fiscales son más bien poco utilizados por los grandes empresarios de la droga. Estos prefieren sistemas sofisticados para poder hacer uso de este dinero de forma que tienden a depositar sólo cantidades residuales en dichos paraísos" (Suendorf en Fernández, 2008, p.180).

La ilegalidad de la narcoviolencia constituye un nuevo concepto de poder que le hace contrapeso al poder legitimado. Requiriendo del pluralismo teórico para su diagnóstico. Las ciencias sociales se teorizan deontológicamente y no ontológicamente. Las RRII deben des-teorizar para re-teorizar ontológicamente, en este caso, al sistema narcoviolento paralelo o simplemente al subsistema trasnacional narcoviolento.

Teoría isla o general para la realidad internacional narcoviolenta, que posibilite una verdadera integración entre México y Colombia para diagnosticar sus políticas de manera soberana y que 
detenga los impactos desastrosos a los estándares mínimos de los DDHH. Y dejen de seguir los mandatos de su hegemón, conviniendo en la calidad de ser Estados superados por las ESol narcoviolentas.

Los reales narco-estados no serían ni Colombia ni México, pero son las matrices de otros, que si podrían clasificar como tal: Guinea - Bisauu "se ha convertido en un punto de tránsito de casi una cuarta parte de la cocían que los traficantes iberoamericanos exportan a Europa, actividad comercial que supera hasta 7 veces el producto nacional... Afganistán... que condena moralmente el consumo de drogas pero permite al mismo tiempo su producción a cambio de cobrar varios impuestos... Corea del Norte. Las primeras evidencias sobre actividades relacionadas con el comercio de drogas se remontan a... 1970, pero todo indica que ese negocio cobró auge tras la caída del Muro de Berlín. Como consecuencia del drástico recorte en las ayudas recibidas de la US y China... se vio la necesidad de buscar nuevas fuentes de ingresos... según informes de los servicios de inteligencia de EEUU y Corea del Sur, y de algunos desertores del régimen, el propio Kim Jong -II ordenó a principios de los años noventa desarrollar la industria de las drogas y crear varias fábricas farmacéuticas que incluyeran en sus tareas de producción de heroína y metanfetaminas... promedio de 30 a 40 toneladas de opio anuales... no es casual que se haya acusado al régimen norcoreano de colaborar con la Yakuza japonesa, las tríadas chinas y otras organizaciones criminales rusas, de Europa occidental y el sudeste asiático" (Ávila en López, 2010, p. 315-318). 


\section{CAPÍTULO V: EL HEGEMÓN Y EL SISTEMA MUNDO: ASIMETRIAS E INFLUENCIAS JURÍDICO- POLÍTICAS DE LA POSGUERRA FRÍA Y EL FLORECIMIENTO DE NUEVAS AMENAZAS}

El sistema mundo ha variado radicalmente las interacciones que se suceden en los Estados clásicos y contemporáneos. Igualmente el tipo de enfrentamientos mutó a nuevas formas, más internas que internacionales, que resultan siendo intermésticas.

En 1945 la Unión Soviética y EEUU resultaron vencedores en la Segunda Guerra Mundial -IIGM-, convirtiéndose en potencias globales. EEUU, líder de occidente, poseía el "70\% oro del mundo no socialista... 50\% industria mundial... monopolio nuclear... dominio del sistema financiero... desarrollo económico... expansionismo militarista... La Unión Soviética (se consolidó como) superpotencia... más (por) elementos políticos militares que (debido) a su potencial económico"(Zeraoui, 2011, p. 82).

La Guerra Fría- GF- impregnó al sistema mundo el enfoque de la teoría de los bloques de poder, en el marco de un esquema bipolar que partió "de la división del mundo... enfatizando la zona de equilibrio <<Europa occidental y Europa oriental >> y la zona de seguridad tanto estratégica como económica-estratégica...aunque los orígenes del proceso de GF pueden ubicarse desde la IIGM o inclusive desde la formación de la Unión Soviética, la fecha simbólica... es 1948, con el... Golpe de Praga" (Zeraoui, 2011, p. 82).

Fundamentado lo anterior, en la manifestación formal y oficial de las dos potencias de tener más de lo necesario -overkilling capacity- para desaparecer a la otra. EEUU "24 veces a la URSS, mientras que ésta puede destruir a aquel 42 veces" (Zeraoui, 2011, p. 89).

Silva definió por Zona de equilibrio al "conjunto de países con condiciones tales (población, extensión territorial, fuerza económica, etc) que si cualquiera de ellos pasara de una zona de (equilibrio) a otra, tendría lugar un cambio cualitativo (sustancial) en el balance de poder" (Zeraoui, 2011, p. 69). Sin embargo, Zeraoui anotó que: "las características señaladas... deben ser matizadas. Ni la población ni la extensión territorial son determinantes. La fuerza económica, o sea, el grado de desarrollo y la situación estratégica... son los elementos fundamentales... (Ahora bien) para fines analíticos es necesario... subdividir la periferia en una zona de seguridad, una de 
influencia y la periferia propiamente dicha... Para Estados Unidos, América Central y el Caribe, conforman su zona de seguridad geoestratégica mientras que el Medio Oriente, por su importancia en hidrocarburos es su zona de seguridad económica” (Zeraoui, 2011, p. 70-71).

En cuanto a las RRII, la zona de influencia representa a los lugares donde "hace presencia la superpotencia (y)... no necesariamente recubre toda la zona de seguridad" (Zeraoui, 2011, p. 74). Los bloques de poder se acoplaron a lo definido por George Kenan a través de la Doctrina de la Contención y la teoría de los Dos Mundos de Zhdanov. Se hicieron fuertes en la década del 50 y empezaron su plan de expansión al Tercer Mundo. Determinando la realidad bipolar a "los procesos regionales con mayor fuerza (durante los periodos de GF) o con menor presencia de las potencias globales (durante la distensión)...hasta 1989 cualquier análisis regional (se enfocó desde) el marco bipolar" (Zeraoui, 2011, p. 66).

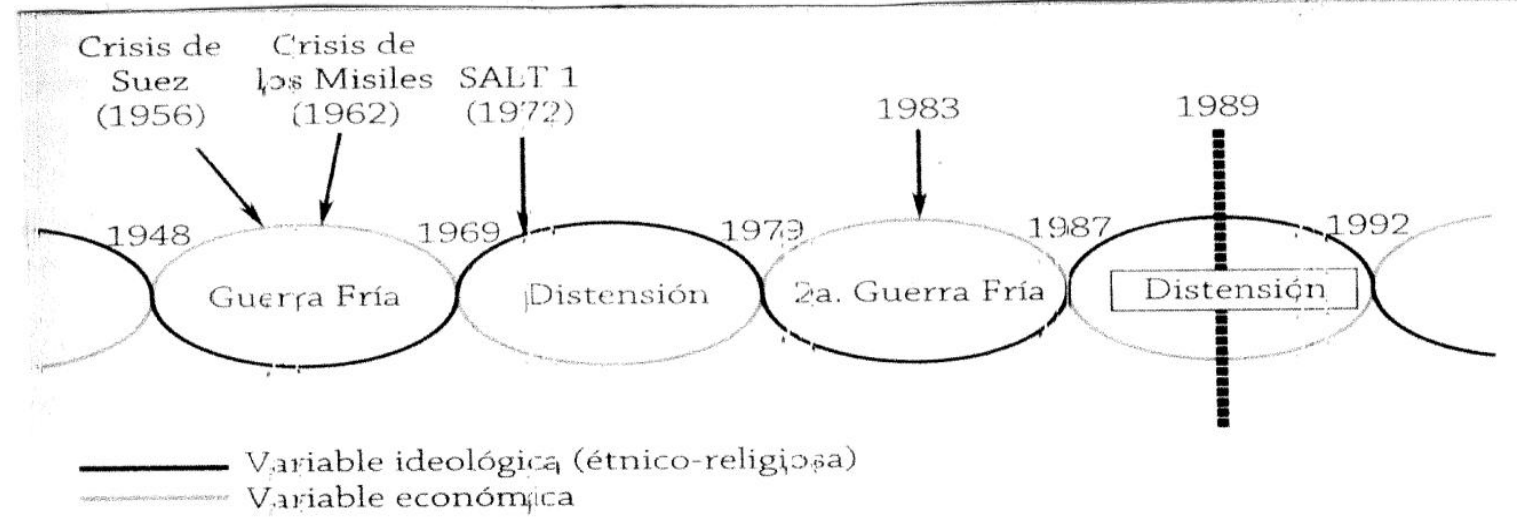

Cuadro adoptado de la obra citada. (Zeraoui, 2011, p. 77).

Los pactos económicos de la URSS sobrepasaron sus arcas, lo que provocó, el principio del fin de la GF. Gorvachov debilitó al politburo- donde se hace la política - entre 1987 y 1990, mediante reformas relevantes a las personas de nacionalidades no determinantes dentro de la Unión Soviética, se autonombró Presidente del Presidio del Soviet y determinó que una vez terminado su periodo, el líder se denominará Presidente de la República. En realidad fue un cambio de forma y no de fondo. Sin embargo, al ampliarse el sistema político permitiendo la multiplicación de partidos, los conflictos nacionalistas florecieron. 


\subsection{NACIONALISMO DE LA POSGUERRA FRIA -PF- DESPUES DEL DERRUMBE DE LA UNION SOVIETICA}

La PF no cuenta con consenso sobre sus etapas. Se produce una vez concluido el periodo de GF que dominó el sistema mundial del Siglo XX y que parecía perpetuo, pues se actuaba bajo una lógica predecible que visualizó alianzas políticas, económicas y militares. La cuestión ideológica dominante desapareció como elemento catalizador. Al terminarse el modelo, los sujetos y actores internacionales, perdieron los conceptos analíticos en un esquema nuevo sin definiciones, por lo que, "las contradicciones internas e interestatales se agudizaron frente a la ausencia de la pugna interbloquista" (Zeraoui, 2011, p. 66).

En 1989 Kaplan (Arenal, 2010, p. s.d) refirió el cambio de un esquema bipolar flexible a un esquema no definido. Lo que permite pensar que a partir de la década del 90, el sistema mundo se caracterizó por la presencia de una unipolaridad norteamericana, manifestada en intervenciones armadas, que se extendieron hasta el año 2008, principalmente. Lo que desató múltiples crisis nacionalistas.

Dos obras destacadas sobre el tema son las de Francis Fukuyama que reduce los diversos enfrentamientos a una pugna filosófica de los griegos entre materialismo (modelo comunista o socialista - URSS) vs idealismo (capitalismo o la sociedad liberal). No obstante distingue dos elementos sueltos: fundamentalismo islámico y nacionalismo. Modelos que se pueden aplicar solo en regiones culturales limitadas. Contrariamente se manifestó Samuel Huntington en su obra el Choque de las civilizaciones, en la cual sostuvo que el asunto primordial de poder no es el económico sino la cuestión nacionalista o civilizatoria, que termina en conflictos culturales (occidentales; latinoamericanos; islámicos; japoneses; africanos; hindúes; chinos; budistas; ortodoxos).

EEUU ha liderado el sistema mundo y ha condicionado muchos Estados al convertir a "la seguridad internacional en una preocupación básicamente estadounidense... después (del 11S)... el mundo, cayó en una recesión económica (Salazar en Zeraoui, 2011, p. 196-197). Esto manifiesta la relación que hay entre seguridad militar y seguridad económica... gracias a los procesos 
globalizadores" (Zeraoui, 2011, p. 196-197). 2005 influenció en la seguridad global, debido a que la llegada de los demócratas al Congreso de EEUU, menguó la política exterior de amigo-enemigo.

Desde 2008 se considera el fin de la etapa de unipolaridad por el ascenso político de la comercial China comunista y de Estados como Arabia Saudita; Quatar; Emiratos Arábes con superávit comercial, económico y financiero que se convierten en exportadores de empresas globales y otras potencias tradicionales. Un verdadero sistema multipolar se instaló.

Esto produjo el debilitamiento del Estado-Nacional a nivel global (liberalismo-neoliberalismo) pues su capacidad de acción fue más limitada. El gran inversionista clásico fue el Estado que superado por las operaciones privadas de las empresas multinacionales o trasnacionales, que no cesan de construir poder como actores internacionales, conllevando la disminución en la concentración de poder político estatocéntrico.

\subsection{CONDICIONAMIENTOS DE LA POSGUERRA FRIA A LA POLÍTICA EXTERIOR LATINOAMERICANA}

1945 no sólo partió en dos la historia de las RRII y del derecho internacional sino que contrapuso sus estructuras o modelos, relacional e institucional. Es decir, en 1945 al terminarse la IIGM y dar comienzo al periodo de GF, la escuela clásica o relacional de las RRIl que se caracterizó por legitimar el uso de las FFAA para resolver controversias internacionales; que limitó al Estado a ser el sujeto único de derecho internacional, y; que se fundamentó en un reconocimiento internacional del Estado como elemento constitutivo del mismo, se extinguió viendo nacer a su antónimo, a través del establecimiento de la escuela contemporánea o institucional que prohibió el uso o amenaza de las FFAA para resolver las controversias internacionales con contadas excepciones; multiplicó los sujetos de derecho internacional, y; eliminó al reconocimiento internacional como elemento constitutivo del Estado, para convertirlo en un reconocimiento meramente declarativo de la voluntad política de los demás Estados.

Una de las excepciones es el uso legítimo de la FFAA contando con Resolución ONU, conforme lo acordado en 1992, que permitió la intervención, es decir, una injerencia legítima y directa que los 
Estados mismos aprobaron. Resultado del debilitamiento del Estado que ya no controla directamente su territorio al ceder a la intervención, sea voluntaria o condicionadamente.

Ahora bien, las excepciones al uso de la fuerza armada pueden sintetizarse así:

1. Medidas de seguridad colectiva de la ONU;

2. Recurrir a la fuerza en caso de guerra de liberación nacional. Excepción sumamente politizada;

3. Guerra defensiva por agresión previa - Legítima Defensa.

Comencemos ubicando a Colombia y México dentro la política hemisférica de EEUU durante y después de la GF. En la interacción EEUU-AL puede decirse que la GF no ha terminado, tan solo ha sido objeto de transformación. Si bien, después de finalizada la IIGM y hasta principios de la década del 70 , cualquier decisión relativa al campo de la política internacional, recayó sobre el precepto Seguridad.

EEUU mantuvo una visión estatocéntrica, dentro de la cual, quien no estaba de acuerdo, sencillamente, estaba en contra. Entonces, durante la GF, la seguridad prevaleció dentro de una agenda internacional de tipo vertical. Además, este período se caracterizó, por el uso del derecho internacional clásico dentro del escenario interestatal que posibilitaba la mera acción entre los Estados como únicos sujetos de derecho internacional.

EEUU durante la GF manifestó su preocupación por la amenaza que representaba la suma de los riesgos desestabilizadores de su estadio de seguridad y que se albergaban en la región latinoamericana y en especial de la subregión andina.

Políticamente AL en la década del 70 estuvo prácticamente estática. Erigidos en muchos Estados, regímenes autoritarios, con excepcionales sistemas democráticos, como el caso colombiano, que en realidad se ejercitaban con violencia, violación sistemática de la ley y la permanencia de estándares de impunidad, se replicaron los clamores latinoamericanos en una sinfonía de debilidad institucional profunda patrocinada por los EEUU en su campaña autoritaria del regime change. Un pensamiento de talante neorrealista. 
En efecto, EEUU intervino durante la GF a nivel político y a nivel económico condicionando la estabilidad de los gobiernos militares mediante la persecución de focos revolucionarios socialistas. Mientras que la Unión Soviética hacía lo suyo, y a la inversa, como un reflejo de la política amigoenemigo, colaborando con los revolucionarios en Latinoamérica, por ejemplo, en el caso cubano. No obstante, esta influencia soviética en el caso colombiano y mexicano no resultó tan marcada.

La GF se convirtió entonces en brillante plataforma de lanzamiento de conflictos de baja intensidad en AL, más concretamente en Centro América y en los últimos tiempos, en el conflicto armado colombiano y el no reconocido conflicto mexicano, que ha de ubicarse en un punto entre los conflictos de baja e intensidad intermedia, según otra clasificación recurrente proveniente desde el norte.

En la década siguiente, el retroceso se evidenció en la dimensión económica. AL había sido encomendada para empezar una tarea democratizadora en donde se extinguieran los valores construidos tras los diferentes golpes de Estado y los abusos de poder efectuados en los 70s, que como mencionamos, fueron auspiciados por la administración norteamericana.

Ahora bien, luego de los atentados del 11S se amplió la "gama de intereses de quienes hacen las guerras... grupos ilegales, con raíces o no en viejos conflictos, están armados y están violando los derechos de miles de personas solamente para ganar dinero" ${ }^{17}$.

Desde 2001, la seguridad nacional estadounidense se trasladó nuevamente "a la esfera internacional... la seguridad internacional... estaría definida por... la seguridad global...transfronteriza" (Zeraoui, 2011, p. 183-184).

La seguridad nacional "es estar libre de amenazas y la capacidad de los Estados de mantener su identidad, su independencia, integridad y funcionamiento ante fuerzas hostiles" (Salazar en Zeraoui, 2011, p. 186). Según Buzan y Waever (Buzan, 2003, p.s.d), el sistema mundo de la PF debe ser analizado a través de 3 teorías: 1 . Neorrealismo: estatocentrismo y sus alianzas; 2.

17 El Tiempo, 6 de febrero de 2012. Consultado el 21 de octubre de 2012. HOWLAND, Todd. Representante en Colombia de la Oficina de la Alta Comisionada de las ONU para los DDHH. DIH en las nuevas guerras. www.asuntosdelsur.org/opiniones/opinion/221. 
Globalista: actores no estatales y aspectos culturales, trasnacionales y economía política; 3. Regionalista: alternativa ecléctica.

En el esquema clásico la regla general fue la presencia de guerras clásicas y en el esquema contemporáneo y en especial a partir de la posguerra, menguaron los enfrentamientos interestatales para dar paso al ciclón de las nuevas guerras.

Una guerra clásica interestatal, "se conduce en contra del ejército regular de un Estado... y son reguladas por el derecho internacional público...las nuevas guerras, son conducidas por diversos actores muchas veces no estatales sin algún tipo de regulación legal... Las nuevas guerras... (o) guerras incorrectas... son guerras de desintegración del Estado, como consecuencia del fracaso de una estatalidad robusta"(Munkler, 2000, p. 13-14).

\subsection{NUEVAS GUERRAS: EL CASO DEL PARAMILITARISMO DE LAS AUC EN COLOMBIA}

Los antecedentes de los paramilitares se remontan a la década del 80 mediante la creación de grupos como el MAS -Muerte a Secuestradores - como una reacción más del narcotráfico frente a la acción insurgente. En 1994, Álvaro Uribe como gobernador de Antioquia encendió el interruptor de lo legal, y confirmó la necesidad de las Asociaciones Comunitarias de Vigilancia Rural - CONVIVIR ${ }^{18}$-, avaladas mediante Decreto 356, involucrando civiles armados bajo la dirección de las FFAA ${ }^{19}$. En 1998, el presidente Andrés Pastrana, canceló las licencias como muestra de voluntad política pro resultados del proceso de paz.

En 1997, los dispersos grupos de autodefensa y miembros remanentes de las CONVIVIR decidieron coordinarse para conformar las Autodefensas Unidas de Colombia - AUC, de la siguiente manera: "las Autodefensas de Córdoba y Urabá copan, hacia el norte, las sabanas de la costa Caribe y, hacia el sur, el departamento del Chocó, mientras que las Autodefensas del Magdalena Medio y las del sur del Cesar y Santander avanzan hacia el norte de esta región y llegan a copar los departamentos del Cesar, Bolívar y los Santanderes... dotados de un plan

18 Miembros acusados de graves violaciones a DDHH. Base sólida para la expansión del paramilitarismo en Antioquia.

19 A finales de 1997, 400 licencias permitían a Las CONVIVIR. Se financiaron de empresarios que buscaban protegerse. 
estratégico de aplicación territorial y de un discurso político que los ha llevado a reclamarse como actor político" (González, 2006, p. 63 -64).

Recogiendo "la cosecha de varios años de construcción de un verdadero ejército... no se trataba de grupos armados subordinados a otros poderes, eran ejércitos de combatientes con una doctrina, identidad simbólica (uniformes, escudos, himnos) y armamento de guerra, que garantizaban la primacía de sus jefes sobre el poder local... se hacen llamar autodefensas y niegan su carácter de paramilitares... en las escuelas de formación del Bloque Central Bolívar... repetían a los nuevos reclutas en la clase de formación política: las autodefensas son un grupo político, militar, antisubversivo, al margen de la ley, anticomunista, antiterrorista, que busca la paz del país... Nosotros solo matamos guerrilleros" (Duncan en Cubides, 2005, p. 110).

Así se convirtieron en una "federación de grupos regionales... de una estructura flexible, efectiva para obtener dividendos de cara al proceso de negociación... con diversidad regional y capacidad de cooptar e integrar a su estructura cualquier grupo... formado como reacción a las acciones de la guerrilla"(Cubides, 2005, p. 80).

Sostuvieron ser la solución a un Ejército que ha demostrado no poder vencer militarmente a la insurgencia, autoproclamándose como la única fuerza efectiva capaz de hacerle frente a la guerrilla en todo el territorio nacional mediante el uso generalizado del terror, frecuentemente ejecutado, a través de masacres. Así, el Estado se fue subordinando ante los beneficios de los actos paramilitares contra la guerrilla, generándose "una relación de dependencia... sin (ellos) el Estado (corría) el riesgo de ser desbordado" (Pizarro, 2006, 117-118).

\subsubsection{FACTORES DE RECLUTAMIENTO PARAMILITAR}

Tienen creación por varios factores. Unos sostuvieron su constitución al estar "fatigados por los excesos criminales de la guerrilla, tales como el secuestro y la extorsión. Otros fueron impulsados por narcotraficantes como el desaparecido Gonzalo Rodríguez Gacha, para no continuar pagando el impuesto de guerra, el llamado gramaje a las FARC. Algunos más, fueron directamente conformados, por oficiales del Ejército en el marco de la guerra de contrainsurgencia. Finalmente, otros fueron constituidos por conocidos y controversiales líderes 
de las minas de esmeraldas"(El Espectador, 10 de octubre de 1987). En 2014 debemos sumar a la variedad de cauces a grandes sectores políticos, económicos, policiales, sociales e incluso religiosos, nacionales e internacionales.

De igual manera, el fenómeno paramilitar ha sido concebido desde diversas posturas. Algunos lo conciben como: "una política terrorista impulsada por el Estado, mientras que otros lo miran como tercero en discordia, víctima del fuego cruzado de insurgentes de izquierda y vigilantes de derecha. Finalmente, otros analistas tienden a vincularlos a una especie de gamonalismo armado, que expresaría cierta dislocación del Estado" (Pizarro, 2006, p.59). Mientras que la academia lo entendió como "un proyecto político, social y económico con alcances nacionales y diversidades regionales, al vaivén de las coyunturas políticas, de la interacción con sectores sociales determinados y con respecto a las políticas públicas... constituyen, en cuanto actores de la violencia a escala nacional, en irregulares del Estado..., y, simultáneamente, en una modalidad de dominación regional por medio del gamonalismo armado"(Palacios, 1995, p. 189).

Para las ONGs configuran "una política de Estado... que cuenta con el apoyo y aquiescencia de las FFAA... del poder ejecutivo, por carecer de voluntad política para tomar medidas encaminadas a desmantelar(los)... del poder judicial, al situar las acciones y la investigación sobre los hechos perpetrados por los paramilitares en un plano secundario, que conduce a reforzar los mecanismos de impunidad"(González, 2006, p.59). Del legislativo, sobornando políticos para influir en la formulación de las leyes, así como el uso y la amenaza del uso de la violencia y del terror, en cuanto a las elecciones se refiere.

Así, a través del uso de paramilitares se facilitó la instalación del Estado modernizante, con el concurso del sector privado (González, 2006, p.62) y se financiaron con el narcotráfico mediante "un ingreso continuo y calculable sobre una base tributaria clara: los recursos obtenidos de quienes quieren comprar seguridad. A todo esto se añade un sistema de recaudación de contribuciones más o menos forzadas, que no obstante, son predecibles" (Cubides, 2005, p.75). En 2001, el Departamento de Estado norteamericano, incluyó a las AUC en la lista de los grupos terroristas, "y, con ella, la posibilidad de extradición"(Cubides,2005, p.121). El gobierno indicó que "hasta un $80 \%$ de la financiación de las AUC provenía del narcotráfico y que se había hecho imposible diferenciar entre paramilitares y narcotraficantes"(López, 2005, p.222). 
Ante el escenario violento, como elemento legitimador político, Uribe como presidente en 2002, reactivó un grupo similar a las CONVIVIR, puesto que facultó "una red de cooperantes... bajo el control...de los comandantes militares, policiales y de los organismos de seguridad del Estado... (para) vigilar permanentemente a sus vecinos e informar a las autoridades... cualquier circunstancia o persona sospechosa, según el criterio de cada informante... a cambio... reciben recompensas... asignan(do) a las personas civiles funciones de inteligencia militar" (Gallón, 2006, p. 129).

Paralelamente, impulsó "la figura de los soldados campesinos, como un medio adicional de penetración territorial" (Pizarro, 2006, p. 305). Produciéndose claramente la violación de un principio fundamental del DIH, el de distinción, que compone simultáneamente, una garantía en la promoción y protección de los DDHH.

Negoció con los paramilitares a través de la Ley de Justicia y Paz "bajo una condición básica: un cese al fuego unilateral... en XII/2002... las AUC... anunció un cese total de hostilidades... el gobierno... designó una comisión exploratoria para un eventual diálogo de paz... el 13 de marzo de 2003 culminó... la Fase de acercamiento entre la comisión gubernamental... Carlos Castaño y Salvatore Mancuso y se inició la etapa siguiente llamada de negociación... para incorporar alrededor de ocho mil combatientes"(Pizarro, 2006, p.309).

El 15 julio de 2003, se firmó el Acuerdo de Santa Fe de Ralito, entre el cual el gobierno ${ }^{20}$ y las AUC (Echandía, 2010, p.91), acordaron lograr la paz nacional, casi con un dictado internacionalista buscando el fortalecimiento de la gobernabilidad democrática y la recuperación del monopolio de la fuerza. De dicho Acuerdo, nació todo el fenómeno de la para-política. Es decir, la inserción del paramilitarismo en el sistema político y los políticos al servicio de los lineamientos paramilitares.

Según el mensaje oficial interno e internacional, ya no son más una organización terrorista, sino por el contrario, son grupos de crimen organizado que no revisten peligro a la seguridad interna ni internacional porque en teoría no ostentan intereses políticos, sino la cooptación territorial del Estado para sus negocios ilícitos y prestando servicio de seguridad privada a empresas nacionales

20 Representado por Luis Carlos Restrepo, alto comisionado para la paz y las Autodefensas Unidas de Colombia (AUC). 
o multinacionales. Sin embargo, la clasificación teórica, de ser grupos no estatales, encuentra opositores pues el paramilitarismo sigue inserto en el sistema político.

\subsection{EL CONDICIONANTE POLÍTICO EXTERNO: IMPACTOS DE LAS ASIMETRIAS MARCADAS POR LA POSGUERRA}

El narcoterrorismo es un concepto made in usa que refirió la convergencia entre narcotráfico y terrorismo. La ambigüedad conceptual se debe a la facultad política de los Estados poderosos a clasificar a sus enemigos y con ello, los mecanismos para exterminarlos y salvaguardar los intereses nacionales.

La narcoviolencia es la violencia resultante de los grupos narcotraficantes. Este concepto elimina la posibilidad de convertibilidad política que representa el terrorismo o la práctica de actos terroristas. Propiciando el terrorismo político como garantía, pues "los gobernantes utilizan la maquinarias del Estado legítimamente constituido para ejercer violencia ilegítima contra sus enemigos" (Prieto en Zeraoui, 2011, p. 207-208).

El terrorismo perpetuado por los grupos de extrema derecha, no pretende desagregar el Estado, por el contrario, trata de reforzar la presencia del mismo, por lo cual no se entiende muy bien, si es terrorismo de extrema derecha o simplemente es un terrorismo de Estado, debido a que sus vínculos son de difícil comprobación, porque el Estado es quien detenta el ejercicio del poder y si el fenómeno terrorista le es favorable, no lo denunciará, convirtiéndolo en terrorismo de Estado, que pasa desapercibido, en su proyecto de instauración del para-estado.

El terrorismo de Estado puede operar "directamente, por medio de agencias del Estado mismo, o indirectamente, mediante la utilización de entidades sustitutas, como otros Estados o grupos o individuos"(Schulz en Zeraoui, 2011, p. 208).

No obstante, la política del terror no erradicó la guerrilla y "Washington entró al conflicto por la puerta de atrás. Las compañías petroleras, instaladas en Colombia, las fabricas de armas y las Sociedades Militares Privadas SMP, gastaron seis millones de dólares en lobby para lograr que el Congreso estadounidense aprobará el Plan Colombia... sobre los 1300 millones de dólares 
asignados al Plan Colombia por Estados Unidos se gastaron 1130 millones sin que un solo funcionario colombiano (viera) un céntimo. Hasta las sumas provenientes del Banco Mundial para ese Plan (serían) canalizadas desde Washington hacia las SPM" (Calvo en Azzelini, 2003).

Así, EEUU importó a Colombia y con la Iniciativa Mérida a México, su doctrina de ataques preventivos "recurriendo a una forma moderna de mercenarismo... empleados que pagan impuestos y trabajan en empresas de seguridad que a su vez firman regulares contratos con el Departamento de Estado y son controladas en relación a los términos del contrato firmado... son ex militares que manejan alta tecnología y que... se reciclan dentro del mismo sector, esta vez no estatal, sino privado. Es la terciarización de la guerra, que permite... no poner tantos muertos en los conflictos y no tener que rendir cuenta por ellos" (Rossi, 2009, p.118). En Colombia y México, los paramilitares son funcionales para aumentar las desapariciones masivas, mediante el uso de fosas comunes, hornos crematorios, tigres, cocodrilos, descuartizamientos, etc, y así, reducir el reporte oficial de homicidios dolosos.

El escenario internacional representa un salvavidas para los ciudadanos de sistemas jurídicos corruptos y violadores de DDHH. A pesar de los sinsabores que deja el sistema jurídico nacional e interamericano sobre la verdad real y su reflejo en la verdad procesal, se produce un verdadero control de convencionalidad (CC) en cuanto se refiere crímenes internacionales.

Veamos la influencia de la política internacional en los marcos jurídicos nacionales y del Sistema Interamericano de DDHH -SIDH-, a través del estudio de la masacre de Mapiripán, que fue concebida por los paramilitares como un genocidio pues asesinaron a los pobladores por ser auspiciadores de la guerrilla, bajo la teoría política de amigo-enemigo, y donde el Estado colombiano participó activamente.

Aclarando que existen, como este, muchos hechos aberrantes similares. Su repaso nos mostrará como el sistema mundial ha cambiado en cuanto a la complementariedad o subsidiariedad de los sistemas jurídicos internacionalizados, previa manifestación de los Estados a adherirse a ciertos tratados, pero lo cierto es que en las relaciones asimétricas, el estado de la periferia claramente está condicionado a otros Estados centrales. 
EEUU representa para Colombia como para México, su condicionante externo, y esto, le reporta ventajas y desventajas a la soberanía. Ventajas pues se escuda frente a terceros y el grado de atención es bajo cuando no se representa una confrontación a sus intereses nacionales. Desventajas cuando el Estado le representa controversia. Estados superados por ESol narcoviolentas y por su Superador Hegemónico: EEUU.

\subsection{SUBSIDIARIEDAD DE LA JUSTICIA INTERNACIONAL EN EL SISTEMA MUNDO}

La Cort.IDH creó el concepto de CC, que "plantea alternativas para el control judicial interno de convencionalidad... implica la consulta sobre convencionalidad de normas elevadas a un tribunal superior competente para atender y resolver la consulta (conllevando) la armonización de la jurisprudencia nacional y evitando la multiplicación de decisiones judiciales discrepantes" (García, 2011, p. s.d.).

El CC fue rechazado en un inicio por el SIDH - y como señala Rey Cantor (2008, p.81-90), se sucedió un cambio jurisprudencial desde el Caso Suárez Rosero ${ }^{21}$ al Caso Castillo Petruzzi ${ }^{22}$. Así, su primera aparición se dio en el Caso Myrna Mack Chang ${ }^{23}$ en 2003, y dentro del SIDH ocurrió el 26.4.2006 cuando la Cort.IDH se pronunció en el Caso Almonacid Arellano Vs Chile, de la siguiente forma: "los jueces y tribunales internos están sujetos al imperio de la ley y, por ello están obligados a aplicar las disposiciones vigentes en el ordenamiento... cuando un Estado ha ratificado un tratado... también están sometidos a ella"24.

El CC en primera instancia lo realizan "judiciales domésticos, haciendo una comparación entre el derecho local y el supranacional, a fin de velar por el efecto útil de los instrumentos internacionales, sea que surja de los tratados, del lus Cogens o de la jurisprudencia de la Cort.IDH;

\footnotetext{
21 Cort.IDH, Caso Suárez Rosero Vs. Ecuador, Sentencia de 12.11.1997, Serie C No. 35, párr. 98; véase también el Voto Razonado del Juez Caneado Trindade en el caso "La Última Tentación de Cristo" (Corte IDH, Caso "La Última Tentación de Cristo" [Olmedo Bustos y otros] Vs. Chile, Sentencia de 5.22001, Serie C No. 73, párr. 13. 22 Cort.IDH, Caso Castillo Petruzzi y otros Vs. Perú, Sentencia de 30.5.1999, Serie C No. 52 23 Cort.IDH Voto razonado del Juez Sergio García. Caso Myrna Mack Chang Vs. Guatemala, Sentencia de 25.11.2003, Serie C No. 101. 24 http://derechoshumanos-unab.blogspot.com/2012/05/el-control-de-convencionalidad-derecho.html. Control de Convencionalidad: Derecho a la Carta. Párrafo 124.
} 
y luego esa tarea debe ser ejercida por (ella), si... el caso llega a sus estrados" ${ }^{25}$. Su aplicación subsidiaria procede de oficio.

La masacre ocurrió en 1997 y en 2005 el Estado colombiano reconoció su responsabilidad en ella, sin embargo, el número de víctimas fatales de la masacre no pudo ser determinado pues la mayoría de los cuerpos fueron descuartizados y arrojados al rio Guaviare y ese mismo año la Cort.IDH condenó a Colombia a reparar a los familiares de las víctimas, entre otras medidas.

Una vez reparados, en 2011 el Estado colombiano denunció en escenarios nacionales e internacionales, que personas fueron reparadas haciéndose pasar por falsas víctimas. Empezaremos por explicar brevemente la estructura del SIDH y los hechos fácticos y jurídicos de la masacre, a nivel nacional e internacional, para posibilitar al lector, decidir su posición al respecto.

\subsection{MISIÓN DEL SIDH: MECANISMO DE PROMOCIÓN Y PROTECCIÓN DE LOS DDHH}

Lo pueden activar los ciudadanos de los Estados americanos para obligar a los Estados violadores de los DDHH a reparar a sus víctimas. La estructura jurídica principal constituye 2 órganos autónomos de la OEA: 1) La Comisión Interamericana de Derechos Humanos (CIDH) con sede en Washington D.C. y la Corte Interamericana de Derechos Humanos (Cort.IdH), ubicada en San José de Costa Rica. Sus fundamentos se soportan sobre la Declaración Americana de los Derechos y Deberes del Hombre ${ }^{26}$ (1948) , la Carta de la OEA (1948) y en la Convención Americana sobre Derechos Humanos -CADH ${ }^{27}$ - firmada 1969 y vigente desde 1978.

Los Estados miembros de la OEA son: Antigua y Barbuda, Argentina, Bahamas, Barbados, Belice, Bolivia, Brasil, Canadá, Colombia, Costa Rica, Chile, Dominica, Ecuador, El Salvador, Estados Unidos, Grenada, Guatemala, Guyana, Haití, Honduras, Jamaica, México, Nicaragua, Panamá,

25 HITTERS, Juan. (2009). Control de Constitucionalidad y control de convencionalidad. Comparación. Estudios constitucionales. 10.4067/\$0718-52002009000200005. Año 7, No 2, 2009, pp. 109-128. UNLP, Argentina.

26 Primer documento internacional de derechos humanos de carácter general.

27 En XI.1969 se celebró en San José de Costa Rica la Conferencia Especializada Interamericana sobre DDHH. Los EM de la OEA convinieron la CADH (vigor 18.7.1978), al haber sido depositado el undécimo instrumento de ratificación. 
Paraguay, Perú, República Dominicana, Saint Kitts y Nevis, Santa Lucía, San Vicente y las Granadinas, Suriname, Trinidad y Tobago, Uruguay y Venezuela.

La CADH a 2013 fue ratificada por 25 países: "Argentina, Barbados, Brasil, Bolivia, Chile, Colombia, Costa Rica, Dominica, República Dominicana, Ecuador, El Salvador, Granada, Guatemala, Haití, Honduras, Jamaica, México, Nicaragua, Panamá, Paraguay, Perú, Suriname, Uruguay, Venezuela" ${ }^{28}$ y Trnidad y Tobago.

\subsubsection{COMISIÓN INTERAMERICANA DE DERECHOS HUMANOS - CIDH}

Se compone de 7 personas expertas en DDHH, actúan a título personal y no representan los Estados de los cuales son originarios o nacionalizados. Son entonces, elegidos por meritocracia en Asamblea General del OEA, de un listado presentado por los Estados miembros - EM-, y se prohíbe, que existan dos expertos de la misma nacionalidad. A parte de promover y proteger los DDHH, sirve de órgano consultivo de la OEA. Su acto originario fue la Resolución de la Quinta Reunión de Consulta de Ministros de Relaciones Exteriores en Santiago de Chile (1959), comisionando por primera vez en 1960. El periodo de los comisionados es de 4 años y pueden ser re-elegidos por un período igual. En 1965 la CIDH recibió y procesó denuncias o peticiones sobre casos individuales de violación de DDHH. De cada caso elabora un informe detallado al público. Entre las funciones principales encontramos:

\section{Funciones aplicadas a EM:}

Estimular la conciencia de los DDHH en los pueblos de América.

Formular recomendaciones a los gobiernos para que adopten medidas progresivas en favor de los DDHH.

Preparar estudios e informes, programas-presupuestos.

Solicitar a gobiernos informes sobre DDHH.

Atender las consultas que, por medio de la Secretaría General de la OEA, le formulen.

Practicar observaciones in ${ }^{100^{29}}$ en un Estado, con la anuencia o a invitación del gobierno.

\section{Funciones de la CIDH aplicadas a EM de la CADH:}

Diligenciar peticiones y otras comunicaciones.

28 www.oas.org/es/cidh/mandato/Basicos/intro.asp.

29 En 1961 la CIDH comenzó a realizar visitas in loco. 
Comparecer ante la Cort.IDH en los casos previstos

Solicitar a la Cort.IDH medidas provisionales en asuntos graves y urgentes que aún no estén bajo su conocimiento

Consultar a la Cort.IDH acerca de la interpretación de la Convención o de otros tratados regionales sobre DDHH

Someter a la consideración de la Asamblea General - AG - de la OEA proyectos de protocolos adicionales.

Someter a la AG de la OEA propuestas de enmienda a la Convención.

\section{Funciones de la CIDH aplicadas a EM - OEA que no son partes de la CADH}

Observancia de los DDHH

Examinar comunicaciones que le sean dirigidas y dirigirse a los gobiernos para obtener

informaciones pertinentes y formular recomendaciones.

Verificar si los procesos y recursos internos fueron debidamente aplicados y agotados.

\subsubsection{CORTE INTERAMERICANA DE DERECHOS HUMANOS - COrt.IDH}

Órgano autónomo judicial de la OEA que goza de aplica e interpreta la CADH y otros tratados de DDHH, a los cuales se somete el Ilamado SIDH. Son idiomas oficiales el español, francés, inglés y portugués. Se compone de 7 jueces nacionales de los EM de la OEA, elegidos por 7 años con posibilidad de una única reelección, elegidos por meritocracia, sin que pueda haber más de un juez de la misma nacionalidad y no representan a sus Estados.

Sesionó por primera vez el 29 de junio de 1979 en la Washington, D. C., y su instalación oficial fue septiembre de 1979 en San José de Costa Rica. En su sesión No. 9, la AG de la OEA aprobó el Estatuto de la Cort.IDH y en 1980 aprobó el Reglamento Interno que fue reformado en 2009. Adicionalmente, en 1980 se creó con sede en San José de Costa Rica, el Instituto Interamericano de DDHH mediante convenio entre la Cort.IDH y Costa Rica que busca promover académica e investigativamente los $\mathrm{DDHH}$, haciendo hincapié en las enfermedades crónicas de la región. Este Instituto apoya al SIDH en la protección a los DDHH. Las principales funciones de la Cort.IDH, dentro de su competencia contenciosa y consultiva, pueden sintetizarse así:

Funciones Corte Interamericana de Derechos Humanos:

1. Competencia contenciosa

EM de la OEA que han ratificado la CADH.

Tiene competencia en casos relativos a interpretación y aplicación de las disposiciones de la Convención, siempre que los Estados partes hayan aceptado la competencia. 
Conoce casos de vulneración de un derecho o libertad protegidos por la Convención, siendo necesario el agotamiento de los recurso internos.

Las personas, grupos o entidades que no son Estados no tienen capacidad de presentar casos ante la Corte, pero sí pueden recurrir ante la CIDH. La Comisión puede llevar un asunto ante la Corte, siempre que el Estado cuestionado haya aceptado su competencia. La CIDH siempre comparece ante la Corte.

El procedimiento contradictorio termina con sentencia motivada, obligatoria, definitiva e inapelable y en los debidos casos llevará los salvamentos respectivos.

En caso de duda sobre el sentido o alcance del fallo, la Corte lo interpretará a solicitud de cualquiera de las partes, si se solicitó dentro de los 90 días siguientes a la notificación de la decisión.

\section{Competencia Consultiva}

Los EM de la OEA pueden consultar a la Corte acerca de la interpretación de la CADH o de otros tratados de DDHH regionales. Así mismo, pueden consultarla, en su especialidad, los órganos de la OEA.

A solicitud de un EM de la OEA, puede dar opiniones sobre la compatibilidad entre leyes locales y Tratados.

La Cor.IDH ha sido blanco de críticas, en especial, por su politización ${ }^{30}$, pero el caso de Mapiripán, ha multiplicado las dudas de funcionamiento de la misma.

\subsection{HECHOS DE LA MASACRE DE MAPIRÁN JULIO 15-20 DE 1997}

Los antecedentes se remontan al 12 de julio de 1997, cuando desde aeropuertos militarizados de Necoclí y Apartadó del Urabá antioqueño, partieron dos aviones que trasportaron a los paramilitares y las respectivas municiones, que generarían la macabra matanza. Estos aviones aterrizaron en otro aeropuerto militarizado, policial y con batallón anti-narcóticos, en San José del Guaviare, Departamento del Meta.

Según la Fiscalía, el Ejército permitió el aterrizaje y el abordaje de camiones que allí los esperaban, pues según las audiencias jurídicas donde se manifestaron los hechos, se confirmó que el mismo 15 de julio de 1997 el General Jaime Humberto Uscátegui Ramírez, recibió del Mayor Hernán Orozco Castro, Comandante de la VII Brigada, un comunicado oficial informando los posibles hechos. En el Urabá, los miembros de las FFAA de la Brigada XVII bajo la comandancia

30 José Francisco García G. y Sergio Verdugo R., Libertad y Desarrollo, "Radiografía Política al SIDH”. 
del General Rito Alejo del Río, amigo cercano de Uribe, y condenado por actos vinculados con el paramilitarismo e investigado por homicidio, coordinó el embarque.

Los paramilitares pernoctaron en la Inspección de Policía de Charras y manifestaron públicamente en la plaza central la muerte a todo el que pagara vacunas a las FARC y al amanecer del 15 de julio se dirigieron a Mapiripán, y durante cinco días, cometieron actos de barbarie como violaciones y mutilaciones y masacraron a su población, controlaron las comunicaciones y las instituciones. La masacre se caracterizó, además de la constante crueldad y sevicia de los asesinatos, por el descuartizamiento de los cuerpos y su desaparición al arrojar las partes de las víctimas al río Guaviare, lo que generó la consecuente indeterminación del número de las personas masacradas, y que según Castaño, fueron 49.

Los actores materiales fueron Salvatore Mancuso, Vicente Castaño, Cumbia, y de 40 a 60 paramilitares a su mando, dentro de la estructura terrorista. No obstante, quedan dudas sobre la autoría intelectual de la misma. Por ejemplo, se comprobó durante las audiencias de Justicia y Paz, en el proceso contra "el ex paramilitar Humberto Victoria Oliveros, alias 'Don Raúl'... que un grupo de ganaderos financiaron con 50 millones de pesos la masacre" ${ }^{31}$.

Las etapas de investigación y juzgamiento realizadas en Colombia, fueron objeto de duras críticas nacionales e internacionales. Entre ellos, el abogado de las víctimas, Luis Guillermo Pérez ${ }^{32}$, mediante acción de tutela, logró que los militares implicados fueran objeto de juicio por parte de la justicia ordinaria, pues su trámite en un inició ocurrió respetando el fuero militar, en la justicia especial.

La falta de determinación del número exacto de las víctimas es de la responsabilidad del Estado, en aquella época, por parte de la Unidad Nacional de DDHH de la Fiscalía General de la Nación. Sin embargo, declaró como víctimas a personas que no lo eran. Falsas víctimas reconocidas como tales por el Estado el 4.3.2005, y previamente, por sus tribunales nacionales penales, disciplinarios y contencioso.

31 Ganaderos financiaronmasacredeMapiripán: Exparamilitarhttp://wnw.elespectador.com/noticias/judicial/articulo-321684. 18.1.2012. El Espectador.

32 Miembro del Colectivo de Abogados. 


\subsubsection{MAPIRIPAN EN EL SIDH}

El 6 de octubre de 1999 el Colectivo de Abogados José Alvear Restrepo - El Colectivo- y el Centro por la Justicia y el Derecho Internacional, denunciaron la masacre en procedimiento jurídico internacional ante la $\mathrm{CIDH}$.

El 22 de febrero de 2001, en sesión No. 110 la CIDH aprobó el Informe de Admisibilidad № 34/01, conforme el cumplimiento de lo establecido en los artículos 46 y 47 de la CADH. El 9 de marzo de 2001 la CIDH instó a las partes, sin éxito alguno, a llegar a una solución amistosa. El 8 de febrero de 2002 adoptó medidas cautelares a favor de testigos en el proceso judicial. El 12 de abril del mismo año, dictó medidas cautelares al Teniente Coronel Hernán Orozco Castro, quien se desempeñaba como comandante interino del Batallón "Joaquín París" cuando se produjo la masacre.

El 4 de marzo de 2003, en sesión No. 117ㅇ y de acuerdo al artículo 50 la CIDH aprobó el Informe de Fondo No. 38/03, y concluyó la responsabilidad internacional del Estado: "Colombia es responsable por la violación de los derechos a la vida, integridad y libertad personales de las víctimas de la masacre... del derecho al debido proceso y la protección judicial de las víctimas y sus familiares, previstos en los artículos 8 y 25 de la Convención Americana, así como del incumplimiento de su obligación de asegurar el respeto de los derechos previstos en dicho Tratado, en virtud de su artículo 1" y procedió a formularle recomendaciones, cuya naturaleza jurídica no conlleva obligatoriedad pero sí al sometimiento del caso ante la Cort.IDH.

El 5 de junio de 2003 la CIDH remitió al Estado el mencionado Informe y le otorgó un plazo de dos meses para que comunicara las medidas que adoptaría y se sirviese manifestar su posición acerca del posible sometimiento del caso ante la Cort.IDH, notificando a los peticionarios el informe y solicitándoles comunicar su posición respecto del posible sometimiento del caso a la Cort.IDH. El 9 de julio de 2003 los peticionarios confirmaron su intención del juzgamiento de la Cort.IDH. El 22 de agosto de 2003, después de dos prórrogas otorgadas por la CIDH, Colombia informó acoger las recomendaciones formuladas. 
La CIDH presentó la demanda ante la Cort.IDH el 5 de septiembre de 2003, conforme los artículos 50 y 61 de la $C A D H$, fundándose en la denuncia radicada bajo el No. 12.250 la Secretaría de la CIDH el 6 de octubre de 1999. Los fundamentos de derecho objeto de investigación pueden sintetizarse en los siguientes artículos: 1.1 (Obligación de respetar los derechos); 4(Vida); 5 (Integridad Personal); 7 (Libertad Personal); 8.1 (Garantías Judiciales); 19 (Niños); 22 (Circulación y Residencia); 25 (Protección Judicial).

La Corte confirmó su competencia conforme los requisitos establecidos en el artículo 62.3 de la $\mathrm{CADH}$, argumentando que el Estado colombiano es miembro de la misma desde el 31 de julio de 1973 y reconoció la competencia contenciosa de la misma el 21 de junio de 1985. El 28 de octubre de 2003 la Secretaría, previo examen preliminar del Presidente al texto de la demanda, notificó a las partes los plazos de contestación y de designación de representantes jurídicos. Adicionalmente, comunicó al Estado sobre su derecho de designar un juez ad hoc.

El 26 de enero de 2004, los representantes presentaron su escrito de solicitudes, argumentos y pruebas. Por su parte, el 2 de abril de 2004 el Estado presentó su escrito de excepciones preliminares, contestación de la demanda y de observaciones a las solicitudes y argumentos. El 19 de mayo de 2004 la $\mathrm{CIDH}$ y los representantes presentaron sus alegatos escritos sobre las excepciones preliminares. El 28 de mayo de 2004 Colombia presentó un escrito de réplica a las observaciones que el Presidente resolvió no aceptar pues se trataba de un acto procesal que no estaba previsto dentro del trámite jurídico internacional.

El 26 de enero de 2005 los representantes solicitaron conforme el artículo 45 del Reglamento de la Corte, ordenar al Estado suministrar toda la información correspondiente a las diversas diligencias probatorias surtidas internamente, referentes. El 28 de enero de 2005 el Presidente expidió Resolución de conformidad con los artículos 44 y 47.3, requirió a testigos y otorgó plazo improrrogable de 7 días, a la CIDH y el Estado, para que presentaran sus observaciones. Además, convocó a los interesados a audiencia pública para el 7 de marzo de 2005 y ordenó al Estado suministrar la información requerida. 
La Corte dictó Sentencia sobre los hechos reconocidos ${ }^{33}$ y declaró continuar con el conocimiento sobre hechos ocurridos no abarcados en el reconocimiento de responsabilidad formulado por el Estado y continuó con la audiencia pública fondo, las reparaciones y costas, y escuchó los testimonios y el peritaje.

El 8 de abril de 2005 el Estado, la Comisión y los representantes presentaron sus alegatos finales escritos. Así mismo, presentaron amicus curiae ${ }^{34}$ : el 9.5.2005 la Fundación Manuel Cepeda Vargas; El 15.5.2005 el Centro Internacional por la Justicia Transicional presentó; y, el 30.8.2005 la Fédération Internationale des Ligues des Droits del'Homme.

La Sentencia o Resolución ${ }^{35}$ de la Cort.IDH declaró por unanimidad, que el Estado violó los fundamentos de derecho invocados por los peticionarios y debería, entre otras medidas: determinar la responsabilidad intelectual y material de los autores y colaboradores o auspiciadores; individualizar e identificar, en un plazo razonable, a las víctimas ejecutadas y desaparecidas, así como sus familiares y garantizar sus condiciones de seguridad así como otros ex-pobladores de Mapiripán, que se hayan visto desplazados, puedan regresar a Mapiripán, en caso de que así lo deseen; construir un monumento ${ }^{36}$ apropiado y digno para recordar los hechos; implementar programas de educación en DDHH y DIH permanentes en las FFAA.

\subsubsection{MAPIRIPÁN DESPUES DEL SIDH}

Dentro de los trámites de la polémica Ley de Justicia y Paz, atentatoria del derecho internacional y local, pero campantemente vigente, se conocieron las falsas víctimas indemnizadas. La Corte supervisa el cumplimiento íntegro de la Sentencia y da por concluido el trámite jurídico solo cuando Colombia cumpla cabalmente lo ordenado. En cuanto a las reparaciones se ordenó al Estado a que "individualice e identifique las víctimas ejecutadas y desaparecidas, así como sus familiares... tomando en cuenta normas pertinentes (como el)

\footnotetext{
331 Cfr. Caso de la "Masacre de Mapiripán". Excepciones Preliminares y Reconocimiento de Responsabilidad. Sentencia de 7 de marzo de 2004. Serie C No. 122 . un paso hacia el cumplimiento de sus obligaciones internacionales.

34 Los Amicus Curiae son memoriales ante órganos judiciales nacionales o internacionales que aportan argumentos a favor de una posición. http://cejil.org/amicus-curiae. Consultado el 7.17.2012.

35 Serie C No. 134 http://www.corteidh.or.cr/docs/casos/Artículos/seriec 134_esp.doc

36 Muy criticado pues no lleva nombres, específicamente, para evitar controversias por indeterminación de las víctimas.
} 
Manual ONU sobre la Prevención e Investigación Efectiva de Ejecuciones Extrajudiciales, Arbitrarias y Sumarias" ${ }^{37}$.

Por su parte, la Resolución No. 1/03 dictaminó sobre Juzgamiento de Crímenes Internacionales que: "Ios Estados deben considerar que los crímenes internacionales -tales como el genocidio, los crímenes de lesa humanidad... de guerra (y agresión) - aun cuando atañen a toda la comunidad internacional por su gravedad, afectan principalmente al Estado... Por tal motivo el principio de territorialidad debe prevalecer en caso de conflicto de jurisdicciones. Asimismo... exhorta a los Estados a que adopten las medidas necesarias para considerar estos crímenes internacionales como delitos que dan lugar a extradición".

El Estado informó en 2007 a la Cort.IDH que existía incertidumbre acerca de 2 casos de reparación por personas que se habían hecho pasar por víctimas. La Cort.IDH el 26.11.2008 le informó al Estado que tuvo conocimiento de esos hechos desde 2002, pero que sin embargo, solo notificó de los mismos hasta después de fallado el caso mediante Sentencia o Resolución y sostiene que el Estado no puede alegar los nuevos hechos en la etapa de supervisión. Estimó que el SIDH juzga fundamentándose en los hechos y pruebas aportadas por las partes y recordó que cuando ocurren violaciones a DDHH el Estado está obligado a investigar y no puede trasladar la carga de investigación a las víctimas ni a sus representantes.

El Estado denunció en 2011 fraude en la Sentencia condenatoria de la Cort.IDH por el conocimiento de al menos 12 falsas víctimas de las 20 reparadas. Personas que se habían declarado desaparecidas o muertas en la masacre, aparecieron vivas o murieron en circunstancias ajenas. Algunos casos:

\begin{tabular}{|l|l|l|l|}
\hline Beneficiario & $\begin{array}{l}\text { Millones } \\
\text { pesos }\end{array}$ & Hecho alegado Mapiripán & Hecho real \\
\hline Familia Pinzón & 258 & Asesinato Jaime Riaño & Falleció 1989 \\
\hline Wilson Molina & 395 & Su propio asesinato & $\begin{array}{l}\text { Desplazado } 1999 \text { y en } 2003 \\
\text { realizó cambio de cédula. }\end{array}$ \\
\hline
\end{tabular}

37 Sentencia Cort.IDH, Mapiripán. (párr.305). 


\begin{tabular}{|l|l|l|l|}
\hline $\begin{array}{l}\text { Mariela } \\
\text { Contreras }\end{array}$ & 1.751 & 1 asesinato; 2 desparecidos & $\begin{array}{l}\text { Muerte anterior a los hechos y } \\
\text { los desaparecidos uno fue } \\
\text { dado de baja en las FARC y el } \\
\end{array}$ \\
& & $\begin{array}{l}\text { otro se desmovilizó de la } \\
\text { guerrilla en 2008. }\end{array}$ \\
\hline
\end{tabular}

Por ejemplo, la Sra. Contreras denunció en instancias nacionales e internacionales y fue reparada por el Estado por el asesinato de un familiar y la desaparición de otros dos de los suyos dentro de los hechos ocurridos en Mapiripán.

Posteriormente de recibir casi dos mil millones de pesos, "admitió en audiencia que la desaparición de sus dos hijos y la muerte de su esposo, ocurrieron en circunstancias ajenas a la masacre...su esposo fue asesinado por guerrilleros antes de $1997 . .$. uno de los hijos... realmente estuvo militando desde 1995 hasta el 2008 en la guerrilla" ${ }^{38}$. No obstante, a sus contradictorias y comprobadas declaraciones, acusa al colectivo de abogados CCAJAR como brazo jurídico de las FARC, mientras expone que: "los abogados se aprovecharon de su ignorancia" (El Espectador, 28.10.2011), sostiene que no conocía sobre el trámite de “demanda por una indemnización... creía que ellos buscaban a la gente, y eso era lo único que... quería”39.

El colectivo ha manifestado que su actuación como defensores de los DDHH "se basó en las declaraciones de las víctimas y las decisiones de tribunales nacionales a nivel penal, disciplinario y contencioso administrativo, que fueron tenidas en cuenta por el Estado de Colombia para reconocer el 4 de marzo de 2005, su responsabilidad internacional por la Masacre" ${ }^{40}$. "Ella nos dio su versión... (y) la sostuvo ante la Fiscalía... Si ella ahora dice que no fue víctima... es ella quien debe aclarar sus actuaciones ante la Justicia y el Estado tendría que proceder a demandarla por falso testimonio" ${ }^{41}$.

Frente a los nuevos hechos, el 26 de Octubre del 2.011, el Colectivo acusó a la Fiscalía General por omisión en la identificación de cadáveres que generaron las falsas denuncias. Adicionalmente,

38http://m.eltiempo.com/justicia/fiscalia-denuncia-falsos-muertos-en-masacre-demapiripan/10636224/1/home. Consultado el 17.7.2012.

39 CAICEDO, Jorge Alberto. (2011). La Guerra Jurídica sin Máscara. Consultado el 17.7.2012. http://www.restauracionacional.org/?cat=282 Jorge Alberto 12.12.2011.

40 www.colectivodeabogados.org/CCAJAR-Comunicado-a-la-opinion 1.11. 2011. Consultado el 17.7.2012.

41 ¿Cuáles son las dudas y certezas de lo ocurrido en Mapiripán?http://www.semana.com/nacion/mapiripan-dudas-certezas-masacre/174190-3.aspx 
han manifestado devolver el dinero recibido por honorarios, solicitando número de cuenta para consignar, sin embargo, el Estado se ha rehusado a recibirlo. El Colectivo denunció el hecho ante la Procuraduría.

No obstante, este entramando de negras actuaciones, no deben esconder la realidad macabra de la situación violenta en el Estado colombiano. Por eso, exponemos una pequeña parte del testimonio de un familiar reparado y víctima real: "A mi papá lo mataron, le metieron piedras en el cuerpo y lo tiraron al río. Nunca encontraron su cadáver... (El Colectivo me informó) que al final ellos se quedarían con un porcentaje del dinero que recibiéramos" ${ }^{42}$, del proceso adelantado en el marco del SIDH.

Por esto, rechazamos la deslegitimación del SIDH pues no debe impactar más que "hasta las masacres en Colombia se las roben o se hable de desfalco y no de reparación" ${ }^{43}$, que el hecho de que el Estado coadyuva a asesinar con sevicia mediante grupos paramilitares y omisiones y ayudas de sus agentes oficiales, a personas inocentes y en condiciones de marginalidad, pues efectivamente sin la esfera internacional la cruel realidad de Mapiripán, habría quedado impune.

Al parecer "un caso de errores compartidos. Del Estado y su aparato militar y de justicia. De unos particulares que quisieron hacer negocio con un hecho lamentable... Del... (SIDH), por su propia naturaleza y estructura. EI SIDH es falible... La justicia humana es falible, sea nacional o trasnacional, la Corte IDH funciona como justicia subsidiaria. Por esta razón, a ella no le corresponde investigar los crímenes nacionales, pues esta es una labor de los aparatos investigativos internos" ${ }^{\prime 4}$.

Como estrategia preventiva para evitar hechos como la reparación a falsas victimas el gobierno creó la Agencia Nacional de Defensa Jurídica del Estado. Aunque debería bastar con la óptima actuación de los entes ya creados.

42 www.semana.com/nacion/mapiripan-ahora-victimas-debemos-estado-culpables-masacre/167978-3.aspx. Consultado el 7.17.2012.

43 Foro Universidad Sergio Arboleda. Carrusel de las víctimas!. www.uscateguiesinocente.com. Consultado el 17.7.2012.

44http://www.ambitojuridico.com/BancoConocimiento/N/noti11112105. Consultado el 17.7.2012. 


\subsection{SOBERANÍA Y ARMONIZACIÓN DE ORDENAMIENTOS JURÍDICOS POR CONTROL DE CONVENCIONALIDAD (CC) - BENEFICIOS DE LA POLITICA INTERNACIONAL DE LA POSGUERRA}

El CC propicia la aplicación de normas locales acordes con el cuerpo iuris internacional. Existe un CC difuso y uno concentrado. El difuso lo realizan los órganos de poder judicial del Estado, conforme derecho constitucional y DIDDHH. El concentrado lo ejerce la Cort.IDH aplicando la $\mathrm{CADH}$ en procedimientos contenciosos. En Colombia y en sendos ordenamientos jurídicos, los jueces "forzados por las circunstancias, han incluido como variable real de sus decisiones a la CADH y a los estándares y reglas articulados por las sentencias de la Cort.IDH" (Quinche, 2009, p.163-190).

Así, en diversos fallos de jurisdicción ordinaria... "como la primera sentencia proferida por la jurisdicción de Justicia y Paz...contra del paramilitar Wilson Salazar Carrascal, alias el loro ${ }^{45}$... el sistema de reparaciones acoge las reglas de la Cort.IDH" ${ }^{46}$. Entonces, mientras que, "los tribunales constitucionales controlan la constitucionalidad, el tribunal internacional de DDHH resuelve acerca de la convencionalidad de esos actos. A través del control de constitucionalidad, los órganos internos procuran conformar la actividad del poder público $-y$, eventualmente, de otros agentes sociales- al orden que entraña el Estado de Derecho en una sociedad democrática. El tribunal interamericano... pretende conformar esa actividad al orden internacional acogido en la convención fundadora de la jurisdicción interamericana y aceptado por los Estados partes en ejercicio de su soberanía"47.

El CC entonces, "no se ocupa en sí de las cuestiones locales sino que su tarea es la de inspeccionar si los países han violado o no las convenciones sujetas a su competencia"(Albar, 1998, 584), ni de modificar el derecho local "y por ende no se convierte en una cuarta instancia que deja sin efecto las leyes de los países"(Hitters, 2008, 1169). Pretendiendo evitar que el Estado "incurra en responsabilidad estatal (arts. 1.1 y 2)”(Hitters,2007,875). Estructurándose su naturaleza jurídica en una, "especie de casación regional que sirve para unificar la interpretación jurídica de los países plegados al modelo, que abarca en el ámbito interamericano más de trescientos millones de habitantes" ${ }^{\prime 48}$.

45 Tribunal Superior de Bogotá. Sala de Justicia y Paz. Sentencia 3.19.2009. No. 11001600253200680526.

46 Consejo de Estado. Sala de lo Contencioso Administrativo. Sección 3ra. Sentencia 1.28.2009. 30340 (R-20030015801).

47 Corte IDH, Caso Tibi. voto concurrente razonado del Juez Sergio García Ramírez, párr. 3.

48 Tratado UE, art. 56: casación ante el Tribunal de Luxemburgo, contra sentencias del órgano Jurisdiccional de 1 Instancia. 
El CC refuerza el derecho a la verdad y garantiza que las reclamaciones de reparación no configuren cargas procesales excesivas que re-victimicen a los lesionados y sus causahabientes. Posibilita además, en el caso de que aparezcan "nuevos hechos o pruebas que puedan permitir la determinación de los responsables... pueden ser reabiertas las investigaciones, incluso si existe una sentencia absolutoria en calidad de cosa juzgada" ${ }^{49}$.

En consecuencia, la violación de obligaciones internacionales o supranacionales conlleva la adecuación de los ordenamientos jurídicos internos sin que esto genere riesgo alguno a la soberanía, sino por el contrario, cristaliza su armonización interméstica y configura un verdadero Estado soberano, en el supuesto donde los sujetos de derecho internacional contemporáneo, actúen conforme el deber ser.

La consolidación plena del CC podría generar una congestión judicial interamericana mayor a la que ya presentan los ordenamientos jurídicos internos, lo que probaría las violaciones sistemáticas estatales que configuran una especie de terrorismo soberano. Así, una verdadera soberanía debe estar armonizada con las normatividades internacionales que acoge voluntariamente y aquellas que tácitamente lo obligan como el lus Cogens. El viejo problema visible de ser los Estados, jueces y partes, en un mismo asunto, lo que se cristaliza en la dominación del hegemón en los organismos internacionales. La efectividad de los ordenamientos jurídicos internos debe reflejarse en la inactividad de los instrumentos internacionales de protección de derechos.

Conforme lo descrito anteriormente podemos concluir que existió la masacre de Mapiripán y el Estado reconoció su responsabilidad por el apoyo militar directo en el descuartizamiento de personas. Es el Estado quien debe determinar las víctimas, y actualmente, sigue omitiendo su deber. Si existen falsas víctimas, este hecho no anula, la cruel realidad y la responsabilidad del Estado. Aquellos que no fueron identificados como víctimas deben ser la prioridad, los maleantes deben pasar a un plano secundario. La masacre no puede centrarse en un aspecto cuantitativo.

49 Caso de la masacre de La Rochela contra Colombia. Sentencia 11.5. 2007. Serie C No. 163, párrafo 197. 
El negacionismo afecta el derecho a la verdad. Así se contribuirá efectivamente al mantenimiento de la paz y la seguridad internacionales bajo el concierto de las Naciones Unidas.

Las sentencias internacionales contribuyen a un Estado superado para que no se presenten altos grados de impunidad. Pero muchas veces el no asumir ciertas posiciones internacionales, les conlleva consecuencias políticas que generalmente son más lesivas que las sanciones jurídicas. El Estado Superador sería aún más ilegítimo en sus actuaciones que los mismos Estados Superados. 
CAPÍTULO VI: LA LUCHA ARMADA CONTRA EL NARCOTRÁFICO EN COLOMBIA Y MÉXICO: UN ANÁLISIS A LA LUZ DEL ARTÍCULO 3 COMÚN A LOS CONVENIOS DE GINEBRA ${ }^{50}$.

La aplicación del artículo 3 común a los Convenios de Ginebra sobre conflictos armados internos es relevante y de especial interés en el análisis de los conflictos que se presentan en Colombia y México, debido a que en la variada gama de conflictos y la prescrita variedad de tipología de los mismos, resultan insuficientes los parámetros para abarcar todas las creaciones delincuenciales en cuanto al fenómeno de la narcoviolencia se refiere. Fenómeno trasnacional que muchas veces escapa a la calificación de conflicto, puesto que sus estructuras son adaptables rápidamente a los cambios de Seguridad Nacional que se le plantean.

En Colombia y México, abundan diversos actores, legales e ilegales, que generan violencia en el desarrollo de sus actividades, a saber: actores armados, insurrectos, paramilitares ahora BACRIM, terroristas de Estado y meros terroristas, narcotraficantes, sicarios, pandilleros, contrabandistas, extorsionistas, secuestradores, etc.

Por lo que resulta preciso abordar el artículo 3 común, que es el resultado de una dinámica de reflexión multidisciplinaria internacional desarrollada en el marco de la escuela contemporánea. Es decir, el mundo internacional y sus reglas se partieron en dos en 1945, en cuanto al uso de la Fuerza Armada y en cuanto a las tendencias de los enfrentamientos, se refiere.

La terminación de la IIGM, consolidó el vergonzoso andamiaje del que se valieron los líderes del sistema internacional de la época, para admitir que se debía reformular la estructura de funcionamiento moral y normativa que venía rigiendo las relaciones entres los Estados, que terminaban destruidos, involucrados y desangrados, por los enfrentamientos de sus clases dirigentes y las ejecuciones de los Ejércitos. Este resultado de reflexión estructural dio nacimiento a la ONU y se terminó de cerrar el capítulo de la escuela clásica internacional.

50 Artículo asociado al proyecto Derroteros para el fortalecimiento d la protección de la población civil y Seguridad Jurídica en el marco del Derecho Operacional en Colombia, del grupo de investigación Derechos Humanos del Centro de Estudios Estratégicos en Seguridad y Defensa -CEESEDEN- . La autora fue Jefe de Investigación Formativa de la Escuela Superior de Guerra de Colombia. 


\subsection{LOS NARCOVIOLENTOS Y EL ARTÍCULO 3 COMÚN}

En 2014, Colombia, México y EE.UU “se encuentran en guerra... interna contra el crimen organizado, que está involucrando crecientemente a los países centroamericanos, en especial a Guatemala y Honduras. EE.UU apoya estas guerras mediante: Plan Colombia e Iniciativa Mérida" (Rojas, 2010, p.12-13). No obstante, los llamamientos de la sociedad internacional en materia de violaciones sistemáticas a los DDHH como daño colateral producido entre los enfrentamientos de los Ejércitos contra los grupos de la narcoviolencia y los enfrentamientos entre diferentes grupos narcos, no han cesado en ambos Estados.

Por su parte, en el marco normativo del Derecho Internacional Humanitario se aplica el concepto de guerra y el de conflicto armado interno acorde con sus principales corrientes como La Haya, Ginebra, Nueva York y su específica confluencia, desde los Protocolos de 1977, para evitar y sancionar los tratos crueles de los intervinientes y no intervinientes y los bienes de estos últimos, limitando los medios y métodos de confrontación. Sin embargo, según un sector doctrinal, estas normas son inaplicables a otros actores armados, cuya estatalidad es difusa, pero que en principio, escapan a dicha estructura o no la confrontan ideológicamente, como los grupos narcoviolentos, denominados en Colombia como BACRIM y en México como meros clanes familiares en disputa territorial.

Otra corriente por el contrario sostiene, que a los grupos narco-violentos, jurídicamente podrían encasillarse como actores del conflicto armado, "puesto que el DIH no toma en consideración las razones por las cuales se inician las hostilidades. El actor no estatal puede combatir en nombre... (de) cualquier otra ideología...los conflictos pueden ser de carácter internacional o... enfrentamientos en el territorio de una misma Nación, de las fuerzas armadas regulares y grupos armados disidentes, o grupos armados entre sí" (Asuntosdelsur.org, 2012).

Adicionalmente, "como toda empresa criminal, los narcotraficantes han instaurado sus propias estructuras de protección. En Colombia, BACRIM: grupos armados entrenados y financiados por los traficantes para proteger sus laboratorios, sus rutas de distribución, etc. Algunos... tienen una formación militar y parecen obedecer a una cadena de mando... desafían la soberanía del Estado 
tratando de controlar un territorio... se observa el mismo fenómeno en el norte de México... (donde) los carteles... disponen de grandes grupos de hombres, muy bien armados y entrenados que conducen una guerra desleal para tomar el control de las principales rutas del contrabando" (Jaramillo, 2008).

Estos nuevos grupos, son grupos de crimen organizado que en teoría no ostentan intereses políticos, sino la cooptación territorial del Estado para sus negocios ilícitos y prestando servicio de seguridad privada a empresas nacionales o multinacionales. Sin embargo, la clasificación teórica, de ser grupos no estatales, encuentra opositores pues la narco-política o para-política, sigue penetrando las esferas públicas.

Las organizaciones narco-violentas en Colombia y México representan el combustible para mantener el poderío de las "nuevas guerras urbanas del siglo XXI, (donde) participan diversos actores que no siempre pretenden apoderarse del Estado, sino que defienden algún recurso o un territorio local, o que quizás sólo intentan crear espacios de orden público para sí mismos. Que se desee llamar a esta situación una guerra o no, es otra cuestión" (Rodgers, 2010).

Así el término guerra se utiliza para describir la lucha contra el narcotráfico en sentido retórico atendiendo el tamaño de la narco-amenaza sustentada por los cuantiosos recursos con los que cuentan los grupos narco-violentos y prefiriendo la clasificación de nuevas guerras dentro de conflictos armados con matrices nacionales pero de alcance trasnacional en ámbitos legales e ilegales. Estas nuevas guerras son "el síntoma inherente del supuesto debilitamiento del Estado, el uso de violencia privatizada... impulsado en gran medida por Occidente" (Azzelini, 2005).

Por lo anteriormente descrito es necesario dilucidar si el artículo 3 común a los Convenios de Ginebra representa un impedimento para la lucha contra el narcotráfico de las FFAA en Colombia y México. Para ello, describiremos someramente los ámbitos de aplicación de los Convenios de Ginebra y particularmente el artículo 3 común.

\subsection{LOS CONVENIOS DE GINEBRA Y SUS PROTOCOLOS ADICIONALES}


I Convenio de Ginebra - 1864: tratamiento de las víctimas del campo de batalla.

II Convenio de Ginebra - 1906: tratamiento de las víctimas de la guerra naval.

III Convenio de Ginebra - 1929: tratamiento de los prisioneros de guerra.

III Convenio de Ginebra - 1949: tratamiento de los civiles en tiempo de guerra.

Protocolo I - 1977: modificación a la protección de víctimas en conflictos internacionales.

Protocolo adicional II- 1977. conflictos no-internacionales.

Protocolo III - 2005: modificación a la adopción del emblema Cristal Rojo.

Entraron en vigor el 21 de octubre de 1950. 194 Estados son Parte: lo que representa su aplicabilidad universal ${ }^{51}$. Los Protocolos adicionales no han contado con la misma suerte (Levie, 1987). Por ejemplo, el Protocolo II no ha sido ratificado por países como Estados Unidos, Turquía, Israel, Irán, Pakistán y Irak, entre otros Estados, que lo firmaron ${ }^{52}$.

Son tratados internacionales resultado de la crueldad de la Guerra y cuyo espíritu fundamental buscó limitar el sufrimiento en cualquier tipo de enfrentamiento armado que ocurra en los territorios de los Estados miembros.

Son la espina dorsal del DIH, aquel conjunto de normas jurídicas establecidas para regular los diferentes tipos de conflictos armados con miras a minimizar sus consecuencias, en especial, mediante la protección de personas ajenas a ellos (civiles, personal sanitario, miembros de organizaciones humanitarias) y a los que se encuentran inhabilitados para continuar en el enfrentamiento armado (heridos, enfermos, náufragos, prisioneros de guerra, rendidos).

\subsubsection{CONTENIDO DE LOS CONVENIOS DE GINEBRA}

CG - I: versión moderna del Convenio de Ginebra sobre los combatientes heridos y enfermos de 1864, 1906 y 1929. 64 artículos. Protege heridos, enfermos, personal médico y religioso, sus herramientas y medios de transporte. Reconoció emblemas distintivos. 2 anexos: un proyecto de acuerdo sobre zonas y localidades sanitarias, y una carnetización de los intervinientes.

CG - II: protege, durante la guerra, a los heridos, los enfermos y los náufragos de las FFAA en el mar. Remplazó el Convenio de La Haya de 1907. 63 artículos. 1 anexo que contiene un modelo de tarjeta de identidad para el personal médico y religioso.

CG - III: Aplicable a prisioneros de guerra. Derogó el Convenio sobre prisioneros de guerra de 1929. 143 artículos. Amplió las categorías de prisioneros de guerra. Una vez ocurra el cese de las hostilidades los prisioneros deben ser liberados y repatriados. 5 anexos: modelos de

51 conventions/overview-geneva-conventions.htm

52 Protocol Additional to the Geneva Conventions. (Protocol II), 8 June 1977. 
acuerdos y tarjetas de identidad.

CG - IV: Protección a civiles inclusive en territorios ocupados. Los Convenios de Ginebra anteriores a 1949 nunca involucraron protección a civiles sino exclusivamente a militares.

Los 4 Convenios portan como fecha de creación el 12.8.1949 pues ese día se firmó el Acta Final de

la Conferencia Diplomática, que los compiló. Representan el pilar del DIH contemporáneo. Contienen las normas esenciales para proteger a heridos, enfermos, náufragos, prisioneros de guerra y civiles, incluidos los civiles que viven en situaciones de ocupación. Todos deben ser atendidos sin discriminación. Afganistán (2001-2002), Irak (2003-2004), sur de Líbano (2006) y el conflicto entre Georgia y Rusia (2008), representan escenarios cercanos y claros de aplicación de los Convenios.

\subsubsection{CONTENIDO DEL ARTÍCULO 3 COMÚN A LOS CONVENIOS DE GINEBRA}

En caso de conflicto armado que no sea de índole internacional y que surja en el territorio de una de las Altas Partes Contratantes, cada una de las Partes en conflicto tendrá la obligación de aplicar, como mínimo, las siguientes disposiciones:

1) Las personas que no participen directamente en las hostilidades, incluidos los miembros de las fuerzas armadas que hayan depuesto las armas y las personas puestas fuera de combate por enfermedad, herida, detención o por cualquier otra causa, serán, en todas las circunstancias, tratadas con humanidad, sin distinción alguna de índole desfavorable, basada en la raza, el color, la religión o la creencia, el sexo, el nacimiento o la fortuna, o cualquier otro criterio análogo.

A este respecto, se prohíben, en cualquier tiempo y lugar, por lo que atañe a las personas arriba mencionadas:

a) los atentados contra la vida y la integridad corporal, especialmente el homicidio en todas sus formas, las mutilaciones, los tratos crueles, la tortura y los suplicios;

b) la toma de rehenes;

c) los atentados contra la dignidad personal, especialmente los tratos humillantes y degradantes;

d) las condenas dictadas y las ejecuciones sin previo juicio ante un tribunal legítimamente constituido, con garantías judiciales reconocidas como indispensables por los pueblos civilizados.

2) Los heridos y los enfermos serán recogidos y asistidos.

Un organismo humanitario imparcial, tal como el Comité Internacional de la Cruz Roja, podrá ofrecer sus servicios a las Partes en conflicto.

Además, las Partes en conflicto harán lo posible por poner en vigor, mediante acuerdos especiales, la totalidad o parte de las otras disposiciones del presente Convenio.

La aplicación de las anteriores disposiciones no surtirá efectos sobre el estatuto jurídico de 
las Partes en conflicto.

La norma cobija específicamente a los conflictos armados no internacionales, llámense guerras civiles, conflictos internos con consecuencias internacionales, conflictos internos con intervención internacional, etc.

El artículo 3 común "extiende los principios de los Convenios de Ginebra a los conflictos armados no internacionales y deja de lado algunos obstáculos de la soberanía nacional” (Spoerri, N.D.). Es un mini convenio al que la Corte Internacional de Justicia se refirió como un compendio de consideraciones de humanidad elementales.

La proliferación de los conflictos armados internos o no internacionales materializó el contenido de la disposición tercera común a los Convenios de Ginebra cuyo ámbito de aplicación recae en conflictos no internacionales y que se suscitan en territorio de algún Estado parte.

Frente a las disposiciones del artículo 3 "ningún Gobierno puede sentirse molesto por tener que respetar, por lo que atañe a sus adversarios internos, sea cual fuere la denominación del conflicto que a ellos los opone, este mínimo de reglas que, de hecho, respeta cotidianamente en virtud de sus leyes" (Pictet, 1958).

El contenido de la obligación simplemente dignifica el ser humano y lo protege de tratos crueles que han venido siendo utilizados indiscriminadamente en el desarrollo de los diversos enfrentamientos armados. El artículo 27 trató de definir trato humano desde una estrategia excluyente, es decir, no ofrece una definición de lo que significa el trato humano sino enumeró una lista taxativa de actuaciones contrarias al mismo. Lo que conlleva a criticar dicha rigidez normativa, pues en el entramado de la maldad humana: ¿será posible determinar conductas inhumanas?.

En cuanto a la toma de rehenes, condenas y ejecuciones sin juicio legítimo, el artículo 3 buscó evitar las ejecuciones extrajudiciales, por lo tanto, la disposición común no conlleva ningún tipo de inmunidad y los Estados están en libertad de operar sus sistemas judiciales. 
El artículo 3 se aplica a miembros de las fuerzas armadas y a civiles. Para los miembros de las fuerzas armadas, corresponde igualmente atender, las disposiciones del III Convenio, en el desarrollo de sus operaciones militares.

Cabe resaltar, que si bien todo ser humano tiene derecho a un trato humano independientemente de su nacionalidad, los arrestados podrán adoptar medidas especiales de prevención en materia de Seguridad, dependiendo de la nacionalidad particular. Por último, se ha identificado el artículo 3 como un mini-convenio integrante de los Convenios de Ginebra, debido a que faculta a las partes en conflicto a realizar un Acuerdo Especial, mediante el cual solo se obligan a respetar el contenido del mini-convenio.

\subsection{CONFLICTOS ARMADOS NO INTERNACIONALES}

Definición: "conflicto que tiene lugar... en el territorio de una Alta Parte contratante entre sus fuerzas armadas y fuerzas armadas disidentes o grupos armados organizados que, bajo la dirección de un mando responsable, ejerzan sobre una parte de dicho territorio un control tal que les permita realizar operaciones militares sostenidas y concertadas y aplicar el presente Protocolo" ${ }^{\prime 53}$.

Darfur, Sudán, Colombia, Congo, Afganistán, Irak, Somalia: representan los más relevantes conflictos armados no internacionales en la actualidad. No obstante, estos conflictos internos suelen desbordarse comúnmente sobre las fronteras soberanas de otros Estados. Adicionalmente este tipo de conflicto se trasforma rápidamente lo que dificulta su neutralización. Pueden enfrentar al Gobierno con grupos armados, pero también pueden enfrentarse con otros grupos armados.

El Protocolo II es el "primer tratado internacional dedicado exclusivamente a las situaciones de conflicto armado no internacional" (ICRC, 2013).

53 Artículo 1 del Protocolo II. 


\subsubsection{ELEMENTOS CONSTITUTIVOS DEL CONFLICTO NO INTERNACIONAL}

1. El conflicto tiene lugar en el territorio de un Estado;

2. Se oponen fuerzas armadas del Estado a grupos armados que no reconocen su autoridad;

3. Estas fuerzas y grupos armados deben estar bajo el mando de una autoridad responsable (tener una dirección militar o política que asuma la responsabilidad);

4. Ejercen dominio sobre una Parte del territorio del Estado que les permita realizar operaciones militares sostenidas y concertadas, y aplicar las disposiciones de derecho humanitario del Protocolo II.

El artículo 3 se aplica sin condición de reciprocidad y su ámbito de aplicación se destina, como se mencionó anteriormente, a situaciones prescritas como conflictos armados no internacionales o internos, teniendo como criterios de calificación no estrictos pero determinantes, las tendencias a la calificación del conflicto que se reflejan cuando existen realidades que resumen los siguientes casos:

1. La parte armada ilegal cuente con una organización militar y en su cabeza autoridad que se responsabilice de los actos que comenten.

2. Cuando la parte armada ilegal se enfrente al Ejército dentro del territorio del Estado.

3. Cuando el Ejército debe enfrentar insurrectos.

4. Cuando el Gobierno reconozca a insurrectos la condición de beligerantes.

5. Cuando un grupo armado se auto-considere y autoproclame como beligerante

6. Cuando un Gobierno reconozca la calidad de beligerantes exclusivamente para la aplicación del Convenio

7. Cuando el enfrentamiento se declare como amenaza a la paz y la seguridad internacional por el Consejo de Seguridad de la ONU.

8. Cuando la organización ilícita ejerce autoridad sobre una determinada población y/o zona del Estado. 
Atender dichas tendencias al diagnosticar un enfrentamiento interno posibilitará diferenciar la existencia de un conflicto armado a una mera tensión interna, un acto vandálico masivo o disturbio interior. En síntesis, una desorganización social significativa y violenta. El conflicto armado interno conlleva muchos elementos comunes de las guerras clásicas pero estos se desarrollan al interior de un Estado.

Finalizando éste apartado, un conflicto interno es internacionalizado cuando "uno o más estados extranjeros intervienen con sus propias fuerzas armadas a favor de una de las partes" (Verri, 1998).

\subsubsection{DISTURBIOS INTERIORES Y TENSIONES}

EI CICR los ha definido cuando sin que medie un conflicto armado interno se presentan enfrentamientos violentos de relativa gravedad o permanencia dentro del territorio soberano de un Estado. Por ejemplo: tensiones y violencia por motivos políticos, raciales, culturales, sociales, religiosos, sexuales, económicos, etc.

Cuando se presentan disturbios interiores o tensiones, es normal el aumento de los daños colaterales, a saber: detenidos políticos en masa, práctica de tratos inhumanos y temerarios, inaplicabilidad de garantías constitucionales, administrativas y judiciales, declaración de estados de excepción, desplazamientos, desapariciones, entre los más comunes.

A este tipo de disturbios también se aplican las disposiciones normativas del artículo 3 común de los Convenios de Ginebra y el Protocolo II. El artículo 3 y el Protocolo II son el marco jurídicopolítico convencional humanitario aplicable a los conflictos armados no internacionales. Cuando exista un elemento insurgente se debe aplicar adicionalmente los marcos de la Haya.

\subsection{CONVERGENCIA NORMATIVA: GINEBRA - HAYA}


Derecho de Ginebra y Derecho de La Haya: el conjunto de estas disposiciones normativas configura el lus in bello, es decir, la parte del derecho de la guerra por la que se rige el comportamiento del Estado en caso de conflicto armado. Derecho a la guerra - lus ad bellum ha desaparecido prácticamente (Swinaraki, 1984).

El CICR, creado en 1863 tras la inspiración de la obra de Henry Dunant, ha desempeñado el liderazgo en el proceso de desarrollo del DIH y la protección de los DDHH. El DIH es un derecho de excepción que opera en situaciones de enfrentamiento armado; los DDHH se aplican en ausencia de la violencia. Si bien los DDHH deben aplicarse en todo momento, en tiempo de guerra es improbable garantizar derechos como el de asociación o expresión, por ejemplo. El CICR se encarga de la efectividad de las garantías del $\mathrm{DIH}$; las organizaciones internacionales de los DDHH.

De otra parte, es necesario establecer que frecuentemente las partes en conflicto son renuentes a calificar los conflictos o indeterminarse, para no ser sujetos de sanción por el incumplimiento de este tipo de disposiciones normativas. La calificación del conflicto armado la pueden realizar:

1. Las Partes contendientes;

2. Las organizaciones internacionales;

3. EI CICR (la neutralidad es su fundamento de acción).

Cuando el conflicto armado interno se convierta en internacional, no basta la aplicación del artículo Tercero Común.

De esta manera y a partir de 1949, el DIH convencional se aplica en la situación de conflicto armado no internacional. Estos instrumentos de protección aunque están lejos de ser completamente efectivos son contundentes en cuanto a la protección de las personas que sufren los conflictos armados y han elevado la impronta de que los asuntos humanitarios están por encima de los estamentos soberanos nacionales pero nunca en contra.

El conflicto es inherente a la aplicabilidad de las normas del DIH. Los Convenios de Ginebra y sus Protocolos Adicionales dirigen sus medidas a dos tipos de conflictos: conflictos armados internacionales y conflictos armados no internacionales o internos. Los organismos humanitarios siempre deben actuar de manera neutral sin ningún tipo de consideración ideológica, propiciando siempre un trato humano y con la reserva que le ordena el principio de discreción. 
Las medidas mínimas (Ángel, 2012) que debe adoptar un Estado en el transcurso de los conflictos armados son las siguientes:

Antes del Conflicto Armado: Los Estados deben implementar medidas preventivas que garanticen el cumplimiento del DIH: multiplicar los contenidos normativos y las sanciones a que da lugar el cumplimiento de los mismos.

- $\quad$ Durante el Conflicto Armado: Los marcos normativos deben cumplirse en todo momento del conflicto, desde su inicio hasta su finalización formal.

Después del Conflicto Armado: El Estado debe adoptar las medidas respectivas para lograr unas condiciones lo más similares al statu quo ante. Adicionalmente, deberá ejecutar medidas de normalización como la liberación de prisioneros, la repatriación de extranjeros, el retorno de víctimas a sus lugares de origen, el seguimiento de tratamientos médicos, la limpieza de campos minados y la contención psicológica requerida para superar los traumas generados por el desarrollo de los conflictos armados.

La clasificación del conflicto es trascendental pues diferencia una situación de violencia general de un conflicto armado concreto. "La distinción es importante, porque el modo en que se caracteriza la situación determina el derecho aplicable" ${ }^{24}$. Por ejemplo, los combatientes enemigos capturados en medio de enfrentamientos de un conflicto armado no se consideran prisioneros de guerra pues el término se refiere a un estatuto especial que el III Convenio de Ginebra confiere a los soldados enemigos capturados únicamente en el marco de conflictos internacionales.

Por todo lo anteriormente expuesto, podemos concluir que los grupos del crimen organizado como los miembros que ejercen la narcoviolencia en Colombia y México, si son destinatarios de las obligaciones jurídicas del articulo 3 y el II Protocolo. La problemática radica en la imposición de la sanción a estos actores temerarios.

No obstante, debemos recordar que éste área del Derecho Internacional Público está en plena evolución y pese a no ser medianamente efectiva, ha cosechado triunfos a lo largo de las historias de crueldad que se despliegan en el transcurso de los innumerables tipos de enfrentamientos

54 Conflictos internos u otras situaciones de violencia: ¿cuál es la diferencia para las víctimas?10-12-2012 Entrevista videohttp://www.youtube.com/watch?v=HnT12T9RsA0 
armados que se surten en el siglo XXI. Las normas internacionales ratificadas en materia de DDHH prevalecen sobre las normas internas (Constitución Política de Colombia, 1991, Art.93).

En Colombia el narcotráfico es el factor de crecimiento más dinámico 55 . "Los grandes bancos perciben ganancias del lavado de dinero" (El Tiempo, 2002). Más grave aún la situación en México puesto que, "la relación entre el ejército y los paramilitares es entonces mantenida por los políticos del PRI, bien sean diputados nacionales o regionales, así como alcaldes y consejeros de distrito, que financian y conducen el terror" (Centro de Derechos Humanos Fray Bartolomé de Las Casas, 1996, p.94).

Sin embargo se siguen cometiendo crímenes internacionales que burlan la imperatividad de las normativas agrupadas en el lus Cogens.

Una estructura internacional fundamentada en principios democráticos que nada tiene que ver con la "realidad social" (Canalsolidario.com, N.D.). Plagado de "injusticias, desigualdades y exclusiones y que tienden a ser propositivas en contextos históricos específicos" (Archila, 2008, p.18). Lo que arroja a la población marginal a enlistarse en las filas laborales de los narcoviolentos.

Si bien, los postulados del DIH están destinados a desarrollarse en el ámbito de los conflictos armados, brilla por su ausencia una definición del mismo en los Convenios de Ginebra y en sus Protocolos. Únicamente el II Protocolo establece, como vimos, los requisitos del "conflicto armado no internacional" (Salomón, N.D.).

En cuanto a la clasificación del conflicto se aconseja "adoptar una interpretación flexible de los conceptos en los que descansa el DIH... Si el umbral es excesivamente bajo se corre el riesgo de favorecer el bandidaje y la delincuencia común que se encuentran dentro del ámbito de acción de la policía y las leyes penales internas. Por el contrario, si el umbral es excesivamente alto se puede generar situaciones de desprotección para las víctimas de los conflictos armados" (Tomuschat, 2003).

55 Constituye alrededor del 6\% PIB y un porcentaje igualmente alto de la ocupación. Un 40\% del patrimonio total en Colombia. 
Lo que debe predominar es la protección de los seres humanos "en las situaciones en que más peligran su vida y su dignidad" (CIJ, 1970, p.32). En consecuencia, la CIJ fallando el caso de Barcelona Traction recordó que las normas humanitarias "por su naturaleza (brindan a)...todos los estados... un interés jurídico para que esos derechos sean protegidos" (Carrillo, 2001).

La tipología de conflictos no debe continuar siendo taxativa pues presenciamos "un retorno de las antiguas guerras que precedieron a la aparición de los estados naciones" (Grunewald, N.D., p.288308). Al respecto Hobsbawn, señaló que las nuevas formas de conflictividad son "signo característico del siglo XXI donde las guerras ya no serán solo entre estados, sino entre estados y organizaciones no estatales suficientemente ricas y fuertes" (Grunewald, N.D., p.288-308). Dando lugar a la aparición de 3 conflictos de tercera generación (CICR, N.D., p.20):

a) Conflictos de identidad o étnicos: limpieza étnica.

b) Conflictos desestructurados - Estado fallido o failed State: enfrentamientos generalizados entre diversos grupos no estatales frente a un Estado de papel, es decir, evidentemente insuficiente para brindar seguridad y las garantías fundamentales a la totalidad de sus integrantes. Thürer (1999) sostiene que "los estados fallidos son producto del colapso de las estructuras de poder que proveían de base política al Derecho y al orden, lo que genera el colapso de las instituciones del Estado, especialmente la policía y el poder judicial, lo cual resulta en una parálisis de gobierno, un rompimiento del Derecho...bandidaje y caos generalizado" (p.731-761).

c) Conflictos asimétricos: un Estado, hegemónico o no, es atacado por actos terroristas globalizados. Un grupo terrorista que tiene alcances globales con sucursales a nivel mundial. Un grupo que en su conjunto es prácticamente no identificable. Condorelli lo comparó con el "pulpo de mil tentáculos" (Condorelli, 2001, p.829).

En consecuencia, debemos rechazar el problema planteado puesto que el artículo 3 común a los Convenios de Ginebra y sus Protocolos Adicionales, no es un impedimento para la lucha contra el narcotráfico que ejecutan las Fuerzas Armadas en los territorios de Colombia y México. La normativa analizada no contraviene los principios relativos a la soberanía de los Estados como la independencia y la no injerencia en los asuntos internos ni mucho menos en el derecho legítimo de defensa que tienen los Estados mediante sus estrategias de Seguridad Nacional. 
Tal vez un problema de fondo radica en no identificar claramente las estructuras delincuenciales, pues para que exista conflicto armado calificable, deben existir al menos dos partes enfrentadas claramente determinables. Las estructuras de narcoviolencia mutan rápidamente, muchas veces bajo la aquiescencia de los Estados y del sistema internacional, lo que hace aún más difusa su posibilidad de sanción a través de las normas del DIH.

Por lo que muchos conflictos armados se presentan como meros "disturbios interiores y tensiones internas (que) deben, en principio, regularse por las disposiciones del propio Derecho interno en consonancia con el DIDH" (Jiménez, 1998). En la interpretación relativa a normas de DIH Rousseau definió que consiste en una "operación intelectual (para) determinar el sentido de un acto jurídico, precisar su alcance y aclarar los puntos oscuros o ambiguos (Rousseau, 1969).

Por lo mismo convergen los principios comunes al DIH y DIDH: “(i) inviolabilidad, que se refiere a los atributos inseparables de la persona (vida e integridad física y psíquica); (ii) no discriminación, que significa que todos deberán ser tratados sin distinción desfavorable de ningún tipo; y (iii) seguridad, alude a la seguridad personal" (Pictet, 2001).

Resaltando a la Convención de Viena sobre el Derecho de los Tratados (1969) que determinó: “una norma imperativa de Derecho Internacional General es una norma aceptada y reconocida por la comunidad internacional de estados en su conjunto como norma que no admite acuerdo en contrario y que solo puede ser modificada por una norma ulterior de Derecho Internacional general que tenga el mismo carácter". 


\section{CAPÍTULO VII: CONSTRUCCION DE NARCOIDENTEIDADES EN COLOMBIA Y MÉXICO ${ }^{56}$}

Nos proponemos reflexionar acerca del carácter identitario de la narco-cultura en Colombia y México con miras a conceptualizar los grupos sociales que se identifican y viven en un narco-mundo como una narco-nación, que se fundamentan en las utilidades de las ESol- narcoviolentas en Colombia y México. Ellas son su pilar financiero y económico.

Desaparecen paulatinamente "los sistemas homogéneos y nos vamos encontrando con sistemas heterogéneos, lo que permite hablar de subsistemas... fragmentación del espacio mundial... subsistemas regionales (en el que los Estados y los pueblos manifiestan una solidaridad de destino en el interior y el exterior... subsistemas ideológicos... económicos...civilizatorios" (Pereira,2009, p.57-58). Pues "La cultura de un país reside en el corazón y el alma de sus habitantes"(Gandhi). Base metodológica para comprender la construcción de narco-subsistemas dentro de las ideologías nacionales predominantes antinarcóticas.

Para ello partimos de la base de que la narco-cultura conlleva elementos comunes y diferenciadores en cuanto a las unidades de análisis referidas: Colombia y México. Iniciaremos apoyándonos en conceptos básicos para despejar la hipótesis de la narco-nación en construcción, como cultura, costumbre, comunidad y sociedad.

\footnotetext{
${ }^{56}$ Capítulo producto de seminario doctoral aprobado por el Dr. Carlos Escudé y publicado por el IRI en la edición del año 2014.
} 
Ahora bien, "dentro de la teoría de la investigación para la Paz y el estudio de la violencia en sus diferentes dimensiones (encontramos) la violencia directa, la violencia estructural y la violencia cultural" (Heyck, 2011, p.1).

La violencia cultural ha sido definida como un complejo de "facetas culturales que de una u otra forma apoyan o justifican las realidades y prácticas de la violencia. Si la violencia directa es generada desde el propio agresor, y la violencia estructural está organizada desde el sistema - la estructura - la violencia cultural lo hace desde las ideas, las normas, como alegato de aceptación natural de las situaciones provocadas por ella. Es decir, todo aquello que, en definitiva, desde la cultura legitime y/o promueva la violencia de cualquier origen o signo"(Jiménez, 2004, p.21).

Por su parte la "violencia estructural... alude a una violencia que está inscrita en los fundamentos de sociedades y culturas que favorecen y premian comportamientos de exterminio real y/o simbólico de todo lo que no se ajusta a sus escalas de valores, modelos de gestión política, económica y social, sistemas de creencias, esquemas de configuración del orden, prácticas de organización social” (García, 2010, p.200-201). Exterminios legitimados.

Por su parte la conflictología pretende explicar a la violencia a través de la tríada "necesidad, miedo y acción" (Heyck, 2011, p. 19).

El Diccionario de la Real Academia ${ }^{57}$ de la lengua española define por cultura al conjunto de modos de vida y costumbres en una época.

Por costumbre entiende al hábito o modo habitual de proceder establecido por tradición o por la repetición de los mismos actos y que puede adquirir fuerza de precepto, que se hace por carácter o propensión comúnmente. También la asume como el conjunto de cualidades y usos que forman el carácter distintivo de una nación o persona y como el conjunto de rasgos propios de un individuo o de una colectividad que los caracterizan frente a los demás y sobre lo cual tienen conciencia.

57 http://lema.rae.es. Consultado el 11.8.2013. 
En cuanto a comunidad refiere al conjunto de personas de un pueblo, región o nación vinculados por características o intereses comunes.

Por nación conceptúa al conjunto de habitantes de un país regido por el mismo gobierno; conjunto de personas de un mismo origen y que generalmente hablan un mismo idioma y tienen una tradición común.

El concepto de nación nos remite a dos sentidos: el jurídico-político ligado a la soberanía estatal y el sentido ideológico social, relativo a costumbres derivadas de una contextualización cultural que comparte lengua, raza, cultura, hábitos, creencias y comportamientos que los identifican como comunidad.

A su vez, nación puede definirse en términos etnológicos lo que conlleva a que su existencia no requiera la existencia del Estado o ficción jurídico-política. Como podría predecir la estructura de un narco-gobierno como autoridad de una narco-comunidad.

El concepto psicológico de la nación como "singularidad de existencia histórica reposa sobre los pivotes de la cohesión e individualidad del grupo social que lo constituye como apto para darse un orden político interno autónomo" (Zeraoui, 2011, p.100). En términos psicológicos la narcocomunidad al compartir fines y conductas sería una nación literal.

En otro enfoque se pronunció Ernest Reman rechazando las "teorías naturalistas de la nación porque... la raza, la sangre, el territorio y el idioma no bastan para explicar los contenidos trascendentales del nacionalismo... para el filósofo José Ortega y Gasset la nación es un conjunto de convivencia total en una empresa común a la cual se adhieren los hombres" (Zeraoui, 2011, p.100).

Contemporáneamente la nación representa "un estilo de vida colectiva. Y el estilo es rúbrica de nuestro más íntimo y auténtico ser moral; en el fondo de cada estilo individual está latente y actuante un estilo colectivo" (Zeraoui, 2011, p.101). 
Entonces bajo esta mirada menos exegética la narco-cultura se perfilaría como una narco-nación en construcción con muchos factores de riesgo que impedirán su cristalización como ente legal.

De otra parte, la nacionalidad social refiere la pertenencia a un grupo social de fuerte personalidad identitaria entre nación y Estado que se pretendió generalizar en Europa finalizada la IGM (consecuencia directa de los 14 puntos de Wilson) y en la mayor parte del mundo tras la IIGM (al unísono de los procesos de descolonización). Tal pretensión, en ambos casos, demostró ser imposible de realizar en la práctica dada la multiplicidad de identidades y confusión entre diferentes comunidades, culturas, lenguas, religiones, territorios y fronteras.

Por su parte, el nacionalismo representa una ideología o movimiento político-social que surgió concomitantemente con el concepto de nación en la Edad Contemporánea, caracterizada por la Revolución industrial, burguesa y liberal, desde finales del siglo XVIII. Algunos lo definen como "la ideología y el movimiento político que encarna el sentimiento del grupo humano de pertenecer a una misma nación"(Lozano en Zeraoui, 2011, p.98).

Anthony Smith expone como criterios del concepto de nacionalismo a:

"1.Distinguir los elementos de cultura e ideología que llevan consigo la conciencia de nacionalismo; 2. Distinguir los grupos sociales que sustentan la ideología conducente al nacionalismo... establece que hay una ideología central del nacionalismo cuyo postulado es que <<la humanidad está naturalmente divida en naciones >>... agrupa las teorías del nacionalismo en:

- 1. Teorías históricas, según las cuales nacionalismo es una ideología inventada en Europa a comienzos del Siglo XIX...

- 2. La concepción de nacionalismo como anticolonialismo, en el cual éste se considera la respuesta nacional a la opresión extranjera...

- 3. Perspectiva funcionalista: ...relacionadas con el concepto de modernización, en donde se considera al nacionalismo como una subespecie de ideología que crece en detrimento de la desintegración de las estructuras tradicionales...

- 4. Teorías que ven al nacionalismo como un medio de transición a una sociedad moderna... 
- 5. Consecuencia del proceso de industrialización con efectos integradores y divisorios para la naturaleza de los Estados-naciones, la cual también plantea que cuando la industrialización sea globalmente completa, el nacionalismo desaparecerá"(Smith, Anthony, 1976, s.p.).

La crisis de los nacionalismos aconteció al finalizar la GF provocando el "resurgimiento de la cuestión nacional... como un fenómeno decimonónico ajeno a la problemática ideológica del Siglo XX... la cuestión bipolar marginalizada... y un cuestionamiento del Ilamado Estado-nación" (Zeraoui, 2011, 97).

Ahora bien, resaltemos que no existe definición en el Diccionario de la Real Academia de la Lengua al prefijo narco, pero paradójicamente lo relaciona a conceptos como narco-dólar y narcotraficante, claro está. Como si fuera posible definir conceptos derivados de un no concepto.

Así "plantear una teoría del narcotráfico, es la imposibilidad de definir con claridad los límites entre el objeto de estudio y el planteamientos del problema, debido a lo que Baudrillard llamaría la obscenidad del objeto, la ansiedad por lograr su plena exposición... falta una teoría salvaje para representar un objeto salvaje"(Ramírez, 2011, p. 171-172).

\subsection{LAS NARCO-OPORTUNIDADES}

Narcotraficante es aquel que se desarrolla dentro de la cadena de producción y distribución de los narcóticos, excluyendo a los consumidores.

El narcotráfico es un ámbito excluyente de oportunidades para satisfacer las diversas necesidades sociales como la "proyección oscura del dominio de los símbolos de la alteridad (por oponerse) al proyecto de lo subalterno, porque elimina la voluntad y la vida de quienes no son funcionales en la dinámica del sistema"(Ramírez, 2011, p.15). 
De allí la importancia de conceptualizar la posibilidad de que los grupos ESol narco-violentos estén construyendo una especie de nación que representa identidad a diversos grupos sociales con el narco-mundo.

Consideramos que para llevar a cabo el estudio propuesto y concreto en el marco de las RRIIdebemos asumir a la variable cultural como independiente: "Finalmente el narcotráfico es un asunto cultural"(Ramírez,2011, p. 31), por más que conlleve factores de seguridad, salud pública, subempleo, narco-oportunidades, entre los principales.

En consecuencia, los medios de comunicación como principales gestores de la variable cultural rechazan y condenan la narco-cultura y alegan sus derivados violentos. No obstante reproducen las producciones de entretenimiento narco-violento porque generan los mayores niveles de audiencia - rating -, lo que produce ante tal perturbación una salida cómica y superficial que alivia el instinto cotidiano de la mortalidad.

La humanidad siempre utilizó la violencia para resolver conflictos. Sigmund Freud enfocó el uso de la violencia como un resultado "de los instintos de vida y de muerte, de Eros y Tanatos" (Tello, 2010, p. 282).

Einstein indagó a Freud sobre sí: “¿es posible controlar la evolución mental del hombre para protegerlo de la psicosis de odio y destrucción? (Einstein, 1979, p.72). Freud le contestó: "constituye un gran principio el que los conflictos de intereses sean resueltos a través del empelo de la violencia. Esto es verdad para el conjunto del reino animal y no hay razón para pensar que la especie humana sea diferente" (Freud en Tello, 2010, p. 59).

Asimilando la violencia humana como la "agresión entre los animales. La diferencia radica en que los animales la utilizan para solucionar conflictos de territorio, reproducción, etc, pero... se encuentra sometida a numerosos límites que los humanos (hemos) perdido. Nosotros no reconocemos los signos de sumisión del oponente que indican el final de la lucha" (Martínez, 2007, p. 62). Uno de los códigos del narco es la agresión como multiplicador de narcoconcluoportunidades. 


\subsection{NARCO-ECONOMÍA VIOLENTA}

Naomi Klein señala al "performance del terror del narcotráfico (como)... variable del proceso de desestabilización de las economías estatales, particularmente en los países subdesarrollados" (Ramírez, 2011, p.48).

Por ejemplo, el blanqueo de dinero de las ESol narco-violentas en México impregnó en un 70\% “la economía nacional (us 25 mil millones)... Cifras que algunos académicos llegan a elevar a 40 mil millones... involucra de manera directa a más de 1 millón de personas y que ha generado un estrato cultural impresionante incorporando su imaginario simbólico a cualquier forma de expresión: música, películas, literatura, artes plásticas, etc... La ONU considera que el narcotráfico es la octava industria más importante de las economías del mundo y el comercio de crimen organizado más importante a nivel global... En Estados Unidos, el valor de las ganancias generadas por el narcotráfico no solo resulta escandaloso, sino que también es contradictorio: DEA us 100 mil millones anuales, el Departamento de Estado entre us 19 y 30 mil millones... en todo el mundo... más de 250 mil millones de euros...; aunque la Agencia del Crimen Organizado (SOCA, Seious Organised Crime Agency) llega hasta los us 325 mil millones anuales (Forgione, 7276)"(Ramírez, 2011, p. 24-25).

Sin embargo se ha considerado que el narcotráfico no representa un problema estructural de las economías de Estado sino por el contrario reviste un "problema de las economías de mercado. Plantear al narcotráfico como un problema económico es pensar que deriva de la pobreza, lo que simplifica el problema" (Ramírez, 2011, p. 27).

En Colombia y México la empresa ilícita o subterránea de los narcóticos "comenzó como un síntoma social, se convirtió en un problema social y ha derivado en una estructura social, aunque su evolución no ha implicado la cancelación de las fases anteriores... la estructura social del narcotráfico generó una cultura singular, que en algunas fases de su imaginario simbólico manifiesta la insatisfacción de los individuos (particularmente de quienes son marginados de la representatividad social en la polis) contra el hacinamiento que supone tolerar el neoliberalismo" (Ramírez, 2011, p.27). 
Se desarrolla la narco-sociedad en un esquema que se puede considerar como un desorden mundial que genera localmente narco-empleos dentro de la "peligrosa pirámide mercantil del mundo del narcotráfico, las bases pueden ganar apenas ochenta a cien euros mensuales, mientras que la punta alcanza ganancias de hasta medio millón de dólares por el mismo periodo de trabajo"(Ramírez, 2011, p. 65).

La ONU delimitó a las regiones de América Latina y África como las más peligrosas y "violentas por actividades del narcotráfico, pero no son las sedes principales del consumo, situadas en Estados Unidos y en Europa central y oriental. Tampoco son las naciones más importantes ni del lavado de dinero, aunque hay una participación, principalmente, en Centroamérica y en el Caribe /Costa Rica, Belice, República Dominicana, Granada, Guatemala, Panamá y Filipinas)”(Ramírez, 2011, p. 157).

En cuanto a los paraísos fiscales de los narco-violentos la OCDE estimó un rating en el "que se deben observar las ausencias. En la medida que la crítica ha ejercido su labor sobre el llamado secreto bancario, que tradicionalmente ha distinguido a pequeños países europeos (con economías no tan pequeñas) como Mónaco, Liechtenstein, Luxemburgo, Suiza y Bélgica, la OCDE ha eliminado a estos países de su índice de paraísos fiscales... Estos paraísos se encuentran incluso muy lejos de las zonas de violencia del narcotráfico, pero en las inmediaciones del llamado G-3, las naciones más poderosas de Occidente: Estados Unidos, Francia y Alemania”(Ramírez, 2011, p. 157-158).

\subsection{NARCO-CONTEXTUALIZACIÓN}

Desde Al Capone y la violencia del crimen organizado desatada en Chicago entre 1920 y 1930, se cuenta con cifras aberrantes de homicidios dolosos: 20 mil muertos (Ramírez, 2011, p. 35).

La ONU considera al narcotráfico como el principal hilo de unión en las RRII entre EE.UU y América Latina "cuya industria químico-farmacéutica promovió, durante la época de los cuarenta del siglo 
XX, con obreros asiáticos y latinoamericanos, el cultivo de marihuana y amapola tanto en el norte de México (Sinaloa, Tamaulipas y Durango, principalmente), como en la zona caribeña de Colombia (Barranquilla, Cartagena de Indias, San Andrés, Valledupar, Montería, Santa Marta, Sincelejo y Rioacha). Diez años después la ONU intentó prohibir el crecimiento del sistema, cuando ya era el sustento y principal motor de la dinámica social de poblaciones enteras" (Ramírez, 2011, p. 101).

Las élites políticas y socio-económicas nacionales e internacionales comenzaron a lucrarse directamente del narcotráfico "que, legal y reconocido durante diez años, estaba al margen de la normativa determinada por la ONU en la década de los cincuenta que permitía el cultivo de opio, coca y marihuana a Turquía, Afganistán, la India, Irán y la antigua Yugoslavia (Montoya, Rodríguez y Fernández, 2009). El escenario se derrumbó en los siguientes treinta años. Las sanciones económicas de la ONU impuestas a Afganistán, Irán y la India impidieron el desarrollo del sistema de drogas en esas regiones... El mercado fue una diáspora que dejó en México y Colombia el mayor trabajo de producción (Nacaveva, 1967, 365), sin obtener las ganancias mercantiles del sistema. Recoincidiendo con la prohibición del sistema del tráfico de drogas, comenzó el auge de los... paraísos fiscales... una de las primeras aspiraciones económicas del siglo XXI fue trasladar la economía de los Estados a la economía de los mercados, con lo que también despareció el valor real del trabajo del campesinado dedicado a esos cultivos"(Ramírez, 2011, p. 102).

De esa manera, en el mundo contemporáneo se arraigaron localmente narco-comunidades, que al emerger ilegítimamente producen "hombres bomba del sicariato que en su exposición violenta construyen (cuando destruyen) un vacío simbólico"(Ramírez, 2011, 69). La palabra "sicario proviene de sica, pequeñas navajas persas... (así) los romanos las llamaron" (Ramírez, 2011, p. 39).

Entrada la década del 70 los norteamericanos triplicaron sus niveles de "consumo de drogas... luego de la Guerra de Vietnam, el inicio de la Guerra Fría y la primera revolución Hippie, Estados Unidos era el primer consumidor de droga en el mundo"(Ramírez, 2011, p. 103-104). Y en 2014 esta posición se ha ratificado. 
Desde la década del 90 México y Colombia experimentaron las estrategias militares provenientes de Norteamérica para enfrentar el flagelo narcótico, que en fondo y forma minan la capacidad de respuesta soberana al fenómeno narco-violento.

En el caso mexicano "los operativos de inteligencia militar se desplegaron en toda su franja occidental: Jalisco, Michoacán, Sinaloa, Sonora y Baja California Norte (Gómez y Fritz, 2008, 8588). Sin embargo, veinte años después, la presencia de espionaje y contraespionaje en las estructuras sociopolíticas de México ha alcanzado otras escalas, que muestran las erosiones de todo su sistema hegemónico estatal... lo que demuestra que la opacidad hegemónica del poder vuelve a superar las responsabilidades del Estado"(Ramírez, 2011, p. 106). En Colombia ocurre la misma fusión colombo-americana en cuestiones militares y de inteligencia.

La estrategia militar estadounidense desarrollada en territorio mexicano y conocida como Iniciativa Mérida gastó "1400 millones de dólares a ejecutarse durante cuatro años a partir de 2007. Durante los años 2010 y 2011... 650 millones de dólares... (destinados para) compra en infraestructura militar y el pago de honorarios de un ejército binacional (Carreño Figueras, 2010)... Bell, DynCorp, Cessna y Haarris han recibido pagos del Gobierno estadounidense... para fabricar equipos militares"(Ramírez, 2011, p. 144-145). La Iniciativa "ha dejado arcas Ilenas en algunos grupos empresariales de uno y del otro lado de la frontera"(Ramírez, 2011, 109).

Calderón permitió que en su gobierno EE.UU instalará un real "centro de espionaje... la Agencia de Inteligencia Militar (DIA), la Oficina Nacional de Reconocimiento (NRO) y la Agencia Nacional de Seguridad (NSA)... El Departamento de Justicia... con tres agencias: el FBI, las DEA y el Buró de Alcohol, Tabaco, Armas de Fuego y explosivos (ATF). La política estadounidense está convencida de la incapacidad de México para resolver los problemas que Estados Unidos creó en América Latina"(Ramírez,2011, p. 107-108).

No obstante la mutación de las revoluciones armadas en Colombia y México, cuentan con la ventaja de la flexibilización de sus máscaras o cartas de presentación y la posibilidad de reorganizarse acorde con las circunstancias. 
Los grupos de crimen organizado dedicados exclusivamente al narcotráfico han sabido adaptarse al constante "mutatis mutandis (que) no solo los integra con el tiempo líquido posmoderno (sino que) les da un amplio margen de flexibilidad frente a las obtusas construcciones cerradas y herméticas del control del Estado. No se trata de organismos policelulares, son entes amorfos, como los describe Marcola, que comienzan en una trayectoria anónima y se transforman, a partir de esa construcción enigmática, en otros entes plasmáticos... Así las redes del narcotráfico son inaprensibles. Mientras más persevere la voz oficial del Estado, que ha logrado capturar alguno de los grupos, más fácil será la expansión del grupo original, mutado"(Ramírez, 2011, p. 181-182).

En consecuencia la despertenencia representa también a la nueva pertenencia. En otras palabras, "el sentido de pertenencia a un grupo social ya no se determina por la fantasía de compartir un bien común sino por el sentimiento de oposición a quienes no pertenecen a la Crew (Tribu)... estos personajes clonados y anónimos, renombrados, se agrupan para confrontarse a otros grupos que tienen características similares... repeticiones de un mismo soldado, sujetos desconocidos que se unen para atacar a otro grupo... El narcotraficante vive en dos mundos y está dispuesto a renunciar a uno de ellos para reivindicar la realidad clonada... por eso cuando modernidad niega la condición posmoderna del narcotráfico, renueva la condición posmoderna de la narcorealidad"(Ramírez, 2011, p. 188-189).

\subsection{LA NARCO-CULTURA}

La relación de la variable cultural se liga íntimamente a postulados tales como los que enaltecen la teoría de la dependencia: imposiciones culturales que representan formatos sociales que prevalecen sobre otros, a nivel nacional o internacional.

En palabras más sencillas, unas culturas provenientes de estructuras político-sociales más fuertes que otras, tienden a imponerse sobre los patrones culturales periféricos. Un claro ejemplo lo representa la tradicional tensión cultural entre occidente y oriente a niveles macro-culturales. No obstante, la narco-cultura representa patrones micro-culturales que chocan entre sí, dentro y fuera, de los territorios soberanos superados. 
Edward Said se refirió al estado de las tesis del orientalismo como menguadas por las "teorías de Occidente, (que) en el diseño de sus políticas de expansión, moldean las culturas, las religiones y los países de Oriente... Estados Unidos es el poseedor de símbolos, dueño del poder omnívoro, devorador de ilusiones, consumidor de imágenes, Gran Hermano de Latinoamérica. Satisfecho del proceso de desconstrucción cultural, edifica sus propias fantasías... Este fenómeno de aprehensión cultural es el que enjuicia a la llamada colombianización de la violencia, síntoma de la construcción exótica de la violencia. No es la dispersión global de la violencia, es la suposición global de que la violencia se origina en países como Colombia”(Ramírez, 2011, p. 87) y México.

La narcocultura ha sido identificada como "el sistema cultural generado al margen del mercado global del tráfico ilegal de estupefacientes... la primera tendencia señala que la narcocultura es la generación de productos, hábitos y manifestaciones (canciones, literatura, grafismos, iconos de culto) que orbitan sobre el tema del tráfico legal de estupefacientes, con influencia geográfica desde Latinoamérica hasta Estados Unidos de Norteamérica, con particular énfasis en Colombia y México, países identificados como las capitales latinoamericanas de las drogas. La segunda tendencia, principalmente en México, explica la narcocultura como la <<predisposición corrupta>> de la sociedad latinoamericana"(Ramírez, 2011, p. 13-14).Una tercera corriente podría considerar a la narco-cultura como una manifestación social emergente de las exclusiones nacionales e internacionales que consume los productos que rechaza violentamente.

Latinoamérica "siempre se ha considerado una cultura marginal, incluso en las definiciones socioeconómicas de sus países, impuestas por la ONU: del Tercer Mundo, en transición, emergentes o subdesarrollados"(Ramírez, 2011, p. 14).

Es lo que Noam Chomsky relacionó con lo expresado anteriormente como Estados Fallidos con la finalidad de rechazar la política de EE.UU "en su obsesión por establecer su interpretación de la democracia del mundo, es retomada por Glenny para describir el sistema de una era que, en su etapa de decadencia, suprime las estructuras del Estado"(Ramírez, 2011, p.165).

La narcocultura en algunos casos es la respuesta agónica y satírica de "los sujetos frente a una realidad asfixiante... la expresión de Estados fallidos permite comprender, precisamente, que el problema de los vacíos simbólicos de las ideologías de Estado no podría situarse en las naciones 
latinoamericanas como las únicas depositarias del tráfico ilegal de estupefacientes... además, las naciones latinoamericanas, identificadas como sociedades narcotraficantes deben convivir con la construcción de la América Latina violenta... la comprensión de la cultura popular latinoamericana originada durante el narcotráfico requiere una operación de desconstrucción: deslindar una cultura popular de narcotráfico" (Ramírez, 2011, p. 168-169 y 171).

La variable cultural antinarcótica sigue predominando bajo el patrocinio mediático y político sobre la de los narco-identificados, aunque parece que dicho rechazo refuerza la identidad de los interesados en forjar los lazos y cimientos de las narco-comunidades que a su vez chocan entre ellas mismas, dependiendo de factores sociales determinados por las regiones, lo que propicia mejor un definición de narco-sociedades.

En contraste, la plataforma mediática occidental coadyuva a una cultura democrática antinarcótica, y en ocasiones armada, que se adueña de la conceptualización en el marco de los estudios en RRII. Resultando preciso identificar los contextos de donde emerge la narcolegitimidad.

Es por ello que los militares, en especial en ámbitos de inteligencia, analizan "el contenido de narcocorridos"(Hernández, 2012, p. 398). Mientras que los sicarios ultiman narco-artistas ligados a "la increíble popularidad de la narcocultura ilustra el grado de arraigo de los traficantes en la sociedad... pero los cantantes hacen más que poner música alegre a las matanzas. Les ponen además un guión. Siguiendo una tradición que tiene siglos de antigüedad, los corridos son una forma de informar a la gente de la calle, describen algunas fugas carcelarias, carnicerías, nuevas alianzas y pactos rotos que lee poca prensa... el propio narco-cine mexicano ha producido literalmente millares de películas desde los años ochenta... estas producciones, llamadas videos domésticos, se liquidan en dos semanas de rodaje, utilizando por lo general como actores a personas que se interpretan a sí mismas: campesinos auténticos, prostitutas auténticas, e incluso matones auténticos con pistola y todo... sin embargo, los principales consumidores de películas y cedés de narcocorridos no viven en las polvorientas aldeas mexicanas, sino en Texas, en California, en Chicago y en otros núcleos de latinoamericanos de Estados Unidos... pero por muchas películas que se vendan, los productores de narco-cine cuentan con otra fuente especial de ingresos: los narco-dólares. Los capos financian películas para blanquear dinero"(Grillo, 2012, 273 y 275-277). 
Para la cultura narcotraficante mexicana, "que escriban una balada sobre ellos es como obtener un doctorado"(Grillo, 2012, p. 284). Mientras que la nueva especie de "los corridos enfermos...cuenta con detalles gráficos que unos sicarios van a una casa y mutilan a toda una familia" (Grillo, 2012, p. 286).

Los hijos de los narcos sinaloenses, en contraste cultural, "mandan a sus hijos a centros docentes caros y se relacionan con la alta sociedad. En la última generación se pueden encontrar jóvenes de familias traficantes que parecen yuppies, y retoños de ricas familias hacendadas que parecen traficantes. Los jóvenes sinaloenses de esta narcocultura híbrida se llaman buchones y visten con un estilo que mezcla lo urbano y lo rural, lo tradicional y lo moderno"(Grillo, 2012, p. 287).

Aunque la manifestación "más feroz de la narco-religión es la del cartel La Familia de Michoacán. La Familia inculca a sus seguidores su propia versión del cristianismo evangélico, mezclada con elementos políticos de rebeldía campesina. El jefe espiritual de la banda, Nazario Moreno, el Más Loco, llegó a escribir su propia biblia, que de lectura obligada entre las tropas"(Grillo, 2012, p. 297). Para alabar a la Santa Muerte "el día 1 de cada mes miles de creyentes se apelotonan delante del altar para una celebración especial en la que cantan, bailan, beben cerveza, fuman marihuana y expresan su amor a la muerte"(Grillo, 2012, p. 304).

\subsection{CÓDIGOS NARCO}

Una de las principales claves para los estudios culturales en construcción de patrones identitarios, la representa la "comunicación intercultural ${ }^{58}$ que parte del principio de la dificultad o imposibilidad de comunicación entre los implicados... empieza con la percepción de las diferencias que sugiere que los participantes a menudo no comparten normas, creencias, valores y ni tan siquiera modelos de pensamiento y conducta"(Alsina, 1959, s.d.p).

\footnotetext{
58 “La creación de la Sociedad de Naciones (1920) y, sobre todo, de la ONU (1945) y otras organizaciones internacionales (Organización Mundial de la Salud, Banco Mundial, UNESCO, etc) puso claramente de manifiesto la necesidad de comunicación entre los distintos pueblos y culturas. Los Estados Unidos como potencia hegemónica de la época, $y$ dentro del contexto de la guerra fría, estaba muy interesada en cimentar su influencia exterior. Así pues, la comunicación intercultural era un instrumento estratégico de importancia evidente. Uno de los pioneros, en los años 50, de la comunicación intercultural fue el antropólogo norteamericano Edward T. Hall. De hecho, donde se utilizó por primera vez la expresión "intercultural communication" fue, en 1959, en su libro The Silence Language.
} 
No obstante, las producciones de comunicación intercultural de los grupos ESol narco-violentos reportan cada vez más miembros, adeptos y utilidades.

En la comunicación intercultural mediada se pueden dar "contextos de recepción muy dispares y que nada tengan que ver con el contexto de producción del mensaje" (Alsina, 1959, s.d.p). Lo que produce una narco-polarización que incrementa la multiplicación y empoderamiento de las ESol narco-violentas.

Ahora bien, la argumentación que fundamenta la "legitimidad del poder político varía según el ámbito cultural de cada sociedad. Las razones para que una cultura consienta al poder, responden a circunstancias propias, y esto hace que las motivaciones de la obediencia política no tengan por qué coincidir con las de los otros conglomerados sociales" (Suárez, 2004, p.1).

La realidad internacional, conlleva el estudio de aspectos técnico-metodológicos y el estudio de aspectos filosófico-epistemológicos, lo cual hace prever la dualidad de versiones sobre una misma realidad, lo que puede entenderse más claramente como los aspectos ontológicos y los aspectos deontológicos de una investigación determinada.

Así, los discursos de los medios de comunicación proporcionan modelos de identidad a diferentes niveles: personales, colectivos, profesionales, sub-culturales, culturales, etc. Estos modelos que se muestran a los espectadores les ayudan a formar o a renegociar su identidad. El mass media es en 2014 el principal constructor de los estereotipos culturales y de la identidad cultural (Alsina, 1959, p. 1), y en especial, del prototipo anti-narco. Pero también conllevan la plataforma de difusión trasnacional, gratuita y no regulada, para las ESol narco-violentas.

Los narco-identificados adquieren productos narcofashon mientras fortalecen la narcocultura de la que "subyace una incesante voluntad de poder, una desmesurada necesidad de vivir, que parece coincidir con el logro más alto del objetivismo; la reproducción de la vida (la clonación) y con ella la abolición de la muerte (la obscenidad)"(Ramírez, 2011, p. 190).

\subsection{MARCO TEÓRICO PARA ESTUDIAR LA NARCO-VIOLENCIA}


Al indexar los conceptos clásicos de guerra a los términos contemporáneos de conflictos entre actores armados, es viable analizar como punto teórico de partida a la dialéctica que considera que "la guerra es quizás la manifestación más alta a la que llega un conflicto entre los opuestos, es la resolución del mismo por medio de la violencia, es una expresión de la contradicción y el movimiento" (Tello, 2010, 282).

Para Waltz "el comportamiento de los Estados puede ser explicado por medio de las propiedades del sistema internacional, que son su estructura anárquica y su configuración en polos de poder. Por ello las guerras no están situadas ni en el <<seno de los hombres ni en el seno de la estructura interna de los Estados >>: estas existen porque nadie las impide"(Tello, 2010, p. 64).

Konrad Lorenz denominó a la agresión como un mero instinto que sirve para "asegurar la supervivencia del individuo y de la especie" (Lorenz en Tello, 2010, p. 65). Otros consideraron la agresión como producto de la frustración (Dollard, 1930, p. 1). La frustración de los seres humanos, de manera individual o social, puede devenir en explosiones de las más diversas formas de violencia.

En este caso, la consolidación de Estados Superados, los cuales no son capaces de garantizar efectivamente los fines esenciales democráticos: servir a la comunidad, promover la prosperidad general y garantizar la efectividad de los principios, deberes y derechos constitucionales, facilitar la participación de todos en las decisiones que los afectan y en la vida económica, política, administrativa y cultural, defender la independencia nacional, mantener la integridad territorial y asegurar la convivencia pacífica y la vigencia de un orden justo. Protegiendo a sus habitantes en su vida, honra, bienes y demás libertades y derechos constitucionales, entre los principales.

Estos narco actores internacionales superan en sectores parciales a los Estados de Colombia y México aprovechando la frustración de su población marginal. Su deseo es ascender en la escala social y cubrir su indefensión en cuestiones de seguridad, pues si no ingresan al narco-mundo voluntariamente podrían ser exterminados o estarían condenados a la miseria terrenal dentro de la crisis y debilitamiento de los Estados-Nación. 
Es fundamentado en los anteriores elementos que el espíritu de la narco-cultura se abrirá camino ante un Estado Superado.

\subsection{LA CONSTRUCCIÓN DE LA NARCO-NACIÓN}

La globalización del Siglo XIX y el neoliberalismo reprodujo el sentimiento de la minimización del mundo que en la antigüedad fue inmensamente abierto.

Los Estados Superados por Guerras promiscuas son Estados Obedientes o Educados que responden a las necesidades o intereses de sus superiores políticos.

Las Guerras Promiscuas agrupan enfrentamientos internos donde la autoridad del Estado es parcialmente cuestionada por el remplazo del proveedor de medios de supervivencia o la simple neutralización de grupos sociales mediante el uso de la narco-amenaza o el empleo de la narcoviolencia.

Los Estados Superados se asemejan en aceptar las solicitudes del hegemón modernizando con su ayuda a sus Ejércitos mediante la cooperación militar, lo cual no reviste mayor gravedad, por el contrario, revitaliza los estándares de Seguridad y Defensa nacionales cuando no se extralimitan ni se omiten las funciones de ley. Pero la realidad muestra como las CMP son financiadas para labores concretas a través de dinero provenientes de los planes armados norteamericanos.

La unidireccionalidad de tratamiento al complejo fenómeno que requiere una Guerra Promiscua trasnacional y millonaria, la hace permanente.

Las ESol narco-violentas superan sus Estados al ejercer poder político en ciertos territorios, al imponer reglas de juego para que sean protegidos frente a otros grupos armados ilegales como las guerrillas y grupos ESol narco-violentos, las cuales realizan el mismo procedimiento generando muchas veces que los pobladores sean amenazados desde diversos grupos, quedando a merced de la suerte y la casualidad. Lo anterior, se ha querido denominar en términos de narcoprosperidad. 
También la permeabilidad del sistema financiero legal por parte de las finanzas narco-violentas es un resultado de la inserción de dichos actores como dirigentes de un desorden mundial, o incluso, trasnacional.

La omisión del Estado Superado a la hora de cumplir con sus finalidades, es este caso democráticas, recuerdan la incapacidad del Estado que plantea dicho autor a nivel ambiental en la Sociedad del Riesgo (Beck, 1998, p.s.d.), que puede adaptarse a las actuaciones de las ESol narcoviolentas.

En términos ontológicos, ofrecer seguridad a quien contrata el servicio independientemente de la ilegalidad del mismo, como por ejemplo lo hacen las empresas trasnacionales para asegurar la inversión extranjera. Permitiendo la violación de los derechos individuales, lo que posibilita que los habitantes busquen protegerse con estrategias ilegales. Esta opción de organización política social en Colombia y México es una realidad.

Las CMP destinan sus servicios espacialmente en el territorio de sus "Estados Fracasados"(Tello, 2010, p. 307) y se insertan en los sistemas políticos legales de los Estados Superados. Facultan a militares "retirados el potencial para una segunda carrera... pueden ganar entre dos y diez veces lo que ganan en el ejército regular" (Singer en Tello, 2010).

México en 2013 refleja lo descrito en el párrafo anterior y confirma la gran "diferencia que existe entre soldados convencidos que pelean por la gloria y soldados más dispuestos que luchan a desgano para la ambición de otros"(Maquiavelo en Tello, 2010, p. 303).

Ahora bien, para la versión oficialista de los EEUU las ESol narco-violentas representan una amenaza global, aunque reconoce su política exterior, que hay temas más importantes.

No obstante, la narco-violencia mexicana parece alertar más a los EEUU en 2014 que la colombiana, por su posición contigua e intrínseca en la economía norteamericana. Donde los consumidores in situ generan un lavado de activos automático e imperceptible. 
Colombia ha sido considerado como el patio trasero pero ha construido poder político a través de la obediencia a la política estatal norteamericana de los últimos tiempos que lo catapulta como líder sin importar constituir un Estado Superado por actores armados no estatales y estatales. Lo que refleja la inmensa asimetría estructural en la formulación de la política exterior en 2014.

La política exterior estadounidense se convierte en poderosa respecto a las márgenes de independencia en la lucha contra la narcoviolencia en especial y en las interacciones del Sistema Mundo en general.

Entre tanto, el diagnóstico hegemónico errado y tercamente impuesto enciende los focos de las Guerras Promiscuas y retiñe la impronta de Estados Superados, lo cual resulta conveniente a los gobiernos de los mismos y al Hegemón, en cuanto al mantenimiento de las relaciones cordiales entre las partes negociantes.

En dicho contexto Colombia y México adoptan una legislación anti-narcótica "que reproduce tendencias internacionales impulsadas principalmente por los Estados Unidos y caracterizadas por altas dosis de represión que, parece no haber tenido efectos significativos"(WOLA, 2011, p. 49).

En 2014, la alternativa sigue siendo la legalización de la producción, distribución y consumo de drogas. Es ilógico como en los países se permiten consumir dosis mínimas de droga pero se prohíbe la producción y la distribución.

Por supuesto, "cuánto mayor es el riesgo, mayor es la ganancia para quien esté dispuesto a afrontar el peligro. Y cuanto mayor es la ganancia, mayor será la violencia que se aplicará para defenderla... Lo mismo ocurrió cuando a los norteamericanos se les ocurrió poner una enmienda en su Constitución que prohibía las bebidas alcohólicas. Una prohibición legal no anula una demanda del mercado, así que los norteamericanos siguieron tomando bebidas alcohólicas, sólo que de mucha peor calidad, y en el proceso generaron una mafia dedicada al rubro, y una violencia incalculable, que pudo eliminarse sólo cuando se regresó a la normalidad, derogando la enmienda que establecía la ley seca... Lo mismo ocurrirá, en escala pavorosa, con la cuestión del narcotráfico"(Escudé, 2001). 
México atraviesa por un escenario narco-violento que corre el riesgo de entrar en metástasis por el alto índice de niveles de corrupción en sus Instituciones y Fuerzas Armadas. Las armas norteamericanas se utilizan no solamente para operaciones violentas ilegales sino como moneda de cambio por la droga recibida de carteles de Colombia, México y de intermediarios centroamericanos.

Por ejemplo, "un ex agente de la DEA reconoció que durante su servicio en la corporación llegó a vender más de una treintena de armas de alto calibre a carteles mexicanos de droga, y son recurrentes tanto la acusación a las autoridades mexicanas de que el tráfico de armas en su país proviene de distribuidores de Estados Unidos, como la negación del hecho por parte de las corporaciones militares estadounidenses (Notimex, 2010, 16).

Adicionalmente no se mediatizan las noticias que afectan la imagen de EE.UU y des-satanizan las narco-violencias colombianas y mexicanas, a saber: "más de 30 mil muertos estadounidenses por motivos relacionados al narcotráfico, según los informes de la DEA... las mafias mexicanas se encuentran... en 195 ciudades, realizando pagos al sistema judicial o a otras bandas de capital estadounidense (Arvizu y Merlos, 2010)" (Ramírez, 2011, p. 147).

Entonces los Estados Superados nutren sus ejércitos para combatir actores ilegales, que con armas no convencionales montan pie de fuerza a cualquier tipo de estrategia o inteligencia militar.

Fomentando la multiplicación de ESol que evolucionan en guerras bastardas, es decir, sin padres reconocidos $\mathrm{y}$ donde se asientan los enfrentamientos indirectos en remplazo de choques interestatales.

La modalidad de la perturbación ecléctica se ha vuelto común en el Siglo XXI y se originó desde el florecimiento de la incertidumbre política que ordena la militarización unidireccional que reproducen los círculos viciosos narco-violentos. En consecuencia, las Ilamadas intervenciones democráticas conllevan dominación si se sucede la prolongación en el tiempo del conflicto y su aplicación produce efectos colaterales. 
Los considerandos estatales colombianos y mexicanos acerca de la tipificación de los grupos ESol narco-violentos, apuntan a la no estatalidad de los mismos y su evidente organización criminal, obviando los diferentes fallos condenatorios nacionales e interestatales que confirman la inserción de las ESol narco-violentas en la estructura de poder político y su conjugación con los sistemas económicos y financieros, nacionales e internacionales, legales e ilegales.

Ahora bien, los Estados que decidan no obedecer los diagnósticos de los EEUU y a cimentarse en tal moral politizada, deberán asumirse dentro de los postulados de la irrelevancia de la racionalidad de EEUU.

Es decir, puede que un Estado Superado sea realmente irrelevante para los intereses norteamericanos, pero al no seguir los lineamientos del hegemón puede ser atacado no porque represente una verdadera amenaza sino para amedrentarlo y obligarlo a seguir sus postulados. Si la narco-amenaza representara un riesgo latente para los intereses vitales de EEUU no serían confrontados directamente porque allí sí estaría en riesgo el interés vital del hegemón.

Algo similar sucede dentro de los Estados Superados con sus propios actores superadores. Si son realmente violentos podrán más fácil acceder al poder público, de lo contrario, estarán marginalizados del proceso de toma de decisiones estatales.

Los Estados Superados dentro del contexto de la globalización presenciaron la "mundialización del delito. En Colombia... (las) nuevas organizaciones delictivas... se suman al narcotráfico, a la violencia insurgente, el trueque de drogas por armas, la industria del secuestro... (y, a) la equivocada política norteamericana de luchar contra la droga puertas afuera, desde el lado de la oferta en vez de la demanda, exportando aún más violencia a Colombia (y a México, lo que demuestra que dichos Estados no tienen ni)... el poder ni la influencia necesarias para cambiar la política norteamericana. Ni siquiera vale la pena intentarlo... Lo único peor a la innecesaria pero casi inevitable guerra venidera es padecerla sin las bendiciones del Departamento de Estado, que es el responsable de la penosa perspectiva" (Escudé, 2001).

Un hegemón que no necesita ni de México ni de Colombia en cuanto a intereses nacionales se refiere. No obstante, si necesitan de los productos narcóticos para satisfacer las necesidades de 
los consumidores norteamericanos, los cuales al adquirir la droga realizan un blanqueo automático e imperceptible de dineros ilícitos que se insertan en la economía legal estadounidense y mundial.

Tal como lo afirmó Marc Cooper en el periódico The Nation: Plan Colombia traduce "wrong issue, wrong enemy, wrong country ("asunto equivocado, enemigo equivocado, país equivocado")... México, que es el verdadero peligro narcotraficante para el país del norte... los norteamericanos no atacan la verdadera raíz del problema, que se encuentra en su propia sociedad, principalmente en el consumo... muy raramente se incauta (droga) en su propio territorio... La guerra grande se Ileva a cabo puertas afuera. Los norteamericanos no quieren abordar el problema... ello significaría un estallido de violencia en los Estados Unidos....También significa una mayor capacidad para... políticas encubiertas ilegales, como cuando se aliaron a la banda paramilitar y narcotraficante de Los Pepes para matar a Pablo Escobar. Implica poder terciarizar la fuerza militar, usando mercenarios, y no ser responsables frente al público" (Escudé, 2001).

Adicionalmente el negocio trasnacional de las ESol narco-violentas produce beneficios a sectores no mafiosos, "sectores del establishment de las grandes potencias que ganan mucho dinero como resultado de la industria de la droga y la lucha contra la misma:

1. La industria de armas. Desde Estados Unidos a Rusia, pasando por Israel y varios otros países, son varias las industrias que se lucran ya sea con la provisión de armas al Plan Colombia, o a la guerrilla y el narcotráfico.

2. Funcionarios retirados del gobierno de los Estados Unidos, incluyendo ex secretarios de Estado y de Defensa, que pasan a ocupar altos cargos ejecutivos en grandes empresas mercenarias (o "de seguridad", como eufemísticamente se las llama), que a su vez son contratadas por el Pentágono...old boys, que pasan a ganar sumas muy superiores a las que obtenían cuando estaban en el poder.

3. La industria química y de substancias biológicas transgénicas, que obtiene un fructífero campo de experimentación fuera del laboratorio.

4. Las prestigiosísimas aseguradoras de Lloyd's y sus pares en Estados Unidos, que ganan grandes sumas con los seguros de secuestro, rescate y extorsión.

5. Los paraísos fiscales de la Corona Británica, como las islas Caimán, las islas del Canal, Gibraltar y la isla de Man, que a pesar de pertenecer al Reino Unido tienen una legislación bancaria más laxa, que las convierte en el mecanismo ideal para transferir 
beneficios a la economía británica, a través de las ganancias que sus bancos obtienen del blanqueo del dinero de la droga, una parte interesante de este gran negocio. La filosofía parece ser: el negocio es malo, pero mientras exista no seremos excluidos de sus beneficios.

6. Finalmente, los grandes bancos como el Citibank, que lucran con estos mecanismos para el lavado de dinero y que siempre que son descubiertos en algún negocio sucio culpan a alguno de sus ejecutivos, que se distrajo" (Escudé, 2001).

Generándose "circuitos subterráneos intercomunicados entre sí: narcotráfico, lavado de dinero, tráfico de armas, guerrillas y terrorismo. Estos submundos, a su vez, tienen vasos comunicantes con las más altas esferas del poder político y económico de los establishments más prestigiosos" ${ }^{25}$.

Por lo que la narco-política se torna incontrolable: "de hecho, el narcotráfico domina todas las estructuras de control en México y Colombia... compra diputados, paga alcaldías, financia campañas electorales, extorsiona policías. Logra asfixiar sin asumir las responsabilidades del liderazgo"(Ramírez, 2011, p. 28 y 30). Particularmente se considera que en México domina e infiltra en Colombia.

No obstante ser las estructuras de gobierno propensas a los beneficios que obtienen por la obediencia de las tareas que les dicta su hegemón, algunos de los receptores de la violencia legítima contra las ESol narco-violentas, producen en contraposición su estallido narco-violento, siguiendo postulados dogmáticos como: "Hay tres formas de hacer las cosas: como usted cree, como ellos creen y como yo digo"60.

Lo que conlleva a la construcción de la narco-identidad como factor determinante de la narcocultura.

\subsection{NARCO-IDENTIDADES}

59 Iberoamérica y el mundo www.Argentina-rree.com/home_nueva. Consultado el 18.8.2013.

60 Expresión utilizada por Pablo Escobar representado por Andrés Parra e n la serie: Escobar: El patrón del mal. 
La narco-identidad se produce desde el escenario del narcotráfico que representa "una nueva conducta sociocultural... y comienza a provocar movimientos en las estructuras políticas, tanto de Estados Unidos como de Latinoamérica... el narcotráfico...podría considerarse rasgo de identidad comunitaria" (Ramírez, 2011, p. 159).

La globalización y el neoliberalismo representan el contexto ideal para la expansión de la narcoempresa y por ende la consolidación de las narcoidentidades. En cuanto al su diagnóstico prima la necesidad de su comprensión pues "existen varias correlaciones, y se confunden las causas con los

efectos; desorden que pertenece a la obscenidad de los problemas y la incapacidad para nombrarlos. Tal vez las respuestas para dialogar con la confusa constitución del narcotráfico se encuentra en los esfuerzos por interpretar éste sistema sociocultural"(Ramírez, 2011, p.70-71).

\subsubsection{NARCO-IDENTIDAD EN COLOMBIA}

Colombia no tiene una única identidad nacional, existen varias identidades regionales donde actores ilegales que se insertan con relativa facilidad y legitimad en el sistema político y bajo los telones de ilegalidad, se mueven como peces en el agua dentro del escenario legal nacional.

Las identidades se construyen a partir de contextos violentos, políticos, ideológicos entre tantos, pero la violencia política ha sido la constante, donde prevalece el clientelismo y donde todo valor es negociable.

Francisco Thoumi bien señaló "la contradicción del planteamiento de la guerra contra el narcotráfico, porque la corrupción y el narco son síntomas de problemas sociales más profundos... apela a la historia social de Colombia, cuyos tejidos se han movido entre la transa, la ilegalidad, la corrupción y la desviación de las normas institucionales y sociales. Según la historia económica colombiana, ser honesto no es rentable... la ilegalidad de las drogas favorece sus ganancias, precisamente porque desobedece las legislaciones estatales (Córdova, 2008)"(Ramírez, 2011, p. 67). 
En Colombia el "narco es nuestro gran relato. Y cuando de pensar país se trata, somos los hijos del narcotráfico: hemos vivido, soñado, comido de su negocio y su cultura. Sin narco no hay Colombia. Por eso nuestras grandes obras televisivas del siglo XXI han sido sobre nuestra alma narco, antes en versión no-oficial de los ilegales (El cartel), ahora en la versión oficial de la historia y los medios (Escobar)" ${ }^{\prime 61}$.

El 28 de mayo de 2012 en horario AAA fue el estreno de Escobar: El Patrón del Mal, se registró el más alto rating histórico: 26.9 de rating personas y $62.7 \%$ de share. Otras narco-series de excelente rating: El cártel de los sapos I y II (También en cine), Sin tetas no hay paraíso (Ilevada al cine), Muñecas de la mafia, Rosario Tijeras (película del mexicano Emilio Maillé) y El capo I y II.

Por su parte, el hijo de Pablo Escobar montó un negocio narco-fashion de jeans y camisetas en Medellín con la cara de su padre al establecer la marca Escobar Henao con una facturación multimillonaria que centra su diseño en imágenes del capo con "su cédula de identidad, su licencia de conducir o su tarjeta de crédito. La ropa se vende en Estados Unidos, México, España, Japón y otros países, pero no en Colombia” ${ }^{62}$.

Por lo que más que la colombianización de México lo que se ha producido es una transnacionalización de la escobarización ${ }^{63}$. Desde los inicios de la escobarización como pilar narco-mundial, los precios de la droga se han mantenido estables durante décadas, lo que supone una gran oferta. El asesinato de Escobar no acabó con el narcotráfico sino por el contrario le hizo mutar y adaptarse a los nuevos retos de inteligencia, lo que lo internacionalizó y revivió el mito del Capo, que aunque muerto, sus accionar vive en millares de narco-rincones del planeta.

Colombia no ha implementado una "política de Estado coherente y sostenida en el largo plazo"(Infante,1995, p. 17), lo que resulta en la "ambivalencia estatal frente al fenómeno del narcotráfico: tolerancia durante un tiempo y fuerte represión durante otro" (Infante,1995, p. 18).

\footnotetext{
61El Patrón del rating. El Tiempo. Junio 1 de 2012. Ver artículo completo disponible en:

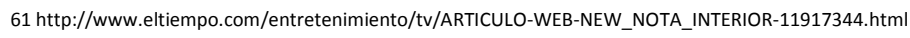

62 Sobre este tema consúltese:

62http://www.perfil.com/ediciones/2012/9/edicion_706/contenidos/noticia_0055.html Fecha de consulta: 17 enero 2013.

63 Artículo completo de Antonio Caballero en Revista Semana. La patrona del mal. Fecha de consulta: Enero 12 de 2013.

63http://m.semana.com/opinion/articulo/la-patrona-del-mal/259258-3
} 
Lo anterior, fiel reflejo del diálogo de paz 2014 sin cese de hostilidades con la guerrilla de las FARC que se narco-financia. Lo Ilamativo resulta cuando Estados Unidos y la sociedad internacional felicitan a Colombia por el diálogo, cambiando radicalmente su discurso y por ende la etiqueta de terroristas para volver a llamarlos guerrilleros. Resaltando que no es criticable la finalidad sino la ambivalencia.

\subsubsection{NARCO-IDENTIDAD EN MÉXICO}

México al igual que Colombia no posee una unidad identitaria en el enfoque de nación y a lo largo de su territorio se construyen otro tipo de identidades totalmente radicales a los del Distrito Federal. Por ejemplo, en la frontera del Rio Grande con EEUU, la narco-identidad que construye la narco-cultura, ha trascendido al país del Tío Sam.

La identidad tradicional de México proviene de "las expresiones de la cultura popular (que) reafirman la identidad nacional, al distanciarse de la ideología global, el neoliberalismo y de su envés siniestro, el narcotráfico"(Ramírez, 2011, p. 28).

La narco-identidad en contraste emerge del escenario ilegal de la narco-realidad. Es usual encontrar videos piratas donde "los criminales graban sus ejecuciones y envían videos a los medios o los suben a Youtube después de someterlos a una cuidadosa postproducción. La mediosfera es el duty free del narco, la zona donde el ultraje cometido en la realidad se convierte en un informercial del terror (Villoro, 2008)" (Ramírez, 2011, p. 28).

Difusión que conlleva la consolidación de la narco-cultura polarizada: el establecimiento del terror a quienes rechazamos tales imágenes o simplemente la adicción a la narcoviolencia como entretenimiento.

A nivel musical "el corrido cuenta cómo la situación de la granja (México) se encuentra en un momento caótico, porque la perra (el narcotráfico) está fuera de control a pesar de las advertencias del abuelo (el PRI) y los esfuerzos del zorro (la transición política), auxiliado por los riquitos (diputados y senadores), que en realidad sólo cuentan los huesos (los muertos acaecidos durante la guerra contra el narcotráfico)" (Ramírez, 2011, p. 54-55). 
Estos mensajes que comunican los narco-corridos facultan demostrar "cómo la identidad y los sentidos de pertenencia del sicario alcanzan dimensiones globales. El regionalismo se globaliza, incluso trasciende la ilusión de concepto de la aldea global. El sicario protagonista de los narcocorridos es un campesino globalizado. Recorre el mundo tratando de aunar su antigua moral posrevolucionaria con la agresividad de un hombre bomba, en las calles de Wall Street, de los Campos Elíseos, o de los senderos de Beijing" (Ramírez, 2011, p. 60-61).

Calderón desde 2007 emprendió el camino militarizado contra el narco y sus daños colaterales y delitos conexos no se hicieron esperar ni se pudieron ocultar, pasando de ser un país sin índices significativos de violencia ( 8 homicidios dolosos por 100 mil habitantes ${ }^{64}$ ), a producir aproximadamente 60 mil muertos desde entonces.

\subsection{NARCO-TENDENCIAS}

En consecuencia, "la acción militar solamente alteró equilibrios entre cárteles, dejó plazas vacantes por lo que se iniciaron nuevas guerras entre jefes narcos. Estados tradicionalmente tranquilos se volvieron escenarios de una inconcebible violencia” ${ }^{65}$. Movimientos similares a los que se presentaron en Colombia. Lo que nos permite identificar una tendencia en el escenario global de la narco-violencia.

Dentro de las diversas identidades mexicanas la narco-identidad aflora contundentemente en las zonas donde se establecieron las ESol narco-violentas por ausencia del Estado y por la cercanía a la frontera norteamericana. Los jóvenes que crecen con la narco-cultura aceptan un sistema mortal en el cual ellos son piezas claves. Existiendo narco-iglesias y narco-religiones. Algo así como lo representó la película de la Virgen de los Sicarios en Colombia.

64 http://www.infolatam.com/2012/05/14/dogma-de-fe/. Consultado el 24.8.2013.

65NIÑO GUARNIZO, Catalina. (2011). La seguridad de América Latina: respuestas fragmentadas a desafíos trasnacionales. En Seguridad Regional en América Latina y el Caribe ANUARIO 2011. MATHIEU, Hans; NIÑO GUARNIZO, Catalina. (Editores). Programa de Cooperación en Seguridad Regional. Friedrich Ebert Stiftung. Pg. XXVI. Y www.costabonino.com/mexico.htm consultado el 2.6.2012. 
Por lo que en dichos "contextos de ausencia o debilidad estatal, el crimen organizado se convierte en un mecanismo de inserción de algunos sectores sociales excluidos en las dinámicas económicas de la globalización e incluso en las domésticas" ${ }^{66}$. Una tendencia más.

Influyendo en la economía mundial mediante la generación de plazas de trabajo, lo cual potencia la aparición de un narco-desorden y un narco-sistema que actúa como empresa trasnacional ilícita permeando en las economías lícitas.

La población marginal en la frontera norte de México, en especial, aquella de edades adolecentes, si desea evadir el narco-mundo debe abandonar los territorios por ellos cooptados. Desplazándose al norte o a otros sectores del territorio mexicano o arriesgarse a residir en sus hogares en trabajos arduos y de mala paga.

Son millares de jóvenes sin identidad diferente que la proveniente de la narco-cultura. Millones de películas, series, canciones, fiestas, ropajes y narco-accesorios. Ya no importará si se es narco o no para estar dentro de la narco-cultura. Por ejemplo, la moda sinaloense se ha asentado en Guatemala.

La institucionalización de la narco-cultura se expande sobre identidades débiles. El analista Edgar Gutiérrez explica la evolución de la narcoactividad. Apunta a cómo ciertos sujetos dedicados al tráfico ilícito de drogas son aclamados por el pueblo. Ante una población sin identidad se convierten no solo en referente fundamental: en héroes populares. Ello les da legitimidad y reproduce los símbolos de la narco-cultura" ${ }^{67}$.

Convirtiéndose la violencia legítima contra las ESol narco-violentas en Colombia y México, es "la principal violencia engendrada... que tiene como base su prohibición y el mercado negro que ésta implica" ${ }^{68}$. Ocasionando muchas veces más daños colaterales que beneficios directos.

\footnotetext{
66 Gered, Marcela. De la narcoidentidad y sus albores Se va transformando a sí misma, convirtiéndose en un engendro de los narcos http://elperiodico.com.gt/openx2/www/delivery/ck.php?n=ae13eab8\&amp;cb=INSERT_RANDOM_NUMBER_HERE'target='_blank'><imgsrc='http://elperiodico.com.gt/openx2/ww w/delivery/avw.php?campaignid=439\&amp;cb=INSERT_RANDOM_NUMBER_HERE\&amp;n=ae13eab8' border='0' alt=" /></a > 67 http://www.elperiodico.com.gt/es/20110829/opinion/200154. Consultado el 19.8.2013.

68 Drogas y el afán prohibidor Un ensayo sobre las drogas, las prohibiciones y los delirios colectivos Una idea de Jordi Cebrián http://prohibicion.blogspot.com.ar/2006/05/tercerdogma-prohibicionista-la-droga.html. Consultado el 19.8.2013.
} 
De otro lado, en cuanto a la identidad política y a la política de identidades ${ }^{69}$, se trae a colación lo expresado por Mary Kaldor en el sentido de la reivindicación del poder basada en identidades concretas: nacionales, religiosas, de clanes, lingüísticas y, añadiríamos, las identidades armadas ilegales.

Los conflictos implican generalmente choques de identidad, sin embargo, aquellas identidades finales que chocan fueron producidas en contextos particulares influenciados por los intereses nacionales respectivos que deciden la manera de gobernar (elites de gobierno y alianzas en Colombia y México) e igualmente condicionados por factores externos (Política Estatal EEUU).

Entonces, "la nueva política de identidades consiste en reivindicar el poder basándose en etiquetas. Se suele afirmar que la nueva oleada de política de identidades no es más que un retroceso al pasado, la reaparición de antiguos odios que estaban bajo control durante el colonialismo y la guerra fría. Las nuevas identidades etno-nacionalistas no se basan tanto en la posesión de unos rasgos objetivos...una comunidad nacionalista no es una comunidad tradicional, orgánica, sino un sector de la población movilizado contra el Estado.... funcionalidad necesaria para articular identidades alternativas" (Ramírez, 2011, p. 54-55).

En otras palabras se trata de intereses particularísimos de las sociedades privilegiadas abalados por el slogan de los intereses nacionales soberanos pero que generalmente solo producen efectos positivos a dichas sociedades pero negativos al pueblo. Como sucedió con "los habitantes de la actual Riviera francesa (que) se acostaron un día a dormir como italianos y despertaron al día siguiente como franceses, porque así lo había decidido un puñado de diplomáticos"70.

\subsection{LA OFERTA DE SEGURIDAD DE LAS NARCO-IDENTIDADES}

69 Revista letras Identidad política y política de identidades. Jon Juaristihttp://www.letraslibres.com/revista/convivio/identidad-politica-y-politica-de-identidades. Consultado el 25.8.2013.

70 LIBRO SEgUNDOCAPÍTULO PRIMEROLA NACIÓN COMO COMUNIDAD MORAL DE HÁBITOS Y DE INTERESES Índice de Nacionalismo y cultura de Rudolf Rocker http://www.antorcha.net/biblioteca virtual/politica/nacionalismo/1a.ht. Consultado el 26.8.2013. 
La lucha internacional contra las drogas liderada por EE.UU se ha focalizado erróneamente en Colombia, México y otros países ligados a la ESol narco-violenta mexicana, "cuando es posible que suponga el primer conflicto global" (Ramírez, 2011, p. 22).

Paralelo a la gesta narco-violenta se consolidó la industria mercenaria: en la década del 90 y "conducida por tres dinámicas: el fin de la Guerra Fría, las transformaciones en la naturaleza de la guerra que confundieron los límites entre militares y civiles, y una tendencia general hacia la privatización y tercerización de las funciones del Estado. Estas tres fuerzas se alimentan unas a otras" (Singer en Tello, 2010, p. 307 -308).

Las ESol narco-violentas prestan sus servicios como CMP a quienes demanden el servicio de seguridad privada, diversos actores y sujetos legales e ilegales. Mecanismo de financiación de la ESol narco-violenta.

Por ejemplo, el grupo de los Zetas se compone de mercenarios, una amenaza que se podría denominar como narco-mercenarismo. La narcoviolencia como se mencionó anteriormente "es utilizada por las grandes potencias para sostener y/o incrementar su poder e intereses" (Tello, 2010, p. 12).

De otra parte, Costa Rica, Honduras, Guatemala, Panamá y Nicaragua se han convertido en los principales Estados de tránsito de narcóticos a los EEUU. La narcoviolencia ejecutada por grupos transnacionales y locales hace de la América Central, una de las regiones más peligrosas en todo el mundo y con mayor tendencia de ser superados los Estados por actores millonarios narcoviolentos.

Más de una década de lucha frontal no ha contribuido "a reducir los costos internos de un enfrentamiento frontal y solitario contra el narcotráfico"(Tokatlían, 1995). Este fenómeno se caracteriza porque "tiene la peculiaridad de ocurrir en un entorno internacional donde los principales protagonistas son Colombia como productor y Estados Unidos como consumidor, en el marco de dependencia"(Infante, 1995, p. 18), y México, como intermediario y en 2014 como gran productor. 
Narcotizando las agendas externas de los Estados Superados mediante la utilización de guerras promiscuas que se valen de cualquier método e ideología para hacer respetar su ley.

Los narcotraficantes se copiaron de las estrategias de las guerrillas para ascender en la escalera política mediante la violencia comprable, por lo que consideraron que si "el Estado podía negociar y dar un trato privilegiado a las guerrillas izquierdistas, también podía hacerlo con ellos" (López, 2005, p. 202), que le representaban mayor amenaza violenta a los colombianos y (mexicanos, y, potencialmente a cualquier nacional de cualquier Estado o condición social, ideológica, racial o política) y al mismo Estado, pues sin ellos, la guerrilla seguiría legitimando su camino hacia la toma del poder estatal. Así los factores estructurales de la narco-violencia se traducen en "la internalización... y la internacionalización" (López, 2005, p. 202).

El Estado Superado en la esfera internacional acepta con prioridad las obligaciones internacionales a que se acogen condicionados por la existencia de sus Guerras Promiscuas, que a la vez, legitima sus discursos políticos y su manteamiento en los poderes domésticos.

Lo que resuelve el por qué desde 1993 “DynCorp está presente en Colombia. Junto a más de 30 CMP, participa en la lucha contra las guerrillas de las FARC, el ELN, y en la represión al movimiento social, aunque sus actividades son presentadas como parte de la denominada guerra a las drogas. Estas CMP están bajo contrato directo con el Departamento de Estado EEUU, el Pentágono o la Agencia para el Desarrollo Internacional, USAID, por lo tanto responden a los intereses de la superpotencia. EEUU clasificó a Colombia como el principal conflicto interno privatizado del mundo, después de Irak" (Calvo, 2005).

\subsection{EL CARIBE: EL PUNTO DE INTERCONEXIÓN DE LA TRASNACIONAL DEL NARCOTRÁFICO}

En 2014 es normal encontrarse con noticias que informan sobre la captura de narcotraficantes en la zona del Caribe colombiano, señalados de sacar la droga en lanchas rápidas 
y contenedores, para llevarla a Centroamérica y venderla a los carteles mexicanos que se (encargan) de pasarla a Estados Unidos y comercializarla ${ }^{71}$.

Dentro de las declaraciones de los capturados se referenciaron a los municipios costeros del Atlántico, Bolívar y La Guajira como las zonas narco-geoestratégicas de recepción para la distribución trasnacional de los narcóticos y otros productos que ahora comercializan los grupos económicos narcoviolentos colombianos, con escala en Jamaica, Centroamérica y México como zonas de tránsito para llevar los narco-productos al territorio del Tío Sam, donde se encuentran la mayor cantidad de consumidores de drogas del mundo. La noticia anterior del pasado 17 de junio de 2014 es resaltable porque en esta captura en especial, cayó el líder narcotraficante Don Mario junto con 8 de sus colegas.

En cuanto a la demanda narcótica norteamericana se realza el riesgo de la exportación de la narcoviolencia que ocurre en los territorios productores. Al respecto, Fedotov señaló que las narcoactividad que expandió sus productos al tráfico de armas, seres humanos y productos ilegales con el lavado de activos, ciber-delitos y procesos de corrupción sistemática, corresponden a una amenaza inmediata y significativa para la región $n^{72}$.

Por su parte la Oficina de la ONU contra la Droga y el Delito (ONUDD), creó el programa regional para la Comunidad del Caribe (CARICOM), una zona que considera muy vulnerable por ser punto de tránsito de la cocaína. Este programa tiene las siguientes características:

Presupuesto de 11,7 millones de dólares para el periodo 2014-2016, cuando ya se hicieron los primeros llamamientos a donantes internacionales para cubrirlo. Asimismo, incluye cinco actividades prioritarias: lucha contra el tráfico ilícito de drogas y el terrorismo; combate a la corrupción y el lavado de dinero; prevención del delito y mejora de la justicia criminal; aspectos médicos (tratamiento de adicciones, prevención, VIH) y actividades de investigación y forenses.

Es decir, el presupuesto es realmente un llamado de beneficencia contra el narcotráfico y la narcoviolencia gestada en Suramérica y Centroamérica y el temor de los norteamericanos de la

\footnotetext{
71 17.6.014. Policía anuncia 14 capturas por narcotráfico en el Caribe http://www.elheraldo.co/judicial/policia-anuncia14-capturas-por-narcotrafico-en-el-caribe-156322. Consultado el 22.6.2014.

${ }^{72}$ Leandro Maceo. El Caribe en el mar del narcotráfico. http://www.granma.cu/mundo/2014-04-15/el-caribe-en-el-mardel-narcotrafico. Habana. Consultado el 22.6.2014
} 
trasplantación de las consecuencias exógenas que conlleva el consumo endógeno de narcóticos. Igualmente se sigue revolviendo agua y aceite en la lucha anti-narcótica, al considerar como blancos a las realidades narcotraficantes y terroristas.

Ahora bien, si desde la década del 60 el Caribe significó la zona de tránsito soñada para los narcotraficantes, su declive narco-geoestratégico empezó a sucederse en la década del 90 por la implementación de medidas de inteligencia en la costa de la Florida, conllevando el cambio de estrategia de los narcotraficantes colombianos que identificaron al territorio azteca, como la ruta ideal para los nuevos desafíos de seguridad que planteaban los EEUU.

No obstante, las actividades del narcotráfico en el Caribe han resurgido en 2014 tras el aumento de la narcoviolencia en México y Centroamérica. Igualmente la mutabilidad geográfica del narcotransporte es condicionado por políticas norteamericanas de Seguridad y medidas de inteligencia militar, desarrolladas en territorio mexicano con la Iniciativa Mérida y la Iniciativa de Seguridad Regional Centroamericana de 2012.

Según la DEA, 87 toneladas de cocaína fueron incautadas en el Caribe en 2012, casi el doble del año anterior; 44 toneladas en la primera mitad de $2013^{73}$.

Finalmente, respecto al planteamiento de si los narcos colombianos y mexicanos han construido o no una nación, podemos señalar:

1. Las proto-naciones ${ }^{74}$ o cuasi naciones no son trasnacionales en cuanto a la narco-cultura se refiere. No obstante, la actividad que desempeñan en la estructura ESol narco-violenta si enfrenta un negocio trasnacional.

2. En consecuencia, la narcoeconomía es trasnacional; la narcocultura es meramente nacional o inclusive regional.

\footnotetext{
${ }^{73}$ Aumenta el narcotráfico en el Caribe. http://www.laopinion.com/noticiaslatinoamerica/article/20131105/Aumentael-narcotrafico-en-el-Caribe. Consultado el 22.6.2014.

74 Proto nación. - algo que va a hacer una nación si la amalgama lo permite. 12.6.2013. definción creada por Carlos Escudé en clase.
} 
3. Los intereses comunes se convierten en narco-intereses que provienen de una narcoeconomía que fortalece el narcolenguaje y por ende a la narco-identidad como base de la narco-cultura que perfila los cimientos de una narco-nación de un narco-mundo virtual.

4. La narcocultura se construye a través de la presencia y expansión de la actividad de las narco-economías que despliegan las ESol en partes específicas de los territorios nacionales de Colombia y México.

5. Aclarando que la mayoría del control territorial de dichos Estados Superados es monopolizado por las FFAA de Colombia y México. Lo que los diferencia de ser Estados Fallidos. Aunque el nivel de corrupción de la fuerza legal en México es desmesurada.

6. La narcocultura es un mecanismo de socialización de la narcoidentidad que se construye paulatinamente, al unísono de la participación popular en la estructura ESol narcoviolenta, sea de manera voluntaria, destinataria o forzada.

- Voluntaria: jóvenes arriesgados y aventureros; personas deprimidas que no les importa más su vida; población marginal que desea vivir con mejores condiciones y por qué no decir, con óptimas condiciones sociales; personas influenciadas por la narcoidentidad; entre las principales razones de reclutamiento voluntario.

En zonas de marginalización extrema de la sociedad, siempre habrá personas dispuestas a asumir los riesgos de la ilegitimidad del narcoempleo para generar su propio bienestar.

- Destinataria: personas nacidas en familias que lideran la narcocultura y proyectan la construcción de una nación bajo sus propios códigos y conductas, es decir, nacido en la narcocomunidad que se perfila como una narconación mancomunada; y personas que persiguen estándares mínimos de dignidad y por las vías legales no lo consiguen.

Las ESol narco-violentas en Colombia y México son ejemplos de Estados Superados por actores narco-violentos que los obligan a acomodarse a las políticas estatales norteamericanas que les dictan alinearse "con la privatización de la violencia militar mediante un mecanismo económico y socialmente atractivo, y una capacidad de reclutamiento de jóvenes excluidos y marginalizados, a quienes la economía de paz no 
ofrece oportunidades"(Nueva Sociedad, 2004, p. 192). Una "naturaleza dinámica de los problemas, asentados en arraigados vínculos entre política y sectores ilegales" (Nueva Sociedad, 2004, p. 192).

- Forzada: personas reclutadas a las actividades de las ESol narco-violentas a través de las amenazas e intimidaciones. La inserción se produce igualmente pero la diferencia es que quien se inserta no lo hace por su propia voluntad sino por miedo.

7. En igual sentido, Informes RSF y CEPET concluyeron que "los periodistas mexicanos hoy tienen dramáticas alternativas: autocensurarse, exiliarse o exponerse a una muerte cierta y con total impunidad"(Ramírez, 2011, p. 133).

8. Las guerras promiscuas que adelantan las ESol narco-violentas dentro de los territorios de los Estados Superados aunque Soberanos de Colombia y México, portan la característica principal de poseer una lógica "en donde el fin del conflicto no está previsto, sino que más bien se producen olas de menor y mayor violencia" (Ramírez, 2011, p. 185).

9. Una alternativa de "aprovechamiento que hace Estados Unidos de las crisis y tensiones bilaterales para hacer avanzar su interés estratégico de transformar la región andina de área de su influencia en perímetro de su seguridad"(Ramírez, 2004, p. 192).

10. Puede decirse, tal y como lo escribe Chomsky que la defensa de los DDHH por parte de los EEUU "no es más que una falsa excusa para en realidad alcanzar sus intereses económicos y geopolíticos" (Ramírez, 2004, p. 192). Por ejemplo, las Naciones Unidas no cumple con el requisito de nación pues las identidades que allí convergen son diversas y generalmente chocan entre sí y más allá quien dirime el conflicto son los aliados de la Guerra, quienes legislan sobre la base de un orden establecido por la fuerza.

11. Desde que la ideología del nacionalismo dejó de ser subversiva y se volvió hegemónica y los Estados empezaron a disfrazarse de naciones. 
12. Uno de los principales problemas que enfrentan las identidades latinoamericanas es que portan muchas características comunes lo que multiplica los intereses de dominación pues abarcaría una región entera, la identidad primaria.

13. La cadena ESol que construye la narco-cultura en ciertos territorios de identidad narco, la integran una diversidad de actores y sujetos ilegales y legales. Paramilitares, guerrilleros, políticos, miembros de las Fuerzas Armadas y de Policía, empresarios, ganaderos y narcotraficantes de distintos niveles en la escala de producción, encuentran asiento en realidades e intereses económicos que se ven acompañados de la violencia como mecanismo de monopolización. Representan un grupo de presión trascendental cuyas fronteras no son susceptibles de determinación así como el terrorismo.

14. El negocio trasnacional del narco y su posicionamiento trasnacional se debe a la prohibición, es decir, a trascurrir en escenarios supuestos de ilegalidad. Podemos afirmar que los narcos son el producto final de la ilegalidad pues dicho contexto eleva los precios de los objetos ilícitos comercializados que son rápidamente asumidos tanto por los intermediarios como por los consumidores y por todos los actores legales e ilegales que mencionamos en el numeral anterior.

15. El mantenimiento del fenómeno de la narcoviolencia durante décadas demuestra que el fenómeno no afecta los intereses vitales de los EEUU. Los Estados Superadores como EEUU no intervendrían Estados Pares sino intervienen a Estados Superados pues los mismos no le representarían un pie de lucha. Se omite la intervención en Estados que responderían la violación de los estándares soberanos con el uso de la fuerza y el deseo de posicionarse sobre el hegemón. Reforzando la idea que "existe menos guerra porque tenemos Estados más débiles" ${ }^{75}$.

16. En consecuencia el fenómeno de la ESol narco-violenta enfrenta a los Estados de Colombia y México contra identidades específicas que se desarrollan dentro del marco social que plantea la narco-cultura. Es común que las nacionalidades sean disfrazadas de Estados.

75 ANGEL CENTENO. BLOOD AND DEAD. Existe menos guerra porque tenemos estados más débiles The Pennsylvania State University PressUniversity Park, Pennsylvania ISBN 0-27102165-9 (cloth : alk. paper) 1957- http://www.columbia.edu/itc/journalism/stille/Politics\%20Fall\%202007/Readings\%20--\%20Weeks\%201-5/Centeno\%20-\%20Blood\%20and\%20Debt\%20-Latin\%20American\%20state.pdf. Consultado del 18.8.2013 
17. Los Estados Superados que no obedecen a su hegemón o Estado Superador en cuanto a la lucha específica del conflictos intermésticos (de interés nacional e internacional) generados por actores ilegales que igualmente los superan realizando algunos de los fines del Estado democrático, tiende a salir perdiendo. Es decir, les va peor estar peleados que dominados o condicionados en el mejor de los casos.

18. Lo que traduce que en los tiempos actuales, la política exterior más adecuada para llevar avante este tipo de incidencias, es adoptar un bajo perfil y no necesariamente definirse en términos geoestratégicos. Los Estados Superados necesitan al Hegemón así éste no los necesite. Por ello, siempre resulta menos traumático obedecer o estar de acuerdo con el Hegemón que ir en su contra.

19. Lo anterior puede devenir hasta con sistemas comunistas puesto que no tiene nada que ver el realismo periférico, producto de las interpretaciones historiográficas, con las cuales se puede o no coincidir.

20. Las dimensiones materiales no son reversibles pues el hombre casi nunca desinventa. La dimensión jurídica política en cambio siempre es reversible, puerta que muchas veces no es abierta, ya que los Estados no defienden principios sino intereses.

21. Existen Estados fuertes que asumen posiciones de no beligerancia (toman posición pero no actúan); Estados Beligerantes (toman posiciones y actúan) y Estados Neutrales (no toman posición). EEUU desde su fundación consensuó que la democracia liberal era el único modelo admitido para sus intereses. Un mínimo disenso es exportar la democracia y sus instituciones.

22. EEUU es el mayor demandante de productos narcóticos y oferente de servicios mercenarios.

23. La oferta de la seguridad privada legal e ilegal es muy amplia. La legal es de libre acceso a través de páginas web y oficinas alrededor del mundo. Dicha proliferación de ejércitos 
$\operatorname{privados}^{76}$ parece consolidarse como pilar de la política internacional. Los servicios privados de seguridad publicita a "Colombia, Guatemala, Argelia, la ex-Yugoslavia, Sri Lanka, las ex-repúblicas soviéticas, Angola, Ruanda, Mozambique y otros Estados africanos entre sus clientes"(Times, 9.5.1998).

24. Los diferentes estamentos oficiales y privados buscan legitimar la terciarización de la violencia señalando la utilidad que han significado sus procederes en cuanto a la posibilidad que las mismas abran espacios obligados de negociación que sin dicha violencia jamás serían concedidos.

25. En cuanto a la legalización, la estrategia debe recaer en un asunto de responsabilidades compartidas entre países productores y países consumidores. Pues de nada valdría legalizar la oferta sin legalizar el consumo en los Estados céntricos como Estados Unidos y de la Unión Europea, pues son precisamente las zonas del mundo donde se hace gigantesco el negocio de las ESol narco-violentas con matrices colombianas y mexicanas.

26. La Narcoviolencia se ha prostituido tanto que el pasado 1 de noviembre de 2013 los medios de comunicación colombianos denunciaron que turistas colombianos que viajaron a México para sus vacaciones fueron secuestrados por carteles mexicanos que piden sumas desde 50 mil dólares para dejarlos retornar al país.

27. Finalmente el fracaso permanente durante décadas del combate militar anti-narcótico se demuestra fácilmente al analizar la rentabilidad de la empresa narcoviolenta cuyas narcoutilidades permean un sinfín de crímenes internacionales así como a las economías legales internacionales y las instituciones democráticas. Los diagnósticos soberanos y no superados podrían evitar que la cooperación se trasforme en intervención o en dominación"(Arias, 2014, p. 77).

76 http://www.argentina-rree.com/home nueva.htm. Consultado el 26.8.2013. 


\section{CAPÍTULO VIII: NARCOVIOLENCIA COMO EMPRESA SUBTERRÁNEA EN COLOMBIA Y MÉXICO: INCIDENCIAS DE LA POLÍTICA NORTEAMERICANA EN LOS ESTADOS SUPERADOS}

Las políticas estatales norteamericanas direccionan el ritmo y flujo de las interacciones multisectoriales de la región latinoamericana a nivel general y en México y Colombia de manera específica y referida al campo de la Seguridad. También influencian mediante la implementación de su política exterior hegemónica la determinación de los destinos de las negociaciones que se desarrollan en los diversos sectores del Sistema Internacional.

La internacionalización de la política representa, "una decisión explícita y consciente, aunque condicionada por el escenario internacional, de incluir agentes externos"(Borda, 2007. P.66-89). Pudiendo ser, "normalmente definida como intervención... (al) reconoce(r) abiertamente las asimetrías de poder a nivel internacional" (Borda, 2007. P.66-89). Revelando, "un constante y serio debilitamiento de la autonomía... de tomar decisiones relativamente independientes" (Borda, 2007. P.66-89).

La política exterior de los EEUU proviene de sus intereses estatales determinados por las minoritarias y radicales élites de poder que requieren aliados o enemigos para ejercer simultáneamente soberanía y dominación.

Los Estados de Colombia y México no están facultados para formular con real independencia y autonomía su política doméstica y exterior, por ser la estabilidad una consecuencia de la influencia en el Sistema Mundo o mejor en el Sistema Internacional, ya que no enfocaremos un abordaje dialéctico y anti-hegemónico sino un estudio que parte del punto de vista de los actores y sus actividades dentro de la estructura del sistema.

Es pertinente aclarar que al indicar a la influencia como un factor de estabilidad en el sistema internacional, nos referimos a la multiplicidad de interacciones que se suceden previa celebración de alianzas políticas y económicas a nivel internacional y doméstico, donde se cede soberanía y por ende se pierde la autonomía pro intereses de élites de poder tanto públicas como privadas, así como internas e internacionales, legítimas o ilegítimas. 
Por lo que resulta siempre necesario analizar la prevalencia de factores externos "para la comprensión de las variables de la política doméstica" (Hurrel, s.a.e., p. 62). Atendiendo al régimen político democrático occidental que representa el "centro neurálgico de la toma de decisiones gubernamentales... una realidad política concluyente en el proceso de formación de la política exterior"(Lasagna, 1995, p. 387).

El régimen político constituye la estructura del sistema político, es "un subsistema de aquel, en el cual reside... la dirección política central de la sociedad" (Lasagna, 1995, p. 387). O, por lo menos, se supone que reside. En términos amplios, sistema "es un conjunto de variables que se encuentran interrelacionadas entre sí, internas o externas al sistema, pero que de una manera directa o indirecta inciden en el mismo"(Dallanegra, 2003, p. 10).

Ahora bien, la estructura política internacional al terminar la GF no pacificó las interacciones violentas sino por el contrario multiplicó sus formas, entre ellas, la que despliegan las ESol narcoviolentas.

Desacreditando a quienes afirmaron la llegada de un pacífico periodo de posguerra fría "y una redistribución de los gastos militares en beneficio del crecimiento y bienestar de los pueblos... (No obstante) los Balcanes, el Cáucaso, África, Cercano y Medio Oriente, América Latina, dieron por concluidas las esperanzas de paz... una estrategia de espacialización de la violencia desde los países más desarrollados hacia el mundo subdesarrollado... (donde) las guerras no han desaparecido...(sino que) han ido adoptando diferentes características y formatos" (Tello, 2010, p.281-282).

\subsection{LOS ESTADOS SUPERADOS}

Las realidades narcoviolentas en Colombia y México reflejan lo que denomino como la teoría de los Estados Superados. Aquellos Estados que si bien no son calificados como Estados Fallidos, han sido superados por grupos narcotraficantes, autónomos, que sacian falencias estatales mediante los cuantiosos recursos que le significa su actividad ESol narco-violenta, lo que les permite asumir las funciones no desarrolladas por los aparatos jurídico-políticos estatales, en 
ciertos lugares del territorio soberano. Resaltando que el territorio de los Estados Superados sigue siendo soberano.

Los Estados de Colombia y México controlan la mayor parte de sus territorios y cuentan con instituciones medianamente estables aunque también impregnadas de las actividades de las ESol narco-violentas.

Urilch Beck consideró el remplazo de la estructura estatal por empresas multinacionales. Ahora lo que ocurre es que el actor que supera al Estado mediante su directo remplazo es un actor ilegal y generalmente violentamente despiadado. Igualmente Beck asimiló la actuación de los grupos terroristas como ONGs de la violencia, planteamiento extensible, a los grupos narco-violentos o narcotraficantes trasnacionales puros.

La incapacidad del Estado incrementa la insuficiencia e incapacidad del Estado que pasa a ser remplazado paulatinamente (Beck, 2004, p.166), en espacios concretos del territorio.

Remplazo al Estado mínimo planteado por Nozick (1998, p.74), que debe contratar y camuflar la calificación estatal de compañías-sociedades-organizaciones militares privadas -CMP-SMP-OMP y grupos para-estatales, para encargarse de la seguridad y justicia, en términos deontológicos, pues en términos ontológicos, solo le ofrece seguridad a quien contrata el servicio independientemente de la ilegalidad del mismo, como por ejemplo lo hacen, las empresas trasnacionales para asegurar la inversión extranjera.

Los Estados Superados por actores ilegales para-estatales o no estatales (dependiendo de cada grupo ESol narco-violento), como son los diversos grupos narcotraficantes, generan un nuevo desorden mundial que puede fácilmente extenderse a los Señores de la Guerra y a los actores de las Nuevas Amenazas, que en realidad no son tan nuevas.

Las ESol narcoviolentas actúan como narco-compañías armadas privadas que superar funciones estatales como la seguridad, empleo y satisfacción de necesidades básicas. Un remplazo por brindar narco-oportunidades que eliminan la frustración de ciertas comunidades. 
Estos narco actores internacionales superan, en sectores parciales, a los Estados de Colombia y México aprovechando la frustración de su población marginal, su deseo de ascender en la escala social y su indefensión en cuestiones de seguridad, pues si no ingresan al narco-mundo voluntariamente podrían ser exterminados o estarían condenados a la miseria terrenal dentro de la crisis y debilitamiento de los Estados-Nación, como se mencionó en el capítulo anterior.

\subsection{DEBILITAMIENTO DEL ESTADO NACIÓN Y PRIVATIZACIÓN DE LA VIOLENCIA: DE GUERRAS CLÁSICAS A GUERRAS PROMISCUAS}

El debilitamiento del Estado potencializa el crecimiento de actores no estatales que perturban "los centros de poder legalmente constituidos, lo que impone referirnos a una hipercomplejidad... Los Estados Unidos, con su enorme capacidad de despliegue de fuerzas en todo el planeta se han trasformado, voluntaria o involuntariamente, en un perturbador mayor del orden internacional" (Tello, 2010, p. 315-317).

La disminución de enfrentamientos interestatales o guerras clásicas ha multiplicado las guerras promiscuas entre otros nuevos tipos de conflictos, caracterizados por contradecir sus "intereses encapsulados en conflictos de valores... (destinados) a $<<$ domesticar $>>$ determinadas áreas del mundo refractarias a la adopción de sus formas y contenidos de organización política... Esta realidad anuncia conflictos armados con todas las condiciones para devenir absolutos es decir, conflictos por medio de los cuales se trata de imponer un sistema de valores a cualquier precio al oponente, o hacerlo desaparecer. Por sus características, son confrontaciones que tienden a ascender a los extremos en los términos de Clausewitz cuando éste se refería a acciones recíprocas, por ello es tan importante el ejercicio de un férreo control político sobre el instrumento militar, para impedir que las mismas terminen transformándose en grandes masacres debido al empleo eventual de armamentos sofisticados o de destrucción masiva". (Tello, 2010, p. 318).

Swadesh Rana, agrupó los conflictos contemporáneos en 4 categorías. La primera constituye a "enfrentamientos de bloques con pocas posibilidades de ocurrencia; los de Segunda Generación asignados por las confrontaciones entre Estados (India- Paquistán, Somalia-Chad ó Etiopia-Eritea, 
etc.); los de Tercera Generación definidos por enfrentamientos internos donde la autoridad del Estado es cuestionada por grupos organizados que buscan beneficios políticos o económicos; y los de Cuarta Generación en los cuales no hay adversarios organizados, objetivos establecidos, líderes y campos de batalla. Estos últimos están caracterizados por la explotación repentina de la violencia... no requieren enfrentamiento formal ni intensivo"(Tello, 2010, p. 325).

Así resulta necesaria la inclusión del concepto de Guerra Promiscua, como aquella que agrupa las nuevas guerras o conflictos de Tercera y Cuarta Generación. Son las que utilizan cualquier herramienta en la consecución de sus diversos objetivos personalismos pero planificados en red como lo exige el Sistema Internacional.

Por consiguiente, en una mixtura entre conflictos de Tercera y Cuarta generación "debemos incluir al terrorismo, a los movimientos insurgentes y a diversas manifestaciones de violencia urbana, vinculadas en muchos casos con reivindicaciones de carácter religioso, con el tráfico de drogas o demandas destinadas a la obtención de un beneficio económico y social.

Estos elementos configuran la base de las asimetrías presentes en gran parte de las guerras contemporáneas, "dando lugar a la denominación de conflictos de baja intensidad que... pueden ser de altísima intensidad para aquellos que los sufren... las guerras de liberación nacional y revolucionarias del siglo XX deben ser comprendidas dentro del marco teórico de las guerras absolutas"(Tello, 2010, p. 328-329). Y en especial, al fenómeno ESol narco-violento en Colombia y México.

En consecuencia, al ser la violencia "una manifestación primaria y ancestral de la condición humana... es necesario entender que si bien una de las mayores fuentes actuales de conflictos y confrontaciones armadas... encuentra su origen en el debilitamiento de los Estados como actores centrales del sistema mundo. La realidad actual muestra un puñado de actores del poder mundial con gran capacidad de decisión pero sin legitimidad, y una innumerable cantidad de dirigentes políticos y sociales con legitimidad de origen pero escaso o nulo poder"(Tello, 2010, p. 14). 
Lo que podría significar el remplazo, parcial o especializado de los Estados por actores no estatales, no necesariamente con facha de violento pero legitimado conforme a relaciones de negociación política.

Lo que conduciría a la sistematización del remplazo de las funciones estatales para ser asumidas por los grupos narco-violentos ilegales que desarrollan las ESol. En últimas, la conducción de la sistematización del remplazo paulatino de lo ilegal a lo legal. La sustitución se da de manera espontánea, configurando una posibilidad de codificación ilegítima en su estado jurídico pero legitimada desde la órbita política.

\subsection{NARCO-EMPRESARIOS VIOLENTOS QUE SUPERAN SUJETOS INTERNACIONALES}

Las agrupaciones mercenarias son tan antiguas como "la civilización y hoy reaparecen con fuerza en varios escenarios de conflictos armados, el monopolio de la violencia legítima por parte de los Estados no es una condición inmutable ni natural, sino de un proceso dialéctico... los mercenarios fueron cambiando su imagen en cada época. En algunos momentos estuvieron muy desprestigiados (como en la actualidad). Otras veces se los consideró eficientes, valientes, responsables y más baratos que los propios soldados"(Tello, 2010, p. 303).

En el mundo contemporáneo el mercenarismo directamente contrató con el Estado y organismos internacionales. Las CMP, son efectivas en escenarios con "degradación de la seguridad... con sede principalmente en los Estados Unidos y Gran Bretaña... comprometidos en todo el mundo en una guerra de baja intensidad pero prolongada... al mismo tiempo que alistan sus fuerzas armadas para grandes confrontaciones, no pueden debilitar su liderazgo retirándose de espacios de menor importancia estratégica"(Tello, 2010, p. 311).

De 71 CMP con sitio web "18... tienen sede en el Reino Unido, 37 en los Estados Unidos, 2 en Alemania y una en Austria, Dinamarca, Francia e Israel, Bélgica y países del Tercer Mundo... borran las categorías tradicionales civil/militar y privado/público, como actores híbridos, operan normalmente en redes informales que favorecen la criminalidad, la corrupción y el manejo de fondos no sometidos al control de la ley... las privadas no están obligadas a respetar premisas de 
seguridad... obedecen exclusivamente a las reglas del mercado"(Tello, 2010, p. 312) y suelen pactar alianzas con las ESol narco-violentas para evitar confrontaciones entre ellos, tranzándose en tipos de subcontratación. Actores privados que ejecutan operaciones militares, provocando una "zona borrosa poblada por gente en una situación jurídica muy poco clara"(Uesseler en Tello, 2010, p. 309).

Human Rigths Watch sostuvo que "si el Pentágono piensa utilizar contratistas privados para misiones militares o de inteligencia, debe asegurarse de que se encuentren sometidos a restricciones y controles legales, puesto que permitir actuar a estos operadores en un vacío jurídico es una invitación a los abusos. Por su parte, la Universidad Nacional de la Defensa de Washington señaló que la privatización puede ser menos onerosa que una intervención militar, pero pueden quedar afectados la calidad del resultado y el respeto a los derechos humanos"(National Defense University, 2000, p. 240).

Ahora, el ejército norteamericano en particular y los ejércitos en general están preparados "para derrotar otros soldados. Por desgracia, los enemigos... (que enfrentará)... no serán soldados... sino guerreros primitivos erráticos de lealtad voluble, acostumbrados a la violencia y sin intereses en el orden civil" (Peters en Tello, 2010, p. 324). Una guerra híbrida donde "las doctrinas militares convencionales del siglo XX dirigidas contra Estados-Nación y ejércitos de masas de la era industrial están efectivamente muertas" (Hoffman en Tello, 2010, p. 322).

El concepto híbrido refiere "la letalidad de los conflictos entre los Estados con el fervor de las guerras irregulares o pequeñas guerras de Clausewitz. El término híbrido captura tanto su organización como sus medios, pudiendo tener las organizaciones una estructura política jerárquica... pueden ser emprendidas tanto por Estados como por actores no estatales y los desafíos a los Estados provendrán de ambos, quienes podrán servirse ya sea de las tácticas convencionales como de las no convencionales por medio de usos intensivos de tecnologías. Los campos de batalla... serán las ciudades del mundo en los países en vías de desarrollo"(Tello, 2010, p. 324).

La asimetría de los enfrentamientos contemporáneos, lleva a los ilícitos a "combatir en las ciudades... le permite restablecer el equilibrio frente a las ventajas tácticas que a un ejército 
moderno le brindan las nuevas tecnologías... Salidos de la población, los defensores cuentan con buenos informes de inteligencia, mientras que el invasor se desplaza en medio de la bruma. Este último se encuentra por otro lado frente a un dilema: para evitar los daños colaterales modula el empleo de la fuerza aun aceptando bajas en sus filas, o bien emplea todos los medios - cañones, tanques, aviación - con el riesgo consiguiente de masacrar civiles. En ambos casos habrá de ofrecerle a los medios un espectáculo difícilmente defendible frente a una sociedad democrática" (Lemoine, 2009, p.4).

Un verdadero "redimensionamiento del Estado-Nación, de manera que éste ya no es el monopolizador de la guerra... una imbricación entre actores estatales, paraestatales y privados, donde cada uno de ellos obtiene sus propias ganancias materiales e ideológicas de la guerra y, por tanto, la posibilidad de una paz duradera resulta de difícil consecución" (Rovira, 2005, p. 184).

Las ESol narco-violentas también ayudan a los gobiernos de Colombia y México a no poner tantos muertos en el conflicto mediante la práctica de la desaparición y el uso de fosas comunes, uso de ácidos, hornos crematorios, cocodrilos y tigres. En audiencias de los reinsertados narcoparamilitares colombianos se han denunciado las órdenes del gobierno a las estructuras narcoviolentas de utilizar el método de la desaparición para reducir los índices de homicidios dolosos y así mostrar una reducción de la violencia y resultados positivos en materia de seguridad.

En México, se prefiere aún como en épocas pasadas en Colombia la exposición de la crueldad como arma de disuasión a los detractores de la violencia y como elemento de construcción y mantenimiento de poder territorial y por ende político. No obstante, el Estado mexicano se perfila como un candidato a adoptar las desapariciones, en especial, por los llamamientos de la sociedad internacional para que cesen los crueles asesinatos.

La cadena ESol la integran una diversidad de actores y sujetos ilegales y legales. Paramilitares guerrilleros, políticos, miembros de las FFAA, Empresarios, Ganaderos y narcotraficantes de distintos niveles en la escala de producción, población marginal, suicida y aventurera, encuentran asiento en realidades e intereses económicos que se ven acompañados de la violencia como mecanismo de monopolización. Representan un grupo de presión trascendental cuyas fronteras no son susceptibles de determinación así como el terrorismo. 
Se presenta la convergencia entre el narcotráfico y la insurgencia, en cuanto a la condicionalidad externa del sistema político se refiere. Y la utilización del terrorismo en actividades de la narcoviolencia. Recurrir a actos terroristas es una alternativa "para revertir un determinado statu quo" (Duncan, 2005, p.55) o para mantenerlo.

Similar a las estructuras mercenarias narcotraficantes o narcotraficantes de diversas gamas criminales, inclusive, bajo los ropajes legales más inmunes o frente al narco-terrorismo más mediático y desparpajado.

$\mathrm{Ni}$ la ONU ha logrado consensuar la definición de terrorismo ni de las nuevas amenazas globales. Lo que asevera la ambigüedad conceptual resultado de conflicto de "interpretación política o ideológica del fenómeno que, en un contexto de fuerte heterogeneidad... existe (para el terrorismo) una definición de la Unión Europea, otra de los Estados Unidos y diversas posturas"

(Tello, 2010, p. 334) nacionales. Por lo que el concepto de narco-terrorismo, resulta sin sustento teórico alguno, pero con toda la escolta política.

\subsection{NARCO-VIOLENCIA: UN MERO TIPO DE VIOLENCIA TRASNACIONAL}

En este caso, la ambivalencia entre la represión y el diálogo como mecanismo de confrontación contra la narco-violencia debilita la efectividad de las estrategias impulsadas por las instituciones. Si no se tiene claro el diagnóstico la estrategia para enfrentar el problema de la narco-violencia crece en proporción a la falta de certeza política.

La narcoviolencia exporta sus diagnósticos a otros territorios incrementando su poder político y geoestratégico mediante la consolidación de alianzas, para cuyo funcionamiento, requiere a su vez de otro tipo de acuerdos con las élites del establishment. También representa la plataforma laboral para la población que ha sido excluida de las oportunidades oficiales como para mantener el superávit de la industria legal e ilegal de armas y las narco-inyecciones financieras a sectores legales. 
Como se mencionó, la narco-violencia ejecuta sus propias CMP o se pone en muchos casos, al servicio de seguridad privada de diversos actores y sujetos legales e ilegales. Es una de las fuentes de financiación de la ESol narco-violenta. Por ejemplo, el grupo de los Zetas se compone de mercenarios, una amenaza que se podría denominar como narco-mercenarismo.

Lo que puede significar que estas denominadas nuevas amenazas se encuentran repotenciadas al realizarse la inversión de la fórmula de Clausewitz, pues las mismas se reinventan pero no desaparecen, se adaptan a los nuevos desafíos que les implica la inteligencia militar y le recorta al Estado la libertad del cumplimiento de los fines, pues por su imponente poder económico, logra satisfacer necesidades de la población, voluntaria o forzosamente.

Tal vez el Sistema Internacional contemporáneo se parece cada vez más a la organización de "la Alta Edad Media, caracterizada por la fragmentación y descomposición del poder a escala global y por una transferencia importante del mismo hacia empresas trasnacionales que organizan sus espacios y sistemas de control y represión en función de intereses particulares y no generales... El derecho internacional público que tiene como fundamento el modelo de guerra entre Estados, resulta hoy impotente para encuadrar las bandas armadas que en muchos casos permiten augurar las realidades conflictivas del tercer milenio"(Tello, 2010, p. 314). 


\section{CAPÍTULO IX: GRUPOS NARCOVIOLENTOS COLOMBO-MEXICANOS}

La narcoeconomía colombo-mexicana surgió en la década del 70, entre el cartel de Sinaloa (México) y el cartel de Medellín (Colombia). En 2014 las políticas estatales norteamericanas intervienen a estos Estados mediante la figura de la cooperación directa y a través de los diversos organismos internacionales que lidera EEUU. EEUU califica a la narco-violencia como una amenaza trasnacional y a su seguridad.

Las narcoeconomías como forma de economía subterránea incrementa el PIB mundial y constituye un tipo de economía "asociada con actividades al margen del código legal de un país, debido al alcance que tiene la economía del narcotráfico y la economía informal evasora de la legislación fiscal y laboral"(Arango, 2004, p.2).

La guerra contra el holding narco-violento no es la típica guerra clásica, en su declaración formal, se ha convertido en "un mero trámite" (Kaldor, 1999, p.1), que desconoce la concepción de las nuevas guerras incorrectas.

La estabilidad económica de la narco-violencia es reflejo de "la pobreza, la desigualdad social y la ausencia de oportunidades económicas para los jóvenes... factores que han permitido que el narcotráfico prospere en la región de América Central y el Caribe"77.

En 2011, la INTERPOL y la UNODC calcularon que "el mercado ilícito de cocaína a nivel mundial tiene un valor de más de 80.000 millones de dólares"(Informe Mundial). Adicionalmente, los mayores productores de heroína consumida en América del Norte "siguieron siendo el Afganistán, Colombia y México. Según la Dirección de Lucha contra las Drogas, el 58\% de la heroína incautada en los EEUU procedía de Colombia y el 39\%... de México"(Informe Mundial, p.68-69). Ambos Estados manejan el mercado de marihuana y cocaína, y, México se ha especializado en la producción y tráfico de metanfetaminas (31 toneladas incautadas en 2013).

77 Informe Mundial sobre las Drogas: los mercados de la droga se estabilizan, pero aumenta el consumo de drogas sintéticas y de venta con receta. Nueva York/Viena. 23 de junio de 2011. www.unodc.org/wdr. Consultado el 1.6.2012.Pg 57 y 58. 
No obstante, en cuanto a la producción de heroína, en 2013 Afganistán "es considerado el mayor productor mundial de opio -las ventas equivalen al $15 \%$ de su PIB" ${ }^{\prime 7}$. De otro lado, "el $82 \%$ de los cultivos de adormidera están en Afganistán. Punto de origen del 93\% de toda la heroína que se consume en el mundo... La exportación de productos obtenidos de este cultivo aportaron al país el más de la tercera parte de su PIB, representando unos ingresos de 4.700 millones de dólares"79.

México es el segundo productor mundial de opio, heroína y marihuana, de acuerdo al Reporte Mundial sobre Drogas del 27 de junio 2013 de la ONU. En cuanto a la amapola, la ONU informó que el $74 \%$ se cultiva en Afganistán. Igualmente estimó que la producción de heroína en México es 30 veces mayor que la de Colombia.

No obstante, EEUU sigue señalando a Colombia como su principal proveedor de adormidera. El informe indicó la existencia de indicios de un aumento de la actividad de fabricación en América Central.

EEUU estimó "que un $90 \%$ de la cocaína consumida en América del Norte proviene de Colombia"(Informe Mundial, p. 77). Entre 2010-2011, la Organización Mundial de Aduanas reportó incautación de narcóticos producidos en Colombia en Indonesia, Líbano a través de Bélgica, Israel, Albania y Australia, entre los más dicientes. A 2014, en Colombia se ha disminuido el combate ideológico desde fuentes oficiales hacia la marihuana.

El Presidente Santos pidió replantear la lucha mundial contra la droga, pero se refirió solo a la marihuana. Manifestó: "Si un hijo mío es adicto prefiero que vaya a un centro de rehabilitación que a la cárcel. Hay una contradicción ideológica entre el ilícito del campesino colombiano que cultiva (y se ataca) y el norteamericano que se fuma su barillo en Colorado" ${ }^{80}$. Pareciendo aún más contradictorio, la flexibilización del lenguaje político, atendiendo las nefastas consecuencias que la lucha ha dejado en materia de DDHH.

78 http://www.elespectador.com/noticias/actualidad/articulo-417472-epidemia-de-heroina-afganistan. Consultado del 7.7.2013. 79http://www.20minutos.es/noticia/1774170/0/afganistan/cultivo-opio/crece-2013/\#\#xtor=AD-15\&xts=467263. Consultado el 7.7.2013. 80 Noticias RCN Internacional Colombia. 6.12.2012. 
En cuanto a la cocaína, y su proporción referida a las utilidades de producción respecto al área sembrada, debemos decir que la utilidad depende de muchos factores climáticos, pero en promedio, en Colombia una hectárea sembrada de maíz produce alrededor de 15 a 18 toneladas para ganado y de 9 a 12 toneladas para consumo humano. Cifras similares maneja México. Ahora bien según WOLA Colombia produce 2,7 kilos de cocaína por hectárea sembrada. Lo que nos permite realizar reflexiones profundas.

Parece no importar el costo social y ambiental del glifosato, pero si el de la cocaína. Es como si fuera mejor que la gente se muera por la contaminación ambiental producida legalmente a que se muera (siendo extremistas) por su elección propia de consumir cocaína-heroína o peor aún, que muera por contaminación ambiental siendo un no consumidor que se ve afectado por políticas internacionales. Es acaso más loable morir por un efecto no elegido?.

El Estado no puede seguir invadiendo las libertades y los derechos fundamentales por la seguridad del Interés Nacional de otro país con mayor ejército y capacidad de guerra, de consumo y destrucción o simplemente por un agente perturbador. Así el Interés Nacional es más importante que la persona humana, que en últimas, es quien le da vida.

\subsection{COLOMBIA}

Los narcotraficantes emergen en la década del 60 y 70 con el auge de la marihuana y experimentaron mutaciones que terminaron de acoplarse en las dos últimas décadas del S. XX, con el incremento sorpresivo de la cocaína y la heroína en menor medida, y la consolidación de los principales Carteles de la droga, Medellín y Cali.

Desde la década del 80, concomitante con la creciente ola cocainómana, encontraron en los políticos terreno fértil para asegurarse inmunidad y poca represión.

Produciéndose la narcotización de la agenda externa de los Estados Superados mediante el combate militar público y privado a los actores que engendran guerras promiscuas que se valen de cualquier método e ideología para hacer respetar su ley. 
Desde el año 2006, "el escenario del mercado de las drogas ilícitas en la región, y muy precisamente en Colombia, (cambió) radicalmente. Los grupos alzados en armas al margen de la ley, paramilitares y guerrillas, controlan casi la totalidad del negocio... y los principales carteles de la mafia narcotraficante quedaron englobados en diferentes maneras dentro de la dinámica del conflicto" (Rangel, 2005, p. 10).

Las reglas de la lucha narcótica provienen de "la internacionalización del diagnóstico norteamericano y su recetario respectivo para combatir la problemática de los narcóticos" (Tokatlian, 1995, p. 36). Requiriéndose, "desmitificar la presentación del fenómeno de las drogas, realizada por el discurso oficial" (Tokatlian, 1995, p. 36).

Colombia y México deberán desdoblarse ${ }^{81}$ y esto los superara aún más; deberán ser funcionales hacia adentro y hacia fuera, simultáneamente. Es decir, los intereses nacionales de los Estados Superados nada pueden hacer sin el beneplácito de la política estatal de su hegemón.

No es más sino pensar en los actuales diálogos de paz con la guerrilla de las FARC que se narcofinancia, claro está, resaltando la vigencia de los operativos militares durante los mismos. Mientras que Estados Unidos y la sociedad internacional los denominó terroristas, felicitan al gobierno Colombiano por su voluntad política de lograr la paz.

Sintetizando el recorrido en 2014 de dichos diálogos (Arias, 2013, p.1) podemos manifestar que desde el pasado 14 de junio de 2012, el Presidente Juan Manuel Santos Calderón, recibió aprobación por parte del poder legislativo al proyecto de ley que puso a su consideración y cuyo objeto principal trata sobre la reinserción o reintegración de actores al margen de la ley, en principio, integrantes de las FARC.

Desde entonces, las reacciones no se han hecho esperar, no solo desde la tradicional oposición nacional, la sociedad internacional, sino también desde la nueva oposición política que enfrenta el gobierno actual por parte de sus competidores pre-electorales, como lo afirmó, el mismo

81 SCELLE. Desdoblamiento funcional. Reflexión que surge luego de la revisión del material de estudio de la maestría en Relaciones Internacionales en el Instituto de Relaciones Internacionales (IRI) - Universidad Nacional de la Plata. Apuntes del Dr. Profesor CONSANI, Norberto. 
Presidente Santos ${ }^{82}$ al referirse a los twitters constantes del ex Presidente Uribe. Así, las posiciones frente al tema están polarizadas.

No obstante, ser el principio general que orienta a las negociaciones: "Nada está acordado, hasta que todo esté acordado" 83 , produce la necesidad de esperar un acuerdo definitivo para poder tomar posiciones, pues antes, resultaría impropio.

Una de las razones para que las críticas frente al diálogo no cesen, recae en la historia de las negociaciones entre el gobierno, y en especial, con las FARC. Por ejemplo, el crecimiento del grupo armado al margen de la ley en la antigua zona de distensión del Caguán bajo los acercamientos con el gobierno Pastrana y el exterminio de los miembros o aliados políticos de la Unión Patriótica por grupos paramilitares, reviven las experiencias negativas en la memoria de los colombianos y del resto del mundo.

No obstante, la realidad de un conflicto armado, presenta dos posibles vías para su resolución: los enfrentamientos armados o los acercamientos dialogados. Seguramente, la vía ideal es el diálogo, pero sin cese de hostilidades frente a los actos repudiables de los ilegales y sin el quebrantamiento de los estándares jurídicos.

En la actualidad se acordó en la mesa de negociaciones el punto agrario y se lleva a cabo las negociaciones frente a la participación en política de los miembros de las FARC, aunque los avances solo se materializarían al final de las conversaciones.

En cuanto al Agro, según información de la Mesa de Conversaciones El Gobierno y las FARC -, en cumplimiento de lo establecido el 26.8.2012, informaron haber acordado:

- Iniciar transformaciones estructurales de la realidad rural y agraria con equidad y democracia, contribuyendo así a la no repetición del conflicto y a la construcción de una paz estable y duradera. Centrada en el bienestar y buen vivir de la gente del campo y de las minorías.

82 En entrevista con Rodrigo Pardo. Programa trasmitido el 8.8.2013.

83 www.mesadeconversaciones.com. Consultado el 10.8.2013. 
- Lograr la integración de las regiones, la erradicación de la pobreza, la promoción de la igualdad, el cierre de la brecha entre el campo y la ciudad, la protección y disfrute de los derechos de la ciudadanía y la reactivación del campo, especialmente de la economía campesina, familiar y comunitaria.

- Mediante la promoción de diferentes formas de asociación y cooperativismo, la generación de ingresos y empleo, la dignificación y formalización del trabajo, la producción de alimentos y la preservación del medio ambiente. Lo anterior sin perjuicio de la necesaria articulación entre esta y otras formas de producción agrícola. Se adelantará en un contexto de globalización y de políticas de inserción en ella por parte del Estado que demandan atención especial de la producción agropecuaria nacional y con énfasis rural.

- Para garantizar la efectiva protección de los derechos de propiedad en el campo, se acordó la creación de una jurisdicción agraria que tenga cobertura y capacidades regionales.

La participación en política podría ser obstruida por los postulados provenientes del Estatuto de Roma de 1998 mediante el cual se creó la Corte Penal Internacional, cuya competencia se fundamentó en el adicionado político 02/2001 realizado a la Constitución Política en el artículo 93. Fecha desde la cual transcurrió el periodo de transición de armonización en las estructuras normativas nacionales e internacionales, hasta la efectiva consolidación del bloque de constitucionalidad que se surtió en el mes de noviembre de 2009, momento a partir del cual la Corte Penal Internacional tiene competencia subsidiaria en materia penal frente a los crímenes internacionales que ocurren posterior a dicha fecha en el territorio colombiano.

La Corte Penal Internacional contempla cuatro crímenes internacionales: Crímenes de Lesa Humanidad; Genocidio; Crímenes de Guerra; y, Crímenes de Agresión. Ante la comisión de los mismos Colombia se comprometió a no conceder ningún tipo de indulto o amnistía a quienes hayan cometido este tipo de crímenes ni permitir su participación política.

Muchos se preguntan por qué el Estatuto de Roma de 1998 no representó un impedimento para la promulgación y la puesta en marcha de la Ley de Justicia y Paz - Ley 795 de 2005, mediante la cual 
el gobierno del ex Presidente Uribe negoció con criminales de Lesa Humanidad, concediendo penas máximas de 8 años. Por lo cual, resulta sorprendente su negativa rotunda a las conversaciones que adelanta el gobierno de Santos en la Habana.

La respuesta es de tinte jurídico aunque sin estar reteñida por el resaltador de la justicia, pues al momento de la expedición de la misma, no se encontraba vigente la competencia de la Justicia Penal Internacional, que como se expresó, solo puede conocer de violaciones a las obligaciones internacionales contempladas en el Estatuto de Roma y adquiridas mediante el proceso constitucional de aprobación y ratificación de tratados, a partir de la entrada en vigencia y sólo hacia adelante, aplicando el principio de la irretroactividad de la ley.

En 2014 se acordó igualmente el álgido punto sobre el narcotráfico, y aunque lo acordado, es objeto de reserva de los diálogos de paz, se presume que no se contempló la legalización de la producción ni la distribución narcótica, sino que se hizo mayor énfasis, en la sustitución de las aspersiones con glifosato por la erradicación manual y nuevo proyectos productivos para la población involucrada en la narco-producción.

Consideran los negociadores del gobierno que los acuerdos convendrían a la reducción significativa del narcotráfico por ser las FARC uno de los principales actores de la ESol narcoviolenta. Los campesinos, grupo que se desarrolla ejerciendo actividades dentro de la cadena de producción del narcotráfico, cultivando y cosechando. Más de "100.000 familias involucradas"(Schultze-Kraft, 2010, p. 440).

Los narco-delitos son "la tercera causa por la cual las personas son privadas de su libertad...pudiendo ser fácilmente sustituibles en las redes de fabricación y tráfico; se caracterizan por tener escasa formación académica y condiciones socio-económicas precarias"(WOLA, p. 50).

No obstante, a finales del 2012, "el ministro de Defensa, Juan Carlos Pinzón, aseguró que los ingresos netos de las FARC procedentes del narcotráfico oscilan entre los 2.400 y los 3.500 millones de dólares al año y estimó sus miembros en 8.147 guerrilleros" ${ }^{84}$. En 2013, el Ministerio

84 http://confidencialcolombia.com/es/1/105/3007/Las-cifras-de-las-Farc-seg\%C3\%BAn-el-Gobierno-Mindefensa-Pinz\%C3\%B3n-Farc-narcotr\%C3\%A1fico-combatientes.htm 
de Defensa estimó la cifra aproximada de 7,500 guerrilleros. Bajo otra mirada, existen hoy mayor presencia de BACRIM en Colombia que de guerrilleros.

Cifra que haría minúscula la ayuda que recibió Colombia "de 500 millones de dólares anuales en concepto de ayuda militar... para intensificar la lucha contra el tráfico de estupefacientes y contra el terrorismo"(Anuario, 2012, p. 462).

Falta acordar respecto al establecimiento de una Comisión de la Verdad, que pretende reparar a las víctimas del conflicto armado a nivel material y el conocimiento de los hechos del conflicto. Así mismo, "firmas como Mari Tech, TRW, Matcom o Alion, utilizan avanzadas tecnologías para fotografiar desde el espacio, interceptar las comunicaciones y analizarlas. Esta información es transmitida al Sistema de Reconocimiento del Comando Sur del Ejército de Estados Unidos (SouthCom) y a la $\mathrm{ClA}$, que la tratan y la redistribuyen a las instancias que eligen. Las fuerzas armadas colombianas son las últimas en ser informadas" (Calvo, 2005, p. 1).

El resultado es un escenario de "conflicto armado como caldo de cultivo del crimen organizado... ni la guerrilla ni los paramilitares reflejan sus orígenes históricos. Hasta finales de la década de los ochenta era relativamente posible distinguir a los carteles del narcotráfico de las guerrillas y paramilitares. Esa distinción se perdió en los años noventa y es virtualmente imposible. Las dos son hoy estructuras criminales fuertemente vinculadas al narcotráfico"(López, 2011, p. 229-230).

Una vez develadas las caras visibles de la narcoviolencia, se sucedió la aparición de "individuos y grupos especializados en transporte y lavado de dinero... por medio de inversiones legítimas... Fabio Ochoa Vasco (Carlos Mario) se ha vinculado con el transporte de cocaína y el lavado de dinero por el Caribe hacia México; se sospecha que Eduardo Restrepo Victoria (el Socio), sea el enlace con el cartel de Tijuana en México;... Daniel Barrera (el Loco), obtiene droga de las FARC-, a las que provee de precursores químicos"(Schultze-Kraft, 2010, p. 441).

El cartel del Norte del Valle retomó el "negocio de los grupos de Medellín y Cali.... Expandió sus operaciones (entre 1998-2002). Clanes familiares, menos jerárquicos... debilitado por la presión de las fuerzas de seguridad y por sus fricciones internas... sólo siguen en el negocio unos pocos capos y sus socios" (Schultze-Kraft, 2010, p. 441). Tras la detención en 2007 de Don Diego y el 
asesinato de Jabón en Venezuela en 2008, “ejercen coerción, intimidación y dominio territorial por medio de los Rastrojos y los Machos" (Schultze-Kraft, 2010, p. 441).

Las BACRIM son el resurgimiento de slogans narco-paramilitaristas, son grupos de crimen organizado que en teoría no ostentan intereses políticos, sino la cooptación territorial del Estado para sus negocios ilícitos y prestan servicio de seguridad privada a empresas nacionales o multinacionales. En agosto de 2013 se estimó que solo las BACRIM de los Rastrojos y los Urabeños, llegan a contar aproximadamente con 4.000 hombres fuertemente armados.

Entonces en 2014, la estructura de la narcoviolencia y la narco-economía, se encuentra disipada y pasó de una organización vertical a una horizontal, de difícil percepción, y adicionalmente, el fenómeno narco-económico violento se integró en todos los sectores colombianos, legales e ilegales.

La Radiografía de las BACRIM la podemos presentar así:

\begin{tabular}{|c|}
\hline $\mathbf{s}^{85}$ \\
\hline $\begin{array}{l}\text { Origen: } 2006 \text { en Norte de Santander. Proyección nacional. } 4.000 \text { hombres. Presencia: región } \\
\text { Caribe, Urabá, Magdalena Medio, Llanos Orientales, Cauca, Nariño, Norte del Valle. } \\
\text { Controlando corredores y puntos estratégicos para la actividad del narcotráfico. Miembros: } \\
\text { desmovilizados de las AUC y nuevos miembros. }\end{array}$ \\
\hline Los Urabeños \\
\hline $\begin{array}{l}\text { Presencia: Golfo de Urabá - Antioquia; sur de Córdoba y norte del Chocó. } 1.970 \text { hombres. Sus } \\
\text { actividades: tráfico de drogas, vacunas, extorsión y asesinatos. Se relacionan con grupos } \\
\text { insurgentes como el ELN y las FARC, con el fin de mantener un control del negocio del } \\
\text { narcotráfico. Ha incursionado en la fabricación de submarinos para el transporte ilegal de } \\
\text { narcóticos. }\end{array}$ \\
\hline Los Paisas \\
\hline $\begin{array}{l}\text { Fundada en Medellín por 'don Berna', luego de la desmovilización de los paramilitares en } 2006 \\
\text { pertenecientes a la Oficina de Envigado. Después de su extradición a EEUU la organización se } \\
\text { separó e independizó. Presencia: Guajira, Córdoba, Sucre y Cesar. Actividades: narcotráfico, } \\
\text { secuestro, producción y comercialización de alcaloides. Organización inestable y cambiante: } \\
\text { indeterminación número de miembros. }\end{array}$ \\
\hline Los Rastrojos \\
\hline $\begin{array}{l}\text { Nacen en } 2002 \text { brazo armado del cartel del norte del Valle. Presencia: norte del Valle y } \\
\text { Risaralda, hasta la frontera con el Perú y Ecuador, Antioquia, Chocó y Norte de Santander. } \\
\text { Actividad principal: narcotráfico Tienen conexiones con las FARC y el ELN. cuentan con } 1.300 \text { a } \\
1.500 \text { hombres }\end{array}$ \\
\hline
\end{tabular}

85 RADIOGRAFIA DE LAS BACRIM. http://www.olapolitica.com/?q=content/d\%C3\%B3nde-est\%C3\%A1n-y-c\%C3\%B3. Consulato el 12.12 .12 


\section{ERPAC}

Origen: Llanos Orientales 2005. Fundador 'cuchillo'. 725 miembros. Presencia: Meta, Guaviare, Vichada y Casanare, Bogotá y algunos municipios de Cundinamarca.

Los Machos

Actúan en el norte del Valle, hecho que les da acceso al Pacifico para transportar narcóticos. Después de la entrega a la Policía de Iván Urdinola en el 2011, 'Los Machos', que se creían extintos, hicieron alianza con 'Los Urabeños', lo que les permitió a estos últimos el acceso al Pacifico colombiano. Por tratarse de un grupo tan inestable, no se cuentan con datos concretos del número de miembros.

Renacer

Surge en 2005 post-desmovilización. Presencia: Chocó, Antioquia y el norte del Valle. Actividad: narcotráfico.

\subsection{MÉXICO}

En 2007 inició la guerra contra el narco, que a 2010 más de 34 mil muertos, de los cuales 15.273 ocurrieron en 2010. El 10 de junio de 2011 se produjeron 83 muertes en 24 horas producto de cruce de cuentas de los carteles y el 4 de mayo de 2012, aparecieron 9 cuerpos colgados en un puente y otros 14 fueron decapitados en Nuevo Laredo. En 2014, los grupos del narco dominan mediante el uso sistemático de la violencia a la población marginal que no cuenta con apoyo del Estado.

Fue en 2008 cuando quedó activado por la gestión del ex Presidente George W. Bush la Iniciativa Mérida, Plan Mérida o Plan México (que se extiende a todos países de América Central), de lineamientos bien similares a los del Plan Colombia en cuanto a la militarización como solución unidireccional al fenómeno del narcotráfico y sus delitos conexos.

Así el Estado inició "una guerra, en el terreno militar, contra el narcotráfico, con el objetivo de fortalecer su legitimidad social. Los resultados, sin embargo, fueron contrarios a los buscados... la acción militar solamente alteró equilibrios entre cárteles, dejó plazas vacantes por lo que se iniciaron nuevas guerras entre jefes narcos. Estados tradicionalmente tranquilos se volvieron escenarios de una inconcebible violencia" ${ }^{86}$.

86 www.costabonino.com/mexico.htm consultado el 2.6.2012 
El término carteles ha sido desestimado por el Embajador de México en EEUU ${ }^{87}$ quien considera que los grupos organizados narco-violentos mexicanos son verdaderas empresas ilícitas de estructura vertical que asumen el reto comercial de variar sus productos conforme los deseos de los consumidores.

Adicionó que la característica especial de los carteles es la coordinación en el mantenimiento de los precios y que dicho desacuerdo es lo que imprime más violencia. En el fondo traduce el mensaje oficial del Estado en desconocer el conflicto armado y la estatalidad o penetrabilidad de los autores a las esferas legales.

Los carteles generan entre 17.000 y 38.000 millones de dólares anuales como producto de sus ventas de cocaína, heroína y marihuana en EE.UU, según el Centro Nacional de Inteligencia sobre Drogas del gobierno estadounidense. Constituyendo "un aspecto importante del PBI (3.1 2011)...45 mil mexicanos trabajan directamente para el narcotráfico"(Cieza, 2009, p.28).

La Junta de Fiscalización resaltó "la fabricación clandestina de metanfetamina a gran escala... pasando ulteriormente por contrabando a los Estados Unidos" (Informe Mundial, p.13-14). En 2012, la "economía subterránea representa hasta el 5.5\% del PIB" 88 , mexicano. En cuanto a "la fabricación potencial de heroína... ascendería a un 9\% de total mundial” (Informe Mundial, p.12).

La UNODC reportó el pódium narcótico específico así: “1,67 millones de heroinómanos en América Latina: 1,2 millones en los Estados Unidos, 114.000 en Canadá y 50.000 a 60.000 en México" (Informe Mundial, p.12).

Los grupos narcotraficantes han contestado a la militarización con más violencia buscando deslegitimizar al Estado y sus fuerzas militares y de policía así como el sistema judicial, mediante la corrupción o amenaza. Se sigue utilizando el territorio mexicano como Estado originario y a la vez de tránsito de narcóticos.

87 EFECTO NAíM. Embajador de México en EEUU. Trasmisión del 11.12.12.

88 www.journalmex.wordpress.com/2001/10/12. Consultado el 5.6.2012. 
Un resultado aprendido del Capo Pablo Emilio Escobar Gaviria, cuyas actividades servirán de pilar para el desarrollo de las organizaciones narcotraficantes protagonistas en las postrimerías del siglo XX y en los inicios del siglo XXI.

Otro factor que asegura el status quo narco-violento es que en la frontera México-EEUU "a lo largo de toda la valla que divide a ambos países hay 6.500 armerías y se realizan 150 ferias de armamento por año" (Cieza, 2009, p.28).

Las ESol narco-violentas "compran armas cada vez más poderosas, de tipo militar, como rifles semiautomáticos Colt AR-15 y AK-47. Según Adriana Rossi, el tráfico que asciende a 22,4 millones de dólares anuales, incluye armas pesadas, lanzacohetes, lanzagranadas, y armas que traspasan blindados"(Rossi, 2009, p.118).

Los carteles sometidos a la represión militar extendieron sus sedes y residencias "a América Central, lo que ha dado lugar a un aumento de la violencia, los secuestros, el soborno, la tortura y los homicidios en esa subregión... zona de re-expedición" (Informe Mundial, p.12). Un negocio trasnacional multimillonario operado por diversos carteles (Borges, 2008), los principales:

\section{a) Cártel del Golfo:}

Creado por Juan Nepomuceno Guerra en la década de 1940. Contrató la impunidad y la funcionalidad política del negocio, en especial, de Tamaulipas y jefes de la policía. Su grupo de sicarios - Los Zetas, está compuesto por desertores de las Fuerzas Especiales del Ejército Mexicano. El jefe de Los Zetas es Heriberto "El Lazca" Lazcano, quien impone la decapitación y la mutilación de los genitales como castigo a cualquier enemigo que encuentre en el camino. Entre sus filas, se han sumado "caibiles" provenientes de las tropas de elite del ejército guatemalteco. Últimamente se ha detectado una fuerte presencia de Los Zetas en Quitana Roo y en Guatemala.

\section{b) Cártel de Tijuana - Baja California:}

Uno de los más grandes y violentos se inició cuando el líder del Cártel de Guadalajara, Miguel Ángel Félix Gallardo, fue capturado en 1989 y se fragmentó en dos cárteles distintos. El Cártel de Sinaloa, a cargo de Joaquín Guzmán Loera, alias "El Chapo", y el Cártel de Tijuana liderado por los herederos del asesinado Ramón Arellano Félix. Actividad: narcotráfico en red de cooperación con el Cártel del Golfo, aunque funcionan como organizaciones criminales independientes.

\section{c) Cártel de Juárez:}

Área de influencia en 21 estados y soborno de autoridades. Comenzó bajo el mando de Amado Carrillo Fuentes, apodado "El Señor de los Cielos" por su innovador sistema para transportar cocaína: una flota completa de aviones Boeing 727. Murió en 1997 durante una cirugía plástica 
que se realizaba con el fin de no ser identificado por las autoridades. Llegó a poseer 25.000 millones de dólares.

\section{d) Cártel de Sinaloa - Cártel del Pacífico}

Dirigido por Joaquín Guzmán Loera, alias "El Chapo". Área de influencia en 17 estados. Trafica y distribuye de cocaína colombiana, marihuana mexicana y heroína asiática. De Culiacán, la capital de Sinaloa, salieron todos los grandes capos que se apoderaron del negocio del traspaso de la cocaína al otro lado de la frontera tras la decadencia de los carteles colombianos. Es ahí donde se forja la amistad entre los hermanos Beltrán Leyva y Joaquín "El Chapo" (petiso) Guzmán, considerado por la Revista Forbes como uno de los más ricos del mundo.

e) Cártel de Colima - Los Reyes de las Metanfetaminas.

De los hermanos Amezcua Contreras. Área de influencia en 7 estados. Actividad: producción y distribución de drogas sintéticas. Se creó en 1988 y originalmente sólo operaba traficando para los cárteles de Colombia y pronto se convirtió en una importante organización criminal para el tráfico y procesamiento internacional de anfetaminas.

\section{f) Cártel Milenio - Los Valencia:}

Dirigido por Luis Valencia. Se separó del Cártel de Juárez en 1999 y tiene presencia en seis estados: Michoacán, Colima, Jalisco, Distrito Federal, Nuevo León y Tamaulipas; su base de operaciones está en Michoacán, donde se produce marihuana y amapola.

\section{g) Cártel de Oaxaca:}

Su área de influencia es sobre siete estados del país: Chihuahua, Durango, Tamaulipas, Veracruz, Chiapas y Oaxaca. Trafican con marihuana (mayor productora zona del Istmo) y cocaína, principalmente.

\subsection{COLOMBIA Y MÉXICO}

Colombia esencialmente productor de marihuana, cocaína y heroína, y México, líder en producción de metanfetaminas, de opio para fabricar heroína, cannabis para marihuana y país de tránsito de narcóticos.

Hillary Clinton, comparó la situación de México con "la de Colombia en la década de 1990"(EI Estado del Mundo, 2012, p. 418-419. Desde allí, constantemente se habla de la colombianización de México, donde el surgimiento de grupos para-militares regionales acelera un proceso muy similar al de Colombia.

Existe una estrecha relación entre los narcos colombianos y mexicanos, ya que "los primeros son básicamente productores y los segundos introducen la droga en EE.UU. Y además, aparecen otros 
actores como los grupos paramilitares y las guerrillas degradadas que se repiten en el escenario mexicano"(Cieza, 2009, p. 118).

Otra tendencia norteamericana es la de impulsar cada vez más la calificación de México como un Estado en riesgo latente de ser un Estado Fallido por razones que en Colombia son el pan de cada día, por ejemplo, los riesgos electorales, la seguridad e integridad de sus ciudadanos y de la totalidad de su territorio.

El origen del concepto de Estado Fallido proviene del "State Failure Task Force Report de la Agencia Central de Inteligencia de los Estados Unidos en el año de 1995... Posteriormente en 2002, después de los ataques terroristas del 11 de septiembre de 2001, el Consejo de Seguridad de Estados Unidos... definió a los Estados fallidos como entes de riesgo a la seguridad nacional de Estados Unidos" ${ }^{\prime 29}$.

No obstante, la narcoviolencia que ejercen los grupos ESol narcoviolentos "no ha cortado el suministro de electricidad ni de agua, y casi todos sus ciudadanos han pasado por la escuela... más útil es el concepto de Estado capturado... los carteles combaten por ciertas parcelas del Estado"(Grillo, 2012, p. 329).

Hay sectores de la doctrina que sostienen la clasificación de fallidos como una falacia (Benítez en Mathieu, 2011, p. 138) pues solo pierde el control del territorio parcialmente y no en su totalidad. Probablemente, al desplegar los planes made in usa, los Estados de Colombia y México se mantienen aún en la teoría como Estados viables pero en la práctica se acercan a ser Estados Superados por las Guerras Promiscuas de las ESol narcoviolentas.

Pero la gran diferencia teórica con los Estados Superados, es que si bien comparten la característica de poder parcial territorial, éstos últimos cuentan con alianzas con funcionarios del sistema político y judicial legal y adicionalmente cuenta con apoyo popular y su característica de permanencia es la transnacionalización.

89 Guía básica sobre Estado fallido y Estado débil. Desmitificación y contextualización. Failed State Index, Fund for Peace. http://zepecaos.wordpress.com/estado-fallido-y-estadodebil/. Consultado el 5.9.2013. 
La definición de Estado Fallido propone falencias estatales para la consecución de sus fines en un sentido amplio como lo comprendió Max Weber en cuanto al mantenimiento del monopolio de la violencia legítima se refiere (Esty, 1995). En un sentido más estricto, podemos referenciar la concepción dada por Noam Chomsky $(2008$, b) que no solo considera el monopolio de la violencia como motivo del fallo sino también incluyó los objetivos del Estado.

Para Brooks (2005, p.1159- 1196) el concepto de Estado Fallido no explica bien las diferentes coyunturas que se viven en los países que tienen conflictos armados y guerras civiles que debilitan su existencia, incluso argumenta que hay una confusión entre Estado Fallido y no-Estado donde hay una ausencia absoluta del Estado. Para Joel S. Migdal (2011, s.p.) hay cuestiones sobre la imagen del Estado coherente con la representación territorial y la capacidad de acción del Estado son mejores parámetros del mismo.

Sin embargo, la falta de deseo de apoderarse completamente del Estado "no reduce la amenaza... el Diccionario de la Lengua de la Real Academia Española define la insurgencia como un levantamiento contra la autoridad... los carteles también emplean tácticas políticas... en el mejor de los casos son rebeldes primitivos (Hobsbawn, 1959)... en el peor, no son rebeldes en absoluto, sólo empresarios psicóticos" (Grillo, 2012, p. 324-326). Clausewitz, "reconocería sin la menor duda que tienen la característica de insurgencia" (Sullivan, 2010).

De otro lado en 2011, Rafael Correa "cuestionó la decisión del Congreso de Estados Unidos de calificar a México como "Estado Fallido" en la lucha contra el narcotráfico" ${ }^{90}$. En 2013 México escaló una posición en la lista de Índices de Estados Fallidos y se ubicó en el lugar 97 y defendió el primer puesto nuevamente Somalia.

Según "la organización Fund for Peace y publicado por Foreign Policy, México aún se encuentra entre los países en riesgo de convertirse en estado fallido (encontrándose) bajo estado de advertencia... está fallando (pero que aún no es fallido) por pérdida de control físico de su territorio o un monopolio en la fuerza legítima... erosión de la autoridad legítima para tomar decisiones colectivas, una incapacidad de proveer servicios públicos razonables y la incapacidad de interactuar con otros estados como un miembro de la comunidad internacional... Los 12

90 http://www.pais24.com/index.php?go=n\&id=113817\&x=Correa,-duro-con-EEUU-por-llamar-a-Me;xico-\%22Estado-fallido\%22-l. Consultado el 5.9.2013. 
indicadores que maneja el índice se dividen en dos grupos principales: Indicadores sociales y económicos e Indicadores políticos y militares. Dentro del primer grupo se analizan factores de riesgo como presiones demográficas (ambientales y sanitarias), fuga de cerebros, desplazamiento interno, desarrollo económico desigual, presencia de grupos delictivos, pobreza y declive económico; el segundo está conformado por indicadores como legitimidad del gobierno, servicios públicos, estado de derecho, derechos humanos, aparatos de seguridad, élites e intervención externa" ${ }^{\prime 1}$.

Aunque el narco-negocio trasnacional de "la narco-economía no lleva una contabilidad pública... el Producto Nacional Bruto sube por las actividades narco-económicas en prácticamente todos los países del mundo. El volumen de la narco-economía, en los países industrializados, es muy alto. En los países en desarrollo, son más bajas las cifras absolutas, pero su importancia relativa, en comparación con las ramas de la economía lícita, es más alta"(Hardinghaus, 102, p. 94).

Afectando directamente la economía mundial y siendo generadores de empleos. Creando un subdesorden y un Subsistema Internacional de la narcoviolencia como empresa trasnacional ilícita permeada en las economías lícitas. 


\section{CAPÍTULO X: NARCO-CORRUPCIÓN ESTATOCENTRISTA: ESTATOCENTRISMO MACHO Y BORRACHO}

Puede considerarse la opción de que el narcotráfico colombiano arribó a tierras colombianas por el efecto globo que produjo EEUU con sus políticas antinarcóticas en territorio azteca. Como veremos en este ítem.

En México se presentó una "formación masiva de asociaciones paramilitares con técnicas que cientos de militares mexicanos aprendieron en los últimos años en el famoso centro de formación del ejército estadounidense School of Americas en Fort Benning, Georgia" ${ }^{92}$. Los grupos paramilitares mexicanos obedecen a una estrategia definida por el Ejército y sus actividades se extienden por todo el territorio nacional, en especial, Chiapas, Guerrero, Oaxaca, Michoacán y Veracruz.

México es un espacio geoestratégico para los intereses económicos norteamericanos y lo contempla al igual que muchos Estados en América Latina como una "reserva estratégica de recursos; como espacio receptor de inversiones que además permiten externalizar costos socioambientales; así como región exportadora de excedentes"(Delgado, 2011, p. 89-100).

En 2014 México, cuenta con una economía notable, tiene una clase media culta, y la cuarta parte de la juventud estudia en universidades"(Grillo, 2012, p.27-28), tristemente se caracteriza por poseer "miles de asesinos en serie. Incluso en los presidios, que están atestados, se producen matanzas espantosas" (Grillo, 2012, p.13). La escalada atroz de violencia ha sido atribuida al enfrentamiento de los cárteles de las drogas. No obstante, los factores son diversos para entender el fortalecimiento de los grupos de las ESol narcoviolentas.

El narcodinero que ingresa en México se presume son depositadas en "cámaras de seguridad de los bancos... los gustos ostentadores de los gánsteres también vierten mucho dinero en las empresas locales... pero el dinero de verdad funda compañías de tapadera. El Departamento del Tesoro de EEUU tiene en la lista negra más de doscientas empresas mexicanas que al parecer blanquean dinero de la droga... Calderón (trató) de remediarlo con más medidas para poner

92 School of the Americas (SOA), centro de capacitación para militares de Latinoamérica financiado por el ejército estadounidense - estrategias para la lucha contrainsurgente. Activistas de DDHH lograron su cierre pero reabrió en 2001 bajo el nombre Western Hemisphere Institute for Security Cooperation (WHISC). www.soaw.org. 
restricciones a los depósitos de dólares en metálico y presentando una importante ley sobre blanqueo de dinero en 2010... sin embargo, en un planeta globalizado, México no (impidió) totalmente que los barones de la droga muevan dinero líquido. Aunque salga de los bancos, el dinero puede ir a otra parte, por ejemplo a EEUU, o a los paraísos fiscales, o a China" (Grillo, 2012, p.238-240).

Las narcoutilidades reproducen las ESol narcoviolentas trasnacionales: "en Sudamérica el kilo de coca se compra en las zonas rurales en 2 mil 500 dólares, en tanto que entre distribuidores se comercia hasta en 45 mil. ¿Y la heroína) Un gramo de esta sustancia, con muy bajo grado de pureza, se consigue en las calles mexicanas a un precio equivalente a 10 dólares, pero con solo cruzar la frontera puede llegar a 318 dólares"(Ravelo, 2012, p. 243).

En México se considera a la cuna del narco-cultivo a los territorios de Sinaloa, Durango y Chihuahua y se le ha otorgado el nombre del "Triángulo Dorado, por toda la droga que producen" (Grillo, 2012, p.38). Los niños del triangulo dorado comienzan a trabajar a los 6 años y no van a la escuela generalmente... "El trabajo físico es arduo... en ocasiones los pequeños mueren envenenados por los potentes insecticidas, como el Tamarón... Algunos infantes también llegan a perecer por insolación"(Hernández, 2012, p.327).

Sintetizando la naturaleza jurídica de la ESol narcoviolenta, sin escándalos morales, el narcotráfico "no es más que una industria. Y como en cualquier industria, la mecánica de preparar y vender productos es más decisiva que las empresas y los ejecutivos... el comercio de droga es tan lucrativo en México que es una de las fuentes de riqueza más importantes del país. Rivaliza con las exportaciones de crudo para ayudar a estabilizar al peso. Proporciona miles de puestos de trabajo, muchos en las zonas rurales pobres... sus beneficios se extienden a... hostelería, ganadería, carreras de caballos, sellos discográficos, equipos de futbol y compañías cinematográficas" (Grillo, 2012, p.218-219).

Los habitantes de los Estados Superados por las ESol narcoviolentas, en especial, aquellos que carecen de los recursos mínimos para subsistir, siempre están propensos a ingresar "al comercio de la droga por desesperación... pero también prueban fortuna muchos elementos de la clase 
media y de la clase pudiente... las drogas son un buen negocio incluso para los ricos, y pocos tienen problemas morales para dedicarse a ellas" (Grillo, 2012, p.224).

El comercio ilegal ha "construido una extensa red de túneles que rivaliza con la de la Franja de Gaza... cada vez que tapan una pasadizo con cemento, se abre otro. No son simples conejeras. Los carteles contratan ingenieros... que construyen túneles de madera, suelos de hormigón, luz eléctrica, e incluso vagonetas y raíles para transportar la droga. Un pasadizo que llegaba hasta Otay Mesa, California, tenía 700 metros de longitud. Otros medía 150 y tenía la salida detrás de una chimenea de Tecate, México de aspecto totalmente inocente" (Grillo, 2012, p.230).

Para comprender el estadio narcoviolento mexicano empezaremos por realizar un recorrido sociopolítico del Estado durante el siglo XX y especialmente desde 1929, cuando el PRI gobernó casi la totalidad del sistema político azteca. El creador del partido fue el general Plutarco Elías Calles, quien posterior a su mandato presidencial, dio vida a la nueva agrupación política que pretendió unificar a los mexicanos bajo una misma ideología nacional influenciada por el totalitarismo comunista proveniente de la Unión Soviética así como del fascismo italiano. No obstante, en la historia política del PRI han gobernado tanto políticos de izquierda como auténticos capitalistas. No obstante debemos dejar claro desde ya que en México del Siglo XXI "el camino que conduce de la policía a la delincuencia está altamente transitado" (Grillo, 2012, p.15).

En 2010 "desertaron cien mil soldados del ejército mexicano... los jóvenes del campo se alistan...reciben la paga... por entrenarse y luego ganan dinero de verdad con la mafia" (Grillo, 2012, p.336). El Estado Superado poniéndose a disposición de las ESol narcoviolentas.

Buscaglia explicó que "la percepción en EEUU sobre México es grave y preocupante, el dinero del narco estaba vinculado a 78\% de las actividades legales mexicanas; además, el cartel de Sinaloa no solo esta afianzado en México, sino que ya se tienen registros serios de que está presente en 38 países. Por eso México se le ve como un peligroso exportador de violencia e ingobernabilidad"(Ravelo, 2012, p. 236).

Muchos analistas mexicanos coinciden en afirmar que desde sus orígenes "el régimen del PRI se basaba en la corrupción. Los empresarios pagaban un diezmo a los caciques de las ciudades 
medianas, que a su vez pagaban otro diezmo a los gobernadores, que a su vez pagaban al presidente. El dinero subía como la espuma y el poder bajaba como el agua. Todos estaban contentos" (Grillo, 2012, p.62-63).

\subsection{NARCO-CONDICIONANTES POLÍTICOS EXÓGENOS: LAS POLÍTICAS ESTATALES DE LOS EEUU}

Si bien los factores endógenos expuestos han ayudado a determinar las narco-dinámicas diferenciadas en Colombia y México, EEUU como factor exógeno, contribuyó, ha contribuido y sigue contribuyendo, en el diseño militarista antinarcótico fracasado. Veamos el recorrido contradictorio y dañino de la política estatal antinarcótica estadounidense.

La batalla frontal contra las drogas en EEUU la inició un fiscal que fue designado en el campo del control a la producción y tráfico de opio. Hamilton Wright en 1911 alertó de la epidemia que significaban las drogas en entrevista brindada a New York Times: El tío Sam es el peor toxicómano del mundo.

Consiguió en 1914 que 13 Estados ratificaran "un acuerdo para frenar la circulación de los opiáceos y la cocaína, y en diciembre de aquel mismo año el Parlamento de EEUU publicó la progenitora de la legislación antidroga de esre oapus, La Ley Harrison sobre Estupefacientes. No fue un prohibicionismo total, ya que el objetivo era controlar y no suprimir los productos. La medicina, entonces como hoy, necesitaba cierta cantidad de opiáceos autorizados. Pero la ley Harrison redundó inmediatamente en la aparición de un mercado negro del opio y la cocaína. Había nacido el narcotráfico" (Grillo, 2012, p.50-52).

Ahora bien, la entrada de México a la narcoviolencia contemporánea y en su fusión con la actividad de las ESol narcoviolentas trasnacionales se contextualiza desde la Ley Harrison, la cual creó una especie de narcoconsorcio entre la Dirección de Estupefacientes, "agentes de aduanas, los consulados y la Secretaría de Hacienda (que) unieron sus fuerzas para llevar a cabo la primera investigación estadounidense de importancia sobre los traficantes mexicanos" (Grillo, 2012, p.54). Resultando que en el ámbito del narcotráfico es posible afirmar que "fueron los estadounidenses quienes crearon la demanda y se fijaron en México como país proveedor" (Grillo, 2012, p.73). 
Las mismas dimensiones de intervención/injerencia que dieron origen a la historia de Al Capone (Grillo, 2012, p.57), se extendieron al narcotráfico, empezando por la regulación enfurecida contra el opio. Es necesario resaltar que "miles de años antes de que los gomeros de Sinaloa fabricasen heroína ya se conocían los efectos del opio. Las cápsulas de semillas de adormidera demuestran que los cazadores-recolectores de Europa rascaban la goma cuatro milenios antes de Jesucristo. Hacia el año 24000 AC, en el sur de Mesopotamia (el Irak actual), los primeros agricultores de la historia dibujaban adormideras en tablillas de arcilla y les daban el nombre de Hul Gil, planta de la alegría. Dos milenios después los egipcios escribieron sobre las adormideras en el llamado Papiro Abers, que es uno de los escritos de medicina más antiguos de la humanidad; y allí se dice que la adormidera es un remedio para evitar el exceso de llanto de los niños. Con el desarrollo de la civilización europea el opio se consumió desde Constantinopla hasta Londres. Pero donde más popular fue la flor fue en China, cuyos poetas decían que su goma era digna de Buda (Stuart, 2004, p. 82), y los fumadores de opio del país se contaban por millones. Los Chinos acabaron por ver el lado desagradable de su apreciada flor a fines del siglo XVIII, momento en que se elevaron crecientes quejas contra la adicción. En 1810, la dinastía Quing publicó un decreto prohibiendo la goma y condenando a muerte a los vendedores. $<<$ El opio es un veneno que mina las buenas costumbres y la moralidad>>(Lo-shu-fu, 1996, p. 380)... La prohibición propició la aparición de los primeros traficantes de drogas, que no eran sino educados caballeros del imperio británico... Cuando los soldados Quing empezaron a asaltar los barcos británicos, los galeones de la reina Victoria replicaron cañoneando la costa. Si la compañía de las Indias Orientales fue el primer cártel de la droga, la Marina Real fue la primera banda de matones a sueldo del cártel. Después de las dos guerras del opio, la compañía consiguió el derecho a traficar en 1860. Los chinos siguieron fumando y se llevaron consigo la adormidera cuando se dispersaron por el planeta. Desde 1860 los obreros chinos viajaron en vapor a Sinaloa para trabajar en el ferrocarril en las minas. Siguiendo su costumbre, los emigrantes chinos llevaban adormideras, goma y semillas para la larga travesía del Pacífico. La árida tierra de la Sierra Madre resultó un suelo ideal... en 1886 señalaba ya que la adormidera era parte de la flora de Sinaloa. La Flor había arraigado (Astorga, 2005, p. 18)” (Grillo, 2012, p.47-48). Una vez arraigada en la fauna mexicana la operación mental resulta muy comprensible, las adormideras sinaloenses se transformarían en dólares (Grillo, 2012, p.52-53).

Tras dicho contexto el opio sinaloense se incrementó de manera desbordada cuando llegó la década de 1940. Lo anterior ha sido argumentado como un resultado de la teoría de la 
conspiración norteamericana durante los acontecimientos deplorables de la IIGM. EEUU requería el "opio para fabricar morfina que necesitaban sus soldados... alcanzados por las bombas japonesas y alemanas. El abastecedor tradicional de adormidera de los laboratorios médicos estadounidenses era Turquía. Pero la guerra cortó las rutas de abastecimiento, ya que los submarinos alemanes patrullaban el Atlántico y hundían los buques mercantes. El Gobierno de Estados Unidos se dirigió entonces a los gomeros sinaloenses e hizo un trato con el Gobierno mexicano para que les dejaran plantar sus adormideras" (Grillo, 2012, p.63-64).

La ESol narcoviolenta echó raíces para transnacionalizarse. La narco-producción no encontraría tropiezos sino utilidades hasta la década de 1970 cuando Nixon llegó a la presidencia. Nixon decidió cerrar la frontera con México y diseñó la famosa Operación Interceptación cuyo objetivo fundamental era la fumigación de las plantas que anteriormente habían sembrado y que florecieron y arraigaron conjunto con los sembradíos de marihuana. Inicialmente, la operación encontró barreras por las consecuencias del uso del agente naranja en Vietnam. No obstante la Operación siguió su curso y terminó sin mayores éxitos tras caotizar la frontera y el comercio legal.

Tras el desconsuelo de los objetivos inalcanzados de la Operación Interceptación, los gobiernos de Norteamérica y México, decidieron adelantar conjuntamente la Operación Cooperación. A través de ésta operación "México se comprometió a tomar medidas enérgicas contra las plantaciones y permitió que agentes estadounidenses operasen al sur de la frontera. Y se desarrolló un nuevo modus operandi en la guerra contra la droga en el extranjero: obligar a los países implicados a destruir los productos en su lugar de origen. En 1971 Nixon aplicó esta táctica con Turquía... También presionó a Francia para destruir la llamada conexión francesa de laboratorios de heroína. Estas medidas tuvieron un serio impacto en la producción turca. Pero fue como agua de mayo para los productores sinaloenses, que ampliaron sus operaciones para cubrir el hueco... durante las elecciones generales de 1972, Nixon hizo de su lucha contra la heroína la piedra angular de su campaña" (Grillo, 2012, p.78).

Así "los estrategas del mundo aprendieron una valiosa lección: la guerra contra las droga es buena política. Con la fundación de la DEA en 1973, Nixon dejó una herencia aún más solida. Fundó la agencia mediante un decreto-ley destinado a <<establecer un solo mando unificado que emprenda una guerra total global contra la amenaza de la droga >> (Grillo, 2012, p.79)... una vez 
instalada en Washington, la DEA fue consiguiendo un presupuesto creciente con el paso de los años. Al principio contaba con 1.470 agentes especiales y con un presupuesto anual de menos de 75 millones de dólares. Hoy tiene 5.235 agentes especiales, oficinas en 63 países, y un impresionante presupuesto que supera los 2.300 millones de dólares" (Grillo, 2012, p.79).

En 1976 EEUU implementó una nueva operación denominada Cóndor mediante la cual 10 “mil soldados peinaron el Dorado, a Culiacán llegaron nuevos jefes de policía, gente dura... la DEA proporcionó aviones para fumigar las plantaciones: en la adormidera utilizaron ácido 2.4-D, y en las de marihuana, el herbicida tóxico Paraquat" (Grillo, 2012, p.84).

Ulteriormente los laboratorios estadounidenses detectaron la presencia de "Paraquat en la hierba mexicana... La mala prensa obligó a los distribuidores a buscar nuevas fuentes de hierba para millones de hippies hambrientos. No se tardó en encontrar un país con tierra, trabajadores y desorden para llenar el hueco: Colombia. Los agricultores venían plantando marihuana en la colombiana Sierra Nevada... intensificaron el cultivo, dando lugar a un periodo de expansión de la propia industria que los historiadores locales llamaron $<<$ bonanza marimbera $>>^{93}$. Los agentes de la DEA no tardaron en localizar la Santa Marta Gold hasta en las universidades de la Ivy League. Este desplazamiento geográfico de la producción de droga ha acabado conociéndose con el nombre de efecto globo. Según este símil, cuando se aprieta una parte del globo del narcotráfico, el aire se limita a desplazarse y a hinchar el resto" (Grillo, 2012, p.87).

En 1978 México determinó estar listo para continuar la erradicación de los cultivos sin la colaboración de los EEUU. En consonancia, Carter que presidió entre 1977 y 1981 "con su menos polémica actitud hacia las drogas no puso objeciones. Pero los agentes destacados se quejaron a sus superiores de que allí había una maniobra de ocultación. Los agentes de la DEA del lado estadounidense también se dieron cuenta de que la marina mexicana volvía a entrar a raudales; al parecer, se había olvidado el miedo a la hierba tóxica" (Grillo, 2012, p.89).

Posterior a 1985 las ESol narcoviolentas mexicanas cobraron importancia en la escena trasnacional al imprimir utilidades a su posición geoestratégica. Estar a "medio camino entre la fuente

93 Castillo, Fabio. (1987). Los Jinetes de la cocaína. Ed, Documentos Periodísticos, Bogotá, Pg, 18 - 21. GRILLO, loan. (2012). El Narco: en el corazón de la insurgencia criminal mexicana. Editorial Urano, S.A., Barcelona - España. P, 85. 
productora y los consumidores. La topografía de México, a lo largo del océano pacífico y las costas del Golfo, permitió que se instalaran incontables pistas de aterrizaje para la recarga rápida de combustible de los aviones que transportaban los enervantes. Igualmente significativa representaba la frontera terrestre de más de tres mil kilómetros entre México y EEUU, ya que más de 95 \% de la línea colindante no tenía vallas o barricadas. Estas eran condiciones inmejorables para que poderosos grupos de Guadalajara crearan sólidos lazos con la mafia colombiana en el tráfico de heroína, mariguana y cocaína a EEUU. Desde luego la DEA estaba el tanto de la peligrosa alianza" (Hernández, 2012, p. 140).

En 1986 y desde Reagan se "instituyó el problema del narcotráfico como de seguridad nacional... ha sido un fracaso, con muchos éxitos tácticos, pero un gran fracaso estratégico"(Youngers, 2005, p. 414).

Reagan y "su palabrería bélica, se convirtió en un arma de fuego en la Ley contra el Consumo de Drogas de aquel año... también aumentó los recursos de la DEA y las aduanas... a pesar de todo, la DEA aún tenía delante un gran obstáculo en América Central: La Guerra Fría. Durante los años ochenta, la región fue un frente de lucha contra el comunismo... la CIA invirtió más que nada en la red derechista de la contra nicaragüense, que se armaba y entrenaba en la vecina Honduras. Tanto los guerrilleros de la contra como los oficiales hondureños sacaban dinero de la cocaína" (Grillo, 2012, p.115).

\subsection{EFECTOS NARCOESTADOUNIDENSES EN TERRITORIO AZTECA}

En 1988 Carlos Salinas de Gortiari asumió la presidencia de México hasta el año de 1994, tiempo durante el cual se evidenció un milagro económico que se desvaneció por completo tras el fin de su mandato, generando una enorme crisis en México. Ante lo cual el gobierno de EEUU en aquel entonces liderado por Bill Clinton, fiel colaborador de Salinas, inyectó miles de millones de dólares a la economía mexicana. Salinas fue capturado en la presidencia de Ernesto Zedillo "por cargos de asesinato y enriquecimiento ilícito" (Hernández, 2012, p. 195). 
Concomitante con la crisis "el tráfico de drogas siguió ingresando miles de millones de dólares y, como cobraba en dólares, la devaluación del peso dio más poder al narcotráfico. Dado el desempleo vigente, los carteles pudieron reclutar soldados por menos dinero que antes... el consumo de droga dura se multiplicó" (Grillo, 2012, p.142).

Los nexos entre la familia de Salinas y las ESol narcoviolentas se cristalizaron con Juan García Ábrego y el cartel del Golfo, por la amistad entre "don Raúl Salinas Lozano y Juan N. Guerra, el padrino y creador de Juan García Ábrego... en aquella época no existía una guerra frontal entre los cárteles... había una convivencia civilizada donde todos gozaban de protección oficial; sobre todo los carteles del Golfo y de Juárez, que inclusive llegaron a asociarse para el traslado de cargamentos de estupefacientes a EEUU"(Hernández, 2012, p. 191).

Entrada la década de los 90 los carteles mexicanos se especializarían en el envío de drogas a EEUU mientras recaudaban "miles de millones de dólares gracias al auge del libre comercio instaurado por el NAFTA (Tratado de Libre Comercio de América del Norte)" (Grillo, 2012, p.16).

En aquel momento, los capos del narcotráfico mexicano eran Juan García Ábrego del cártel del Golfo, Amado Carrillo Fuentes y los Hermanos Arellano Félix. Los 3 saldrían de escena en la misma década: Ábrego se entregó en 1996; Amado según la versión oficial murió en una intervención de cirugía plática; Ramón Arellano Félix, "el psicópata... en 2002 un policía del centro turístico de Mazatlán lo mato de un tiro... Un mes más tarde, fuerzas especiales del ejército detenían a Benjamín" (Grillo, 2012, p.146).

Al desaparecer Amado "la organización del Pacífico quedó formalmente dividida en dos: el cartel de Sinaloa, liderado por El Mayo Zambada, y el cartel de Juárez, comandado por el Viceroy aunque los dos grupos siguieron haciendo algunos negocios conjuntamente, el gran poderío disminuyó"(Hernández, 2011, p. 221).

El cártel del golfo tiene su zona de acción a lo largo de "Tamaulipas, su principal centro de operaciones, a Cohauila, Nuevo León, Durando, Zacatecas, San Luis Potosí, Aguascalientes, Hidalgo, Estado de México, Distrito Federal y Puebla, además de toda la costa del Golfo de México, donde se integran Veracruz, Tabasco, Campeche, Yucatán y Quintana Roo, e incluso cuenta con 
presencia en Michoacán, Guerrero, Oaxaca, Jalisco y Chiapas. Juan García Ábrego y Osiel Cárdenas Guillén conformaron la identidad de este grupo criminal. Sobre todo, llama la atención cómo el último de ellos tomó una decisión sin precedentes al insertar en el aparato de dirección a sus sicarios: Los Zetas. La organización criminal funcionó bajo este esquema hasta principios de 2010, cuando sucedió lo que siempre se advirtió: el grupo de sicarios se rebeló contra sus creadores... esta confrontación tiene actualmente al estado de Tamaulipas sumido en su peor crisis de inseguridad, al grado de que hasta un candidato a gobernador en este estado fue asesinado por un comando de los Zetas, al parecer en venganza porque ese político tenía acuerdo con el cártel del Golfo. Hasta noviembre de 2012, los jefes visibles... eran Jorge Eduardo Costilla, el Coss, y Antonio Ezequiel Cárdenas Guillén, Tony Tormenta, pero la muerte del segundo... en 2010 a manos de infantes de marina, ubicó al Coss como el nuevo y absoluto capo de esa organización criminal. Precisamente, ahora el nuevo líder absoluto del grupo pretende enfrentar a sus ex aliados, Los Zetas... Se prevé... una mayor ola de violencia en el Estado de Tamaulipas" (Garay, 2012, p. 166).

En 2014 los enemigos del Cártel del Golfo son el de Sinaloa y los Zetas. La Familia "anteriormente se hacía llamar La Empresa, asociada a la organización de Tamaulipas... fue una escisión de Los Zetas, grupo de exmilitares de élite autodenominados de esa manera, cooptados en 1999 por Osiel Cárdenas, líder de la organización de Tamaulipas o Golfo"(Garay, 2012, p. 238).

Bajo la idea de cooptar territorios del cártel del Golfo y el escindido grupo mercenario de los Zetas, en el año 2001 se consolidó el primer narco-pacto mexicano de alcances nacionales. La Federación se basó en compartir las narco-rutas y sumaron "las operaciones de 16 entidades federativas, más de la mitad del país: Sinaloa, Sonora, Chihuahua, Coahuila, Durango, Colima, Jalisco, Nayarit, Morelos, DF, Estado de México, Yucatán, Quintana Roo, Guanajuato, Aguascalientes y Querétaro. En la cúspide... se situó Joaquín Guzmán Loera como coordinador y se estableció un liderazgo vertical... él tenía el arreglo con el gobierno federal desde la Presidencia Fox... (El Chapo) dirigió una red de transportes de drogas a gran escala traficando mercancía ilegal en transporte terrestre, aéreo y marítimo, embarcando numerosas toneladas de cocaína de Sudamérica, transportándolas por Centroamérica y México, hasta finalmente desembarcarlas en $\mathrm{EEUU}^{94}$. De vez en cuando ocurrieron luchas internas entre los integrantes de la agrupación, pero

94 Tribunal del Distrito Este de Nueva York, F. núm. 2009R01065/OC-DETF\#NYNYE-616. 
lograron reducirlas al máximo y aseguraron su protección común política y judicial”(Hernández, 2012, p.364 -365).

Una especie de narco-incoterms rigieron las actividades de la Federación, que actuó casi como el sindicato de las ESol narcoviolentas transnacionalizadas del nuevo milenio en México. En la Federación el Mayo seguía al Chapo. Hombre de "extracción muy humilde... comenzó a dedicarse a la siembra de mariguana y amapola... su adorado hijo Vicente Zambada Niebla que era su brazo derecho en los negocios del narcotráfico. Mientras que su hermano, Reynaldo... es su brazo izquierdo y su principal operador... El Mayo fue iniciado en el narcotráfico por José Inés Calderón Quintero, quien entre... 1970 y 1980 fue uno de los principales jefes del narcotráfico en Sinaloa y en el país ${ }^{95}$... (en 2014) Zambada García es el más experimentado de todos los capos. Su nombre aparece en todos los expedientes clave del narcotráfico en México. Por ejemplo, en el llamado Maxiproceso, investigación por la cual el ex gobernador de Quintana Roo Mario Villanueva Madrid se encuentra tras las rejas en el vecino país del norte. Asimismo, el Mayo está involucrado... en el polémico expediente del Grupo Financiero Anáhuac, que puso en jaque y evidencia a miembros del PRI y el PAN... El Mayo tenía el personal, las rutas y los contactos en EEUU, sólo se trataba de comercializar otro producto. Cuentan que cuando inició en el negocio del polvo blanco lo transportaba a través de sus empresas lecheras... lo critican porque supuestamente él es el verdadero jefe de El Chapo, pero prefiere que su compadre jale los reflectores" (Hernández, 2012, p. 365-367 y 371-372). Si esto es así la estructura de sinaloense sigue intacta y craneando su futuro, con el Chapo resguardado de sus enemigos tras las rejas estatales.

Fue por iniciativa del Azul, Juan José Esparragoza, que en el año 2002 se abrió el "nuevo frente de batalla, ahora contra el cartel del Golfo, y acabar con Los Zetas"(Hernández, 2012, p. 405). EEUU lo llama The Peace Maker (El Pacificador), quien privilegia los lazos de sangre en sus narcorelaciones y es quien tiene la capacidad de caerle bien a todos, podría ser la monedita de oro de las ESol narcoviolentas mexicanas actuales. Siempre tiene las palabras precisas y esto le ha permitido utilizar las rutas de sus competidores y hasta lograr negocios mancomunados.

El azul fue uno de los "hombres de confianza de Amado Carillo Fuentes, no como su lugarteniente, sino como su negociador en México y Colombia... hay gente que piensa que El Azul será el gran

95 Proceso, núm. 1744, 4.4.2010. 
vencedor de la guerra entre los narcotraficantes y que su mejor época está por venir"(Hernández, 2012 , p. $384-385$ y 388$)$.

Es de resaltar que "las batallas han sido desiguales. Los ejércitos con los que cuenta uno y otro bando son disparejos. El de Guzmán Loera y sus compañeros esta conformado prioritariamente por altos funcionarios públicos del gobierno federal... (tan frecuente) que parece una política de gobierno... Dos años después de haberse creado la Federación, con el apoyo del gobierno federal, en 2003 Joaquín Guzmán Loera y sus socios decidieron iniciar una nueva guerra. Las baterías que estaban dirigidas al cartel de Tijuana se enfocaron hacia el cartel del Golfo"(Hernández, 2012, p. 395).

Sería este año donde empezaría a gestarse la lucha fratricida que se desarrolló entre el cártel del golfo y el cártel de Sinaloa... en Tamaulipas cuando el Chapo decidió "disputarle la plaza de Nuevo Laredo"(Garay, 2012, p. 234), a Osiel.

En 2005 la AFI se perfiló como aliada de La Federación a través del programa México Seguro. Vicente Fox puso "en marcha un operativo militar, auxiliado por las corporaciones civiles" (Hernández, 2012, p. 442) como las CONVIVIR en Colombia.

En el mismo año, se registró que la "AFI comenzó a operar de lleno con... El Chapo... La agencia... integró escuadrones de la muerte para secuestrar, torturar y ejecutar a los adversarios de La Federación. A cambio, el grupo delictivo - por medio de los hermanos Beltrán Leyva, que administraban la narco-nómina - entregaban maletas y maletas llenas de dólares que crearon súbitas fortunas entre los jefes de la AFI; la más visible e inexplicable: la de Genaro García Luna"(Hernández, 2012, p. 414).

Fue en el año 2007 cuando diversos miembros tanto de La Federación como del Cártel del Golfo celebraron varias narco-cumbres para prever controles a los elevadísimos índices de narcoviolencia entre dichos consorcios pertenecientes al sector de las ESol narcoviolentas.

Lo anterior "parecía algo impensable. Pero el negocio es el negocio. La beligerancia entre las organizaciones les estaba costando mucho dinero y muchas bajas; incluso los respectivos 
contactos de cada grupo en Colombia comenzaron a dudar si sus contrapartes mexicanas seguían siendo confiables... en aquella época los envíos de cocaína de Colombia a México disminuyeron sensiblemente... el pacto inicial fue el cese a la violencia. Se acordó que se repartiría el territorio... y que no se agredirían a las autoridades en los territorios donde operaban. Así el cartel del Golfo se quedaría con Tamaulipas, Coahuila, Veracruz, Tabasco, Campeche y Quintana Roo. Mientras que la Federación tendría Sonora, Sinaloa, Durando, Chihuahua, Nayarit, Jalisco, Guerrero, Guanajuato, Querétaro y Oaxaca. Entidades como Nuevo León, Michoacán, DF, y el Estado de México, cada grupo se quedaría con la parte conquistada... mientras que Aguascalientes, San Luis de Potosí, Zacatecas y Puebla serían una especie de lugares neutrales. Además acordaron, a petición del gobierno federal, intentar acabar con el narcomenudeo y que en la mayor parte de la droga saliera de México. De todos los acuerdos ese sería quizá el más difícil de cumplir" (Hernández, 2012, p. 486-489).

La traición no tardó en llegar: "Vicente Carrillo Fuentes, Sergio Villareal, Edgar Valdez Villareal y el cartel del Golfo se aliaron con el líder del clan de los Beltrán Leyva. Entendieron que si El Chapo y El Mayo fueron capaces de entregar a Alfredo y de intentar que cayera el Barbas, los que seguían eran ellos. La Barbie y El Verdugo, los dos brazos armados, nunca se entendieron del todo bien, pero quedaron juntos en una misma organización y con un mismo propósito: acabar con Guzmán Loera y su clan. Así se generaron dos grandes bandos de narcotraficantes en México: El cártel de Sinaloa, encabezado por el Chapo y el Mayo, y el cartel de los Beltrán Leyva, unidos al Cartel de Juárez, al del Golfo y a lo que quedaba del Cartel de Tijuana. La ruptura en el núcleo de la Federación traería una guerra nunca antes vista en el país" (Hernández, 2012, p. 485-496).

El contador de El Chapo, Amado Carrillo y Héctor Palma Salazar fue Miguel Ángel Segoviano Berbera, quien llevado a juicio manifestó que el primero de ellos "construyó un túnel de 350 metros de longitud y 25 metros de profundidad para mover drogas, indocumentados y también armas en la línea fronteriza de California y Arizona: Guzmán operaba en una cadena que empacaba cocaína en latas de chiles jalapeños. La droga se exportaba a EEUU a través del ferrocarril. A cambio de la droga Guzmán llevó a México millones de dólares empacados en maletas que eran transportadas por avión y llegaban al aeropuerto de la ciudad de México. Se sobornaba a los agentes federales para asegurarse de que no hubiera inspecciones" (Hernández, 2012, p. 172). 
En los hallazgos encontrados en los documentos del contador se evidenció información relativa a la narco-nómina y movimientos precisos de compras y gastos así como nombres de personas y las respectivas cantidades de dinero entregadas a cada quien.

Entre tantos vínculos, "los investigadores de la Fiscalía Especial descubrieron que Segovia... además de estar vinculado con Galce Constructora, S.A. de C.V., también formaba parte de otra compañía llamado Aero Abastos, la cual poseía aviones que se ubicaban en un hangar del Aeropuerto Internacional de la Ciudad de México... lo que se movía en las aeronaves... era droga y dinero... En aquellos días los capos contaban con la ayuda de los hermanos José Luis, Antonio y Jesús Reynoso González... (quienes se establecieron en Los Ángeles como comerciantes de productos enlatados a través de las empresas Reynoso Brothers, Tía Anita, Grocery Depot y Cotija Cheese. Es a ellos a quienes les llegaban las latas de chiles jalapeños con cocaína" (Hernández, 2012, p. 182-185).

Ahora bien, antes de la aprensión del Chapo en 2014, EEUU “ofrecía 5 millones de dólares por la captura del narcotraficantes y 25 millones de dólares por el responsable de los ataques terroristas del 11 de septiembre de 2001 en Nueva York"(Dávila, 2012, p. 133).

En febrero de 2014 el Chapo fue capturado en Guatemala y ésta fue celebrada "entre otros por la Marina mexicana, la DEA estadounidense y el Gobierno priísta de Enrique Peña Nieto... (se) desarrolló sin disparar un solo tiro... los antecedentes del caso abren muchos interrogantes... propone algunas hipótesis: 1. El arresto del Chapo podría ser fruto de una negociación de alto nivel; 2. No hay indicios de que hayan caído otros jefes y no se está desarticulando la poderosa estructura financiera y de lavado que tiene el cartel de Sinaloa; 3.Pareciera que no va a prosperar el pedido de extradición solicitado por EEUU. Como hipótesis se podría conjeturar que el Gobierno del PRI quiere volver a ser un gran ordenador en las pugnas entre los carteles. El arresto del Chapo marca el fin de cierto favoritismo que tuvo bajo el régimen panista, pero de ninguna forma significa el final del cartel" (Cieza, 2014, p.2).

Por el contrario el Cártel de Sinaloa en 2014 es el "más poderoso y peligroso en México... se distingue por mantener diversos frentes de la lucha con otras organizaciones. Abarca Sinaloa, 
Coahuila, Durando, Chihuahua, Sonora, Baja California, Tamaulipas, Nayarit, Jalisco, Guerrero, Michoacán, Colima, Veracruz, Aguascalientes, Estado de México, Morelos, Tabasco, Campeche, Chiapas y hasta el Distrito Federal" (Garay, 2012, p. 165).

\subsection{NARCO-CONTEXTUALIZACIÓN AZTECA}

Empecemos entonces retornando a los orígenes de las organizaciones que nos proveen el escenario narcoviolento actual.

La familia Carrillo Fuentes lidera el cártel de Juárez o La Línea, dirigida por "Vicente Carrillo Fuentes, hermano del extinto Amado Carrillo Fuentes, conocido como el Señor de los Cielos... Su centro de operaciones se ubica en Chihuahua, específicamente en Ciudad Juárez, pero su influencia se extiende a Sonora, Coahuila, Sinaloa, Durango, Nayarit, Jalisco, Morelos, Tamaulipas, Veracruz, Quintana Roo, Chiapas, Zacatecas, Michoacán, Querétaro, Oaxaca, Puebla, Nuevo León, Yucatán, Campeche, Estado de México y el Distrito Federal, principalmente. En 2012, la Línea mantiene en Chihuahua una lucha fratricida contra quienes en el pasado fueron sus aliados, el Mayo Zambada, el Chapo Guzmán y miembros de la organización del extinto capo Ignacio Coronel. De hecho, el estado de Chihuahua ocupa por esta razón el primer lugar entre las entidades estatales con mayor violencia en México" (Garay, 2012, p. 164).

Los hermanos Arellano Félix lideraron el cártel de Tijuana ubicado principalmente en Baja California y con centro de operaciones en Tijuana, cuya ventaja geoestratégica reside en ser uno de los pasos fronterizos más importantes hacia California, uno de los principales centro de consumo. Su influencia también se extiende Baja California Sur, Sonora, Sinaloa, Nayarit, Jalisco, Michoacán, el Estado de México y el Distrito Federal.

Es necesario aclarar que Sinaloa representa la "cuna de las bandas mexicanas, el punto de origen de la más antigua y poderosa red de narcotraficantes... Las autoridades estadounidenses... antes lo llamaban la Federación, y antes empleaban un abanico de nombres, por ejemplo cártel de Guadalajara" (Grillo, 2012, p. 39). 
Generándose especies de narco-fronteras invisibles del Estado soberano Superado, en el que "las pandillas fueron absorbidas por la guerra de la droga... (donde) el precio de una vida humana en Ciudad Juárez es de 85 dólares...según la legislación mexicana, los menores sólo pueden ser condenados a un máximo de cinco años de cárcel sin que importe cuántos asesinatos, secuestros o violaciones hayan cometido" (Grillo, 2012, p. 268).

Este cártel tiene actividades especializadas y se "dedica en $90 \%$ al tráfico de drogas al extranjero y en $10 \%$ al narcomenudeo en Ciudad Juárez... además obtiene recursos de los secuestros, robos, extorsiones, asaltos a comercios y bancos, ejecuciones, contrabando, piratería, tráfico de personas y de armas y falsificación" (Dávila, 2012, p.57).

Desde la década del 90 instaló franquicias en Guatemala "y estableció lazos con los capos locales del narcotráfico para traficar drogas provenientes de Colombia. Igual que lo hicieron con el cartel del golfo... Hasta 2007 cuando se empezó a detectar la presencia de los Zetas, el movimiento de las drogas se efectuaba sin violencia en un acuerdo táctico de no agresión entere los carteles locales, el de Sinaloa y el del Golfo"(Carrasco, 2012, p. 153-154 y 156). Igualmente entre 2006 y 2007 "la Policía realizó 16 operativos contra células ligadas a los cárteles mexicanos del narcotráfico que operaban en Nicaragua"(Fonseca, 2012, p. 153-162).

Sin duda "el roce más importante de principios de los años noventa se produjo entre los hermanos Arellano Félix y... el Chapo, por el tráfico destinado a California” (Grillo, 2012, p. 133). El Chapo, "el mayor de seis hermanos que apenas se llevan un año... Armida, Bernarda, Miguel Ángel, Aureliano, Arturo y Emiliano. Tuvo otros tres hermanos mayores que él pero murieron de la enfermedad de la pobreza cuando era muy pequeño; ni sus nombres recuerda... apenas estudió el tercer grado de primaria... hay quienes afirman que... se enlistó en las filas policiacas, donde conoció a Miguel Ángel Félix Gallardo, un miembro de la Policía Judicial de Sinaloa desde 1963 que trabajaba como escolta del entonces gobernador Leopoldo Sánchez Celis. A mediados de la década de 1970... Félix ingresó en el mundo del narcotráfico. El primer registro que se tiene del Chapo en el ámbito criminal es como chofer de Félix Gallardo... Guzmán fue escalando posiciones porque era inventivo... No obstante... era impulsivo, violento, caprichoso, parrandero y le gustaba tomar de más... todo el poder que Guzmán Loera tenía en esa época se sujetaba a la voluntad de Amado Carrillo Fuentes... la protección a El Chapo por parte de las autoridades de la PGR duró hasta que 
Carillo Fuentes lo quiso. Cuando Joaquín... llegó a la cárcel de máxima seguridad de Almoloya de Juárez, en el Estado de México... le cayó el veinte de que esa protección se había terminado"(Hernández, 2012, p. 57-59).

El chapo o petizo, que alcanza una estatura de 1.68 metros y clasificado por la Revista Forbes como uno de los hombres más ricos del planeta, primo de Arturo Beltrán Leyva, alias el Barbas, que durante la década del 90 trabajó para Amado Carrillo Fuentes, quienes junto "con un equipo integrado por lugartenientes, empresarios y servidores públicos, enviaban grandes cargamentos de cocaína a EEUU por medio de una extensa flota aérea compuesta por aviones como los Boeing 727, y de menor tamaño como los King Air, Learjet y Velocity, cuya detección a través de los radares era casi imposible, por lo que se convirtieron en un dolor de cabeza para la DEA. También usaban lanchas y embarcaciones de mayor tamaño que descargaban la droga proveniente de Colombia en las costas de Yucatán, Quintana Roo y Veracruz, así como en una vasta zona del pacífico. En las aeronaves cargaban voluminosos embarques de hasta 10 mil kilos de cocaína y trasportaban millones de dólares de ganancias" (Hernández, 2012, p. 332-333).

El Barbas empezó a representar un riesgo para el Chapo por el poder que empezaba a adquirir en la narco-industria y "tampoco le gustaba que las lealtades de su primo fuera más cercana a Vicente Carillo Fuentes que a él. El asesinato de Rodolfo Carillo Fuentes, ordenado por el Mayo Zambada y consentido por El Chapo, fue una herida que nunca cicatrizó. La relación de los líderes del cartel de Sinaloa con el Viceroy pendía de alfileres, y les daba temor la estrecha relación que El Barbas tenía con él. Aunque los Beltrán Leyva todavía eran parte de la Federación en 2007" (Hernández, 2012, p. 279-481).

El Barbas posterior a desarrollar su carrera gerencial en la ESol narcoviolenta, fue la diana que "Ios militares cosieron a balazos... hasta hacerlo picadillo y luego decoraron el cadáver con billetes de un dólar" (Grillo, 2012, p. 38). El Barbas comenzó la guerra matando al hijo del Chapo que nada tenía que ver con el narcotráfico. En contraposición el Chapo inició la guerra en Culiacán.

El cártel de los Beltrán Leyva "otro clan familiar convertido en un cártel es el que ahora con la muerte de su hermano Arturo Beltrán Leyva, el Barbas, dirige Héctor Beltrán Leyva... En la escena nacional el grupo causó y causa gran conmoción al participar en cruentos enfrentamientos, 
primero contra los Zetas - que son sus aliados - en Nuevo León, Tamaulipas y Guerrero, y últimamente contra sus ex socios, los miembros del cartel de Sinaloa, lucha que alcanza a los estados de Sinaloa, Jalisco, Estado de México, Morelos y el Distrito Federal... Las venganzas entre ambos grupos es de tal magnitud que ahora el estado de Sinaloa se encuentra dividido por zonas, pueblos y barriadas que pertenecen a uno u otro bando. Sin dar ni pedir tregua, los Beltrán Leyva tuvieron en Édgar Valdés Villareal, La Barbie, su principal escudo y arma de ataque para enfrentar a sus enemigos. O, al menos, eso pensaron... hasta diciembre de 2009, cuando al conocerse los pormenores de la muerte de... el Barbas, acusaron a la Barbie detenido en septiembre de 2010, de traicionarlo y facilitar su asesinato. Se abrió un nuevo frente de batalla, ahora con éste último y su gente. Las confrontaciones han provocado una ola de asesinatos entre los dos bandos en Guerrero, Morelos y El Estado de México, que ha provocado una serie de operativos militares de gran escala para capturar a los líderes... los Beltrán Leyva están señalados por su poder corruptor y de infiltración. Son protagonistas del mayor escándalo de corrupción oficial de la última década dentro de la llamada Operación Limpieza, pues lograron infiltrar no sólo la estructura y mandos del organismo más importante de lucha contra el narcotráfico en México, la Subprocuraduría de Investigación Especializada en Delincuencia Organizada (SIEDO), sino hasta la embajada de EEUU, donde tuvieron un informante"(Garay, 2012, p. 168-169).

El polémico Chapo se sometió a intervenciones quirúrgicas para no ser aprehendido. Le "recortaron las mejillas, le restiraron la piel y le desaparecieron las arrugas... también hizo a un lado a varios de sus rivales"(Ravelo, 2012, p. 245). Identificado "como el capo del panismo" (Carrasco, 2012, p. 222) pues de "2 mil 604 detenidos y procesados por la PGR, solo 303, es decir $11.64 \%$ pertenecían al grupo del Chapo... de acuerdo con los datos... las organizaciones más combatidas han sido el cartel del Golfo y Los Zetas" (Carrasco, 2012, p. 228). Igualmente durante el gobierno de Calderón: "de las 53 mil 147 detenciones realizadas durante los últimos 4 años, ligadas... a delincuencia organizada, sólo 941 (correspondieron) al Cártel de El Chapo Guzmán” (Hernández, 2012, p. 483).

Mientras el joven narcotraficante ascendía en la carrera de las ESol narcoviolentas, Armando Carrillo decidió enviarlo de Guadalajara a Nayarit para que se enlistara en la estructura liderada por Héctor El Güero Palma. "Sin embargo, el Chapo no obedeció la orden... en su lugar mandó a 
Martín Moreno Valdés a Tepic; al mismo tiempo le encargó a José de Jesús Alcalá Castellín que fuera a Guatemala a comprar algunas fincas" (Hernández, 2012, p. 30).

El Chapo según la PGR y organismos de inteligencia fundó "campos de adiestramiento para su gente en los estados de Sinaloa, Sonora, Tamaulipas y Nuevo León. Además... habría reclutado a personas en El Salvador (en particular maras), Guatemala y Panamá. Con ellos pretendía reforzar a sus grupos de sicarios conocidos como Los Pelones y los Talibanes. Edgar Valdez Villareal y Jesús Méndez (mencionado como uno de los líderes de la llamada Familia Michoacana), serían los encargados de esa estrategia" (Garay, 2012, p. 236).

En 1992 resultó ileso de un atentado orquestado por Ramón Arellano Félix y desde aquel momento se desató una verdadera narco-guerra en México. Sufrió un segundo atentado en 1993. Pero éste polémico hecho reveló lo profundo del narco-impacto en la sociedad mexicana de la década del 90. Lo anterior, porque la muerte del Cardenal Juan Jesús Posadas Ocampo en el Aeropuerto Internacional de Guadalajara, afirmó el poder superador de los grupos de las ESol narcoviolentas frente al Estado mexicano.

Las primeras declaraciones sobre la muerte del Cardenal rendidas por el Chapo ocurrieron en el avión que lo transportó desde Guatemala a México y que quedarían asentadas el 9 de julio de 1993 en el oficio número 1387 de la Procuraduría General de Justicia Militar donde sostuvo que "se puso pecho en tierra y se fue arrastrando en el suelo hasta llegar a la sala... ninguno de mis hombres disparó porque sus armas se fueron en las maletas que ya habían sido documentadas... (echando) por tierra la versión (estatal que el Cardenal) había sido víctima del fuego cruzado entre la banda de los Arellano Félix y la de Guzmán Loera... en su confesión... Guzmán Loera admitió que trabajaba para el Cártel de Cali, entonces comandado por los hermanos Rodríguez Orejuela. Aunque sus verdaderos vínculos estaban con el cártel de Medellín de Pablo Escobar Gaviria" (Hernández, 2012, p. 50-53).

Lo revelador de la confesión del Chapo no le cayó en gracia al Estado mexicano por lo cual fue obligado a cambiar el parlamento, el cual finalizaría de la siguiente manera: "no tengo ninguna relación con ninguna persona en Colombia y no es verdad que me dedico al tráfico de droga" (Hernández, 2012, p. 63-64). El Chapo fue amenazado por un alto funcionario del gobierno federal, 
quien le advirtió que lo matarían si no modificaba la versión que había hecho... no tenía alternativa: o cooperaba o se moría" (Hernández, 2012, p. 60).

Así se desarrolló la detención en 1993 del Chapo quien dos años después lograría "su traslado al penal de máxima seguridad de Puente Grande... (donde) se rencontró con su viejo socio Héctor Palma Salazar, recluido ahí desde el 27 de junio de 1995. El Güero había ganado fama y poder trabajando para Amado Carillo desde 1993, cuando ambos entregaron a El Chapo" (Hernández, 2012, p. 209).

En 1999 el Chapo y el Güero que hacían su ley en la cárcel de Puente Grande así como lo hizo Pablo Escobar en su momento en La Catedral, siguieron construyendo su narco-vivienda cuando influenciaron el nombramiento del "comandante Dámaso López Núñez como subdirector de seguridad del penal, y (cuando) Leonardo Beltrán Santana regresaba a dirigir... más que enviado por la SEGOB, López Núñez parecía enviado por sus socios: El Chapo traía padrino. El nuevo subdirector llegó acompañado por un equipo de colaboradores que se hacían Ilamar Los Sinaloas... Todos ellos corruptos de pies a cabeza" (Hernández, 2012, p. 227-229).

El Chapo, El Güero Palma y Arturo Martínez Herrera, el Texas "miembro del cartel del golfo... con el apoyo del comandante Dámaso y Los Sinaloas, eran invencibles... los Tres comenzaron a pagar la llamada Nomina Bital, quizás porque el que no quería entrar... se moría... sin recato se permitía que en el penal se filtraran celulares, prostitutas, licor, cocaína y alimentos procedentes de restaurantes" (Hernández, 2012, p. 237-239).

Un ejemplo de la amalgama criminal construida por la ESol narcoviolenta mexicana, lo representa Ignacio Coronel, conocido como el Rey del Cristal, un policía que se volvió narco y lideró el transporte de droga sintética. Entró al narcotráfico por Amado Carrillo Fuentes y entrando la década de los 90 trabajó con "el Güero Palma, el Chapo, El Mayo, los hermanos Beltrán Leyva y Juan Esparragoza. En 1995 con la detención de El Güero Palma, Nacho Coronel se fortaleció en el negocio al acaparar la plaza de Guadalajara. Y procedió... a exterminar a sus más fuertes competidores... Nacho tenía bajo su mando a los hermanos Luis y Ernesto Rodríguez Olivera, mejor conocidos como los Güeros o los Güeritos, a quienes la DEA investigó durante todo el sexenio de Vicente Fox porque presuntamente eran una de las conexiones de la familia del presidente con La 
Federación... entre sus clientes están el cartel de Juárez y la Federación, así como los colombianos Javier y Víctor Mejía Munera. Recibe directamente cocaína de Colombia y emplea una red de grandes almacenes para guardarla y después distribuirla tanto en México como en EEUU" (Hernández, 2012, p. 381-383).

Una plaza es "una jurisdicción que depende de una autoridad policial... Sin embargo, los contrabandistas se apropiaron del término para referirse al territorio concreto que servía de pasillo para realizar el tráfico... En cada plaza apareció una figura para coordinar el tráfico y negociar la protección de la policía" (Grillo, 2012, p. 90.91).

En 2001 el Chapo se fugó, o mejor, se fue de la cárcel y aquél día "comenzó una jornada particularmente activa. A las 10 am tuvo un partido de volibol... a las 11 comenzó a recibir visitas en su celda... eran tantas las personas que se querían despedir de él que a las dos de la tarde... no se presentó en el comedor" (Hernández, 2012, p. 290).

Después de 8 años en las comodidades de la prisión y en compañía de sus amigos del alma "convocó a los capos que le eran leales y estableció objetivos claros: la expansión del cártel de Sinaloa a todo el territorio nacional y más allá de las fronteras y el fin de los carteles rivales: el de Juárez, con los Carrillo a la cabeza; el de Tijuana, de los Arellano Félix; y el de los Zetas, derivación del Cártel del Golfo... tras la extradición de Osiel Cárdenas, este último... se ha ido plegando a las órdenes de Guzmán Loera y de su compadre y segundo abordo, Ismael el Mayo Zambada"(Rodríguez, 2012, p. 11-12).

En 2002 la justicia federal mexicana "absolvió a los narcotraficantes Héctor El Güero Palma y Arturo Martínez El Texas del delito de evasión de reos por la fuga de Joaquín El Capo Guzmán. El tribunal argumentó falta de pruebas y además les revocó el delito de delincuencia organizada" (Hernández, 2012, p. 310).

Desde 2002 la organización criminal de Tijuana perdió poder pues el Estado mexicano lo había decapitado y exterminó la mayoría de sus miembros. El panismo no luchaba contra "el narcotráfico sino contra los enemigos de la Federación...hay muchos que piensan que la brillante idea de crear un sindicato de narcotraficantes fue una sugerencia de la DEA, cuyos agentes 
visitaron a Guzmán en prisión para que les proporcionara información sobre los Arellano Félix" (Hernández, 2012, p. 363).

El hijo del Señor de los Cielos, Vicente Carrillo Leyva, fue detenido en 2009 por dirigir la organización, ahora liderada por su tío Vicente Carrillo Fuentes, el Viceroy, y reveló los vínculos de su padre con las FFAA y magnates empresarios. En 2014, “Fernando Sánchez Arellano, sobrino de los Arellano Félix, el Ajustador, está encargado de la dirección del cártel; enfrentó con éxito la insubordinación de Eduardo García Semental, el Teo, quien le disputó el mando del grupo criminal hasta su reciente captura en 2010" (Garay, 2012, p. 163-164). Según "fuentes de información del gobierno de México afirman que después de su supuesta muerte, el Señor de los Cielos estuvo durante una larga temporada en Cuba" (Hernández, 2012, p. 220-221).

Finalizando la década de narco-bonanza, México regresó a un esquema de alternancia en su sistema federal democrático después de 75 años del protagonismo presidencial y en las mayorías de las entidades territoriales del PRI. Vicente Fox presidió desde el año 2000 como el nuevo representante del Partido de Alternancia Nacional - PAN-. El ex ejecutivo de CocaCola calmó temporalmente los ánimos mexicanos pero al terminar su mandato México dejó de ser un país relativamente pacífico para representar una seria amenaza a la seguridad nacional de EEUU y muchos lo catalogaron como un Estado Fallido.

Fox no pregonaba una política ni de la izquierda ni de la derecha pues su condición de empresario no se ajustaba a tales marcos políticos. Si bien "se integró en una formación conservadora... Más que una ideología, defendía los valores patrios del trabajo duro y la honradez... abandonó pronto los programas domésticos para dedicarse a recorrer mundo y a agasajar a dignatarios de otros países. Naciones Unidas, la Organización de los Estados Americanos, la Organización Mundial del Comercio y muchos otros grupos celebraron cumbres en las que los críticos hablaban de <<Foxilandia>>"(Grillo, 2012, p. 150).

En cuanto al perfil político respecto al tema narcótico, Fox habló poco "de drogas durante su campaña electoral, ya que se había concentrado en echar al PRI del poder. Los guerreros antidroga estadounidenses esperaban que un presidente democrático inaugurase una nueva era de cooperación... México podría ahora ayudar a los agentes a anotarse detenciones y confiscaciones, 
tal como hacían los colombianos. Fox aceptó... Dijo: Vamos a librar la madre de todas las batallas contra el crimen organizado en México. No lo duden>>"(Grillo, 2012, p. 151).

En 2003 “las fuerzas de seguridad apresaron al jefe Armando Valencia, en el estado de Michoacán, y al capo Osiel Cárdenas en el de Tamaulipas... Y entonces empezó la guerra. Empezó por una bagatela en la ciudad fronteriza de Nuevo Laredo, en otoño de $2004 . .$. el conflicto introdujo una serie de tácticas inéditas: el uso de grupos paramilitares, los ataques generalizados contra la policía y los secuestros en masa. Estas tácticas se difundieron por todo México... En el centro de la batalla de Nuevo Laredo estaba la banda más sanguinaria de México, la de los Zetas. Los ex soldados de fuerzas especiales militarizaron el conflicto, transformando la guerra contra las drogas en una guerra de la droga... para entender cómo surgieron los Zetas, necesitamos saber como se produjo la radical transformación del tráfico de drogas en la zona de Nuevo Laredo" (Grillo, 2012, p. 154-155).

Se afirma que la DEA protegió al cártel de Sinaloa desde 2004 al unísono de la ideología foxista contra el narcotráfico "con el programa México Seguro, que asestó duros golpes a los cárteles de Tijuana y del Golfo" (Ravelo, 2012, p. 259-260).

Si bien no existen pruebas que relacionen directamente al chapo ni con Fox ni con Calderón, se sostiene generalizadamente que la interacción es un simple resultado de la teoría de la conspiración denominada chapuza. También resulta posible que los presidentes no tuvieran nada que ver con "la fuga de Guzmán ni con su ulterior encubrimiento. Sencillamente, Guzmán y sus socios mafiosos fueron muy eficaces y lograron construir una red de funcionarios corruptos en todos los departamentos de la administración. Ni Fox ni Calderón podrían controlar todo el Estado. Con la desaparición del PRI había desparecido también el sistema básico de poder. Y ésta ha sido la clave del desmoronamiento de México"(Grillo, 2012, p.153).

Durante la era de foxilandia el Mayo Zambada "se convirtió en un auténtico dolor de cabeza para el Departamento del Tesoro estadounidense, que expresó molestia por la impunidad con la que actuaba el capo dentro de México y su propio territorio. Zambada operaba una amplia red de empresas a través de las cuales traficaba droga y blanqueaba capitales con la tolerancia o ignorancia de ambos gobiernos. En mayo de 2007 esa dependencia identificó a seis compañías y 
12 personas como parte de la red financiera de El Mayo. Se congelaron los activos que la organización criminal pudiera tener bajo jurisdicción de EEUU y se prohibió que ese país realizara transacciones financieras y comerciales con ellas. Entre las empresas... hay una guardería... otras de las empresas señaladas son Gasolinera Rosario... Multi-servicios Jeviz, Jamaro Constructores, Establo Puerto Rico y Nueva Industria de Ganaderos de Cuiliacán. Si quedara alguna duda de que estas compañías pertenecen al narcotraficantes, en julio de 2008, a la puerta de Nueva Industria, donde el Mayo produce la popular leche Santa Mónica, llegaron en bolsas dos cadáveres de decapitados, con mensajes escritos como "el gobierno te protege mucho y no mandes federales" (Hernández, 2012, p. 372).

Fox no solo resultó bastante permisivo para "combatir el lavado de dinero de El Mayo, sino que incluso... le prestó bienes de la nación para hacerlo. Hasta hoy, las concesiones siguen vigentes... El Mayo... logró inscribir a la empresa Establo Puerto Rico en un programa experimental de UNFCCC (Convención sobre el Cambio Climático de la ONU), realizada entre 2005 y 2006 en México para buscar un mejor manejo de los desechos de ganado productor de leche y disminuir los gases que emiten, como el metano y el óxido nitroso, a través de acciones económicamente sustentables" (Hernández, 2012, p. 374-375). Algo similar sucedió con Agroingreso Seguro en Colombia durante el gobierno de Uribe. Entre 2005 y 2006 se registró un aumento en los secuestros del " $317 \%{ }^{96} \ldots$ por cada secuestro denunciado hay por lo menos diez sin denunciar... la extorsión" (Grillo, 2012, p.405-406), es otra práctica usual.

En 2006 la DEA abrió investigación contra Fox y sus familiares más cercanos al terminar su mandato presidencial. Así mismo, "el cártel de Tijuana estaba casi disuelto... y de los más de dos mil miembros detenidos de la organización... En contraste, ningún de los capos de la Federación... había sido aprehendido" (Hernández, 2012, p. 464).

La misma red corrupta e impune de organismos de seguridad que actuó en Puente Grande al terminar el sexenio de Fox se recicló el gobierno de Felipe Calderón. En 2006, “Tello Peón regresó al ámbito de la función pública durante la etapa de transición del gobierno de Fox al de Felipe Calderón, quien por alguna razón lo quería como secretario de Seguridad Pública federal... Tello

96 Estudio de la Cámara de Diputados de México. 7.9.2010. 
Peón pretextó que por motivos de salud... pero empujó al siempre servil García Luna para que lo ocupara" (Hernández, 2012, p. 315).

Desde 2007 el cártel de Juárez y de Sinaloa "formaron para disputarse el control de los principales puntos del estado, especialmente Ciudad Juárez... la violencia desatada... alcanzó el máximo nivel y puso a esa ciudad como la más violenta del mundo, con 7 mil ejecuciones en poco más de dos años... El de Sinaloa... es el de mayor presencia. Dirigido por Vicente Carrillo Fuentes El Viceroy, hasta el 2007, tenía el control total de la entidad. A partir de ese año el cartel de Sinaloa, dirigido por... El Chapo entra por Guadalupe y Calvo y Guachichi, en el sur, hasta apoderarse de Ascención, Parral, Jiménez, Camargo y Delicias. En el centro, Guzmán se quedó con el control de Benito Juárez y de Villa Ahumada, que es paso estratégico para el trasiego de drogas hacia cualquier punto fronterizo de Chihuahua... mientras tanto la gente de El Viceroy se repliega hacia el occidente: Cuauhtémoc, Madera, San Buenaventura, Galeana, Nuevo Casas Grandes y Casas Grandes. El cartel de Sinaloa pudo penetrar Ciudad Juárez pero no desplazar al grupo local, por lo que se mantuvo esa disputa a muerte por la plaza" (Dávila, 2012, p. 53-54).

En Juárez "los operadores de las células de sicarios... de 20 a 30 años... casi todos vienen de Sinaloa, algunos son ex policías o ex militares... el $90 \% . .$. se dedica al narcomenudeo y el resto, al tráfico de estupefacientes a EEUU... además, cobra por derecho de piso $25 \%$ de las ganancias de la droga que otras organizaciones pasan al otro lado de la frontera" (Dávila, 2012, p. 55-56).

En cuanto a los nexos de los carteles con el Estado mexicano podemos afirmar que: "Sinaloa entre diciembre de 2006 y abril de 2010, 403 funcionarios públicos federales, policías ministeriales estatales y policías municipales fueron detenidos por su colaboración con los carteles del narcotráfico... el patrón es claro: todos los cárteles infiltran agencias estatales y locales, pero en el caso de los sinaloenses y los Beltrán Leyva, antiguos aliados, es más probable que paguen a militares y a funcionarios federales de alto nivel" (Carrasco, 2012, p. 230).

El cartel de Juárez también conocido como la Línea "está principalmente compuesto por policías locales, federales y miembros del ejército mexicano. Ellos son los sicarios de los narcos, con las armas, los uniformes y la charola que se les paga con los impuestos de los mexicanos" (Hernández, 2012, p.394). 
Esta seria la plataforma para que el enfrentamiento entre el Barbas y el Chapo convirtiera a Juárez en "la ciudad con más asesinatos del planeta... docenas de miles de personas provistas de papeles cruzaron corriendo la frontera para vivir en El Paso... los Zetas se habían multiplicado por todo el país, hasta los Estados de Oaxaca y Chiapas y hasta el otro lado de la frontera con Guatemala... en 2010... tenían más de diez mil soldados...un ejército dirigido por Lazcano, el Verdugo"(Grillo, 2012, p. 206-207).

Una gran diferencia estratégica entre el cártel del Golfo y el de Sinaloa es "que en este último no hay confrontación. Se privilegia más la lógica del negocio que la de la pugna o de las luchas internas. Para el gobierno resulta más fácil tratar con grupos abiertos a la negociación"(Astorga, 2012, p. 246).

\subsection{LA MATRIZ EXTIRPADA DE LA ESCINDIDA ESOI NARCOVIOLENTA: GOLFO-ZETAS}

El cártel del Golfo "gastó millones de narco-dólares en financiar el rápido crecimiento de los Zetas... generaron sus propios ingresos... explotaron todo bicho viviente... los agentes mexicanos de inteligencia explican que las células Zetas son como franquicias... los gánsteres de todo México imitaron además la organización paramilitar de los Zetas. Los sinaloenses crearon sus propias células de guerreros, con muchas armas y uniformes de combate"(Grillo, 2012, p. 173174).

En 1997 Osiel Cárdenas Guillén, quien empezó su carrera criminal como Pablo Escobar, robando autos "había llegado a la jefatura del cártel del Golfo matando a todo el que se cruzaba por su camino. Le habían puesto el apodo de Mata-amigos... hizo amistad con un mando de las fuerzas especiales Ilamado Arturo Guzmán Decena... enviado a Tamaulipas para tomar medidas contra las bandas de traficantes" (Grillo, 2012, p. 156-158).

Guzmán "y sus compañeros pusieron en práctica lo que habían aprendido cuando el levantamiento zapatista sorprendió al mundo en 1994. Encabezado por el subcomandante Marcos, revolucionario y fumador de pipa, unos tres mil rebeldes zapatistas se apoderaron del 
empobrecido estado meridional de Chiapas...Sin embargo, y a pesar de la nula amenaza militar que representaban, el gobierno mexicano quiso replicar con dureza y lanzó al GAFE en persecución de los zapatistas... les habían cortado la nariz y las orejas. Aquella carnicería estremeció al movimiento rebelde y Marcos se apresuró a firmar un alto al fuego doce días después del inicio de la sublevación. Desde entonces, los zapatistas han optado por las protestas no violentas, aunque siguen manteniendo un pequeño ejército guerrillero en el interior de la jungla" (Grillo, 2012, p. 158-159)

Guzmán lideró inicialmente la organización ocupó la posición Z1 y quien en un principio contó con "38 ex soldados... Osiel Cárdenas se sintió más poderoso que nunca. La arrogancia lo empujó a cometer un error que le costó caro: amenazó a los funcionarios estadounidenses" (Grillo, 2012, p. 159-161).

A Cárdenas, por su parte, "la DEA puso precio a su cabeza: dos millones de dólares... se convirtió en el primer narco-insurgente... recibió cincuenta balazos...fue un magnífico trofeo para el presidente Fox... con Z-1 muerto y Cárdenas en la cárcel, la banda sinaloense pensó que el cártel del Golfo estaba acabado y se trasladó a su territorio. La mafia sinaloense convocó una narcocumbre para planificar la expansión... Los sinaloenses ya controlaban la frontera desde Juárez hasta el pacífico, dijeron. Y ahora podían hacerse con las lucrativas rutas del este de Texas... la primera fase de la guerra mexicana de la droga consistió en el enfrentamiento del poderoso cártel de Sinaloa con los insurgentes Zetas" (Grillo, 2012, p. 162-164).

Osiel es el pionero del Cartel del Golfo y Z1 era "un joven teniente originario de Puebla y adiestrado en el Grupo Aeromóvil de Fuerzas Especiales - GAFE... los paramilitares adquirieron la responsabilidad de custodiar los traslados de la droga desde México hacia EEUU. Actualmente realizan sus operaciones con contactos en Colombia, Perú y Venezuela... crearon campos de entrenamiento para reclutar civiles y formarlos con disciplina y habilidades militares. Entre los instructores había Kaibiles de las fuerzas especiales contra la guerrilla de Guatemala... trajeron a México la moda de decapitar u desmembrar a sus enemigos como escarmiento público a quien osara enfrentarlos... el gobierno de EEUU los identificó hasta marzo de 2002... en 2005 los informes del FBI señalaban que el grupo paramilitar... tenía entre 300 y 350 integrantes... hoy podrían ser miles, incluyendo a los que el FBI llama Zetitas o Zetas wannabes, grupos de 
delincuentes imitadores de los Zetas que utilizan su nombre y sus métodos para sembrar terror por medio de extorsiones y secuestro... cerca de 279 grupos de ese tipo... algunos de ellos fueron creados por el propio Joaquín Guzmán Loera para hacer inteligencia sobre sus enemigos... Los Zetas... se aliaron con... Los Hermanos Pistoleros Latinos, una banda con base en Laredo, Texas; una parte de esa organización también ha trabajado para Guzmán Loera... así mismo los Zetas formaron vínculos con... la llamada Mafia Mexicana que opera en California, a quienes han contratado como sicarios" (Hernández, 2012, p. 403-405).

Heriberto Lazcano Lazcano, alias EI Verdugo, El Lazca o Z3 es uno de los fundadores de los Zetas. Los Zetas "estaban conformados principalmente por ex integrantes del Ejército mexicano altamente capacitados, algunos pertenecían al GAFE, creado a finales de la década de 1990 para combatir al narcotráfico... Se dice que hoy en día cualquier malandro, por menos de cinco mil pesos, ese enrola en el grupo...la historia oficial de la Sedena sobre Lazcano es que ingresó como soldado de infantería... debido a su buen desempeño... en 1993 ascendió a cabo de infantería... llegó a manejar armamento especial y a comandar escuadra... estaba entrenado para realizar operaciones especiales y encubiertas... EEUU dio parte de ese entrenamiento en el Fuere Benning, en Georgia" (Hernández, 2012, p. 339-401).

En 2003 Cárdenas fue detenido y la Federación nombró como delegatario a la Barbie para que le notificara a El Verdugo que debería abandonar Nuevo Laredo. Edgar Valdés Villarreal, La Barbie o La Muñeca nació en Laredo y a pesar de su cara de niño es un malvado y violento ser. A él se le “atribuían como zonas de operación a los estados de Guerrero, Michoacán, Jalisco, Nuevo León, Morelos y el DF. En 2007 el Departamento de Estado norteamericano lo ubicaba como unos de los colaboradores de los Hermanos Beltrán Leyva, el lugarteniente más cercano a El Barbas y uno de los principales causantes del baño de sangre en México por la disputa territorial entre los carteles. Tras la muerte de Arturo Beltrán, la Barbie y su compadre Gerardo Álvarez, El Indio... querían formar su propia organización... en 2010 Valdez fue capturado...una presunta captura arreglada... decidió entregarse porque se sentía mas seguro con la protección del gobierno federal que en la calle a merced de los Zetas y de Héctor Beltrán Leyva, quien lo había sentenciado a muerte por la supuesta traición al Barbas" (Hernández, 2012, p. 411). 
Los Zetas "basaron inicialmente su cadena de mando en el ejército mexicano... Pero la guerra modificó su estructura, que acabó pareciéndose a la de los guerrilleros latinoamericanos y a la de los grupos paramilitares de ultraderecha, que tienen miles de hombres organizados en células autónomas. Los Zetas entrenaron a los miembros de La Familia en esta guerra de guerrillas en 2005 y 2006, hasta que la banda de Michoacán los traicionó y pelearon por el territorio"(Grillo, 2012, p. 333-334).

En 2008 los Zetas enfrentaban a los sinaloenses y sus socios de la ESol narcoviolenta. Dichos combatientes "hacían cada vez más videos snuff (grabación de asesinatos reales) y dejaban cadáveres decapitados en lugares públicos... de pronto llegaron noticias asombrosas... los zetas y... Sinaloa habían convenido en hacer un alto el fuego... reorganizar(on) el mapa de sus respectivos territorios... El cartel del Golfo y sus Zetas seguirían controlando el noreste... incluido Nuevo Laredo y el Estado oriental de Veracruz; el cartel de Sinaloa conservaría sus antiguos territorios, incluido Acapulco, y además se quedaría con San Pedro Garza, un municipio del área metropolitana de Monterrey y el más rico de todo México. Beltrán Leyva, el Barbas, sería el encargado sinaloense de mantener la paz con los Zetas"(Grillo, 2012, p. 189-190).

No solo "los terroristas empezaron a tender emboscadas a los policías en todo Nuevo Laredo. Luego la policía nacional y la local empezaron a tirotearse entre si... los funcionarios ya no se limitaban a hacer la vista gorda ante el contrabando, sino que colaboraban como secuestradores y verdugos por derecho propio, lo que suponía una seria desintegración del Estado" (Grillo, 2012, p. 169-170).

En 2014 los Zetas incluso secuestran migrantes por cifras como 2 mil dólares. Por ejemplo la matanza de San Fernando donde fueron ejecutados simultáneamente 72 migrantes en 2010 fue gestada por células Zetas. Además obtienen millonarios recursos con la fabricación de Cds piratas y produce Fabrican CD piratas y produce sus propias películas.

Los Zetas dominan geoestratégicamente "el este del país, donde la industria del petróleo es más fuerte. Y cobran a esa industria todos los impuestos que pueden, extorsionando al sindicato y robando gasolina para venderla de contrabando. En Michoacán, La Familia explota la minería y la tala ilegal de árboles, que son fuentes de ingresos del gobierno... el cartel de Sinaloa se limita en 
términos generales a traficar con droga" (Grillo, 2012, p. 238). Una serie completa de narcotributación que ejercen las ESol narcoviolentas en los Estados Superados.

Lo anterior, un ejemplo cristalino de lo que denominamos los efectos trasnacionales del narcocalentamiento global. Aunque si bien resulta "prematuro asegurar que los Zetas actúan a través de las fronteras mexicanas sea realmente del tipo característico de expansión tradicional, pues debe considerarse la posibilidad de su acción se dé bajo el esquema de transplantación... que a diferencia de la expansión. Consiste en la actuación de una red criminal, a través de fronteras de países que no son vecinos, y sobre todo, en lograr que gentes extranjeros, viviendo en países distintos al de origen"(Garay, 2912, p. 305). Colombia se transplantó, esto si no es prematuro afirmarlo, por la evidente existencia de los narco-embajadores nativos

\subsection{LA FAMILIA DE MICHOACÁN}

La Familia cuenta con importantes nexos con clases políticas de Morelia en 2014 y su Sede es Michoacán. Igualmente se “introdujo en Jalisco, Guadalajara, Guerrero, Puebla y el Estado de México, con los pueblos que rodean la capital...el éxito de La Familia, sin embargo, la puso en el radar de la policía" (Grillo, 2012, p. 316).

La Familia se dedica principalmente a la actividad de la ESol narcoviolenta pero sin embargo ha variado su portafolio criminal para proveer nuevas fuentes de ingresos a la organización, tales como el "secuestro, la extorsión, el robo y la piratería. Y su incursión en negocios legales como el lavado de autos, ferreterías, abarrotes, lotes de autos, centros nocturnos, restaurantes, tiendas de autoservicio, farmacias... Empresarios productores de aguacate y frutas de diversas regiones del estado... (La Familia manifestó a sus aportantes forzados que tenían) el control de las autoridades

locales y que podría resolver los problemas que se presentan con policías estatales o federales" (Garay, 2012, p. 239).

Su zona de influencia en 2014 claramente la constituyen los Estados de "Michoacán, Guerrero, Estado de México, Distrito Federal, Guanajuato, Aguascalientes, Querétaro e Hidalgo. Este es el 
cartel más reciente de entre los más poderosos, pero no el menos peligroso... se dio a conocer públicamente en Michoacán en 2006 mediante un desplegado de periódicos... se originó de la ruptura de los hermanos Valencia y Carlos Rosales, bandos asentados en Michoacán, Jalisco y Colima. Sin embargo, una vez confrontados ambos grupos, los hermanos Valencia se alinearon con el cártel de Sinaloa y Carlos Rosales con el cártel del Golfo. Al final, Armando Valencia Cornelio y Carlos Rosales serían detenidos, y los narcos de Michoacán entonces rompieron sus alianzas y declararon la guerra del cártel de Golfo y al de Sinaloa... se mueve entre la violencia extrema y el fanatismo religioso, encabezado por Nazario Moreno González, El Más Loco, José de Jesus, El chango Méndez, Severendo Gómez, la Tuta y Enrique Plancarte, el Tío. Suelen decapitar a sus enemigos y dejar recados sobre sus cuerpos, tales como que su crimen fue obra de la justicia divina. Sus estrategias de lucha se asemejan a actos terroristas, incluidos ataques directos a cuarteles federales o el secuestro de policías, como sucedió luego de la captura de Arnoldo Rueda Median, La Minsa. Pero ni la captura de lugartenientes ni el decomiso de arsenales han frenado la capacidad de fuego y de movilidad de la organización criminal" (Garay, 2012, p. 167-168). Nazario Moreno fue el líder espiritual de La Familia Michoacana y creador de la narco-biblia. En nombre de Dios “Han llegado a coser una cara humana a un balón de futbol” (Grillo, 2012, p. 320).

Considerada La Familia por EEUU como "un cártel por el tamaño de su organización, su expansión y el poderío bélico... se está apoderando de las principales rutas del cártel del Golfo... se han enfrentado contra el Chapo Guzmán y los hermanos Beltrán Leyva, con quienes protagonizaron una de las confrontaciones más crueles de que se tenga memoria en los estados de Guerrero, Morelos y Michoacán" (Garay, 2012, p. 167).

Servando Gómez Martínez Alias la Tuta fue expuesto por su propio hijo, alias el pelón, de manera involuntaria al ser capturado, confesó abiertamente los negocios de su padre. La Tuta era maestro de escuela y pasó a ser uno de los hombres más sanguinarios y poderosos de La Familia y quien infiltró en buena parte los sistemas de seguridad y políticos de Michoacán.

La Familia no obstante haber combatido violentamente al Cártel del Golfo, recientemente procedió a convocarlo para unir fuerzas y combatir a las células Zetas en Tamaulipas(Garay, 2012, p. 256). 
La Familia corresponde a una ESol narcoviolenta trasnacional que ha extendido sus operaciones sobrepasando las fronteras aztecas. Han desarrollado narco-franquicias encargadas de adquirir “los precursores químicos en naciones tan lejanas como China, en Asia, y Holanda y Bélgica... En reciprocidad, La Familia Michoacana ha exportado a China cientos de toneladas de materiales industriales robados en minas situadas en zonas bajo influencia del grupo criminal, según los últimos informes de la Policía Federal. Los precursores químicos son usados en laboratorios clandestinos ubicados en las zonas serrana y de Tierra Caliente del estado, donde se producen drogas como ice, cristal y metanfetaminas que antes de llegar a EEUU pasan por San Luis Potosí, luego Nuevo León y finalmente llegan a Tamaulipas. Otra ruta parte de Manzanillo y se dirige hacia Guanajuato, se enfila a Chihuahua, pasa por Sonora y llega hasta Mexicali y Tijuana" (Garay, 2012, p. 257).

Las contradicciones de los líderes políticos saltaron a la luz pública mediante las diversas posturas acerca de la naturaleza de los conflictos gestados por las ESol narcoviolentas. Por ejemplo, Calderón al vestirse de militar sostuvo que: "no hay cuartel para los enemigos que pongan en peligro la patria; pero luego se enfadaba ante la menor insinuación de que en México se estaba combatiendo una insurrección. El Gobierno de Obama está más confundido aún. La secretaria de Estado (o ex secretaria) Hillary Clinton, aseguró a la gente que en México solo hay crímenes urbanos como la que asoló a Estados Unidos en los años ochenta. Pero luego afirma que se trata de una insurrección semejante a la de Colombia"(Grillo, 2012, p. 20).

La Iniciativa Mérida inyecto a 2014 más de US\$ 2.000 millones de dólares mediante el acuerdo de cooperación militar descrito y la cifra de cooperación estadounidense se mantiene en un aproximado del WOLA de "400 millones de dólares al año, y dos tercios va destinada a las fuerzas militares y policiales" ${ }^{\prime 97}$. Algunos porcentajes de la cuantía de cooperación militar es utilizada por los EEUU como depósito que será rembolsado cuando el Secretario de los EEUU considere que el Estado mexicano cumple lo requerido por su dominante político en cuanto a la garantía de los $\mathrm{DDHH}^{98}$, se refiere. Aunque dichas técnicas militares de combate se alejan realmente a la protección de los DDHH y legitiman completamente a la Escuela Realista de las RRII que tantas violaciones brutales a la condición humana, ha generado, genera y seguirá generando.

97 www.elnuevoherald.com/2014/01/23/1662928/eeuu-debe-apoyar-un-plan-colombia.html\#storylink=cpy. Consultado el 18.2.104.

98 Laura Carlsen. Fuente: Programa de las Américashttp://www.biodiversidadla.org/Principal/Secciones/Noticias/Suspension_de_fondos_a_la_Iniciativa_Merida_salvara_vidas 
No obstante podemos observar algunos elementos diferenciadores entre el PC y la IM: "Con el PC se dio más dinero a un país más pequeño y se contribuyó a transformar las fuerzas de seguridad... en una potencia regional. La Iniciativa Mérida sólo dio unos 500 millones de dólares anuales a México, cuyo presupuesto nacional total para la seguridad era ya de 15.000 millones... Ahora bien... cualquier cosa que hicieran los soldados mexicanos en el terreno pasaba a ser asunto estadounidense" (Grillo, 2012, p. 187-188). Lo anterior resultó efectivo en cuanto a incautaciones y capturas.

El oficialismo norteamericano definió la IM como "un programa histórico de cooperación que reconoce las responsabilidades compartidas de los EEUU y México de luchar contra la violencia generada por las drogas que amenaza a los ciudadanos de ambos países...proporciona habilidades técnicas y asistencia a México para la profesionalización de la policía, la reforma judicial y penitenciaria, el reforzamiento de las tecnologías de información, el desarrollo de infraestructura, la seguridad fronteriza y el fomento de una cultura de la legalidad" ${ }^{\prime 99}$.

Así se perfilaría entonces la nueva estrategia militarizada en materia de seguridad del Estado mexicano, en cinco principales ejes: "1. Fortalecimiento de la presencia de la autoridad pública en todo el territorio nacional mediante operativos conjuntos; 2 . Desarticulación de cadenas y redes operacionales, logísticas, financieras y comerciales...; 3. Fortalecimiento y depuración de las instituciones públicas responsables del combate a la delincuencia organizada en los tres niveles de gobierno; 4. El impulso y la consolidación de políticas de la prevención del delito y de la violencia, por medio de la participación ciudadana; 5. La promoción de la cooperación internacional" (Aguilar, 2012, p.31-32).

Calderón también utilizó a la figura de la extradición, cuando llevaba "un poco mas de un mes como presidente (extraditó)... a quince traficantes... entre ellos... Osiel Cárdenas, jefe del cártel del Golfo, y Héctor Palma, alias el Güero, del cártel del Sinaloa. Dos de los delincuentes más buscados en los EEUU"' (Grillo, 2012, p. 184-186).

Sin embargo y sin lugar a dudas fue la IM “la causa más relevante del incremento de la violencia... el cartel de Ciudad de Juárez tenía 400 elementos antes de la declaratoria de guerra, pero 15 días

99 Camille Apostolo, Eugénie Moreau, Colectivo la Voz de los Xiches, Kamara-Difusión Alternativa y Agencia Subversiones.http://desinformemonos.org/2013/10/el-despojo-y-ladefensa-de-la-vida-desde-mexico-hasta-colombia/. Consultado el 20.2.2014 
después ya contaba con 6 mil. Ante la amenaza... reclutó y armó a las pandillas juveniles de los barrios populares... lo que ocurrió en esta ciudad se multiplicó por todo el país, y los narcotraficantes se hicieron de ejércitos paralelos" (Aguilar, 2012, p. 16). Conforme lo descrito anteriormente.

Para apoyar la afirmación anterior, podemos sostener que entre el año 2007 y el 2011 México registró "16.786 desaparecidos... adjudicados al crimen organizado, pero también a las fuerzas de seguridad del Estado mexicano... de acuerdo con WOLA, el sistema mexicano se ensaña en la detención de los pequeños vendedores y deja libre a los grandes" (Aguilar, 2012, p. 30-31). Igualmente la Iniciativa Mérida "ha surtido impacto alguno en disminuir la disponibilidad de sustancias ilícitas para los estadounidenses. Entre 2006 y 2010, se elevó el nivel de consumo de todas las sustancias salvo la cocaína, que disminuyó en 37 por ciento. La disponibilidad de la metanfetamina creció en 56\%, la heroína 18... mariguana 40" (Aguilar, 2012, p. 21).

Un dato contradictorio a la filosofía realista norteamérica es que la "mayor proporción de la mariguana que se consume en EEUU se cultiva ahí y en Canadá; la producción de México solo es para cubrir los faltantes. $90 \%$ de la heroína que se consumen los estadounidenses proviene de Afganistán y México proporciona el 10 restante, pero este porcentaje esta creciendo. El otro producto son las metanfetaminas cuya producción también tiende a elevarse... el total de la producción de drogas en México vale alrededor de 8 mil millones de dólares anuales" (Aguilar, 2012, p. 23-24). No obstante, siguen machacando campesinos por cultivar narcóticos en Estados Superados.

Calderón insistió en la relevancia de otra problemática que genera incrementos elevados de narcoviolencia en México. Antes de su presidencia sostuvo en el año 2004 "que al prescribir la Assault Weapons Ban en EEUU, se ha producido un incremento en el tráfico de armas de ese país hacia México; se ha disparado la capacidad de fuego del crimen organizado para enfrentar al ejército y a la policía... el ingreso de armas de EEUU a México es histórico, se remota al siglo XIX y forma parte de la compleja relación de una frontera común de 3 mil 200 kilómetros... Barack Obama (sostiene) que no buscará modificar la Segunda Enmienda de la Constitución... el gobierno de EEUUU no ha querido ratificar la Convención de Palermo contra la Delincuencia Organizada... ni 
tampoco la Convención Interamericana contra la fabricación y tráfico ilícito de Armas, ratificada por 30 de 34 países, entre ellos México, que integran la OEA" (Aguilar, 2012, p. 101-102).

El arma favorita del narco mexicano es el cuerno de chivo o Kaláshnikov, que con un "cargador circular puede disparar cien proyectiles en diez segundos. Es una guerra relámpago" (Grillo, 2012, p. 246).

EEUU en el balance de compras de armas "es el máximo importador mundial, lista en la que también figuran Rusia y China... los exportadores más grandes son EEUU... Italia... Alemania... Brasil... Suiza... Austria... y Bélgica. El YearBook 2912 del Stockholm International Peace Research Institute considera EEUU, Rusia, Alemania, Francia y Reino Unido como los cinco principales exportadores del mundo. México tiene un gasto anual de 28 millones de dólares en armamento. La ONU estima que, desde arsenales legales hasta las provenientes del robo y la corrupción, ingresan anualmente al mercado ilegal en el mundo unas 650 mil armas... la población de EEUU constituye cinco por ciento de la mundial, pero en términos de posesión de armas alcanza $40 \%$ de las 875 millones de armas que hay en el mundo" (Aguilar, 2012, p. 105-106).

Así el lobby armamentista norteamericano híper-reacción al tema cuestionado el: “¿por qué deberían los aficionados a las armas de Estados Unidos sufrir los problemas que tiene México?, exclaman. Las armas no matan a las personas. Son las personas... la guerra de México señalaron, se debe a muchos factores y no sólo a las armas, por ejemplo a la corrupción de las fuerzas de policía"(Grillo, 2012, p.336).

Y aunque tienen razón, “en 2008, México envió a la ATF (Agencia estadounidense para el control de alcohol, tabaco, armas y explosivos) el número de serie de cerca de seis mil armas aprehendidas a los gánsteres. Alrededor del 90\%, concretamente 5.114 armas, procedían de vendedores estadounidenses... ente 2009 y abril de 2010, el programa ha identificado otras 63.700 armas... las armerías estadounidenses no son las únicas fuentes de armas de las mafias mexicanas. También se roban a las fuerzas de seguridad, y se han aprehendido grandes alijos que proceden de los militares guatemaltecos. Los traficantes de armas internacionales también han movido mucho material por Centroamérica y el Caribe. Si los carteles mexicanos no compraran armas en Estados Unidos, alega un defensor de las armas, las comprarían en otros lugares. Es posible. Pero el tráfico 
por mar y por Centroamérica sería más lento y más fácil de combatir. Lo cual incrementaría el precio de las armas y municiones... la causa principal del conflicto no (son las armas), pero sin duda (echan) gasolina al fuego... los traficantes de armas pagan a los ciudadanos estadounidenses para que... adquieran armas para ellos... estas operaciones se denominan compras de paja" (Grillo, 2012, p.340-341).

Autoridades manitas "han estimado que el tráfico ilegal podría ser de 2 mil armas al día...de ser cierta, al año ingresarían a México de manera ilegal 730 mil armas...Muchas de estas armas no tienen registro, el número de serie ha sido lijado y nadie puede saber de cuántas se tratan" (Aguilar, 2012, p. 108-109). Relativo a esto, el Instituto Superior de Estudios Internacionales de Ginebra (IHEI) "estimó que existen 875 millones de armas en el mundo, de las cuales 650 millones (75\%) se encuentran en manos de civiles" (Aguilar, 2012, p. 112).

Otro factor de riesgo lo representa la triple frontera entre Argentina, Brasil y Paraguay genera el mayor volumen de tráfico de armas en el mundo, "que aun si el gobierno estadounidense mejorara sus sistemas de control, de venta y de exportación, los carteles mexicanos podrían recurrir con mucha facilidad al contrabando de armas (allí)" (Aguilar, 2012, p. 116).

Conforme lo descrito, Felipe Calderón dejó a Enrique Peña Nieto la estructura made in usa contra el narcotráfico dominada por los apoyos de cooperación militar ejecutados por FFAA de dudosa lealtad a la Constitución y las leyes mexicanas y con estrechos vínculos con los diversos grupos de crimen organizado mexicanos. Así mismo lo reconoció el actual presidente mexicano a principios de su mandato.

En consecuencia es posible afirmar que en el contexto de las ESol narcoviolentas mexicanas "la guerra de la droga está incondicionalmente unida a la transición democrática...Los empresarios que antes pagaban a los funcionarios corruptos empezaron a pagar a los grupos mafiosos. Las fuerzas de policía se enfrentaban entre sí, llegando a veces a producirse tiroteos entre departamentos... Durante los primeros cuatro años de gobierno de Calderón, la guerra de la droga se cobró la alucinante cantidad de treinta y cuatro mil vidas ${ }^{100} \ldots$ más de dos mil quinientos funcionarios, entre los que figuraban dos mil doscientos policías ${ }^{101}$, doscientas personas entre

100 Base de Datos de la Secretaría de Seguridad Pública de México Diciembre 2010. 101 Base de Datos de la Secretaría de Seguridad Pública de México Diciembre 2010. 
soldados, jueces, alcaldes, un destacado candidato a gobernador, el presidente de un gobierno estatal y docenas de funcionarios nacionales.... Un balance más mortífero para un gobierno que el causado por Hamas, ETA o el IRA en sus tres decenios de lucha armada" (Grillo, 2012, p. 26-27).

Antes de Calderón "las estadísticas nacionales e internacionales señalaban que el país vivía la menor violencia de su historia (solo 8 homicidios por 100 mil habitantes);... en 2007 hubo 8 mil 867 homicidios dolosos y, en 2011, 27 mil 199... creció más de tres veces... en total los primeros cinco años de gobierno llegó a 95 mil 659... obviamente no debe confundirse esta cifra con las ejecuciones vinculadas de forma directa con el crimen organizado... por presunta rivalidad delincuencial, la cifra pasó de sólo 62 casos en 2006 a 15 mil 273 en 2010" (Aguilar, 2012, p. 15). Homicidios de 2006 a 2012 "94 mil 357... 11 mil muertos promedio anual” (Aguilar, 2012, p. 19).

La pregunta obligada es: “¿por qué reventó el imperio en 2008?.. Dos argumentos... El primero lo expuso el gobierno mexicano con apoyo de la DEA... la guerra fue el resultado de la continua presión... sobre los carteles... con las históricas confiscaciones... los gánsteres estaban perdiendo miles de millones de dólares... situación que los empujó a pelearse entre sí por conseguir las cuotas de las plazas y para ver quien reponía las toneladas de droga perdidas... el otro argumento venía de los propios gánsteres... periodistas e investigadores mexicanos. La guerra estaba relacionada con la corrupción del gobierno" (Grillo, 2012, p. 191-192). Funcionarios mexicanos dentro de las nóminas de los carteles.

La condición que se observa en los Estados Superados por las ESol narcoviolentas no obedece a una pérdida de control territorial total sino parcial e itinerante. A saber, en México por ejemplo: “Michoacán y la ciudad de Guadalajara. En los años ochenta. Al menos, en el Estado de los Cárdenas no estaba exento de cultivos serranos de mariguana, pero de ninguna manera se trataba de una entidad federativa especialmente penetrada o dominada por el narco... Todo indica que hoy sí lo es. En cambio, a finales de los setenta y casi toda la década de los ochenta, Guadalajara fue prácticamente conquistada por los narcos de Sinaloa, expulsados de su estado nativo por la Operación Cóndor. La Perla de Occidente se volvió un pueblo del Wild West...hoy... es de nuevo un monumento a la belleza... con niveles de seguridad y tranquilidad perfectamente aceptables" (Aguilar, 2012, p. 94). 
Otro factor que incrementa las actividades de las ESol narcoviolentas en México es que el gobierno ha obtenido pocos avances en el juzgamiento de numerosos asesinatos, desapariciones forzadas y torturas perpetrados por soldados y policías en el marco de acciones contra la delincuencia organizada. El sistema de justicia militar, que no opera con objetividad, continúa siendo el ámbito donde se juzga a militares acusados de violaciones de derechos humanos, y se asegura así su impunidad.

Así, "la enfermedad de la narco-cracia mexicana (narcotraficantes, narco-empresarios y narcopolíticos) es contagiosa y comienza a generar focos de infección”(Hernández, 2012, p. 571).

Es por esto que en enero y febrero de 2014 México debe presenciar como GAl se enfrentan bajo premisas muy similares a las de Colombia. En Michoacán grupos de autodefensas que manifiestan estar cansados de los abusos y ataques indiscriminados de los grupos narcoviolentos se han armado y salido a las calles y se han enfrentado directamente sin ningún tipo de pudor frente a los medios y ya han incluso negociado su presencia con el Estado y las fuerzas que se tildan legales.

Debiendo aclarar que no se trata de un fenómeno sin antecedentes en las tierras mexicanas donde las autodefensas surgieron "hace 18 años y ganaron poder hasta ser una amenaza para el gobierno. Tomas de pueblos, enfrentamientos con los narcos, tropas movilizadas. La situación que desborda el estado de Michoacán. Ante el histórico abandono gubernamental sobre las zonas rurales, el origen de los reclamos se apoyaba sobre la desaparición de un Estado de Derecho que los ciudadanos consideraban básico. Robos, homicidios e infinidad de secuestros transformaron la vida cotidiana en una pesadilla y el hartazgo vecinal decantó en patrullajes grupales. La proliferación de grupos irregulares en Michoacán, Chiapas, Guerrero y el estado de México se volvió tan normal que los funcionarios locales decidieron no intervenir" ${ }^{\prime 102}$.

Michoacán es un lugar narco- estratégico donde se cultivan miles de hectáreas de drogas. Las autodefensas siguen empujando a los narcos hacia las afueras de los pueblos y la guerra inunda el campo. Cada cruce de ruta mutó en retenes y decenas de insignias paramilitares que no son de la comprensión de los transeúntes ajenos a los grupos.

El comisionado Alfredo Castillo manifestó que el proceso que se registró en 2000 “con el cártel de La Familia, los cuales comenzaron combatiendo el crimen y terminaron practicándolo... el grupo se

102 1.19.2014 Los paramilitares - El fantasma de una nueva guerra asoma sobre México. Consultado el 20.2.2014. S.D.E. 
hizo del control de buena parte del territorio del estado ante la incapacidad oficial para combatir el narcotráfico y tras divisiones y capturas de algunos de sus líderes dio paso al surgimiento de Los Caballeros Templarios, los actuales enemigos de las autodefensas... al final, La Familia logró expulsar a Los Zetas de Michoacán, un estado agrícola de apetitosos limones, mangos y aguacates o paltas"103.

Raúl Benítez de la Universidad Nacional Autónoma de México sostuvo que "la presencia de grupos armados siempre conlleva riesgos de que se transformen, pero consideró que el caso de las autodefensas es distinto al de La Familia... en este momento las autodefensas no hacen actividades criminales... una cosa es que sean ilegales constitucionalmente y otra cosa es que hagan actividades criminales"104.

Las autodefensas hasta este momento se han limitado a capturar y entregar a las autoridades correspondientes los capos. No obstante, es una delgada línea de cruzar, pasar del porte ilegal de armas y control ilícito del territorio, capturas ilegales que en realidad son detenciones que podrían significar secuestros simples; a pasar a ejecuciones extrajudiciales o participar en la tajada de las narco-utilidades y del narco-poder, como ha ocurrido en Colombia. O simplemente estar en impunidad por resultar funcionales a los intereses de seguridad del Estado mexicano y norteamericano.

Esto muestra claramente como el Estado ha perdido poder soberano o control territorial y ha sido superado por GAl que son más efectivos que las autoridades en cuanto a la captura de los capos narcotraficantes mexicanos y servicios de seguridad. Evidenciando igualmente "un divorcio profundo entre el estado y la sociedad, entre las instituciones y la sociedad" ${ }^{105}$.

La población rural manifiesta con cierta sensatez: "si dejo mi escopeta, vendrán los sicarios y matarán a mi familia. Aquí nos conocemos desde niños y sabemos todo. No hay vuelta atrás en esta decisión y llegaremos hasta la última consecuencia" ${ }^{106}$.

\subsection{IMPACTOS SOCIALES ANTINARCÓTICOS}

103 1.19.2014 Los paramilitares - El fantasma de una nueva guerra asoma sobre México. Consultado el 20.2.2014. S.D.E. 104 1.19.2014 Los paramilitares - El fantasma de una nueva guerra asoma sobre México. Consultado el 20.2.2014. S.D.E. 105 1.19.2014 Los paramilitares - El fantasma de una nueva guerra asoma sobre México. Consultado el 20.2.2014. S.D.E. 106 1.19.2014 Los paramilitares - El fantasma de una nueva guerra asoma sobre México. Consultado el 20.2.2014. S.D.E. 
Desde 2007 a 2014 un promedio de 100.000 personas han sido asesinadas dentro del marco de la narcoviolencia. Y el panorama desgarrador se ha extendido a Centroamérica en dimensiones similares.

No obstante la cantidad de inyección monetaria aportada no se redujo el consumo ni el suministro de narcóticos en México.

Una de las principales causas del incremento de la narcoviolencia y sus fuentes de ingresos son precisamente los miembros de las FFAA vinculados laboralmente con los grupos del crimen organizado para desarrollar actividades de narcotráfico y sus respectivos delitos conexos.

Las autoridades armadas mexicanas participan en desapariciones y ejecuciones extrajudiciales y omiten perseguir a los miembros de los carteles de la droga. En enero de 2013 se reportaron 26.000 casos de personas desaparecidas desde 2007. De las cuales, la Comisión Nacional de los Derechos Humanos (CNDH) de México señalo que 2.443 desapariciones contaban con indicios de participación directa de actores estatales.

Altos índices de impunidad en cuanto a los crímenes cometidos por los miembros de las fuerzas armadas mexicanas se refiere, pues son juzgados dentro de un sistema especial militar corrupto, que a la fecha solo condenó 38 militares pese a recibir entre 2006 y 2013, 8.150 denuncias; 5, 500 de las cuales, se procesaron en la Justicia Penal Militar. ${ }^{107}$

Adicionalmente el sistema judicial admite y valora pruebas obtenidas mediante descargas eléctricas o golpizas y tratos inhumanos.

Acompañando el panorama un saldo de casi un centenar de periodistas asesinados entre 2000 y 2013 y otras decenas desaparecidos. También los sindicalistas han sido víctimas de este tipo de vejámenes. Sólo ha existido una demanda en la que se ha sancionado la libertad de expresión de las 378 denuncias realizadas.

Respecto a la producción de marihuana "el triángulo de producción hemisférico lo constituían México, Jamaica y Colombia. Se reprimía más en un país, en particular mediante el uso de herbicidas, y el cultivo se movía al otro, aunque siempre regresaba al sitio inicial de mayor cultivo. Y así sucesivamente. Un triángulo semejante se produjo con la amapola entre México, Guatemala y

107 Comisión Nacional de los Derechos Humanos (CNDH) de México. Consultado en su página oficial el 20.2.2014 
Colombia. También, en este ejemplo se utilizó la fumigación química para atacar el negocio, con resultados idénticos a los de la marihuana. De hecho, ni se eliminó el problema original de los cultivos ilícitos, ni se desmanteló la parafernalia que ha permitido que las plantaciones ilegales continúen en todas esas naciones" ${ }^{\prime 108}$.

Pero sumemos para ambos casos que en cualquier tipo de plaguicida agrícola apenas el " $1 \%$ llega al insecto plaga en una aplicación aérea, otra parte se queda en el follaje, otra pasa al suelo y de ahí puede filtrarse más profundamente, llegando incluso a contaminar el agua subterránea”109.

La ESol narcoviolenta mexicana es el primer abastecedor de droga de EEUU. "Se calcula que pasan de contrabando el $90 \%$ de la cocaína, la mayor parte de la marihuana y la metanfetamina... y una cantidad importante de heroína. La DEA hace más de un decenio que lo reconoce en informes que presenta al Congreso" (Grillo, 2012, p. 386).

Así en la actualidad de las ESol narcoviolentas en México y de manera adicional a los denominados cárteles de Sinaloa, del Golfo, del Pacífico, de Los Zetas, de los Arellano Félix, de los Carrillo Fuentes, de la Familia, de los Beltrán Leyva y del Norte del Valle, que se encuentra como un cártel activo en México, se informa de nuevas "estructuras de crimen organizado: el cártel de Jalisco, La Resistencia, La mano con Ojos, La nueva Administración, el cártel independiente de Acapulco y las bandas de la Barbie y sus suegro" (El Universal, 2011h)” (Garay, 2012, p. 303-304). Y por supuesto a los Caballeros Templarios.

Es importante resaltar como el cártel del Norte del Valle que se dice desarticulado en Colombia es considerado una ESol narcoviolenta trasnacional y activa en 2014 en México.

La transnacionalización de las ESol narcoviolentas mexicanas ha extendido su negocio mundialmente pues se detectan "en campos tan alejados como Australia, África e incluso Azerbayán. A menudo las excursiones son para comprar ingredientes...sobre todo seudoefedrina y efedrina... En 2008, en una operación patrocinada por la ONU, la Operación Ice Block, fueron aprehendidos en todo el mundo 46 cargamentos ilegales de las referidas sustancias; la mitad se

108 Comisión Nacional de los Derechos Humanos (CNDH) de México. Consultado en su página oficial el 20.2.2014.

109 US. Congress Office of Technology Assessment, 1990, Report Num. OTA 4-4 418. Consultado el 20.2.2014. http://www.caata.org/impactos_en_el_aire_por_plaguicidas.html. Consultado el 20.2.2014. 
dirigía a México. Los países de origen eran, entre otros, China, La India, Siria, Bagdad ${ }^{110} \ldots$ en muchos casos, los cargamentos... hacen escala en África antes de cruzar el Atlántico" (Grillo, 2012, p. 398). 


\section{CAPÍTULO XI: NARCOVIOLENCIA EN COLOMBIA}

La Colombia contemporánea se caracteriza por su permanencia a lo largo de sus casi 6 décadas de violencia política por "confrontaciones directas entre grupos guerrilleros, paramilitares, narcotraficantes y narco-paramilitares. Todos estos grupos han afectado instituciones democráticas... algunas veces confrontándolas, otras veces saqueándolas con la intimidación o aún en la cooperación de funcionarios públicos y otras más infiltrándolas y utilizándolas para sus propios intereses, incluso criminales" (Garay, 2012, p. 69).

El Estado colombiano es lamentablemente conocido por los aberrantes vejámenes a los DDHH cometidos dentro de su prolongado conflicto armado. No obstante, debemos empezar diciendo que tan solo el 10\% (Bagley, 2012) de los homicidios dolosos suceden por causas del conflicto y el resto ocurre por crimen organizado y común. Así, debemos partir de la concepción de una violencia con arraigo en tierras colombianas mucho antes de la presencia narcoviolenta.

\subsection{LA NARCO-ACTIVIDAD COLOMBIANA DESDE LA ESCUELA CONTEMPORANEA DE LAS RELACIONES INTERNACIONALES}

La etapa contemporánea de la violencia en Colombia se desató a partir del Bogotazo, revolución que dejó miles de muertos y que desató por el asesinato de Jorge Eliécer Gaitán, el caudillo liberal, ocurrido el 9 de abril de 1948 en la ciudad de Bogotá. La gente se armó como pudo, hasta el ejército y la policía proveyó algunas armas con el objetivo de asesinar al presidente Ospina. Sin embargo, las municiones del pueblo se agotaron tras un real y largo intento de entrar hasta su oficina a perpetuar el hecho. Ospina manifestó que los responsables fueron moscovitas, procediendo a romper relaciones con la Unión Soviética. Mientras que el supuesto asesino material Juan Roa Sierra fue linchado, los más cercanos a Gaitán, sostienen que fue la CIA quien ideó el crimen mediante la Operación Pantomima.

Tras este escenario comenzaría la mayor guerra civil que haya vivido Colombia. Un enfrentamiento a sangre fría entre los partidos políticos tradicionales de ese entonces: el conservador y el liberal. Esta guerra civil se conoció con el nombre de la Violencia, cuyo recorte temporal ocurrió entre 
1948 y 1960 y que se caracterizó por el ejercicio personalista, letal y discriminatorio de la política, produciendo la percepción del "sistema político como cerrado y como agotadas las vías democráticas de reforma del Estado, lo que condujo a algunos grupos radicalizados a la opción armada"(González, 2006, p.297).

Las disputas bipartidistas propiciaron el surgimiento de grupos guerrilleros que rechazaban el funcionamiento que se hacía del sistema político y del Estado. En 1949 el Partido Comunista expidió "una directiva (por entonces en la ilegalidad y en la clandestinidad a raíz del 9 de abril) acerca de la formación de grupos de autodefensa basados en el campo" (Cubides, 2005 , p. 31). Este fue el primer antecedente de las Fuerzas Armadas Revolucionarias de Colombia - FARC. Campesinos humildes que obligados por la violencia política desatada, se fueron armando de los restos que arrojaba la guerra política de mediados de siglo XX.

En 1957, liberales y conservadores, menospreciando las diferencias que los hizo enfrentarse, consolidaron una coalición bipartidista en la figura del Frente Nacional ${ }^{111}$, logrando derrocar a Rojas Pinilla ${ }^{112}$, que lideró un gobierno Militar entre los periodos de la Violencia y el Frente Nacional. Así, liberales y conservadores, se turnaron el poder, cada cuatro años hasta 1974, extinguiendo la figura de la oposición. Todo esto en pro de la erradicación de las guerrillas, sin embargo, al terminar el período, la insurgencia se fortaleció ${ }^{113}$ mediante la exclusión legítima consolidada.

En definitiva, "un modelo de democracia pactada también estuvo vigente constitucionalmente entre 1958 y 1972, habiéndose prolongado, de hecho, hasta 1991, y amplió la participación a todas las franjas del espectro político" (Archila, 2008, p. 193). Esta Constitución debe su existencia a la iniciativa de jóvenes universitarios que mediante un plebiscito terminaron convocando a la Asamblea Nacional Constituyente.

111 En 1957 fue consolidado a través de plebiscito, garantizando la no exclusión de los partidos tradicionales en el ejercicio del poder, y la prohibición de que nuevas fórmulas políticas participaran en la dirección del Estado, limitando el sistema político a dos únicos sujetos políticos. Mediante la firma de los pactos de Sitges y Benidorm, se consolidó la coalición bipartidista y la extinción de la oposición.

112 El primer presidente del Frente Nacional en un discurso "pronunciado en el Teatro Patria, el 9 de mayo de 1958, en que se deslinda el ámbito del gobierno civil respecto del ámbito propio de las fuerzas armadas. Acabando de salir de un gobierno militar, el discurso, literalmente tan logrado, no puede considerarse, sin embargo, una orientación estratégica para todos los tiempos. Tan solo fue una manera de establecer una transición, y a la vez de estipular una transacción: autonomía creciente para los militares a cambio de no intervenir abiertamente en policiva, respondiendo a la naturaleza del pacto bipartidista del Frente Nacional"

113 El ELN surge en 1965, el EPL (Ejército de Liberación Popular) en 1967 y en 1973 aparece el M-19. 
Se confirmó el modelo establecido en 1886 referente a la organización del Estado. Las funciones políticas del Estado seguirán circunscriptas exclusivamente al nivel nacional, sin embargo, las funciones administrativas fueron ampliadas mediante la implementación del concepto de la descentralización administrativa ${ }^{114}$, que posibilita tanto a los niveles regionales como locales a ejercer funciones administrativas bajo su propio nombre y responsabilidad.

Siendo necesario aclarar que conforme nuestro objeto de estudio es necesario reiterar que solo se estudiará a las FARC pues las demás organizaciones guerrilleras contemporáneas colombianas no pueden concebirse como actores que intervienen en las actividades de las ESol narcoviolentas.

Para comprender a las FARC es necesario apropiarse del concepto de guerrilla y su evolución histórica contemporánea. La guerrilla se equipara a las definiciones de insurgencia o revolución emergentes de los trabajos producidos por obra y vida de Mao Zedong (1893 - 1976) y Ernesto Che Guevara (1928 -1967), entre los más destacados. De esta manera, guerrilla cobija a un grupo que emplea tácticas de tipo militar e irregular dentro de un conflicto bélico, tales como sabotaje, hostigamiento, y llegado el caso, acciones de tipo terrorista. Solo contemporáneamente es posible caracterizar este fenómeno de enfrentamiento de un ejército irregular contra uno de tipo regular, con el objetivo de remover el orden político establecido.

La constitución formal de las FARC se produjo en el marco de "la I Conferencia Guerrillera celebrada en 1964 (Marquetalia, Tolima)... (Cuando) se creó el llamado Bloque Sur mediante los destacamentos de Riochiquito, Natagaima, El Pato, Guayabero y Marquetalia. Dos años más tarde, en la II Conferencia (Cubides, 2005, p.39) Guerrillera celebrada en la región del Río Duda (Meta), el Bloque Sur cambió de nombre... (Pasó) a denominarse Fuerzas Armadas Revolucionarias de Colombia... (Buscó con esto) expresar la voluntad de este movimiento guerrillero de pasar de una estrategia eminentemente defensiva a una estrategia más ofensiva, para lo cual sus 350 hombres... (fueron distribuidos) en seis frentes guerrilleros comandados por Manuel Marulanda y Jacobo Arenas... concebidas por el Partido Comunista como una simple reserva estratégica, dado el caso que eventualmente se produjera en Colombia un golpe militar y se cerraran todas las vías para la acción política legal... (Para ese entonces) este grupo guerrillero se limita a un crecimiento

114 En cuanto el proceso territorial de descentralización se le otorgó autonomía a las entidades territoriales, a saber: 32 departamentos; 1.098 Municipios y; 4 Distritos /Bogotá Cartagena - Santa Marta y Barranquilla). 
puramente vegetativo... su poder de fuego se basa ante todo en las armas que pueden recuperar en el campo de batalla" (Pizarro, 2006, p. 86-76, 147 y 200).

En cuanto a la evolución de las FARC es posible observar cambios. La primera etapa puede definirse como la guerrilla partisana de carácter defensivo que se desarrolló desde 1966 y hasta 1977 y la cual se caracterizó "por un lento desarrollo del número de efectivos, y frentes y una total subordinación al Partido Comunista... se trataba entonces de una guerrilla de partido, entendida como actor subordinado a un proyecto político partidista, que ejercía funciones de dirección sobre el aparato armado" (Pizarro, 2006, p. 151). Una segunda etapa fue reconocida entre los años de 1977 y 1983 “período durante el cual, la guerrilla experimentará una primera expansión, con planes expresados en la VII Conferencia... dotada ahora de un plan y unas metas de crecimiento encaminadas hacia la toma del poder" (González, 2006, p. 40-41).

En consecuencia para que la VII Conferencia alcanzará el objetivo expansivo "fueron necesarias dos condiciones: por una parte, la tregua bilateral firmada con el gobierno de Belisario Betancur en 1984, la cual duraría tres años... Por otra parte, la naciente bonanza de la coca, el banano y la ganadería que a través del secuestro y la extorsión, darían origen a la sólida economía de guerra que habría de construir esta organización en las dos décadas siguientes" (Tokatlian, 1995, p.49).

Entre 1984 y 1987 se vivió la tercera etapa, protagonizada por la Unión Patriótica: un intento de integración política, en el marco del proceso de paz... el cual lograría su mayor desarrollo en 1984, cuando se anunció la tregua con las FARC y se hace realidad un nuevo proceso de incorporación de la guerrilla a la vida política legal colombiana.

La UP fue un movimiento político "auspiciado por las FARC, tendría como principales voceros a algunos comandantes de esta organización guerrillera, junto con dirigentes nacionales y regionales del partido comunista y otras fuerzas menores. En las elecciones locales y presidenciales de 1986, la Unión Patriótica sacaría la mayor votación que hasta entonces había obtenido una agrupación política de izquierda, aunque paralelamente, se había iniciado ya el proceso de asesinatos contra sus dirigentes a manos de grupos paramilitares". (González, 2006, p. 55). 
La Unión Patriótica fue exterminada mediante asesinatos sistemáticos en las personas de sus integrantes, perpetuados por las FFAA ilegales de derecha, representados en los grupos paramilitares.

En la década del 1990 y posterior a los acuerdos de paz celebrados en las siguientes administraciones asumidas por Virgilio Barco Vargas y César Gaviria Trujillo, fueron desmovilizados los grupos insurgentes EPL y M-19. Los espacios territoriales dejados por dichas organizaciones armadas ilegales, fueron ocupados por frentes de las FARC tendiendo a ejercer control y dominio sobre los nuevos espacios abandonados.

Una cuarta etapa que se produjo entre 1987 y 1990 denominada: Recuperación del nomadismo, reorganización y total autonomía frente al aparato político. Entre 1990 y 1993 se produce la quinta etapa comprendida desde el Asalto a Casa Verde hasta la celebración de la VIII Conferencia Guerrillera. Lo que puede sintetizarse diciendo que mediante operativo militar Casa Verde su sede central donde se concentraba el Secretariado de las FARC fue atacado, no obstante haber estado destinado por el gobierno, para el cese al fuego, logrando la concentración territorial de la elite guerrillera. Por este motivo, las FARC inició una estrategia ofensiva que fue catalogada como una de las más grandes en la historia de dicha organización subversiva, alcanzando en los años de 1991 y 1992 los registros más altos en cuanto acciones bélicas se refiere.

La organización en la VIII Conferencia de 1993 inició un proceso que buscó replantear y preparar un "ejército capaz de pasar de la guerra de guerrillas a la guerra de posiciones... exporta claramente la absoluta independencia de las FARC frente al reducido aparato político que quedaba y plantea la necesidad de construir un nuevo movimiento político de carácter clandestino, denominado Movimiento Bolivariano" (González, 2006, p. 142).

Iniciando el siglo XXI, la estrategia fue consolidándose como amplia. Un resultado para el uso de la “combinación de todas las formas de lucha" (González, 2006, p. 54). Según las FARC y sus comunicados, su organización "es una estructura de orden nacional que cuenta con una línea de mando y en la que el principio de obediencia irrestricta es una pauta básica de funcionamiento". (González, 2006, p. 43). 
El grupo armado al margen de la ley pasó de unos cientos de guerrilleros que se proveían de las armas recuperadas luego de la finalización de los combates contra el Ejército y la Policía Nacional a "tener una tropa superior a los 20.000 hombres armados con modernos fusiles, ametralladoras, RPG y toda una tecnología de armas de fabricación propia, que les permite enfrentar al ejército en combates de movimiento. En 1998, la capacidad del aparato de guerra de las FARC quedó demostrada cuando llevaron acabó operaciones contra el ejército como Patascoy y las Delicias" (Duncan, 2005, 71).

En consecuencia a la crisis internacional representada en las pésimas relaciones bilaterales internacionales entre la administración Samper con el gobierno de EEUU, el entrante gobierno de Pastrana, cambió el rumbo de los acontecimientos, debido a la instalación de unas nuevas bases para relacionarse con EEUU, que estrechó sus vínculos con la nueva administración colombiana.

Las FARC, fueron soberanas en el Caguán ${ }^{115}$, territorio Colombiano cedido por Pastrana, donde ejercieron "el poder militar indiscutido"(Cubides, 2005,p. 137). Y se le concedió el status político de beligerancia. Los requisitos para declarar la beligerancia prácticamente desde 1900 son: "a. Existencia de una guerra civil dentro de un Estado...b. Ocupación de una parte sustancial del territorio por parte del grupo insurgente. C. ejercicio de administración e imposición de orden en el territorio de control por parte del grupo rebelde. D. Observancia de las reglas de derecho de la guerra por parte del grupo subversivo bajo la dirección de una autoridad responsable" (Lootsteen en Heyck, 2011, p. 232).

Ahora bien, el secuestro de tres indigenistas estadounidenses por las FARC, logró que EEUU suspendiera los diálogos y "no solo suspendió cualquier diálogo formal e informal con esta organización guerrillera, sino que también empezó a reducir el compás de espera que le había dado al gobierno de Pastrana con respecto al proceso de paz" (Lootsteen en Heyck, 2011, p. 89).

Vendría la imposición consentida del Plan Colombia se hizo notoria la separación y distanciamiento entre las partes en el proceso de paz. Luego de casi 4 años de existencia de una zona establecida estrictamente por tres meses en noviembre de 1998, fue solamente hasta "el 20

115 Zona de distensión (42.139 Km2); anteriormente constituía una reserva biológica, y es geográficamente, el sueño de toda organización guerrillera. 
de febrero de 2002 (cuando) se rompieron las negociaciones de paz" (Lootsteen en Heyck, 2011, p. 297).

Este condicionamiento externo que superó al sistema político y el Estado colombiano "nació en inglés - Plan for Peace, Prosperity, and the Strengthening of the State (Plan para la paz, la prosperidad y el fortalecimiento del Estado), - es el título original del proyecto de Ley S1758 presentado por los senadores Mike DeWine, Grassley y Coverdell el 20 de octubre de 1999, ante la sesión 106 del Comité de Relaciones Exteriores del Congreso de EE.UU”116.

La traducción posterior del documento generó la impresión de que este había sido elaborado en Washington y no en Bogotá... el gobierno (colombiano) decidió elaborar una nueva versión del Plan Colombia enfatizando ante todo en las cuestiones sociales y económicas" (Pizarro, 2006, p. 279).

En síntesis, el Plan Colombia, constituye "una respuesta (a): reconstruir las instituciones estatales (y) (b) debilitar el narcotráfico... un paquete insuficiente... pues importantes dimensiones de la crisis colombiana no están siendo abocadas con la misma profundidad... (y) cuestionable, pues el modelo de la lucha contra las drogas tiene múltiples aspectos negativos" (Pizarro, 2006, p. 259260).

Con el Plan Colombia se militarizó "la lucha antinarcóticos sustentando que pese a que la lucha contra el narcotráfico es una actividad prioritaria para la Policía, el estrecho vínculo con los grupos armados ha forzado a las Fuerzas Militares a concentrarse en la guerra contra esta amenaza"(Pardo, 2004, p. 206).

La cristalización de la extinguida frontera entre la lucha antinarcótica de la subversiva se dio "a partir del 11 de septiembre de 2001 en el marco de la política de Washington tendiente a conformar una Coalición Mundial Antiterrorista, (donde) se abrieron las compuertas para la utilización directa de estos recursos en la guerra interna contra las organizaciones no estatales"(Pizarro, 2006, p. 257).

116 www.visionesalternativas.com 
De este modo, “George W. Bush quebró la línea invisible que separaba la lucha antinarcóticos y la contrainsurgente, permitiendo que la totalidad de los recursos del Plan Colombia y la Iniciativa Andina se pudieran utilizar tanto para uno como para otro" (Pizarro, 2006, p. 285).

La Iniciativa Regional Andina, amenaza a la región, incrementando gota a gota las hostilidades interestatales. Entonces, según la posición crítica en torno al componente de la ayuda norteamericana, sostuvieron que al "visualizar desacertadamente a las drogas como el foco principal del problema colombiano, se cometió el error, como consecuencia, de entender el apoyo al componente social, como soporte para hacer sostenible las tareas antidrogas y no como base para recuperar territorios en el contexto de la guerra" (Vargas, 2005, p. 89). La Unión Europea se distanció de las cuestiones pertinentes al Plan Colombia.

Desde los primeros informes oficiales de la administración Pastrana se hizo de público conocimiento solamente una cara de la moneda, es decir, "la parte blanda de la estrategia, consistente en el apoyo internacional a las negociaciones a través de la Diplomacia para la Paz. Pero como las conversaciones de paz se emprendieron en medio del fuego y en el marco de la lucha contra el narcotráfico, la parte dura de la política fue concebida posteriormente: a nivel doméstico, una restructuración y refuerzo de la capacidad de las Fuerzas Armadas para enfrentar la amenaza de los grupos guerrilleros, y el fortalecimiento de la estrategia contra las drogas, principalmente, a través de la intensificación de las fumigaciones de los cultivos ilícitos con el objetivo de debilitar la principal fuente de ingresos de la subversión y los paramilitares; y en el frente internacional, la promoción del Plan Colombia para financiar estas estrategias" (Pardo, 2004, p. 191 - 192). Fue aprobado por el Congreso de Estados Unidos en junio de 2000" (Pardo, 2004, p. 202).

La rama legislativa del poder público de EE.UU, destinó 1.3 billones de dólares como contribución, tal magnitud, como lo que aporta a sus aliados Israel y Egipto. Del aporte "aproximadamente el $80 \%$ de los recursos fueron donaciones en especie, tales como helicópteros nuevos Black Hawk y repotenciados Huey" (Pardo, 2004, p. 203). 
Las estadísticas muestran que la mayoría de los desplazamientos por violencia ocurren en las zonas donde se planean o ejecutan megaproyectos. Los paramilitares "controlan las rutas claves... el lavado de dinero y... un 70\% de las exportaciones de droga" (Zellic, 1999).

Según la UNODC en Colombia se habían fumigado más de 1,652,840 hectáreas a 2011. Solo ha logrado potencializar los daños en la salud de los consumidores tanto de sustancias lícitas como ilícitas que diariamente están nutriéndose de contaminantes químicos insertos en el medio ambiente como el conflicto en la vida de los colombianos.

Las aspersiones indiscriminadas con poderosos químicos que no corren la desdicha de ser clasificados como ilegales generan efectos a la salud de los pobladores de la región, que no son terroristas, y que sin embargo, padecen ser el blanco directo no solamente de las acciones de los actores nacionales al margen de la ley sino también del inhóspito abandono del Estado en su política nacional.

Soluciones del primer mundo que generan múltiples "reacciones alérgicas de piel como dermatitis, impétigo, abscesos, dolor abdominal, diarreas, infección respiratoria aguda... bronquitis, gripe y resfriados... la visita realizada el 9 de febrero de 2001 a la vereda El Rosal, del Valle del Guamez, permitió entrevistar al dueño de una de las fincas afectadas por la aspersión aérea con agroquímicos; esta persona refirió que se encontraba en el potrero de su propiedad en momentos en que las avionetas pasaban fumigando y al ser alcanzado por la fumigación, presentó reacción dérmica con intenso escozor y dolor de cara. Además, señaló la muerte de gallinas, pollos y ganado porcino... muerte de matas de plátano, yuca, borojó, jadín y otras plantas... sequía de varias hectáreas de pasto para ganado así como de la quebrada que atravesaba el potrero de su finca" (González, 2006, p. 181-182).

Por otro lado, los demócratas argumentaron promover e incrementar el nivel máximo de fumigaciones con glifosato al territorio colombiano, acertando en "afirmar que la reducción de la oferta de drogas por esta vía fue insignificante respecto de la meta del 50\% propuesta por el Departamento de Estado, e incluso contrarrestada por un fuerte incremento en la productividad de las cosechas y el procesamiento que ponen en cuestión el propio indicador de éxito de la política... en números crudos eso significa que por cada hectárea de coca efectivamente 
erradicada fue necesario fumigar 38.5 has, con las connotaciones socioeconómicas, ambientales y humanitarias que pueden derivarse de un procedimiento tan intensivo e indiscriminado en su aplicación" (Puyana, 2007).

No obstante, Bush junto con congresistas republicanos contradijeron lo afirmado por los argumentos demócratas. Los primeros sostuvieron que el Plan Colombia "no ha fracasado porque está agotando las reservas de droga acumuladas por la mafia y llevando a su límite inferior la capacidad de las FARC para financiarse con los dineros provenientes del monopolio de la pasta básica y la exportación de una parte importante de la cocaína. Aunque les disguste el proceso con los grupos paramilitares y muchos narcotraficantes se escabullen a las solicitudes de extradición en su contra, su desmovilización y significará la entrega real de cultivos, rutas y laboratorios, aunque no en la proporción esperada y deseada" (Puyana, 2007).

Cabe resaltar que en el 2004 se concentraron las aspersiones aéreas en 4 departamentos del territorio colombiano y fueron distribuidas casualmente de la siguiente manera: "una cuarta parte de las fumigaciones se adelantó sobre Nariño, otra cuarta parte sobre Guaviare y otra cuarta parte sobre Caquetá y Putumayo... sin embargo, sobre este último sólo se llevó a cabo el 2.8 de las fumigaciones lo cual muestra serias inconsistencias si se trata de responder con esa estrategia frente a la concentración de cultivos de coca... lo que las comunidades perciben a partir de estas cifras, es que existe una selectividad en el impulso de las acciones de fumigación más asociadas a la ofensiva de la guerra contra la cúpula insurgente, que al diseño de una estrategia antidrogas rigurosamente decidida ya evaluada" (Vargas, 2006, p. 116).

Así, las fumigaciones son más una estrategia contrainsurgente que anti-narcótica, pues se trata de destruir los ingresos de los grupos armados irregulares, en especial las FARC. No obstante, las fumigaciones se convierten en un arma de guerra y viola los principios básicos del DIH como demuestra la mera exposición de los impactos sociales y ambientales que genera. Muertes, desplazamientos, enfermedades, abortos, devastación, angustia, afectaciones de cultivos lícitos, contaminación de suelo, aire y fuente hídricas, poniendo en peligro la segu1nda biodiversidad más rica que existe en el mundo. 
El dinero recibido se destina "en particular contra las FARC y no tanto contra otros grupos armados que intervienen en las diferentes fases y regiones del narcotráfico... En efecto, ningún esfuerzo por restaurar la legitimidad del gobierno tendrá éxito a menos que el Estado recupere su monopolio del uso de la fuerza, y considere a todos los ejércitos privados como amenazas importantes a la gobernabilidad democrática" (Arnson en Vargas, 2006).

Lo anterior revela un desfase "en los criterios de focalización y aprobación de recursos para el apoyo directo a los departamentos y municipios con una alta dependencia en la economía ilegal de los cultivos de coca y amapola" (Arnson en Vargas en Vargas, 2006).

Adicional a esto, el manejo diario e ingenuo de los cocaleros respecto al uso de los insumos químicos en el proceso del cultivo de narcóticos potencializa los riesgos de ser víctimas de daños irreparables a su salud y al medio ambiente.

Resulta contradictorio como durante la presidencia de Uribe se lanzó una campaña denominada responsabilidad compartida mediante la cual se pretendió demostrar a los consumidores de cocaína los daños ambientales que genera la producción de la misma pero no expuso los daños que genera la fumigación aérea de químicos norteamericanos. “Asperjar con glifosato es como echar gasolina en un incendio, para después pretender que es lo mejor que hay para apagar el incendio" ${ }^{117}$.

Ecuador ha sido el principal precursor indirecto de la protección ambiental en Colombia denunciando las fumigaciones aéreas que conllevan daños internacionales transfronterizos. En 2007 el Plan Ecuador dentro de sus finalidades se propuso afirmar una política de defensa basada en la protección de la población, de los recursos naturales, del patrimonio nacional y el control efectivo del territorio. Adicionalmente Ecuador en 2013 reportó que 135.000 colombianos buscan protección internacional en su territorio. ACNUR lo expresó como el Estado líder en brindar refugio en el hemisferio occidental.

117 Amira Armenta. Drogas y conflicto en Colombia - Perspectivas para la paz. http://colombiadrogas.wordpress.com/2008/05/27/\%c2\%bfla-responsabilidad-de-quien/\#more-58. Consultado 9.2.2014. 
El Ministerio de Relaciones Exteriores ecuatoriano ${ }^{118}$ en 2007 demandó ante la OEA ${ }^{119}$ la continuación de las fumigaciones que constituyen una violación al derecho internacional (Moreno, 2009). En el mismo año inició demanda contra Colombia en la Corte Internacional de Justicia ${ }^{120}$, ante lo cual Colombia informó parar las fumigaciones tóxicas cerca de la frontera ecuatoriana pero siguió y sigue envenenando en donde dice ejercer soberanía.

Adicionalmente, y "aunque es cierto que la producción ilícita de estupefacientes es responsable de una parte del drama ecológico, no es, sin embargo, la principal responsable del ecocidio en Colombia. Otros sectores económicos, como la ganadería extensiva o la creciente instalación de monocultivos como el de la palma aceitera han contribuido mucho más que la coca al deterioro de los ecosistemas" (Quimbayo, s.d.).

Durante la administración de Uribe y con el aval del Consejo Nacional de Estupefacientes, dirigió la amenaza sobre "los parques nacionales naturales, en donde la fumigación estaba prohibida... existen 50 parques naturales que cubren 10 millones de hectáreas y se hallan entre las cinco principales redes de parques del mundo en cuanto a diversidad de plantas, anfibios y reptiles" (Vargas, 2006, p. 17).

El Plan Patriota, "la ofensiva militar más grande de la historia colombiana contra los grupos armados, a mediados de 2003, marcó también una etapa de mayor intensidad en la cooperación militar entre Colombia y Estados Unidos... el Comando Sur del Ejército de los Estados Unidos participó activamente en su diseño, fue protagónico en su ejecución... a comienzos de $2004 . .$. 1,400 (800 efectivos en las tropas y 600 contratistas estadounidenses)" (Vargas, 2006, p. 90-111), fueron destinados a nuestras tierras.

Conforme lo afirmó el “jefe del Comando Sur, General Brantz Craddock...A pesar de los reveses, el Plan Patriota supone un aprestamiento militar inédito en las Fuerzas Armadas, del que se espera(ba) una ofensiva definitiva sobre las FARC en los próximos años. Ello justificaría la segunda fase del Plan Colombia" (Puayana, 2007).

118 Ministerio de Relaciones Exteriores Comercio e Integración del Ecuador. www.mmrree.gov.ec. Consultado el 20.2.2014 119 OEA (2007). Comunicado de Prensa; “Ecuador presenta en la OEA reclamo a Colombia por fumigaciones de herbicidas en la frontera”; 9 de Enero del 2007. 120 ECUADOR INMEDIATO. Periódico instantáneo del Ecuador. "Declaraciones de Înigo Salvador", -abogado del Estado ecuatoriano en el caso de la demanda del Estado ecuatoriano a Colombia ante la Corte Internacional de Justicia de la Haya por las fumigaciones con glifosato-. www.ecuadorinmediato.com/noticias/100437. Edición del 27 de julio del 2007. 
El eje principial de la Seguridad Democrática es "el plan de guerra contra las FARC, El llamado Plan Patriota se sobrepuso al Plan Colombia... su nueva versión el Plan Consolidación, cambió los precarios logros alcanzados antes con inmensos costos, reduciendo de manera notable la capacidad ofensiva de las FARC. Sin embargo, la tendencia a la guerra sucia en el país, adicionada a la presión presidencial por resultados, ha empañado esos logros con crímenes atroces" (Leal, 2011, p. 66).

El concepto narcoguerrilla (la simbiosis entre grupos guerrilleros y grupos de narcotráfico) fue por primera vez percibido por el mundo en 1982 y al igual que los orígenes del concepto de narcoterrorista, se lo debemos a la gestión estadounidense realizada en Bogotá por el ex embajador Tambs (procesado posteriormente en Costa Rica por delitos de narcotráfico), cuando el M-19 tomó el Palacio de Justicia en 1986. Desde allí utilizado intensamente "sin pruebas contundentes, ha sido constantemente repetido tanto en los medios de comunicación como en artículos publicados en revistas especializadas"121.

Definiciones como narcoguerrilla y narcoterrorismo se orientan a privilegiar el uso de "acciones militares y direccionar la asistencia policial y militar norteamericana hacia actividades de contrainsurgencia. Estos conceptos reducen la visión y el tratamiento político y social del problema de la violencia, buscando asociar a las Fuerzas Armadas de la región con la proyección andina de la política militar de los Estados Unidos"122.

De otra parte, hay quienes sostienen que "la guerrilla ha hecho del dinero no un fin en sí mismo sino un medio, uno de sus principales recursos políticos y, obviamente, el sostén e impulsor de su capacidad bélica"(Rangel, 2000, p. 75). Las FARC-finanzas cuentan igualmente con "dimensiones menos territoriales en la extorsión y el secuestro" (Lair en González, 2006, p. 74).

Manteniendo todo "un sistema impositivo y fiscal sobre las diferentes actividades económicas de la región, especialmente sobre los transportadores, los comerciantes y medianos propietarios, a través de las amenazas. Así mismo, son objeto de amenazas e intimidaciones las familias o

121 RESA, Carlos. "Crimen organizado transnacional: definición, causas y consecuencias". Universidad Autónoma de Madrid. www.uam.es.

122 CELI, Pablo. "El área andina: entre la geopolítica regional y las vicisitudes nacionales". Director de la Fundación Ecuatoriana de Relaciones Internacionales y Estratégicas (FERIS). Profesor de la Universidad Central del Ecuador. www.revistaquorum.es 
personas que prestan sus servicios por contratación a las compañías petroleras" (Lair en González, 2006, p. 160).

No obstante la diversificación de sus finanzas, desde "la década de los noventa, el fortalecimiento las FARC sigue su marcha en estrecha relación con el proceso de producción de base, refinación y transformación del alcaloide" (Echandía, 2004, p. 68).

Si bien están insertos dentro del proceso narcotraficante éste no constituye su finalidad teórica sino un medio para financiar su lucha por alcanzar el poder en Colombia. Aunque en la práctica es prácticamente escasa la percepción de que la guerrilla persiga la toma del poder.

Al vaivén de los considerandos políticos de las FARC ha sido diversamente teorizada como una organización subversiva que en 1999 contó status de beligerancia, escasos 7 años después, le fuera negado siquiera su condición subversiva y se le remplazara a la naturaleza jurídica y conceptual ambigua a una de organización terrorista. Y en 2014 pro beneficio del actual Marco Jurídico para la Paz, se desusó la expresión terrorista, por el uso intencional, de la expresión de guerrilla.

Gran parte de los ex secuestrados comentan que "la mayoría de los ex secuestrados, la mayoría de los guerrilleros son niños o jóvenes analfabetas, que no tuvieron ninguna opción de vida diferente de la guerrilla; ingresaron por mínima supervivencia, para poder tener alimentación y vestido, pero una vez incorporados pierden todos sus derechos, vínculos familiares y hasta el nombre. No pueden formar pareja sin permiso, e incluso se les prohíbe tener hijos. A las mujeres se les obliga a abortar. No pueden nunca desertar de las FARC y si lo hacen son ejecutados. La lógica que se maneja para lograr la disciplina es la del temor". Como "lo describen los tres norteamericanos, los guerrilleros parecen niños disfrazados para el Halloween, que portan armas y visten camuflado y, como lo cuenta el ex diputado Sigifredo López, a veces juegan con carritos" (Heyck, 2011, p, 441).

En la Administración Santos Calderón el Marco Jurídico para la Paz se calcula el número de guerrilleros de las FARC en menos de 8 mil hombres. Los diálogos de paz no cuentan con cese de hostilidades. Se dialoga mientras se combate. 
Mientras que EE.UU y el sistema internacional condenó a las FARC como agentes del terror, existe un extraño beneplácito que se convierte en condecoración al gobierno colombiano por la querencia política de lograr la paz.

Sintetizando el recorrido en 2014 de dichos diálogos (Arias, 2013, p. 1) podemos manifestar que desde el pasado 14 de junio de 2012, Santos recibió aprobación por parte del poder legislativo al proyecto de ley que puso a su consideración y cuyo objeto principal trata sobre la reinserción o reintegración de actores al margen de la ley, en principio, integrantes de las FARC. Una vez Santos venció en 2014 y fue reelecto; Uribe alista su venganza desde el Congreso.

Los puntos que faltan acordar revisten también importancia, como la lucha contra el narcotráfico y el establecimiento de una Comisión de la Verdad, que pretende reparar a las víctimas del conflicto armado a nivel material. Consideran los negociadores del gobierno que los acuerdos convendrían a la reducción significativa del narcotráfico por ser las FARC uno de los principales actores de la ESol narco-violenta.

No obstante los diálogos están avanzando muy lentamente. Santos refirió en octubre de 2013 a través de los medios de comunicación que aquellos que están en contra del proceso de paz son buitres, más exactamente refirió: “A esos buitres del miedo, que les gusta que la población siga con miedo para poderla manipular. A esos buitres que viven de los muertos, de la guerra, no les gusta que los campesinos que hayan sido desplazados por la violencia, les devolvamos sus tierras". A lo que Uribe respondió: "Buitres nos dice el Pte. Santos en equipo con su aliada Farc. Respuesta 'La Patria por encima de los violentos' y de sus promotores". Lo anterior denota un ánimo preelectoral a las presidenciales de mayo de 2014. Y la paz y el bienestar nada que acechan.

En síntesis, consideremos que mientras "las FARC se propusieron destruir la institucionalidad pública colombiana, el paramilitarismo se fijó el objetivo de posesionarse de ella y utilizarla en su beneficio" ${ }^{123}$.

\footnotetext{
${ }^{123}$ Ávila Martínez, Ariel Fernando. Injerencia porlíca de los grupos armados ilegales. López, Hernández, Claudia. (2010). Y refundaron la patria... de cómo mafiosos y políticos reconfiguraron el Estado colombiano. Debate, Rando House Mondadori, Bogota, pp.84.
} 


\subsection{LOS NARCOTRAFICANTES}

El narcotráfico encontró su origen en los años 60 y 70 con el auge de la marihuana y experimentó mutaciones que terminaron de acoplarse en las dos últimas décadas del S. XX con el incremento sorpresivo de la cocaína y la heroína en menor medida y la consolidación de los principales Cárteles de la droga, de Medellín (Pablo Escobar) y Cali (los hermanos Rodríguez Orejuela). Las rutas de transporte que utilizan, han sido las mismas que ha recorrido el contrabando ilegal, desde los inicios de la historia.

El concepto de cártel ha sido usado generalizadamente sin atener precisos elementos teóricos. No todos los que han sido denominados cárteles son fieles organizaciones ilícitas vinculadas al tráfico de drogas o de armas que convienen entre varias empresas similares para evitar la mutua competencia y regular la producción, venta y precios en determinados campos industriales (Grillo, 2012, p. 95". Lo anterior puede resultar de la actividad de las ESol Narcoviolentas pero no de los grupos organizados aislados del narcotráfico.

Ahora bien, "a grandes rasgos se pueden identificar cuatro tipos de agentes en la cadena productiva del narcotráfico. Los llamados cocaleros son el primer eslabón; los intermediarios, que frecuentemente hacen parte de ese mismo primer eslabón, procesan la hoja de coca en pasta de base; los distribuidores aceitan la ruta de exportación; y los acumuladores que se encargan del lavado y reinversión de las ganancias. Un capo contacta y comanda los cuatro tipos de agentes de la cadena" (Ávila, 2010, p. 136).

El narcotráfico representa un grupo de presión trascendental. Cuyas fronteras no son susceptibles de determinación, debido a que constituyen diversas naturalezas o usos de aplicación y adaptabilidad. Los narcotraficantes interactúan de múltiples formas dentro de la actividad narcótica (Vargas, 2006, p. 138), valiéndose a su vez de múltiples actores que en sí mismos, no contemplan el narcotráfico como un fin sino como un medio, tal y como se estableció anteriormente (Duncan, 2006, p. 55-56), al referirnos a las FARC. 
Así que debemos aclarar que primero hablaremos de aquellos que se dedican al narcotráfico como una finalidad meramente económica, y luego, trataremos los casos en que estos se han disuelto en grupos paramilitares (Murillo, 1995, p. 225-226). Ahora llamados BACRIM.

Consolidándose el paramilitarismo como un narco-actor funcional al Estado. Su mayor expresión fue alcanzada por las AUC, organización de extrema derecha cuya constitución formal se produjo a finales del siglo XX y que sin embargo echó profundas raíces al unísono del recorrido históricopolítico que hasta aquí hemos realizado. De esta forma, en la década del 60 se consolidaron paralelo al proceso de germinación insurgente, las células de legalidad intermitente.

El origen del paramilitarismo según la versión oficial se sucede en el Magdalena Medio, una zona que fue colonizada por las FARC, guerrilla que cobraba cuotas por seguridad y apoyo a la organización a los pobladores del lugar e incrementó los mismos rápidamente. Pagos forzados (denominados vacunas) motivaron a "los terratenientes y ganaderos de la región a... organizarse. Crearon la Asociación de Agricultores del Magdalena Medio, ACDEGAM. A través de ésta asociación y mediante acciones cívicas y jornadas de salud, concientizaron a los campesinos de la necesidad de crear grupos de autodefensa. Para ello contaron con la ayuda del Ejército" (Murillo, 1995, p. 1965-1968).

Cabe señalar que se trata aquí de una organización armada de extrema derecha al margen de la ley que se compone de miembros de estratos medios y altos, pro defensa de sus intereses y territorio contra la amenaza y presencia de grupos antisubversivos y sus abusos. No se trata ya de campesinos sino de ciudadanos con conocimientos medios y con un sustento de vida cómodo, que deciden hacer justicia por su propia mano, debido a las notables incapacidades del Estado y sus FFAA de monopolizar debidamente el uso de la fuerza, según sus propias apreciaciones.

Conviene resaltar que finalizando la década del setenta e iniciando la década del ochenta emergieron "organizaciones armadas de distinto tipo como reacción a la reactivación de los grupos guerrilleros en el país" (Pizarro, 2006, p. 119). Vendían seguridad privada e imponían ahora sus propios códigos de conducta. 
Entrada la década del ochenta se propició el incremento del narcotráfico así como el proceso de consolidación de los carteles de la droga: el fundamento necesario para la legalidad intermitente de la existencia de grupos civiles armados funcionales a la fuerza pública. Por ejemplo, el grupo urbano, Muerte a Secuestradores -MAS- es uno de los tantos surgidos en la primera mitad de la década del 80 y constituyó una reacción más del narcotráfico frente a la acción insurgente. La segunda mitad trajo un proceso de expansión y captación territorial en cuanto al proyecto paramilitar se refiere, debido a que en el Magdalena Medio, especialmente en Puerto Boyacá, estaban asentadas las Autodefensas vinculadas al cartel de las drogas de Medellín, conformando un movimiento político, denominado MORENA, que no arrojó ninguna consolidación importante.

No obstante, "pocos días después del surgimiento de Morena, el Gobierno le cerró el paso mediante un Decreto (No. 1824 de 1989) que reglamentó parcialmente la ley de los partidos. En éste se establecía que los partidos políticos, para obtener personería jurídica, debían incluir en sus estatutos una declaración de sometimiento a la Constitución y a las leyes" (El Tiempo 17.8.1989). En respuesta "el Morena manifestó que si no lo autorizaban como partido político pasaría a la clandestinidad" (El Tiempo, 1989, p. 266).

Simultáneamente se sucedieron las incursiones territoriales de las Autodefensas de Córdoba y Urabá, haciendo uso del método masacre, según las órdenes de los hermanos Castaño Gil (Duncan, 2005). Por su parte, y paralelo al efectivo exterminio de los miembros de la Unión Patriótica, bajo el liderazgo de Víctor Carranza, otros grupos urbanos se asentaron en los municipios de San Martín, Puerto López y Puerto Gaitán. Así, "muchos jefes paramilitares, sin abandonar su mentalidad contra-guerrillera (comenzaron) a transformarse lentamente en señores de la guerra" (Pizarro, 2006, p. 138).

Entre 1990-1994, se presentó un relativo estancamiento debido a la muerte de Rodríguez Gacha y producido el desmantelamiento de los grandes carteles, la administración del departamento de Antioquia que lideró Uribe, encendió el interruptor de lo legal y confirmó la necesidad de las Asociaciones Comunitarias de Vigilancia Rural, avaladas mediante Decreto 356 de este mismo año, denominadas CONVIVIR ${ }^{124}$, involucrando nuevamente a civiles armados bajo la dirección de las

124 Uribe, durante su administración, protegió la existencia legal de las CONVIVIR, cooperativas de seguridad privada creadas por el gobierno nacional mediante el Decreto 356 de 1994 y una resolución del 27 de abril de 1995 de la Superintendencia de Vigilancia y Seguridad Privada. Muchos de los miembros fueron acusados de cometer graves violaciones a 
Fuerzas Armadas, que operaron localmente ${ }^{125}$. Su principal misión, estuvo destinada a la recolección de información.

Las CONVIVIR “alcanzaron su mayor desarrollo en las zonas del Urabá y del sur de Córdoba, donde empezaron a cometer los mayores desafueros; los crímenes de Lesa Humanidad obligaron al gobierno de Ernesto Samper a ilegalizarlas... tenían una doble función, por un lado, en su condición de cooperativas, podían poner a circular en la economía legal grandes cantidades de dinero sin importar su origen... por otro lado reclutaban de manera legal los ejércitos privados de los paramilitares, podían adquirir armas, dotación de uniformes, material de intendencia, municiones, transportes, equipos de entrenamiento militar y policial. Al ser declaradas ilegales... rápidamente se desdoblan en un proceso de metamorfosis hacia grupos paramilitares como brazo armado y para-cooperativas que les servían de músculo financiero" (Romero, 2011, p. 254).

Los paramilitares se constituyeron finalmente como una masa mezclada por narcotraficantes, empresarios, políticos, terratenientes, grupos de autodefensas, ex sicarios, miembros y ex miembros de las Fuerzas Armadas y de Policía, inclusive antiguos guerrilleros, capaces de cooptar territorio y posteriormente poder.

Puede afirmarse que "el narcotráfico y el paramilitarismo desarrollaron un modelo de estructura mafiosa basado en el control territorial, incluyendo la seguridad, pero no sólo la seguridad. A ese modelo de mafia colombiana se llega por varias circunstancias: 1. Por el paso de la economía marimbera a la cocalera...2. Por la traquetización y democratización del narcotráfico tras la caída de los grandes capos... y la consolidación de ejércitos privados que se produjo a raíz de esa traquetizacióin.3. Por la extensión territorial, económica y militar que la rentabilidad del negocio demandaba.4. Porque el nivel de acumulación ilegal implicó mayores necesidades de legalización de la riqueza y por lo tanto de proyección política y judicial, y de conexiones con fuente de lavado" (Ávila en López, 2010, p. 135).

los derechos humanos. Muchos de sus integrantes pasaron a formar filas dentro de los grupos paramilitares. Siendo una base bastante sólida para la expansión del paramilitarismo en el departamento de Antioquia.

125 A finales de 1997, la versión oficial sostenía que se habían concedido un poco más de 400 licencias que permitían la creación de este tipo de organizaciones civiles armadas. Las CONVIVIR pudieron existir gracias al financiamiento de empresarios que buscaban protegerse. Ese mismo año la Corte Constitucional sostuvo la legalidad de dichas organizaciones civiles armadas. 
Resultando importante contextualizar el incremento de las presencia de los denominados ejércitos privados en territorio colombiano y que se sucedió paralelamente al crecimiento cocalero, debido a que finalizando la década del 80 "el Cartel de Medellín estaba teniendo problemas para obtener suficientes suministros de base de coca para procesar la cocaína; es esta etapa, Colombia solamente era un agricultor menor... muy por debajo de Perú y Bolivia. Por ese entonces una familia antioqueña de notorios asesinos a sueldo, los hermanos Castaño de Amalfi, intervinieron para asegurar el suministro de pasta de Bolivia al cartel de Medellín. Fidel...y... Carlos fueron sicarios de alto nivel al mando de Pablo Escobar...En 1982... se unieron al MAS (Muerte a Secuestradores)... que incluía a cerca de 163 miembros, entre ellos 59 funcionarios militares, se capacitó...bajo la dirección... del famoso Gonzalo Rodríguez Gacha... con la ayuda del mercenario israelí Yair Klein... los Castaño se distanciaron de Escobar después del notorio asesinato de Fernando Galeano y Gerardo Moncada, en 1991" (McDermott, 2008, p. 70).

En 1997 con la creación de las AUC “el grupo basó su financiación en contribuciones de empresas poderosas de explotación de petróleo (British Petroleum) y de exportación de bananos (Chiquita Brands Inc.), así como de aportes de propietarios de haciendas y empresarios locales" (Adams en Bagley, 2011, p. 73).

Se ha comprobado que "entre 1997 y 2006, Chiquita Brands, a través de la filial Banandex, empresa bananera, y Drummond Compañía, a través de la filial Drumond Ltda, empresa minera, aportaron significativas sumas de dinero a jefes de frentes paramilitares en las zonas bananeras de Urabá y Santa Marta, y en las minas de carbón en el norte del departamento del Cesar. En retribución las empresas recibieron servicios de seguridad y normalización del conflictivo clima laboral en el que operaban...si bien estas empresas han sido objeto de la violencia de grupos ilegales, con la financiación dada a los paramilitares pasaron a ser un actor más de la guerra"126. Finalmente hicieron un arreglo con la justicia norteamericana que adujo un error administrativo pues siempre insistieron en su papel de víctimas y que pensaban que le pagaban al Estado por su seguridad y no ha paramilitares.

\footnotetext{
${ }^{126}$ Romero Vidal, Mauricio. (2011). La economía de los paramilitares: redes de corrupción, negocios y política. Debate, Bogotá - Colombiana, pp. 150-151.
} 
Un año después las AUC y el Cartel del Norte el Valle "fusionaron sus operaciones...el comercio de cocaína pasó de estar bajo el control de los capos narcotraficantes para depender de los señores de la guerra... el cartel del Valle siempre había tenido fuertes lazos con las FARC... algunos de sus miembros intentaron aprovechar la oportunidad de las conversaciones de las FARC con el gobierno... buscando ser incluidos como sus financistas en negociaciones futuras con el Estado... las FARC rechazaron esta oferta... por lo cual el cartel recurrió a las AUC en su lugar" (Adams en Bagley, 2011, p. 76).

No obstante entre los hermanos Castaño imperaron sus propios intereses. Así, "mientras que Carlos Castaño veía a las AUC como la manera de ponerle fin al flagelo de la guerrilla... e incluso había soñado con una carrera política, Vicente Castaño las veía como el vehículo para alcanzar una riqueza inmensa. Por ello Vicente inició la venta de franquicias de las AUC a los traficantes de droga" (Adams en Bagley, 2011, p. 76).

La interacción oficial de la organización con el Estado se haría efectiva, más allá de las "Cumbres Nacionales del Movimiento de Autodefensas... (cuando) funcionarios del orden nacional (así como) la interlocución concedida por dignatarios del parlamento (sendas entrevistas de los presidentes de Senado y Cámara de Representantes con Carlos Castaño, en noviembre de 1997, para las cuales los parlamentarios acuden al campamento de éste),... (con el) Acuerdo del Nudo de Paramillo (agosto de 1998)" (Adams en Bagley, 2011, p. 77). En el primer semestre de 1998 los grupos paramilitares “pasaron a ser llamados autodefensas ilegales” (González, 2006, p. 75).

En 2002 los EEUU acusó a Carlos Castaño por "el contrabando de 17 toneladas de cocaína. Hasta su muerte, Castaño trató de presentarse ante los medios de comunicación como enemigo del tráfico de drogas y parecía haber estado listo para entregarse a los agentes norteamericanos, de darse las condiciones apropiadas. Esta posibilidad creó divisiones profundas en las AUC, lo que llevó a su asesinato en abril de 2004 bajo órdenes de su propio hermano, Vicente Castaño" (Adams en Bagley, 2011, p. 79).

Vicente Castaño continuó al mando de las AUC y mediante la venta de franquicias paramilitares convirtió a Don Berna en "el personaje más poderoso en las AUC, terminó comprando cerca del $60 \%$ de las AUC en el norte del Valle... lideró operaciones desde su base de poder en Medellín 
(bloques Héroes de Tolová y Cacique Nutibara)... las AUC les dieron la bienvenida a traficantes de droga prominentes... como los hermanos Víctor y Miguel Mejía, alias los Mellizos en el departamento de Arauca... bajo el comando del Bloque Central Bolívar; Salvatore Mancuso (Bolívar)... Gordo lindo (Valle)... Pablo Sevillano (Nariño)... Miguel Arroyabe (Meta y Casanare)" (Adams en Bagley, 2011, p. 77).

\subsection{LA OFICINA DE ENVIGADO: NUEVA RAZON SOCIAL DEL CARTEL DE MEDELLIN}

El 28 de julio de 2008 fue asesinado Antonio López, alias Job, ex dirigente del Bloque Cacique Nutibara de las AUC. Job militó en el ELN y estuvo preso por un atentando en Medellín donde murieron 28 personas. En prisión conoció a otros que serían los líderes de las AUC y su carrera criminal cambió de bando y ascendió en ella hasta ser el primer paramilitar que intervino en las instalaciones del Congreso de la República.

Envigado "por muchos años ha sido eje de las actividades ilícitas que se mueven en el Valle de Aburrá y en Colombia... en sus 78 kilómetros de territorio... fue el fortín de... Pablo Escobar... pero a su muerte... fue Don Berna, (quien lideró el territorio)" (Serrano, 2010, p. 39-40).

Pablo Emilio Escobar Gaviria el pilar de las ESol narcoviolentas trasnacionales “ordenó el asesinato del ministro de Justicia Rodrigo Lara Bonilla... del director del Espectador, Guillermo Cano...obtuvo una curul en el Congreso a nombre del movimiento Alternativo, luego de haber sido expulsado del Nuevo Liberalismo por Luis Carlos Galán Sarmiento, a quien mandó a asesinar en 1989. Ese mismo año hizo volar en pedazos un avión de Avianca con 107 personas a bordo y organizó un atentado contra la sede del Departamento Administrativo de Seguridad - DAS - que dejó 70 muertos y centenares de heridos. Dio orden de asesinar a decenas de policías y a varios candidatos a la presidencia de la República. (En 1991 se entregó)... con dos condiciones: no ser extraditado a EEUU y quedar recluido en una cárcel hecha a su medida. La Catedral...en 1992... se fugó...el asesinato (dentro de La Catedral a sus socios por pensar que lo robaban) Moncada y los Galeano... (dichos asesinatos generaron) la conformación de dos escuadrones de persecución: uno de bandidos y paramilitares... Perseguidos por Pablo Escobar - PEPES... y el otro del Estado colombiano, Bloque de Búsqueda... (Finalmente el Capo) cayó abatido el 2 de diciembre de 1993... 
(pero) su oficina nunca dejó de funcionar" (Serrano, 2010, p. 16-17). A su "funeral de Escobar asistieron 25 mil personas" (Hernández, 20121, p. 147).

Tampoco dejaría de funcionar tras el retiro de Don Berna pues a Rey puesto Rey Muerto, el negocio no para por el cambio de dirigentes. Simplemente cambia de dirigentes. Don Berna presumió que con el asesinato de Moncada y los Galeano, la próxima víctima sería él y se unió a Ios PEPES. Y de esta manera gerenció La Oficina.

La Catedral más que una cárcel era un narco-club desde donde Escobar siguió dirigiendo las actividades del Cártel de Medellín. El mismo Capo eligió a los guardias de seguridad y dentro de su reclusión se repetían las fiestas, la entrada y salida de mujeres, amigos, socios, personajes públicos y políticos, comidas de restaurantes exclusivos y todo aquello que estuviese al antojo diario del Capo. En 2014 la Catedral ubicada en Envigado "pertenece a una comunidad de monjes benedictinos, que la utilizan como monasterio y lugar de peregrinación” (Serrano, 2010, p.45-46).

En envigado "residen una 175.000 personas que se entremezclan con la población de Medellín: las fronteras se confunden en el área metropolitana... registra el número de homicidios más bajo para ciudades de más de 100.000 habitantes en Colombia. En la década de los sesenta del siglo pasado... no se quedó al margen de la ola progresista que recorrió el mundo; los años de la gran revolución cultural, social, política y religiosa encontraron en este pequeño municipio antioqueño una comunidad estudiosa e instruida que asimiló los cambios registrados en Europa. Surgieron varios colegios de elevado nivel académico, se disparó el ingreso de jóvenes a las universidades y se inició una lucha frontal contra el analfabetismo. En los años ochenta y noventa comenzaron a observarse nuevos desarrollos urbanos... y se disparó un incremento inusitado del comercio... Por esa bonanza, algunos dieron en llamar a Envigado el Mónaco colombiano...la cobertura educativo de Envigado es del ciento por ciento... en salud la cobertura también es el ciento por ciento, registro único en Colombia" (Serrano, 2010, p. 43-44).

Una vez caído el Capo del Cartel de Medellín el negocio fue liderado por Don Berna quien le dio nueva razón social al cártel que ahora se conoce como la Oficina de Envigado, por ello la famosa desarticulación de los grandes cárteles debe ponerse en entre dicho pues ya suena como a frase leyenda en el mundo del narcotráfico, cuando lo que realmente sucedió fue la captura de sus 
capos y lamentablemente con ello ocurrió la pérdida de identificación temporal de los nuevos líderes.

Se ha sostenido que desde el desmantelamiento de los grandes carteles de la droga se dejó al descubierto "la guerra interna" (Pardo, 2004, p. 160). Resultando "paradójico que precisamente después de la consolidación de la figura de la extradición y del desmantelamiento de los principales carteles de la droga de Medellín y Cali a principios de los 90, es cuando Colombia pasa a ocupar el primer puesto en producción de hoja, pasta y clorhidrato de cocaína. Y es paradójico que esta posición se sostenga después de... años de recibir el mayor volumen de cooperación extranjera en materia de lucha contra las drogas a través del Plan Colombia" (Rangel, 2005, p. 9). En 2014, los rangos de producción de cocaína han disminuido pero no en cifras considerables. Ya no es el primer productor pero no deja de competir el pódium.

Don Berna en la clandestinidad y con las riendas del negocio próspero hizo rendir las actividades de la ESol narcoviolenta. La Oficina contaba con un "completo portafolio de actividades delictivas. Una de ellas era el control de los dólares falsos... en vida de Saddam Hussein, el marcado negro de Colombia se inundó de dinares iraquíes. La Oficina controlaba todas las transacciones de compra y venta de esa moneda. Resultó muy útil para le lavado de activos... Hussein... había autorizado a ciertos bancos de todo el mundo a recibir su dinero a unas tasas preferenciales, y pagaba con petróleo. El dinar cayó al tiempo que el presidente iraquí... Además de reglamentar el cambio, la Oficina determinaba la tasa representativa... se comenzó a manejar dinero falso con personal especializado. Los billetes eran producidos en Cali, enviados a la costa y luego a los EEUU, donde la oficina tenía managers encargados de recibirlo y de distribuirlo mediante el pitufeo, movimiento de pequeñas sumas. Para el manejo del dinero falso, la Oficina entabló en Medellín una relación comercial con la mafia rusa pero luego se hizo a un lado, dejándole a los rusos todas sus conexiones. Ellos son hoy los mayores productores de dólares falsos en el mundo" (Serrano, 2010, p. 87). Mientras que "los mayores lavadores del mundo son los bancos de los EEUU" (Serrano, 2010, p. 92).

Entre otros sectores la ESol narcoviolenta de Envigado dirigió el conflicto entre bandas o comunas en Medellín, la prostitución, cadenas de droguerías, compraventa de automóviles, juegos de azar, narcomenudeo. 
En cuanto a los juegos de azar el control fue tan nacional que la misma Enilse López alias la Gata le rinde cuentas a la Oficina (Serrano, 2010, p. 88-89). La Gata debe su alias por el nombre de su red de apuestas: El Gato. Los cuales iniciaron en Bolívar y Sucre y su poder fue creciendo hasta que su emporio familiar se hizo tan poderoso que terminó liderando sectores políticos y económicos muy poderosos en la costa atlántica.

El poder se centralizó al punto de financiar la primera campaña a la presidencia Uribe. Sin embargo, "el cuasi monopolio que lograron sus empresas de apuestas en la consta no fue pacífico, por el contrario, varios de los empresarios que abandonaron el negocio lo hicieron para proteger su vida. Otros que no se sometieron, no sobrevivieron. En 2008 se registraron 26 atentados con explosivos a empresas del chance en la costa... todas empresas de la Gata" (Romero, 2011, p. 4849).

Pero el poder construido por la Gata se catapultó cuando la rama legislativa colombiana decidió privatizar el sector salud, bajo la entonces ponencia del proyecto del mismo Uribe, para entonces senador de la República. El sistema tiene "en las loterías departamentales una de sus principales fuentes. Sin embargo, el impacto de las modificaciones realizadas en la explotación de los juegos de azar, a partir de 2001, ha permitido el fortalecimiento de una red de apuestas asociadas con el juego del chances en la que se puede encontrar de todo, desde empresarios profesionales hasta timadores asociados con el lavado y la circulación de capitales ilícitos... (así se) crearon las condiciones para el detrimento de las loterías departamentales, también abrieron la oportunidad para el surgimiento de poderosos operadores de apuestas quien con su liquidez, y la posibilidad de lavado de dinero del narcotráfico, se convirtieron en electores claves de la política regional, como ocurrió en la costa Caribe" (Romero, 201, p. 20-21).

Don Berna para defender su territorio debió enfrentarse "a los carteles de Cali y del Norte del Valle... Esto lo obligó a refugiarse en Urabá bajo la protección de Carlos Castaño... Mientras La Oficina regulaba la actividad ilegal en los centros urbanos, el Bloque Cacique Nutibara de Don Berna imponía su ley a punta de violencia en las comunas y zonas rurales. Hasta que el gobierno de los EEUU... pidió en extradición a los cabecillas paramilitares. Entonces no quedó otra que buscar una negociación de paz... y cobró forma en el acuerdo de Santafé de Ralito. Pero la oficina 
seguía operando si obedecer autoridad alguna... el camino le quedó libre a Rogelio, porque a principios de 2007 él mismo liquidó a alias Danielito, pero no contaba con la extradición de Don Berna el 13 de mayo de 2008... uno a uno comenzaron a caer los jefes de su banda... el asunto funciona como en El Cartel de Los Sapos. Rogelio y Don Berna, hablan en EEUU, y hay capturas en Colombia" (Serrano, 2010, p.100-102).

Un ejemplo de un narcotraficante que se disfrazó de paramilitar para desmovilizarse es Diego Murillo actualmente extraditado en EEUU, "Don Berna": fusionó el cartel del Medellín tras su desmantelamiento en la Oficina de Envigado asociada con el paramilitarismo. Una vez desmovilizado creó la Corporación Democracia en la cual los paramilitares desmovilizados serían capacitados. Entonces "la aparente paz que reinaba en Medellín no se debía a la desmovilización de Berna, sino más bien al resultado de su monopolio sobre el crimen en la ciudad después de derrotar a la mayoría de los grupos rivales"127. A capo extraditado capo remplazado pero la Oficina sigue marchando y las BACRIM progresando y continuando la narco-estirpe paramilitar.

Daniel el Loco Barrera fue "un experimentado criminal que establece cualquier alianza útil a sus intereses: con frentes de las FARC, para distribuir en los mercados internacionales la cocaína que ellos producen, con Varela, del Cartel del Norte del Valle; con Miguel Arroyave, el hombre fuerte del Bloque Capital de las AUC, y con su sucesor, Don Mario. Sobreviviente de varias guerras entre narcos, progresivamente acaparó el dominio de las rutas, cultivos y centros de procesamiento de alcaloides en el centro y el oriente del país, puntos clave para exportar toneladas de cocaína vía Venezuela" (Serrano, 2010, p. 168).

Una vez dado de baja Danielito la Oficina "entró a disputar territorio en el bajo Cauca y el Urabá antioqueños. Sebastián y Valenciano se plantaron en el Bajo Cauca... ya ostentaban el control de Medellín. Determinaron que Sebastián se haría cargo de la Comuna Occidental, y Valenciano de la Nororiental. Los medios de comunicación los han hecho aparecer en discordia pero no hay tal... sus delegados siguen operando bajo el control de la Oficina; en Bogotá, Cali y Cartagena el negocio está controlado por los paisas... la gerencia general sigue estando en la capital de Antioquia" (Serrano, 2010, p. 95).

127 INFORME MUNDIAL HUMAN RIGHT WATCH 2014. http://www.hrw.org/sites/default/files/reports/wr2014sp_web.pdf. Cómo la criminalización de las drogas destruye vidas, fomenta abusos y subvierte la justicia Por María McFarland Sánchez-Moreno. Consultado el 16-2-2014. 
Tan poderosa es la Oficina de Envigado que se ha confirmado que para aquella "la seguridad en los alrededores de la Oficina solían prestarla el Ejército y la Policía. Los pistoleros andaban con salvoconductos"128. El negocio de enfrentaba para seguir funcionando contra otros competidores desleales.

La presencia de la Oficina de Envigado es muy fuerte en Bogotá: "los sanandresitos, en Corabastos. Ciudad Bolívar y en los negocios de prostitución y expendio de estupefacientes a pequeña escala...Bogotá paraíso del micro-tráfico de droga (Serrano, 2010, p. 148).

En 2009 Don Berna fue finalmente extraditado a Nueva York y condenado por la justicia norteamericana a más de 30 años de prisión y una sanción pecuniaria de 4 millones de dólares (Adams en Bagley, 2011, p.90).

Desde 2010 Valenciano y Sebastián adoptaron "una tregua para disminuir la violencia en Medellín... tienen el control de parte del presupuesto participativo de la alcaldía de Medellín en las comunas, pues algunos desmovilizados del Bloque Cacique Nutibara se volvieron contratistas... después de la desmovilización" (Serrano, 2010, p. 211). La violencia a menguado a partir del narcomonopolio donde intervinieron sectores legales para asegurar dicho pacto. No obstante el negocio sigue funcionando.

\subsection{CURRICULUM VITAE ABREVIADO DE LAS AUC}

Los períodos de evolución de las AUC pueden sintetizarse de la siguiente manera: una primera etapa de incursión mediante la cual se busca despejar usando el terror generalizado, bastas zonas en las que exista influencia y dominación subversiva, territorialmente hablando, asimilando a la población civil que en dichos lugares residan como bases sociales de apoyo a los grupos guerrilleros, es decir, guerrilleros natos según sus propios principios y convicciones. De la misma manera se avanza en lo que estos grupos paramilitares denominan un proceso para concentrar las tierras, propendiendo por el desarrollo del capitalismo de tipo ganadero,

\footnotetext{
${ }^{128}$ SERRANO, Alfredo. (2010). La multinacional del crimen. La tenebrosa Oficina de Envigado. Debate, Rendom House Mondadori. Bogotá - Colombia, pp. 86.
} 
estructurando una nueva jerarquía de tinte autoritario que erija una organización social de tipo vertical.

La misma corriente doctrinal ha identificado una segunda etapa denominada de consolidación, que se compone de enriquecer la región previamente incursionada mediante la entrega subsidiada de aquellas tierras antes concentradas, usando el asesinato colectivo y los desplazamientos forzados, de manera sistemática y en diversos puntos del territorio nacional.

Es por todo esto que los nuevos pobladores configuran una última etapa "leales al patroncito, que se organizan rápidamente en grupos de autodefensas... legitimación, una vez libradas las regiones de la subversión, dejan de ser ruedas sueltas del Estado. En este sentido, se construyen las estructuras necesarias para la expansión del capitalismo y se facilita la instalación del Estado modernizante, con el concurso del sector privado" (González, 2006, p. 62).

Consecuente a todo lo dicho anteriormente "el esfuerzo investigativo debe encaminarse a observar el fenómeno paramilitar como un proyecto político, social y económico con alcances nacionales y diversidades regionales, al vaivén de las coyunturas políticas, de la interacción con sectores sociales determinados y con respecto a las políticas públicas" (Palacios, 1995, p. 60).

Por último, en el legislativo, sobornando políticos para influir en la formulación de las leyes, el uso y la amenaza del uso de la violencia y del terror, en cuanto a las elecciones se refiere, así como la efectiva presencia de parapolíticos en el Congreso. En la doble administración Uribe el $80 \%$ de la composición del Congreso, está siendo investigada o fue condenada por nexos con los grupos paramilitares.

La justicia ha condenado a 55 congresistas por nexos con los paramilitares, es decir, 55 parapolíticos. Otros están siendo investigados como cientos de funcionarios del sistema. En 2014, el hermano de Uribe, Santiago es investigado por parapolítica y homicidio; se condenó a su primo por nexos con las AUC y su jefe de seguridad General Mauricio Santoyo se declaró culpable en EEUU de colaborar con paramilitares durante el mandato de Uribe.

\subsection{NARCOALIANZAS LEGITIMADAS O NARCOPARTIDOS POLÍTICOS}


Son los partidos políticos los facilitadores de la entrada de dineros ilícitos para financiar sus actividades. E igualmente los "recursos privados que, poco a poco, han entrado a financiar las campañas, cada vez más se orientan al ganador, con independencia de su adscripción partidista. Los empresarios... han optado por invertir en las campañas de los políticos, como una alternativa de las que se espera obtener rentabilidad, actuando en defensa de unos intereses corporativos concretos. Los partidos han perdido legitimidad como instancia de representación política" (Medellín, 2005, p. 23).

En otras palabras lo que "O'Donell ha identificado como otra institucionalidad... desaparecen los límites entre lo público y privado (lo que aparece como público es en realidad privado), y entre política y economía, mientras que los políticos usan la política para enriquecerse, los empresarios financian a los políticos para obtener mayor rentabilidad en su negocio" (Medellín, 2005, p. 28.30). Todo lo dicho anteriormente, como una enseñanza aprehendida, del funcionamiento del sistema internacional y la consolidación política de las asimetrías de poder.

En síntesis, "los procesos electorales están asociados a escaladas de violencia... una paradoja de las reglas del juego de la vida política local: ganar en las urnas mediante el uso sistemático de la violencia" (González, 2006, p. 139).

De otro lado, la segunda postura proviene del sector estatal, político y mediático, "insisten en desvincular al paramilitarismo del Estado colombiano, que es presentado como un tercero en discordia (Rangel, 1998, p. 59) ... situación hace que se debilite el papel del Estado en cuanto a su responsabilidad de mantener el monopolio legítimo de la fuerza, de ser garante de la vida e integridad personal, para convertirse en testigo que pasa a desempeñar un papel contemplativo" (González, 2006, p. 59-60).

Respecto a los paramilitares y sus métodos de acción, podemos afirmar que están fundamentados en el uso generalizado del terror. Masacres y asesinatos selectivos, uso de listas negras para llamar a aquellos condenados por su organización de extrema derecha a muerte. Repitamos entonces, un “orden vertical y autoritario, en el cual rige una dinámica perversa de amigo-enemigo. Los grupos paramilitares han sido responsables de la inmensa mayoría de las masacres que se han producido 
en el país. Estas, definidas como el asesinato colectivo en el mismo tiempo y lugar de al menos cuatro personas" (Pizarro, 2005, 124).

Paulatinamente, el Estado y sus órganos armados se fueron subordinando ante los beneficios que le reportaban.

Uribe acuñó, obteniendo el beneplácito estadounidense que "en Colombia no existía un conflicto armado sino un escenario de actividades narcoterroristas" (Tickner, 2003, p.90-111), frente a lo cual dio prevalencia a la variable de la seguridad así como a los diferentes valores que de ella resultan. Narcoterrorismo, entendido este, como una formulación conceptual del norte tendiente a describir el fenómeno que resulta de la convergencia de otras dos clasificaciones de actividades ilegales: el narcotráfico y el terrorismo.

El conflicto armado Colombia es para el mundo: un test case (Pizarro, 2006, p. 257). "no podemos permitir tener estados parias poblados por narcoterroristas y terroristas internacionales en nuestro propio sur"129.

El terrorismo político va a camuflarse dentro de un proceso revolucionario de un conflicto previamente abierto. Entonces, el terrorismo político, sería la garantía de los partidos políticos dentro de un clima tradicional de violencia política. Esta clase de terrorismo político, se confunde, con el terrorismo utilizado en los grupos insurgentes que se circunscribe dentro de un proceso revolucionario o de liberación y que debe contar con apoyo popular.

Ahora bien, el terrorismo perpetuado por los grupos de extrema derecha como paramilitares, no pretende desagregar el Estado. Por el contrario trata de reforzar la presencia del mismo, por lo cual no se entiende muy bien, si es terrorismo de extrema derecha o simplemente es un terrorismo de Estado, debido a que sus vínculos son de difícil comprobación, porque el Estado es quien detenta el ejercicio del poder, y si el fenómeno terrorista le es favorable, no lo denunciará, convirtiéndolo en terrorismo de Estado, que pasa desapercibido. O denunciará parcialmente, para no parecer tan pasivo.

129 “EE.UU. debe mantener el compromiso con Colombia, dice general Hill”, usinfo.state.gov. 
Los grupos paramilitares controlaron sin disimulo alguno "el punto final de los corredores de drogas en la Costa Caribe y en el Pacífico, teniendo mayor predominio territorial sobre zonas consideradas de embarque de cocaína como Tumaco y Buenaventura”130.

El poder adquirido del paramilitarismo en el Estado colombiano puede describirse y ejemplificarse a través del claro resultado planificado y premeditado de "las reformas en el sector salud... la privatización de los servicios y su financiación, que buscó crear empresarios en el sector salud y de juegos de azar, terminó creando ventajas para delincuentes" (Romero, 2011, p. 10-11).

De esta manera, Uribe en su posición de senador en 1993 (en 2014 es nuevamente senador electo luego de ser dos veces presidente de Colombia mediante la reforma constitucional que generó inseguridad jurídica en Colombia por ser re-elegido por primera vez en la historia) proyectó la ley 100 de 1993 mediante la cual se privatizó el sector de la salud. La norma entraría en vigencia dentro de su mandato presidencial, una década después.

Las Empresas Promotoras de Salud (EPS) son las entidades responsables del manejo de los recursos inmensos del sector. Entre otros órganos principales de la nueva estructura de salud se crearon "las Cooperativas de Trabajo Asociado (CTA), modalidad de asociación entre los profesionales de salud promovida por sus empleadores, la cual reducía los costos laborales, evitaba los derechos de asociación sin violar la ley y sin garantizar una mejor calidad en la atención"(Romero, 2011, p. 15-16).

La reforma significó en las zonas lideradas por las AUC un barril de recursos con fondos infinitos del cual saciarse en cuanto al abastecimiento de sus necesidades de guerra e infiltración a círculos legales, en especial políticos y empresariales. Ahora bien, en dichas zonas de dominio paramilitar "las instituciones privadas y públicas del sector han sido el blanco de redes de intereses ilegales... o simple (imperio) enriquecimiento ilícito de... grupos de intereses entrelazados entre lo legal y lo legal" (Romero, 2011, p. 16-17).

Así se radicó "una política de salud que se fundamentaba en la idea de la oferta y la demanda, en donde le Estado limitaba su intervención. Se equiparó el servicio de salud con el resto de 
mercancías ofrecidas en el mercado, y por lo tanto su precio se calculó de acuerdo con los costos de producirlo" (Romero, 2011, p. 22).

Un ejemplo de cómo se sucedió la paramilitarización del sector salud resulta el caso de la red político-social y familiar de quien fuera senador entre el periodo comprendido durante el primer manato presidencial de Uribe (2002 -2006). Tal "red ligada con los paramilitares del Bloque Norte, se apoderó de una parte importante de los recursos de la salud en los departamentos de la Costa Caribe, a través del simple y llano saqueo de la EPS José Prudencio Padilla" (Romero, 2011, p. 19).

Paralelamente, el Hospital Materno Infantil de Soledad "tuvo como asistente jurídico a un señor Palacios, de Aspis Ltda., empresa de seguridad que trabajaba con ellos; otro de apellido García era el jefe de la oficina jurídica, y le rendía cuentas a HH del Bloque Bananero de las AUC; Aristizabal, quien se desempeñó como gerente y médico, hoy esta preso... (igual que) Palacio, quien (incriminó) a Romero" (Romero, 2011, p. 58). Igualmente, el Hospital de Santa Marta pasó a ser liderado por el Bloque Norte de las AUC.

Así mientras los pacientes morían en los hospitales se gestaban más "pactos paradójicos para referirse a un arreglo de extracción conjunta, basado en un acuerdo a través del cual se articulan actores y agentes ubicados a ambos lados de la línea que separa lo legal y lo ilegal (Gutierrez, 2003, p. 249-288) y que Ilamaremos consocional. En esencia se trata de pactos políticos que viabilizan una situación de hecho, poder compartido entre distintas facciones, en la cual se prescinde de marcos de principios comunes, reglas o instituciones específicas" (Romero, 2011, p. 84).

Narraciones "dinámicas como estas son las que dan lugar a lo que Jenny Pearce denomina como el modelo de gobernabilidad selectiva a través del cual las elites políticas del orden nacional ceden el control de extensas porciones del territorio y la población a estructuras locales de poder. La condición es garantizar una determinada cuota de votos, necesaria para mantener el control renovado del aparato estatal nacional. El modelo está abierto a la competencia entre facciones criminales con influencia en estructuras locales partidistas y estatales, y la expansión y acumulación eventuales de esas facciones puede crear un desafío incontrolable para las elites nacionales en algún momento" (Pearce en Romero, 2011, p. 86). 
Regionalmente, el paramilitarismo es entonces una claro resultado de una "alianza de intereses entre elites locales, hacendados y narcotraficantes y algunas esferas e instancias del Estado colombiano, principalmente las Fuerzas Armadas, en su nivel regional y local" (Pearce en Romero, 2011, p. 60-61).

El 15 julio de 2003 se firmó el Acuerdo de Santa Fe de Ralito ${ }^{131}$, mediante el cual el gobierno ${ }^{132}$ y las AUC, iniciaron una etapa de negociación cuyo objetivo final fue tan amplio y ambiguo, como lograr la paz nacional casi con un dictado internacionalista, debido a que los medios a emplear para alcanzar el objetivo, fueron el fortalecimiento de la gobernabilidad democrática y la recuperación del monopolio de la fuerza. De dicho Acuerdo, nació todo el fenómeno de la parapolítica en Colombia.

Es por esto que muchos afirman que "el carácter contrainsurgente del paramilitarismo es más mito político que realidad militar... también que el carácter social y revolucionario de la guerrilla es otro mito histórico... (ambos) nacieron como grupos de autodefensa, los primero del campesinado y los segundos de terratenientes y ganaderos" (Gutierrez en López, 2011, p.19).

La opción fue reconvertir a sus organizaciones sicariales en ejércitos paramilitares y obtener así los beneficios jurídicos contemplados en la Ley de Justicia y Paz -LJP- de 2005, aprobada para adelantar las negociaciones con los paramilitares" (López, 2011, p. 223).

La LJP concedió "un máximo de ocho años de prisión para quienes se supone han cometido crímenes de lesa humanidad -- son harto benevolentes, y el escándalo para-político apenas revela cuán profundamente las redes criminales representadas por las AUC han penetrado las instituciones políticas colombianas" (López, 2011, p. 223).

La LP ha sido presentada como "el primer experimento de justicia transicional en Colombia" (González en Bagley, 2011, p.115). La Justicia transicional en teoría es un tipo de "justicia extraordinaria y de excepción llamada a regular situaciones de alta turbulencia social y política

131 Del cual emana con más claridad el fenómeno nacional de la parapolítica en Colombia.

132 Representado por Luís Carlos Restrepo, alto comisionado para la paz y las Autodefensas Unidas de Colombia (AUC). 
como suelen ser las de la transición de la guerra a la paz y del autoritarismo a la democracia" (Orozco en Bagley, 2011, p. 1159). Además, "desde el punto de vista político, es un proceso en el cual se intenta atar a otros en el tiempo con el fin de: a). reducir la incertidumbre propia del paso de la guerra a la paz, o de la dictadura a la democracia; b). generar confianza a través de la aceptación de restricciones y de la reparación de los daños realizados en el marco del conflicto" (Arcia en Bagley, 2011, p. 267). Debería representar un "proceso complejo adaptados a sociedades que se transforman así mismas después de un periodo de violación generalizada de los derechos humanos" (Bagley, 2011, p. 18).

El experimento colombiano es uno de los más tardíos en Latinoamérica y sus características llaman harto la atención y desvelan los deseos jurídicos teóricos. Es un experimento con desconocimientos legítimos pero legitimados pues se sucede en medio de "la continuación del conflicto; la desmovilización de sólo uno de los actores armados ilegales; y la no inclusión expresa de la responsabilidad de agentes del Estado en el marco legal que regula el proceso" (Restrepo en Bagley, 2011, p. 567).

Se redujeron las sentencias de prisión para los terroristas desmovilizados que cooperen. Más de 32,000 miembros de las AUC se han desmovilizado y el gobierno sigue reintegrándolos a la sociedad a través de un nuevo Comisionado para la Reintegración. Miles de sus miembros han sido recapturados por homicidios y narcotráfico en 2014. Produciéndose claramente la violación de un principio fundamental del $\mathrm{DIH}$, el de distinción: que compone simultáneamente, una garantía en la promoción y protección de los Derechos Humanos.

Adicionalmente como se señaló anteriormente, muchos desmovilizados se han insertado en el fenómeno de las BACRIM, como sucesores de los paramilitares que no están bajo la lupa del gobierno y se fortalecen día a día cooptando territorios y creciendo en su narco-negocio.

Todos los efectos anteriores producto de la "flexibilidad de la cual gozaron en cuanto al cumplimiento estricto de la LJP, que terminó por generar problemas importantes de gobernabilidad en ciertas zonas del país, las cuales se encuentran hoy bajo el camino de una generación nueva de narcotraficantes" (Arias, 2011, p.508). 
Algo similar al juego de posiciones de los círculos viciosos de violencia política acostumbrados en Colombia. Los peores criminales obtienen rebajas de pena. Y una vez desmovilizados, varios de sus integrantes re-encarnan en nuevas organizaciones de crimen organizado que inician su propio círculo vicioso. Por ejemplo: convivir - paramilitares - actores políticos - desmovilización BACRIM.

Calificadas por el Estado como grupos de criminalidad común, que siguen funcionando en torno a la narco-empresa y son fácilmente adaptables a las situaciones, lo que asegura su supervivencia en una marco de mutación de las revoluciones armadas. Así pues, "la naturaleza de un grupo armado depende de su relación con la población y con el territorio de tal forma que los grupos armados ilegales no operan con características similares siempre, sino que modifican su comportamiento de acuerdo con unas condiciones regionales" (Ávila en López, 2010, p.88).

Entonces en 2014, la estructura de la narcoviolencia y la narco-economía, se encuentra disipada y pasó de una organización vertical a una horizontal, de difícil percepción, y adicionalmente, el fenómeno narco-económico violento se integró en todos los sectores. Por ejemplo, los Rastrojos se estructuraron como "un ejército privado en el cartel del norte del Valle" (Adams en Bagley, 2011, p. 83).

Las BACRIM y las FARC son narco-socios. Según el "informe anual de Barack Obama sobre la lucha contra el narcotráfico, entregado el 3 de marzo de 2011, sentencia que las BACRIM constituyen un reto mayúsculo para Colombia" (Romero, 2011, p. 260).

El poder como bien lo describe Gabo, "es un vicio sin término cuya saciedad genera su propio apetito" (García, 1996, p. 286). Definitivamente "la modificación de las amenazas se inscriben en la lógica de la metamorfosis de la violencia. Al mismo tiempo que la violencia se transforma, la amenaza evoluciona y se desplaza hacia nuevas formas... esta necesidad de amenaza es vieja como el mundo: hay que designar al adversario, ese otro, diferente competidor, oponente y finalmente enemigo. Esa designación es una señal de afirmación de nuestra propia existencia y de nuestro lugar en la sociedad." (De La Maisonneuve, p. 151-152). 
En 2013 la Defensoría del Pueblo reportó el alarmante reclutamiento de menores e indígenas a los diferentes grupos armados irregulares, que adicionalmente comenten crímenes internacionales como los descritos así como violaciones, desapariciones, masacres, torturas, mutilaciones, entre otras tantas formas de usar el terror. En 2013 se abrieron investigación por 2.278 casos de presuntas ejecuciones ilegales perpetradas por agentes del Estado que afectaban a casi 4.000 víctimas pero solo fueron hasta el momento condenados 189 ejecuciones. Alarmantemente, la LJP 2013 solo había condenado 18 personas a mitad de año.

En 2013 solo 3 familias regresaron a sus tierras producto de la Ley de Víctimas y Restitución de tierra expedida por Santos después de 2 años de vigencia; 700 personas que buscan retornar han sido amenazadas y 43 asesinatos están siendo investigados.

Este tipo de políticas contradictorias nacionales, riñen con normatividades internas que ejecutan las Fuerzas Armadas, por ejemplo la "Directiva secreta número 29 del Ministerio de Defensa dejaba en evidencia que la política de incentivos por las bajas de la guerrilla formaba parte de una política de Estado" (Heyck, 2011, 369).

\subsection{MUTABILIDAD DE LAS ESTRUCTURAS NARCOTRAFICANTES}

Las ESol narcoviolentas son adaptables y flexibles ante los retos impuestos por las estructuras soberanas superadas y superadoras. Lo que las convierte en entidades amorfas "son muy difíciles de identificar y aún más difíciles de capturar. Para disminuir los riesgos, ellos tienden a evitar exportar directamente a los Estados Unidos... la industria ilegal evoluciona continuamente y se adapta en respuesta a los cambios de políticas" (Thoumi en Bagley, 2011, p. 317).

Thoumi realiza las siguientes afirmaciones sobre la actualidad de la industria ilegal:

- Bandas emergentes o grupos más pequeños pero más sofisticados

- Han reciclado a los paramilitares a través de LJP

- Las FARC incrementa su narcotización y posiblemente exporta cocaína a través de Venezuela y el sur colombiano

- Los colombianos ceden mercado a los mexicanos 
- Aumento del precio de cocaína en EEUU

- La narco-industria se adapta constantemente a las condiciones endógenas y exógenas (Thoumi en Bagley, 2011, p. 317).

En consecuencia, los Estados Superados tanto por actores y sujetos legales e ilegales, muestran a la actividad de las ESol narcoviolentas como "las drogas ilegales son un síntoma de la carencia del Estado de derecho y que los cambios de conducta deberían reconocer guerrilleros, paramilitares, sicarios y otros criminales no son calamidades que descendieron en Colombia; ellos son individuos criados, socializados y educados en Colombia... los traficantes han aprendió a maniobrar el sistema norteamericano y están usando la extradición como negociación para garantizarse una sentencia reducida en los Estados Unidos, mantener una porción de sus fortunas ilegales y obtener visas de residentes para ellos y sus familias, así como también para entrar a formar parte de la red de identidades protegidas" (Thoumi en Bagley, 2011, p. 318-320).

Encontrándose las ESol narcoviolentas en un tipo sistemático de remplazo a través de "la interacción que existe entre macro-estructuras y micro-motivos (Sambanis en Romero, 2011, p. 269) y específicamente la superposición o confluencia entre la lógica contrainsurgente y la lógica de acumulación de capital.

Esto no significa, sin embargo, que el conflicto bélico pueda considerarse como uno de aquellos que en ciertos ámbitos académicos se clasifican como guerras por recursos (resource wars). Más bien indica la emergencia de economías de guerra (war economies) (Kalulambi, 2003), donde apropiación, transacciones y flujos están apoyados tanto en el ejercicio de la violencia como en la decisión estatal sobre la excepción (en la suspensión temporal no explícita de normas jurídicas), donde la línea divisoria entre negocios lícitos, actividades criminales e instituciones estatales se torna difusa"(Romero, 2011, p. 269-271).

La narco-economía trasnacional que se origina en Colombia cuenta con narco-finanzas estructuradas desde la esfera paramilitar antioqueña, representando el "arquetipo ${ }^{133}$... Debido, entre otras causas, al enrome peso de la economía subterránea ligada al narcotráfico... contribuyó

\footnotetext{
${ }^{133}$ El Renacer de la Parapolítica en Antioquia. Todo empezó en Envigado, El Espectador, Febrero 13 de 2011, pp. 13 y ss.
} 
a crear en la costa el prototipo de una paramilitarismo subsidiario financiado en parte desde el Urabá por empresarios bananeros, hecho ampliamente conocido desde el Valle de Aburrá por la oficina de envigado al mando de don Berna sus vínculos con ACOLSIBA, una asociación cooperativa de la Casa Castaño. Están documentados al igual que con FUNPAZCOR... los acuerdos entre Mancuso y Don Berna... los profundos niveles de corrupción administrativa para poner a disposición del narco-paramilitarismo los dineros públicos” (Romero, 2011, p. 192-194).

Por más que se desarticulen algunos grupos narcoviolentos, las cifras sobre violaciones al DIH y los DDHH siguen siendo muy desalentadoras. Por ejemplo, la Oficina para la Coordinación de Asuntos Humanitarios en Colombia (OCHA) informó que en 2013 ocurrieron 4.967 hechos violentos. Adicionalmente, al mismo periodo se reportaron 5 millones de desplazados y anualmente 150.000 personas promedio son desplazadas; activistas ambientales y de $\mathrm{DDHH}$, líderes sociales, sindicales, comunicadores, entre tantos son amenazados y asesinados. Desde la década del 50 el conflicto armado reportó aproximadamente 230.000 homicidios donde el $80 \%$ de víctimas fueron civiles.

Además, convengamos que en la región andina abundan los yacimientos petrolíferos, punto que se le resta importancia a nivel político y mediático, y que sin embargo, es uno de los pilares del por qué el interés estadounidense en la región en general, y en la subregión andina, particularmente. Sostiene además la autora, que dicha zona andina, es "la puerta de entrada a una región más amplia, la de la Amazonía" (Rossi, 2009). Igualmente, "la participación de Estados Unidos en la reforma del sector judicial, la ampliación y mejoramiento de las medidas de interdicción y la adopción de campañas de erradicación sistemáticas" proveyó a Estados Unidos de puntos de entrada a la política doméstica... (así como) una mayor participación estadounidense en la guerra contra las drogas" (Guaqueta, 2005, p. 37).

Según Jaguaribe, "ser dependiente no implica no tener autonomía para ejercer las funciones... muchas de las cuales son monopolizadas, o en el mejor de los casos, supervisadas por Washington" (Jaguaribe, 1979, p. 91 - 130).

Sin embargo, la pérdida de autonomía puede ser una perdida mayor en el corto plazo, porque según los postulados domésticos y exteriores, Colombia está facultada para generar otro tipo de vínculos o alianzas internacionales que no lo aten a las soluciones estrictamente militares. 
Las autoras norteamericanas han identificado a Colombia como epicentro de la actividad narcótica, señalando que "entre los señores de la guerra y los barones de la droga existe una simbiosis, por lo que esta situación es muy difícil de superar, que además pone en peligro la condición de seguridad y gobernabilidad en ese país, debido a que en algunos segmentos del aparato gubernamental se podría hablar de narco-Estado" (Youngers, 2005).

\subsection{ESOI NARCOVIOLENTA TRASNACIONAL}

EEUU como principal consumidor de drogas desde los años 60, alentó el movimiento de las ESol narcoviolentas trasnacionales. Afectando "a parte de México: a... Colombia, Marruecos, Turquía y Afganistán. En menos de diez años, las drogas recreativas dejaron de ser un vicio localizado y se convirtieron en una mercancía global. En México, el aumento de la demanda transformó a los productores de droga: al principio eran un puñado de agricultores de Sinaloa, y acabaron siendo una industria nacional que... empezó a ingresar miles de millones de dólares y los políticos quisieron sacar tajada. El incremento del capital en juego fomentó la aparición de jefes y desató la primera ola de matanzas relacionadas con la droga. El narcotráfico experimentó un repentino y asombroso período de desarrollo" (Grillo, 2012, p.69).

Entre la década del 60 y 70 se decomisaron en México "29.5 kilos de cocaína... De 1970 a 1976 el monto llegó a 1.089 Kilos. Ya se mencionaba a gente de Sinaloa aprehendida en posesión de la droga en cantidades que no sobrepasaban los dos kilos. La mayor cantidad, 13 kilos, le fue decomisada en el aeropuerto de la ciudad de México a un colombiano en 1976" (Garay, 2011, p. 181-182).

En México en la década del 70 Carrillo Fuentes debutó en las grandes narco-ligas por "conducción de su tío Ernesto Fonseca Carillo. Don Neto era socio y amigo de Pedro Avilés Pérez, un capo de Sinaloa mejor conocido como León de la Sierra, el primer mexicano en traficar cocaína de Sudamérica hacia EEUU: en pocas palabras, el primer jefe de jefes del narco mexicano. Pedro... fue asesinado en 1978 y su relevo fue Miguel Ángel Félix Gallardo" (Hernández, 2012, p. 33). 
Una vez ocurrida la muerte de Carrillo Fuentes, su hijo El Viceroy tomó las riendas de la organización e inicialmente contó con el respaldo de los hermanos Beltrán Leyva, originarios de Sinaloa y provenientes del cártel de Juárez. Gracias a ellos, conservó "los contactos indispensables con Colombia para que le surtieran cocaína, y logró que la plaza conservara sus altos niveles de productividad... numerosas toneladas de cocaína del cártel del Norte del Valle...Además... logró establecer un impuesto para que los otros carteles pagaran por usar su paso fronterizo" (Hernández, 2012, 388-389).

Para la Dirección de Antinarcóticos de Colombia "los narcotraficantes del Norte del Valle fueron pioneros en establecer alianzas con las organizaciones mexicanas. Para (ellos), el verdadero Señor de los Cielos no fue Amado Carrillo, sino Hernando Gómez Bustamante, alias Rasguño" (Garay, 2012, p. 186), narcoviolento colombiano del Cartel del Norte del Valle.

Así, fueron los mismos narco-pilotos quienes en la década del 70 develaron la dimensión trasnacional de la ESol narcoviolenta de matriz colombo-mexicana. Confesaron al ser aprehendidos que "iban cargados de cocaína que levantaban en Barranquilla, Colombia y después se dirigían a Miami. México era el punto donde recargaban combustible... el informe de la DEA confirma que la $\mathrm{ClA}$ era la que en realidad operaba el tráfico de droga y el mantenimiento de las pistas empleadas para el trasiego" (Hernández, 2012, p. 99).

En la década del 80 se sistematizaron las redes ESol narco-violentas, cuando los carteles colombianos "utilizaron a los mexicanos como transportadores o mulas por el amplio conocimiento que poseían de la frontera México/EE.UU y de las rutas internas de distribución de los EE.UU”'134.

Muchos doctrinantes desde entonces afirman que la ClA actuó como el "Dr. Frankesnstein que inventó el monstruo del narcotráfico (no obstante)... las fuerzas del mercado habrían creado el comercio latinoamericano de la coca con o sin la ayuda de agentes secretos. Además, la geografía habría garantizado que éste comercio pasara por México... Sin embargo, el papel de la CIA es crucial para entender la historia de la cocaína. Pone de manifiesto que el gobierno estadounidense

134 INSTITUTE FOR NATIONAL STRATEGIC STUDIES. La Conexión Mexicana: Poniendo al descubierto los vínculos de los cárteles de la droga en la región Andina". Pg.5. www.ndu.edu. Consultado el 4.6.2012. 
no ha sabido tener una política unificada en su guerra contra la droga en el extranjero. Mientras que la misión de la DEA era combatir el tráfico, la de la CIA era fortalecer a la contra, y era inevitable que las dos agencias se estorbaran... el asunto demuestra que donde hay un tráfico ilegal de drogas que mueve miles de millones, habrá grupos rebeldes que correrán a explotarlo. En algunos casos podrán ser aliados de EEUU, como la contra nicaragüense o la Alianza del Norte, pero en otros podrían ser enemigos, como las FARC de Colombia o los talibanes... por desgracia para los jinetes de la coca... la Guerra Fría no fue eterna. El 23 de marzo de 1988 la contra y el gobierno sandinista de Nicaragua firmaron un alto al fuego, con un balance final de sesenta mil personas muertas en las hostilidades. Doce días después, agentes estadounidenses llegaron a Honduras en busca de Matta. No pudieron detenerlo legalmente porque no había tratado de extradición. Pero se lo llevaron de manera ilegal. Las fuerzas especiales hondureñas y los agentes judiciales de EEUU habían hecho un pacto para apoderarse del señor de la droga" (Grillo, 2012, p. 118-119). Así se debió la aparición de la Ley RICO “(Racketeer Influenced and Corrupt Organizations), que se había ideado para combatir a la mafia estadounidense" (Grillo, 2012, p. 103).

Juan Ramón Matta Ballesteros nació mientras finalizaba la II Guerra Mundial en una sociedad marginal de Tegucigalpa, al ser adolecente y no encontrar mayores oportunidades de sobrevivencia, viajó en busca del sueño americano y se casó con una colombiana en New York. Pero pronto, fue deportado de EEUU y como no contaba con documentos de identificación, sostuvo ante los agentes migratorios ser de nacionalidad colombiana, como su pareja. Los gringos lo deportaron a Colombia pero Matta pronto regresó a EEUU, pero nuevamente fue detenido por "falsificación de pasaporte y encerrado en un campo de prisioneros de la base aérea de Eglin. Pero... (Escapó) en 1971 y (fue) a trabajar con los colombianos" (Grillo, 2012, p. 99-100). En el prometedor y creciente mercado de la cocaína.

Matta, hijo de un "miembro del cartel de Guadalajara" (Grillo, 2012, p. 97-98) fue quien de manera efectiva "canalizó el dinero hacia los gánsters de Medellín... Escobar construyó toda una urbanización para los sin techo y fue elegido diputado del Parlamento de Colombia en 1982, aunque fue inhabilitado poco después por sus actividades delictivas. Por esta época los gánsteres empezaron a denominarse cártel de Medellín; era la primera vez que la palabra cártel se utilizaba para describir el tráfico de drogas" (Grillo, 2012, p. 102). Tanto Matta como Escobar en los 
momentos gloriosos de las narco-utilidades, se ofrecieron a pagar las deudas externas de sus respectivos Estados de origen.

La DEA informó a las autoridades colombianas sobre el paradero de Matta y se realizó su captura. No obstante, Matta "consiguió salir cruzando siete puertas cerradas... después de repartir millones de dólares entre los guardianes... volvió a su patria... Honduras (que) no tenía tratado de extradición con EEUU” (Grillo, 2012, p.114).

Matta con su empresa de aviones comerciales-SETCO trabajó para la CIA llevando "ayuda humanitaria a la contra de Nicaragua... Honduras resulta esencial para entender la operación Iráncontra: su territorio fue usado para llevar armas al movimiento contrarrevolucionario y para transportar cocaína hacia EEUU. En 1977... fue el artífice de la sociedad entre el Cartel de Medellín y el cártel de Guadalajara, cuando presentó al colombiano Gonzalo Rodríguez Gacha con Miguel Ángel Félix Gallardo... Rodríguez Gacha nació en una familia campesina. Se abrió paso en medio de una violenta disputa en la zona de producción de esmeraldas en Colombia. Apenas había cumplido 29 años cuando se unió al (cártel de Medellín)... Y tenía 30 años cuando conoció a Félix Gallardo. Entonces el cartel de Guadalajara se limitaba al trasiego de mariguana y heroína a EEUU con una muy bien organizada estructura. Rodríguez Gacha le abrió los ojos al Jefe de Jefes y le mostró un negocio más jugoso: la cocaína. Por un menor volumen de mercancía, la ganancia era mayúscula. El Negro era el contacto en Sudamérica del narcotraficante Alberto Sicilia Falcón, un cubano contrarrevolucionario que llegó a México a crear un imperio de la droga de la noche a la mañana. En su biografía criminal se afirma que... fue el que inició el tráfico de cocaína con los colombianos usando territorio de México. Había una competencia desleal de por medio: los narcos mexicanos tenían el apoyo y la autorización del gobierno mexicano y de la CIA... bajo tortura, Sicilia confesó que trabajaba para la CIA en drogas y operaciones de armas intentando desestabilizar naciones latinas. Ya sin Sicilia Falcón en operación, Matta Ballesteros logró que Rodríguez Gacha y Félix Gallardo se entendieran y que la relación fuera productiva para ambas organizaciones. Rodríguez Gacha se encontró tan a gusto en el modelo mexicano, que al poco tiempo su gusto por la cultura de charrería hizo que se ganara el mote de El Mexicano. En Colombia incurrió en la excentricidad de ponerle a sus ranchos nombres de estados o ciudades mexicanas" (Hernández, 2012, p. 129132). 
Miguel Ángel Félix Gallardo “acabó siendo el contacto más importante entre Matta y los señores colombianos de la droga. Muchos sinaloenses pensaban que Félix Gallardo era el capo más grande de la historia, el indiscutible rey del hampa mexicana de su época... se cree que la canción jefe de jefes de los Tigres del Norte, quizá el narcocorrido más célebre, se refiere a Félix.... Nacido en Culiacán en $1946 \ldots$ se unió a las fuerzas de seguridad... cuando la Operación Cóndor machacó Sinaloa, Félix Gallardo y otros granujas se instalaron en Guadalajara... (practicando) la economía de escala. En vez de comprar la marihuana a los pequeños cultivadores familiares, prepararon plantaciones gigantescas... y en total había más de 5.000 toneladas de hierba. Miles de campesinos habían trabajado allí por seis dólares diarios. Cuando llegó el ejército, todos los jefes habían volado, aunque los campesinos seguían vagando por allí sin agua y sin comida" (Grillo, 2012, p. 108-111).

Matta y Félix Gallardo ingresaron "unos cinco millones de dólares semanales filtrando cocaína por los conductos mexicanos... Matta gracias a unos distribuidores, la introducía en Arizona, California y Nueva York" (Grillo, 2012, p. 110). Matta que se encuentra "pudriéndose en la peor cárcel de EEUU, se ha convertido en una amenaza útil para los fiscales estadounidenses que tratan con narcotraficantes latinoamericanos. <<si no haces un trato - parecen decir- acabarás como Matta〉>. El arquitecto del trampolín mexicano desapareció en el tórrido desierto de Colorado. Pero allá en México una nueva generación de traficantes heredó el trampolín de mil millones de dólares y ha construido otros más grandes, más elásticos, más sangrientos" (Grillo, 2012, p. 120121).

En 1981 apareció en la narco-escena Adler Berriman Seal, alias Barry Seal, quien siendo agente de la CIA, agente de la DEA y miembro de la nómina del cártel de Medellín, ha sido considerado como: "el contrabandista más grande en la historia americana... al igual que El Negro, Barry Seal trabajaba con la ClA para apoyar a la contra nicaragüense. La conexión entre ellos, y los vínculos de ambos con el Cartel de Medellín y el de Guadalajara no es casual bajo ninguna circunstancia.... Seal (dirigió desde) aviones que cargaban 100 kilos de cocaína a un avión que podía transportar hasta una tonelada... le pagaban 1.5 millones de dólares por viaje... comenzó a realizar sus principales viajes... al aeropuerto de Mena... entonces gobernado por Bill Clinton... a cambio de una política de puertas abiertas para su droga, el cártel de Medellín apoyaba a la contra. En esencia, se trataba del mismo acuerdo al que habían llegado con el Cártel de Medellín y el Cártel 
de Guadalajara en México... en 1983 Seal fue detenido cuando transportaba cocaína de Colombia a Florida... recurrió a la DEA, a la cual ofreció información de la organización con la condición que se le brindara inmunidad" (Hernández, 2012, p. 132 y 134-136).

Seal confesó a la DEA que el Cártel de Medellín "tenía un rancho de aproximadamente 16 hectáreas en la Península de Yucatán... donde había un centro de almacenamiento de cocaína para renviarla a EEUU en pequeños aviones ${ }^{135} \ldots$ ya en calidad de infiltrado de la DEA, le solicitó un avión más grande porque el cartel de Medellín le pedía transportar las cargas de 18 toneladas de pasta de coca de Perú a tres laboratorios de tratamiento en Nicaragua una vez a la semana, y desde allí al rancho de Yucatán. La DEA le ayudó... la CIA colocó cámaras y un dispositivo que se podía rastrear vía satélite. La administración Reagan quería usar fotografías tomadas como arma para desprestigiar al gobierno sandinista y que el congreso aceptara liberar recursos para la contra nicaragüense... Seal había revelado que los colombianos querían mostrarle a la CIA su base de operaciones en Yucatán y sus bodegas para almacenar cocaína en Georgia y Florida. El plan era reunir a todos los miembros del cartel de Medellín en un lugar donde pudieran ser arrestados. Sin embargo, cuando estaban ajustando los últimos detalles... estalló la tormenta, dijo un agente de la DEA.... El gobierno de Reagan exigía la extradición de... Pablo Escobar... y en diciembre de 1985 Seal fue condenado por el juez Federal Fran Poliozola a seis meses de libertad condicional por dos delitos de narcotráfico... en 1986... un hombre lo asesinó... se identificó al narcotraficante Jorge Luis Ochoa como autor intelectual" (Hernández, 2012, p. 138).

Ahora bien, fueron los cárteles colombianos quienes revolucionaron desde la década del 80 "la profesión de matarife... El artífice de su maquinaria asesina fue Isaac Gttunan Esternberg, un colombiano descendiente de alemanes que trabajaba para los traficantes de Medellín... inventó la escuela de los sicarios en moto, en la que se matricularon millares de jóvenes de los barrios pobres... en 1991, Medellín (se convirtió en) la ciudad con más asesinatos per cápita de todo el planeta, 6.500 entre una población de dos millones... (No obstante, en 2014, al haberse) reducido la cantidad de asesinatos, sigue siendo muy violenta" (Grillo, 2012, p-249-250).

Así mismo, los matarifes aztecas adhirieron a las técnicas creadas por los cárteles colombianos. No obstante, estos tienden "emboscadas con jeeps y coches deportivos. Y mientras que los

135 Ambrose Evans-Pitchard, The Secrte Life of Bill Clinton, Washington, Regnery Publishing 1997. 
colombianos empleaban pistolas, los mexicanos... Cuernos de Chivo... los agentes locales que trabajan con la mafia bloquean algunas calles para que los sicarios lleven a término el trabajo... Se ha sabido que algunos reclusos de la penitenciaría estatal de Durango salían por la noche, perpetraban un asesinato y volvían a la celda, con la complicidad de los funcionarios de prisiones. Incluso se desplazaban en vehículos de la cárcel y utilizaban las armas de los guardianes" (Grillo, 2012, p. 258-260).

Desde la década del 80 en Oaxaca se fundó "el nudo del tráfico de cocaína. Los principales embarques... venían de Sudamérica... las avionetas Cessna bajaban al Istmo de Tijuana, Juárez y Matamoros, recogían la cocaína y regresaban a su lugar de origen... A veces el propio gobierno de EEUU iba por la mercancía... Quien quería comprar cocaína, ya fuera Félix Gallardo, Pablo Acosta, Amado, García Ábrego, El Mayo Zambada, El Güero Palma, El Chapo, El Cochiloco, El Azul, o el que fuera, tenía que hacerlo a través del gobierno" (Hernández, 2012, p. 127-129).

El cártel de Medellín en la década del 80 "enviaba casi toda su cocaína a las costas de Florida. Era un trayecto de casi 1.500 kilómetros... Los colombianos y sus socios estadounidenses soltaban la carga aerotransportada en el mar... una carga de cocaína lanzada desde el aire atravesó el techo de una iglesia de Florida... El comercio de la coca también inundó de dólares la economía de Florida. Nadie sabrá nunca con cuánto dinero blanqueado se construyeron los rascacielos de Miami" (Grillo, 2012, p. 105).

En 1982 Reagan reaccionó creando el Grupo Operativo Florida Sur y "en menos de ocho meses la incautación de cocaína subió un 56\%... en Colombia sintieron el mordisco... las confiscaciones representaban pérdidas de cientos de millones de dólares; el cártel de Medellín necesitaba replantearse su estrategia. Y recurrió a Matta para que solucionase el problema. Matta había utilizado el trampolín mexicano para introducir drogas en EEUU a principios de los setenta... estos mexicanos podrían aportar una gran solución a los reyes de la cocaína: ¿por qué arriesgarlo todo en Florida cuando podían repartir la mercancía por otros 3.200 kilómetros de frontera terrestre?. Los mexicanos ya tenían rutas de contrabando" (Grillo, 2012, p. 107).

De esta manera, las descritas estrategias norteamericanas propiciaron el efecto globo, es decir, cuando controlaron férreamente a La Florida, propiciaron el desplazamiento de la ESol 
narcoviolenta a otros rincones fronterizos de los EEUU. Dicho efecto globo se repite ininterrumpidamente en la actual escena narcoviolenta trasnacional. Por ejemplo: "los mayores controles impuestos en los niveles de cultivo de coca en Colombia (repercutieron) en los niveles de cultivo en Bolivia y Perú; los mayores controles en la recepción y envío de cocaína desde Colombia a EEUU a través del territorio mexicano han tenido repercusiones en la cantidad de drogas ilícitas que transitan por Guatemala; los controles impuestos a la importación de insumos químicos en Perú han tenido repercusiones en el tráfico de estas sustancias desde Chile. En conclusión, la presión coercitiva ejercida por un Estado sobre los narcotraficantes inmediatamente tiene efectos en Estados vecinos" (Garay, 2012, p. 294). Quienes más peligran son los Estados Superados que pueden alojar a los interesados en desarrollar las lucrativas Guerras Promiscuas.

Entretanto, en 1983 fue protagonista el Grupo Contadora que después mutó al Grupo Rio. Esta organización compuesta, sobre todo por premios nobel, entre ellos, nuestro querido Gabriel García Márquez, convocaron “a los presidentes de México, Colombia, Venezuela y Panamá, quienes... tenían como objetivo diseñar estrategias para restablecer la paz en la zona conflictiva de Centroamérica, por agentes especiales de las fuerzas armadas estadounidenses que intervinieron en la región con el argumento de salvaguardar intereses empresariales... se pretendía activar la explotación económica de Mesoamérica... (pero) las rutas para el desarrollo trazadas... se convirtieron en las rutas del narcotráfico" (Ramírez, 2011, p. 141, 142 y 143).

Ahora bien, una prueba más sobre la existencia de la red ESol narcoviolenta de matriz colombomexicana se dio en 1985 cuando fue capturado en Costa Rica, Rafael Caro Quintero y su pareja sentimental Sara Cosio. Rafael declaró al Ministerio Público que: “Miguel Ángel Félix Gallardo es un traficante de drogas a gran escala, principalmente de cocaína que recibe de Sudamérica para introducirla a EEUU... Gallardo trabajaba con el cartel de Medellín” (Hernández, 2012, p. 102).

En cuanto a los vínculos de la CIA con los narcotraficantes, es preciso relatar esta actuación norteamericana de alto nivel jurídico-político: “¿Podría levantar su mano derecha, por favor?, inquirió el senador demócrata John Kerry... el cubano Ramón Millán Rodríguez... levantó la mano para dejar en claro que, aunque no estaba en una corte sino en una sesión cerrada en el capitolio de EEUU, juraba decir toda la verdad.... el principal contador del... cártel de Medellín... responsable de lavar 11 mil millones de dólares... era uno de los principales testigos del Subcomité de 
Narcóticos, Terrorismo y Operaciones Internacionales, creado en $1987 .$. era el enlace entre Escobar Gaviria y la jefatura de narcos cubano-americanos... habría entregado a la contra nicaragüense 10 millones de dólares a nombre de Pablo Escobar... en 1991, el cofundador del cártel de Medellín, Carlos Ledher Rivas, lo confirmó" (Hernández, 2012, 114-115).

Entre tanto, el Chapo durante 1985 y 1990, narqueó en franquicia con el cártel de Medellín y para Carrillo Fuentes "decenas de toneladas de cocaína en El Tonino, en Compostela, Nayarit... En las inmediaciones de esta localidad de no más de 100 habitantes, El Chapo usaba una pista clandestina y la playa para recibir la droga proveniente de Colombia en aviones y barcos. Su tarea era que la mercancía llegara al boyante mercado estadounidense" (Hernández, 2012, p. 156).

En 1988 se enfrentaron la CIA y la DEA en cuanto a la captura de Matta por el homicidio del Kiki Camarena. Por ejemplo, dicha disputa arrojó datos certeros sobre la creciente red ESol narcoviolenta colombo-mexicana, así "la DEA calculó que el 60\% de la cocaína consumida en EEUU venía de Colombia vía México ${ }^{136}$... En agosto se firmaron los acuerdos de Managua, que incluían llevar a cabo un proceso electoral "democrático" y la desmovilización de la contra de Nicaragua. Al mismo tiempo que Escobar y Félix Gallardo dejaron de ser útiles para los planes de la CIA (pues a cambio de drogas transportaban armas), los capos comenzaron a ser detenidos o asesinados" (Hernández, p. 144-145).

Finalizando la década del 80, "el narcotraficante colombiano Juan Carlos Abadía presuntamente reveló que el cártel de Cali entregaba millonarias sumas a Guillermo Salazar por permitir que cargamentos de cocaína circularan en el país de 1987 a 1991. Esos tiempos coinciden con la época de mayor actividad de Guzmán Loera antes de ser detenido (por primera vez). El Chapo también trabajaba con esa organización delictiva, como él mismo confesó" (Hernández, 2012, p. 77).

Con la llegada impuesta del neoliberalismo, las ESol narcoviolentas mexicanas se expandieron fácilmente en la década del 90, utilizando las mismas estrategias que exigió el capitalismo a las empresas legales. Se fortalecieron hasta desplazar el liderazgo de los colombianos, convirtiéndose en "las organizaciones criminales dominantes en toda América Latina... Jay Bergman... director de la DEA para la región de los Andes... estudió aquel tremendo desplazamiento... explicó: lo

136 DEA History Book. 1985 - 1990. Http://www.justice.gov/dea/pubs/history/1985-1990.html. 
interesante es que la toma del poder se produjo sin hostilidades ni violencias... los carteles colombianos decidían conscientemente la cesión de más parcelas a los mexicanos" (Grillo, 2012, p. 136).

En 1991 “los hermanos Jorge Luis y Juan David Ochoa se entregaron a las autoridades colombianas a condición de no ser extraditados a EEUU. Fueron sentenciados a una condena de tan sólo 8 años... el único extraditado fue Fabio en $2001 . .$. (por) el asesinato de... Seal... condenado a cadena perpetua” ${ }^{\prime 37}$. Escobar fue asesinado en 1993 y a partir de dicha fecha, los líderes del cartel de Cali, los Rodríguez Orejuela, se asociaron con Amado Carrillo para "negociar envíos de cocaína: tres toneladas por viaje. Tenían dos tipos de trato. Uno: Carillos les compraba directamente a los de Cali. Dos: de cada par de kilos uno era de los caleños y tenía que ser introducido a EEUU, y el otro era para Carillo. Pero más que una sucursal de los colombianos fue una necesidad" (Garay, 2012, p. 181-182).

En 1996 cuando fue extraditado el líder del Cártel del Golfo, Juan García Ábrego a EEUU "su hermano Humberto intentaba negociar para que no se desmoronara su relación con el cartel de Cali, Carrillo fuentes comenzó a vivir su mejor época. Sin embargo, más tarde surgiría el escándalo de Raúl Salinas de Gortari y las acusaciones sobre sus presuntos vínculos con el Señor de los Cielos... Para el FBI la organización criminal de Carillo Fuentes era la principal empresa de tráfico de drogas de México. Dirigió la importación de miles de toneladas de cocaína de los cárteles de Medellín y Cali hacía México, y luego las distribuía hacia EEUU” (Hernández, 2012, p. 218-219).

Carillo Fuentes "no solo movió cantidades históricas de mariguana, heroína y cocaína a EEUU, sino que logró conectarse con la clase política, militar y empresarial mexicana, que gustosa lavaba los milloes de dólares que les daba. Así como relacionaron a Carrillo Fuentes con Raúl Salinas de Gortari, su organización también fue vinculada con empresarios como el banquero Roberto Hernández, ex dueño de Banamex. En 1997 el diario Por Esto! de Yucatán presentó un artículo basado en una serie de fotografías tomadas presuntamente en playas de la isla Punta Pájaros... donde se almacenaban envíos de cocaína provenientes de Colombia... los cargamentos llegaban en lanchas rápidas con hombres armados a bordo. En 1998 Banamex se vio involucrado con otros bancos mexicanos, en la escandalosa Operación Casablanca, implementada por el Departamento

137 Hernández, Anabel. (2012).Los señores del narco. Random House Mondadori, Mexico, pp. 146-147. 
del Tesoro de EEUU, en la que se descubrió que diversas instituciones bancarias estaban lavando dinero de la organización de Carillo Fuentes y del cartel de Cali... Desde la década de 1980, el propio líder de la Asociación de Banqueros de México, Arcadio Valenzuela, fue identificado por la DEA como el patriarca del lavado de dinero, al realizar las operaciones de cuello blanco para Miguel Ángel Félix Gallardo y Rafael Caro Quintero. El gobierno de México nunca prestó atención a la denuncia de la DEA" (Hernández, 2012, p. 221-222 y 224-225).

En 2001 Banamex nuevamente fue acusado de lavado de activos por la DEA que manifestó que la empresa "sirvió para realizar operaciones con dinero procedente del narcotráfico del ex gobernador de Quintana Roo, Mario Villanueva Madrid, quien fue extraditado en mayo de 2010 a Nueva York para ser procesado por delitos contra la salud y asociación delictuosa. De acuerdo con el gobierno norteamericano, entre 1993 y 1999 el ex mandatario <<suministró apoyo estatal y federal > para que el cartel de Amado Carrillo introdujera a Cancún cientos de toneladas de cocaína procedentes de Colombia para después transportarlas a EEUU ${ }^{138}$... En mayo de 2001... Fox detuvo al narco-gobernador" (Hernández, 2012, p. 224).

De esta manera, El Chapo y Carrillo Fuentes "gestionaron conjuntamente partidas de toneladas de cocaína de Bolivia y Colombia con destino a Sonora, México, y luego a EEUU a través de Arizona. Durante este tiempo Carrillo Fuentes también trabajó estrechamente con Ismael Zambada García, abriendo rutas de contrabando por Tijuana, Baja California" (Grillo, 2012, p. 132-133).

Posterior a la primera fuga del Chapo los Beltrán Leyva se enlistaron a su bando y durante el mandato de Fox cooptaron 11 estados federales "aunque sus principales feudos fueron Sinaloa y Guerrero... Arturo Beltrán Leyva es primo lejano del Chapo, a quien inició en el negocio de la cocaína" (Cervantes, 2012, p. 216-218).

El Chapo "con su poderío e influencia... vulneró los sistemas de control a través de una intrincada red de operaciones en casas de cambio e instituciones bancarias que le permitió adquirir 13 aviones para ponerlos al servicio de su organización en el tráfico de cocaína entre Colombia, Venezuela, Centroamérica, México y EEUU” (Ravelo, 2012, p. 242).

138 Milenio, 8 de mayo de 2010. 
En diciembre de 2001 fue interceptado el buque Macel. Partió de Mazatlán Sinaloa el 16 de noviembre y a los dos días siguientes planeaba arribar a Manzanillo, Colima con 246 toneladas de cocaína. Un año después "fueron detenidas dos colombianas en el aeropuerto... de México... que intentaron transportar a Colombia de manera ilegal 2.304.560 dólares. Fueron señaladas como parte de la organización dirigida por el colombiano Juan Diego Espinosa Ramírez, alias el Tigre, su esposa, la mexicana Sandra Ávila Beltrán, y su hermano Mauricio Espinosa, esposo de una de las detenidas. También se establecieron vínculos entre esta organización y la tripulación del Macel... nexos entre la organización de Espinosa y la del líder traficante sinaloense el Mayo Zambada. Y en Hermosillo fueron asegurados 225 predios, dos casas y una empresa, propiedades relacionadas con Sandra Ávila. Espinosa llegó a México en los años noventa para servir de enlace entre la organización del colombiano Diego Montoya, alias Don Diego, y los traficantes de Sinaloa como el Chapo Guzmán, el Mayo Zambada, Juan José Esparragoza, alias el Azul, y los hermanos Quintero. Espinosa tenía en México negocios de esoterismo, bronceado corporal, estéticas y líneas telefónicas de consultas psíquicas que se anunciaban por televisión" (Garay, 2012, p. 184).

Según datos elaborados por la DEA se cuenta con evidencia suficiente para confirmar la existencia de "una organización ilícita con centro de operaciones en Cali, Colombia, que desde el año 2001 ha adelantado actividades de tráfico de drogas ilícitas enviadas a México... el proceso de envío que se inicia en Colombia, y continúa de México a los EE.UU, se realiza principalmente por vía marítima en su primera etapa y por vía terrestre en su segunda. La red está principalmente dirigida por los colombianos Víctor Emilio Valencia Espinoza, "El Doctor", y Leyner Valencia Espinosa, "El Piraña"... red... Organización Valencia-Espinosa... forma parte del Cartel del Norte del Valle y es responsable de estar enviando cocaína a Nueva York y a Miami... a través de la Ciudad de México"139.

En 2003 las ESol narcoviolentas mexicanas "redimensionaron su rol para fortalecer su participación e influencia en países de Centro y Sudamérica. Intensificaron su presencia en Colombia, Ecuador, Bolivia, Perú y Centroamérica para la producción de cocaína, y a partir de 2007 se trasladaron a Argentina para la fabricación de efedrina precursora de drogas sintéticas" (Cervantes, 2012, p. 189).

139 GARAY, Jorge Luis; SALCEDO, Eduardo. (2011). Estructura de una red de narcotráfico colombo-mexicano. Vortex Working Paper. No. 4 y 5. Scientific Vortex Group. Consultado el 27.6.2012 en www.scivortex.org. 
El Chapo ubicó sus narco franquicias en las regiones norteñas más marginadas del Estado Federal gaucho e instaló iglesias que le sirvieron de centros de reclutamiento y lavado de activos en Chaco, Formosa y Misiones. Por ejemplo, María Alejandra López Madrid fue enviada por el Chapo al Chaco "tenía como objetivo poner en funcionamiento la Iglesia Evangélica del Nuevo Milenio" (Cervantes, 2012, p. 187). Las mentadas provincias "se encuentran en la zona norte en regiones selváticas o boscosas con un clima tropical y templado... colindan, por un lado con Paraguay y por el otro con Brasil... Argentina (en 2014) se ha transformado en un centro de producción de drogas sintéticas... hay atisbos de presencia de los Zetas en la parte central del país en Córdoba y Santa Fe" (Cervantes, 2012, p. 185-186).

Igualmente, la ESol narcoviolenta colombiana se transplantó efectivamente en el nuevo milenio a diversos Estados Superados de Latinoamérica "entre ellos México, Perú, Venezuela, Panamá, Brasil, Paraguay, Argentina, República Dominicana, Costa Rica y Uruguay... con estrategias sofisticadas. A través de testaferros que fingen como inversionistas compran negocios acreditados - discotecas, hoteles, restaurantes, bares, etc - y locales exclusivos en centros comerciales, montan distribuidoras de carros, se apoderan de los juegos de azar y los prostíbulos, invierten en empresas de transporte público y en equipos de fútbol, negocian pases de deportistas reconocidos... han llegado incluso a asociarse con inescrupulosos pastores cristianos para lavar capitales a través de las ofrendas de los fieles" (Serrano, 2010, p. 121).

En 2006 la DEA informó que "ex paramilitares vinculados con la Oficina de Envigado habían empezado a distribuir estupefacientes en los EEUU, Canadá, México, Europa y el Medio Oriente y que habían abierto rutas por áfrica" (Serrano, 2010, p. 134-135). Y vislumbra el alcance corruptor del narco-dinero, la publicación en el mismo año de la Revista Cambio, mediante la cual "reveló que en cateo realizado a las propiedades del mexicano, las autoridades de Colombia encontraron un convenio por 60 millones de dólares que familiares del narcotraficante habrían pagado al gobierno de EEUU a cambio de no ser involucrados en actividades ilícitas y mantener a salvo el resto del dinero del capo. La pregunta obligada es si Rodríguez Gacha realmente está muerto o fue el pago de su jubilación por los servicios prestados" (Serrano, 2010, p. 146). 
Concomitante a lo anterior, la Policía colombiana "capturó a Leyner Valencia... Leyner y sus hermanos William, Víctor y Darío eran conocidos como los Pirañas, hermanos de Ana Cecilia Valencia, alcaldesa de Zarzal, Norte del Valle, al momento de su captura. En 2002, los hermanos Valencia se instalaron en México para manejar las rutas y los contactos de Don Diego con las organizaciones de Juárez y Tijuana... El 10 de septiembre de 2006 fue capturado... Diego Montoya, líder de la organización de traficantes del Norte del Valle... Era uno de los hombres más buscados por el FBI... era el responsable de aproximadamente el $70 \%$ del tráfico de cocaína hacía EEUU y Europa, y de más de 1500 asesinatos... creador del grupo criminal Los Machos y de las Autodefensas Unidas del Valle... semanas después... fueron detenidos por la Policía Federal Juan Diego Espinosa y Sandra Ávila. El 31 de diciembre de 2008, Espinosa fue extraditado a EEUU para ser procesado... El 10 de septiembre de 2010, Víctor Emilio Valencia Espinosa, alias el Doctor, y su hermano Darío, alias el Remache, fueron detenidos en la ciudad de México... hubo intercambio de información de inteligencia con la DEA y la Policía Nacional de Colombia... Víctor Emilio residía en México hacía 26 años. Su hermano Leyner hizo negocios con Arturo Beltrán Leyva, quien formaba parte de la coalición de traficantes liderada por Joaquín el Chapo Guzmán. Se convirtió en uno de sus principales operadores para transportar droga en lanchas rápidas desde Tumaco y el Chocó hasta Acapulco. Enviaba entre 250 mil y 300 mil dólares semanales de México a Colombia ocultos en televisores. Al principio recibía una comisión del 2\% por cada envío, que luego subió a 7\%. Un periódico mexicano de circulación nacional vinculó a los hermanos Valencia como colaboradores del gobierno de EEUU para la captura de Sandra Ávila. Temieron por su vida. Edgar Valdez Villareal, alias la Barbie, intercedió ante Arturo Beltrán para que no fueran asesinados. Posteriormente, trabajaron directamente con la Barbie. Víctor era el presunto dueño de la propiedad donde se refugió la Barbie" (Garay, 2012, p. 185-186).

Arturo Beltrán Leyva se asoció con Vicente Castaño Gil, alias el profe, quien posterior a la falsa desmovilización de las AUC a través de la ilegítima Ley de Justicia y Paz creó las Águilas Negras, según lo informado por la PGR en expediente No. "(SIEDO/UEIDC/1662009- (México)) sobre la red de servidores públicos que hicieron las veces de escudo para que los hermanos Beltrán Leyva edificaran en Morelos su principal refugio y sobre todo, su centro de operaciones... Que los hermanos Beltrán Leyva - una escisión del cártel de Sinaloa - tenían socios en Colombia para el suministro de cocaína... que uno de esos contactos era Vicente Castaño... Una de sus tareas era atender a su socio y líder de la contrainsurgencia colombiana... Beltrán (cobró y asesinó en México 
al deudor) una deuda de 7 millones de dólares a nombre de... Vicente" (Lizárraga, 2012, p. 169-170 y 173). Miguel ángel y Víctor Manuel Mejía, Los Mellizos, continuaron el negocio de Vicente a través de "las águilas Negras... (las cuales) surgieron tras la desmovilización de las AUC" (Lizárraga, 2012, p. 175 y 176).

Por su parte, Jorge Milton Cifuentes Villa, narcotraficante colombiano y socio del Chapo, "estableció en México al menos seis empresas para lavar dinero producto del narcotráfico... también conocido con el alias de Elkin de Jesús López Salazar, obtuvo incluso la nacionalidad mexicana... datos de las actividades... salieron a la luz pública el 6 de agosto de 2011, cuando la policía colombiana detuvo a su hermana Dolly por el delito de narcotráfico y lavado de dinero. Desde 2002, estableció sus primeras empresas... en Panamá, Ecuador, España, EEUU y México" (Campa, 2012, p. 177-178).

Cifuentes Villa y el poder de su ESol narcoviolenta comenzó a fundirse en 2007, cuando "la DEA empezó a vigilar a María Patricia Rodríguez, la viuda de Francisco Cifuentes Villa... la mujer había logrado hacerse socia del Chapo desde Colombia...era una ama de casa que disfrutaba del dinero y la opulencia que le brindaba su esposo... quien amasó una enorme fortuna de la mano primero del capo Pablo Escobar... lejos de amedrentarse, la viuda conoció rápidamente los vericuetos del negocio... y en 2010 fue extraditada a EEUU" (Campa, 2012, p. 181-182).

Daniel Rendón, alias Don Mario “se convirtió en el más poderoso capo de drogas de Colombia y el socio del cartel de drogas más grande de México... fue encausado en una corte federal de Manhattan por tráfico de drogas y por apoyar actividades terroristas de las AUC... es el clásico nuevo narcotraficante colombiano, con negocios paralelos ilegales de drogas con las FARC y organizaciones paramilitares" (Adams en Bagley, 2011, p. 84-85).

Rasguño, quien trabajó en una estación de servicio de gasolina en el Norte del Valle, retomó el negocio arrebatado tras la desarticulación de los legendarios carteles de Medellín y Cali. En 2014 fue condenado en EEUU a 30 años por ingresar al adicto país, aproximadamente "500 toneladas de cocaína y que incluyó varios asesinatos y el lavado de millones de dólares... Rasguño (fue) un socio clave de los paramilitares y -sin dejarse afectar por el baño de sangre que protagonizaban los otros capos del norte del Valle: Wilber Varela, alias Jabón, y Diego León Montoya, alias Don 
Diego- su negocio siguió creciendo... en 2004 fue capturado en Cuba con un pasaporte falso que lo identificaba como ciudadano mexicano y que evidenciaba sus socios en México. En 2007 fue deportado de esa isla a Colombia y ese mismo año fue extraditado a EEUU” ${ }^{\prime 140}$.

La ESol narcoviolenta colombiana se ha pavoneado con la realeza. En 2008 el Príncipe de Arabia Saudita, Nayef Bin Sultan Bin Fawwaz al-Shaalan, fue condenado a 10 años en Francia "por su activa participación en una red internacional de narcotráfico... (transportaba) toneladas de cocaína en su avión privado... los narcos colombianos habían hecho de España la base para sus operaciones en Europa y África. Sin embargo, en años recientes ha llamado la atención de las autoridades un nuevo elemento: el nexo entre la mafia colombiana y las organizaciones terroristas islámicas. El rastro de esta alianza criminal ha podido se rastreado en los EEUU, España y Suiza. Dos de sus fichas principales son el nombrado príncipe Saudí y el próspero empresario español José María Clemente Marcet" (Serrano, 2010, p. 131).

Entre los nuevos líderes visibles de la ESol narcoviolenta colombiana se ha identificado a Harold Mauricio Poveda Ortega, alias el Conejo, quien hace una década se enlistó en el narco-negocio trasnacional entre México y Colombia. Su par mexicano, es Edgar Valdez Villareal, alias la Barbie, quien también... dirigía operaciones de gran magnitud... entre Colombia, México y EEUU. Poveda Ortega... inició operaciones (con)... Don Diego... tuvo la función de ser el enlace entre el cártel de Sinaloa... con quien dejó de trabajar a principios de 2008 para aliarse con el extinto Arturo Beltrán Leyva... (su mayor enlace) uno de los mayores jefes de las FARC, identificado como Comba. Los cargamentos... eran introducidos principalmente por vía marítima en lanchas rápidas y submarinos... Sin embargo, sus relaciones con capos mexicanos no estuvieron exentas de problemas, especialmente cuando se convirtió en el principal abastecedor de droga de los Beltrán Leyva. Su captura, (ocurrió) el 5 de noviembre de 2010" (Garay, 2012, p. 212-213).

La ESol narcoviolenta colombiana efectivamente se encuentra fusionada con las narco-empresas ilícitas violentas mexicanas, lo cual ha disminuido sus ganancias relativas en un 50\% aproximadamente pero ha generado una sólida matriz trasnacional liderada por los países del café y de los tacos. También hacen parte de la ESol narcoviolenta colombo-mexicana, organizaciones

$140 \quad$ http://www.elespectador.com/noticias/judicial/condenan-30-anos-de-carcel-alias-rasguno-articulo-461829. Consultado el 10.6.2014. 
de nacionales brasileros, "rusos y de otros países... Según un estimativo, los productores colombianos ganan apenan un $25 \%$ de la cantidad recibida por ventas de cocaína en las calles de las ciudades estadounidenses y europeas (Posso, 2002, p. 438) ... miles de latinoamericanos continúan muriendo cada año en batallas entre pandillas de la droga que luchan por proveer el mercado estadounidense, pero actualmente la mayor parte de ellas son mexicanas. $Y$ hay indicios de que esta violencia se está trasladando a EEUU. Desde 2010, los carteles mexicanos de la droga operan en ciudades estadounidenses y cometen crímenes relacionados con la droga... la dramática caída de las utilidades provenientes de la exportación de cocaína ha lesionado gravemente la capacidad de financiación de las FARC. Mientras que los ingresos de este grupo guerrillero por concepto de las drogas eran del orden de USD 600 millones anuales a fines de los años noventa, sus ingresos se han reducido a cerca de USD 100 millones 10 años después" (Kline en Henderson,2012, p. 331).

América Central podrá convertirse en una Región Superada por Guerras Promiscuas, pues las ESol narcoviolentas colombo-mexicanas, desde allí "transportan la cocaína en barcos, submarinos o avionetas... sobre todo Cessnas monomotores comprados en Estados Unidos a unos 50.000 dólares la unidad... mientras que la droga se dirige a EEUU, individuos de todos los pelajes ganan dinero con ella... la mercancía suele comprarse y venderse muchas veces por el camino... pero esta dinámica industria tiene un sólido centro de gravedad: los territorios o plazas....Las plazas fronterizas se han convertido en cuellos de botella que no se ven en otros países productores de drogas, como Colombia, Afganistán o Marruecos. Es una de las razones fundamentales por las que las guerras internas en México son tan sangrientas" (Grillo, 2012, P. 223-224).

Es decir, la narco-política exterior de los narcos mexicanos es pacífica comparada con la de otras ESol narcoviolentas trasnacionales, para mantener una especie de seudo-monopolio que expanda el negocio a través del sistema mundo capitalista, sin embargo, dentro del territorio azteca la superviviencia o las narco-políticas aztecas, son marcadas por el grupo interno más violento o mejor asociado respecto al control de las plazas dentro del Estado Federal mexicano superado parcialmente por Guerras Promiscuas.

La narco-alianza entre las redes narcoviolentas ESol de matriz colombo-mexicanas se caracterizan por no ser violentas entre ellas. No obstante, "hay algunos casos de traficantes colombianos 
pequeños asesinados en México, quizá por tratar de operar por cuenta propia... La Unidad Especializada en Delincuencia Organizada- UEDO (confirmó en 2003)... la llegada a México de articuladores de cinco o seis organizaciones de traficantes no mencionadas, de paramilitares y guerrilleros colombianos (para) asegurar el paso y el control de rutas de la cocaína por territorio mexicano y su introducción a EEUU debido al éxito autoproclamado de las autoridades mexicanas en la desarticulación de los primeros grupos. Prácticamente todos los grupos vinculados al tráfico de drogas en Colombia habrían enviado a sus operadores" (Garay, 2012, p. 182), a territorio azteca.

No obstante, "la progresiva incursión de mexicanos en el tráfico de drogas hacia Europa y su presencia en África y en países europeos como España e Italia, que ha sido predominio tradicional de narcotraficantes colombianos, pueden en algún momento, conducir a aquéllos a la búsqueda de la subordinación de los narcotraficantes colombianos en el mismo territorio colombiano, para así poder relacionarse directamente un situ con los procesadores y distribuidores mayoristas de cocaína y heroína en Colombia como principal proveedor internacional” (Garay, 2012, p. 188).

EEUU ha clasificado a las ESol narcoviolentas mexicanas como "la amenaza más grande para ese país, aunque se reconoce que el mercado de las drogas es surtido por una variedad de organizaciones extranjeras y estadounidenses. Entre las demás organizaciones extranjeras están las colombianas, dominicanas, jamaiquinas, asiáticas (particularmente chinas y vietnamitas), nigerianas y ruso-israelíes" (Garay, 2012, p. 183).

Por su parte, el territorio de Honduras "ha sido desde hace mucho una importante escala para los transportadores de cocaína... Mata Ballesteros dirigía su imperio allí en los años ochenta... fue llamada república bananera en 1904 (por)...William Sydney Proter que hablaba del poder de las compañías fruteras extranjeras. Los bananeros todavía dominan la economía local y el país... con la mitad de la población sumida en la pobreza, una inestabilidad política que dio lugar a un golpe de Estado en 2009, y con uno de los peores niveles de violencia de todo el globo. Pan comido para los cárteles mexicanos...han comprado muchas tierras en Honduras, sobre todo en la selva, en las montañas y en la costa, donde apenas hay habitantes. Las adquisiciones blanquean dinero al misto tiempo que proveen de lugares de almacenaje y tránsito para la cocaína... construyeron una pista de hormigón en la plantación para que aterrizaran allí los aviones cargados con oro blanco... 
monomotores ligeros como los usados por el cartel de Sinaloa. Pero... también aviones de más fuste para cargar muchas toneladas de cocaína. Además de despegar de Colombia, muchos transportes de cocaína despegaban igualmente de Venezuela... los capos mexicanos... trabajan con las bandas criminales propiamente hondureñas... la Mara Salvatrucha y Barrio" (Grillo, 2012, p. 399-401).

Principalmente, en 2011, el cartel colombiano del Norte del Valle recogió el negocio desarticulado con el asesinato de Pablo Escobar en 1993 y la correspondiente desaparición del cartel de Medellín que tuvo vinculación con el cartel de Sinaloa desde la década del 70. La distribución de esta red de narcotraficantes transnacional a México, la encabezan: Vicente Carrillo Fuentes, líder reconocido del cartel de Juárez e Ismael Zambada García, del cartel de Sinaloa. Un eslabón de redes o "conexiones y tendencias que solo se pueden entender globalmente y que ello se debe, sobre todo, al carácter trasnacional del narcotráfico" (García, s.f.e., p. 3).

En 2014 las ESol narcoviolentas mexicanas y en especial "el Cartel de Sinaloa, son las únicas que operan en todas las regiones de EEUU y son consideradas por el Departamento de Justicia como la mayor amenaza de tráfico de drogas" (Departamento de Justicia EEUU en Hernández, 2012, p. 353).

De esta manera podemos afirmar que la actividad narcoviolenta de las ESol en 2014 se "encuentra en una transformación radical en la estructura... una mayor participación de narcotraficantes mexicanos que han asumido la tarea de ingresar a EEUU las drogas ilegales producidas en Colombia y en otros países andinos. Algunas razones para justificar este cambio estratégico... (son los) fuertes controles de interdicción aérea y marítima establecidos por EEUU a lo largo de sus costas. Otra razón consiste en las 1592 millas de frontera terrestre entre México y EEUU, con un intenso intercambio comercial y transporte masivo de mercancías... otras razones se relacionan con el desmantelamiento de los grandes carteles colombianos... y su sustitución por pequeñas y medianas redes con menos poder criminal y menor capacidad de negociación internacional... lo anterior... no quiere decir que no haya narcotraficantes colombianos enviando droga directamente a EEUU... (pues diariamente) correos humanos y semi-sumergibles... parten de los puertos aéreos y marítimos de Colombia hacia EEUU. También se sabe de narcotraficantes colombianos movilizándose hacia las costas de África Occidental, para recibir la droga... que pasa por Venezuela 
y Brasil, y luego es ingresada en países europeos. Sin embargo, en lo relacionado con el mercado estadounidense algunos narcotraficantes colombianos han aceptado disminuir sus utilidades mientras ceden a los narcos mexicanos la tarea de introducir la droga a EEUU... En principio sería más fácil sobornar o cooptar agentes de seguridad en México que en EEUU... Esta situación de debilidad institucional que se observa en México ha sido claramente aprovechada por narcotraficantes colombianos y mexicanos... redes ilícitas que, aunque concentradas en el narcotráfico, cada vez incursionan más en distintos mercados ilegales como el de la extorsión, la piratería y el tráfico de armas; de personas y de recursos naturales... si México mejorará sus controles... los narcotraficantes colombianos, entre otros, seguramente adecuarían sus rutas y estrategias para transportar drogas... Guatemala se ha convertido en un país corredor en el tráfico de drogas... 962 kilómetros de frontera casi carente de controles... con México... e instituciones más débiles aún" (Garay, 2012, p. 16-18).

Posibilitando ofrecer el concepto de. Es decir las reglas consuetudinarias establecidas por las ESol narcoviolentas y que delimitan la construcción de las diferentes narco-identidades trasnacionales. Por ejemplo, “pensemos en la cocaína. Un agricultor colombiano podría vender por 80 dólares un fardo de hojas de coca de un campo de una hectárea. Las hojas pasan por un sencillo proceso químico en laboratorios rurales que en Colombia se llaman chagras, y el kilo de pasta de coca obtenida se puede vender por 800 dólares en las montañas colombianas. La pasta vuelve a procesarse para que cristalice y se convierta en un ladrillo de cocaína pura de un kilo... (que) en puertos colombianos, valía 2.147 dólares en 2009, una cantidad que podría alcanzar los 34.700 cuando llegara a la frontera de Estados Unidos, y los 120.000 cuando se vende en las calles de New York $^{141} \ldots$ el beneficio es del 150.000 por ciento...los cárteles mexicanos tienen en Colombia embajadores que hacen los pedidos de la cocaína. Pero aquéllos consiguen que sean los propios colombianos los que les entreguen el polvo discotequero en México o en América Central. Sobre todo en Panamá y en Honduras... los traficantes mexicanos están por encima de los productores colombianos... en un modelo legítimo, ¿ quién tiene la última palabra, Colgate (producto) o Walmart (cadena de comercios)?. En realidad, es Wallmart quien dice: "Quiero pagar tanto por esto, el precio por unidad será tanto, quiero que me lo entreguen tal día, y así es como ha de ser"... este es el moderno de la cocaína con que estamos tratando" (Grillo, 2012, p. 222-223).

141 World Drig Report. (2010). Oficina de Naciones Unidas para drogas y delincuencia (United Nations Office on Drugs and Crime. 
Otros factor importante y que contribuye al mantenimiento y expansión de las ESol narcoviolentas es la basta migración que se sucede dentro del continente americano y que tiene como punto crucial el paso de la frontera México-EEUU, que desde los 60s "facilitó el desarrollo de las redes de distribución ilegal"' (Thoumi en Bagley, 2011, p. 309-310).

No obstante los factores descritos es necesario resaltar que si bien "la amapola y la coca ilícitas pueden crecer en muchos países y regiones... solo tres países producen más del $90 \%$ de estos dos cultivos. Uno puede encontrar muchos países con gobiernos débiles y conflictos sociales entre diferentes grupos que podrían cultivar esos productos pero no lo hacen... existe otra condición necesaria: la capacidad de desarrollar redes ilícitas y de vincularse con las cadenas criminales internacionales... así la economía internacional aumenta la probabilidad de crecimiento de la industria ilegal" (Thoumi en Bagley, 2011, p. 308-310).

La ONU, por su parte, señaló que "la superficie sembrada de hoja de coca en Bolivia, Colombia y Perú se ha mantenido estable y abarca unas 160 mil hectáreas al año; también ha sostenido la producción de cocaína pura, que ronda las 850 toneladas métricas anuales; que se coloca prácticamente en cantidades iguales en EEUU y Europa. A pesar de la reducción de consumo de cocaína en EEUU, la demanda sigue siendo grande y no cambia la condición de México como país de tránsito" (Aguilar, 2012, p. 22-23).

En las redes trasnacionales contemporáneas es posible identificar 3 tipos de agentes, a saber: "cada agente que aparece en una red social puede tener un rol organizacional y un rol institucional. El rol organizacional se refiere a la entidad u organización a la que pertenece... En el primer caso se habla de un rol institucional legal y en el segundo, de un rol institucional ilegal. Así, se tiene que el rol organizacional y el rol institucional no siempre coinciden. Es decir, una agente social puede pertenecer a (las siguientes clasificaciones):

1. Agente social Claro/Bright: su rol organizacional es legal y su rol institucional es legal. Ejm: funcionario público que promueve el cumplimiento de las leyes.

2. Agentes social Oscuro/Dark: su rol organizacional es ilegal y su rol institucional es ilegal. Ejm: narcotraficante que promueve el incumplimiento de las leyes

3. Agente social Gris/Gray: su rol organizacional y su rol institucional no coinciden, bien sea por la combinación legal/ilegal... ilegal/legal. Ejm: funcionario público que 
promueve incumplimiento de las leyes - narcotraficante que promueve cumplimiento de las leyes." (Garay, 2012, p. 45-46).

Se evidencia en la actividad de las ESol narcoviolentas, el protagonismo de "individuos/agentes sociales grises que facilitan una hibridación entre lo legal y lo ilegal para avanzar en la realización de intereses socialmente ilegítimos e incluso abiertamente criminales. Los acuerdos entre narcos y políticos, funcionarios públicos, agencias de seguridad y empresarios, son algunos ejemplos de esta amplia zona gris que no corresponde al puro ámbito legal ni tampoco moral y psicológico en el que las instituciones, aparentemente democráticas y legítimas, son usadas para consolidar la ilegalidad" (Garay, 2012, p. 19).

Es importante resaltar que la doctrina ha denominado como Hub al agente de la red con "el mayor indicador de centralidad directa... es decir, el que más relaciones sociales concentra y, por lo tanto, el más popular... el segundo criterio de centralidad está sustentado en los conceptos de capital social, huecos estructurales (structural holes) y puentes estructurales (structural bridges) (Burt, Christman y Kilburn, 1980)... el hecho de estar muy conectado, como en el caso del Hub, no garantiza la mayor concentración de capital social o... (la) capacidad para arbitrar información” (Garay, 2012, p. 41-42 y 45).

Por consiguiente podemos describir que la ESol narcoviolenta de matriz colombo-mexicana en 2014 "implica el establecimiento de redes trasnacionales... con rango de acción a través de Sudamérica, Centroamérica y EEUU. Este eje permite el desarrollo de las acciones necesarias para producir y movilizar los narcóticos entre los dos principales actores de la estructura: el principal oferente de drogas ilegales y el principal demandante de ese mismo producto... una red ilícita (nos permitirá ejemplificar) la estructura de las relaciones que establecen narcotraficantes y otros agentes colombianos y mexicanos para movilizar la droga a través del eje trasnacional mencionado... la incautación de una cargamento de droga proveniente de Colombia, en el Buque Macel, que se encontraba matriculado bajo la propiedad de una empresa legalmente conformada por algunos miembros de la red ilícita. La movilización de dicho cargamento resulta, entonces, de la articulación de agentes colombianos y mexicanos... los agentes colombianos, provienen del Norte del Valle... Aparecen en la red algunos líderes del cártel de Júarez y del cártel de Sinaloa. Por ejemplo, participan Vicente Carillo Fuentes... Ismael Zambada García... principales 
articuladores de la red se concentraron en entregar en México la droga proveniente de Colombia, para que ésta luego fuera enviada a EEUU por parte del cártel de Juárez o el Cártel de Sinaloa... los principales miembros de la red ilícita desarrollan sus actividades en la Ciudad de México... implementando una serie de empresas dedicadas a realizar diversas operaciones con recursos de procedencia ilícita $^{142} \ldots$ un agente de la DEA en México informó que la red opera diversas actividades... al calcular el indicador de centralidad directa, con el fin de identificar al agente con mayor cantidad de relaciones directas, se encuentra que el hub... alias el Doctor... modelo que permite suponer que los narcotraficantes colombianos que han establecido acuerdos con narcotraficantes mexicanos no ha iniciado, al menos directamente, procesos de Captura o Reconfiguración Cooptada en las instituciones mexicanas" (Garay, 2012, p. 171-175 y 178- 179).

La captura del Estado puede entenderse realizada cuando "intervienen individuos o grupos ilegales, como mafias, narcotraficantes o grupos paramilitares o subversivos, podría configurarse un tipo de captura avanzada del Estado (CAdE), gracias a la intervención de agentes con capacidad para ejercer violencia como mecanismo que sustituye o complementa el soborno...un proceso originado desde fuera del Estado y realizado por agentes externos" (Garay, 2012, p. 36).

Un proceso subsecuente es la Reconfiguración Cooptada del Estado (RCdE) que ocurre cuando se presentan "situaciones de corrupción avanzada y compleja, y presenta las siguientes características: 1. Participación de individuos y grupos sociales legales e ilegales, que mediante práctica legales o ilegales pero ilegítimas buscan sistemáticamente modificar desde dentro el régimen e influir en la formación, modificación, interpretación y aplicación de las reglas del juego social y de las políticas públicas... para obtener beneficios de largo plazo y asegurar que sus intereses sean validados política y legalmente, para así obtener legitimad social... la iniciativa no sólo se da a partir de agentes externos al Estado" (Garay, 2012, p. 36-37).

Por ejemplo el narco-paramilitarismo colombiano logró la RCdE al "cooptar las decisiones administrativas, políticas y judiciales de... Soledad... a partir de la estructura configurada en el municipio... se pusieron en marcha procesos de cooptación que alcanzaron instituciones incluso nacionales, como el Congreso y las agencias de seguridad" (Garay, 2012, p. $69-70$ y 73).

142 Resolución de situación Juzgado 10 Distrito Procesos Penales Federales, 2004. 
Demostrado lo anterior a través de fallos en firme que relatan los procesos de "corrupción, CdE y RCdE. Por ejemplo... el jefe de la rama ejecutiva del municipio de Soledad actuó como el puente estructural entre los agentes legales e ilegales, permitiendo el flujo de información y arbitrando en la calidad y la cantidad de esa información tanto entre miembros de las AUC, funcionarios públicos y la cantidad de esa información tanto entre miembros de las AUC, funcionarios públicos y agentes privados con funciones públicas, como con aquellos miembros de la sociedad civil que, encargados de verificar el cumplimiento de las obras civiles, recibieron sobornos para no denunciar incumplimientos en la ejecución de los contratos" (Garay, 2012, p. 74-75). La descrita red de Soledad es solo un ejemplo de los diversos casos de "Corrupción Sistémica (CS) a gran escala establecida con el propósito de favorecer los intereses económicos de las AUC. No obstante, también se evidencia Captura Instrumental de instituciones democráticas... La Captura Instrumental de Instituciones (CII) democráticas configuraría, entonces, un escenario de Captura Avanzada del Estado (CAdE), así como una etapa hacia la Reconfiguración Cooptada del Estado /RCdE) a nivel local y nacional, adelantado por las AUC" (Garay, 2012, p. 82).

En cuanto a las relaciones sociales de la red de Sucre se determinó que es "una subred, o módulo, de una red ilícita de mayor tamaño que se configuró en cinco departamentos vecinos... la violencia es un tipo de relación social muy poco usado... no se registra el soborno ni cualquier otra práctica de corrupción tradicional... situación social cercana a la (RCdE) a nivel de la región e incluso en importantes instancias institucionales del nivel central" (Garay, 2012, p. 277).

Dichas redes sociales alcanzaron a proyectar e impulsar redes sociales a niveles nacionales una vez cristalizado el fenómeno de la parapolítica en Colombia.

Entonces, la RCdE "siempre se caracteriza por procedimientos de Captura Instrumental de Instituciones (CII); es decir, captura de determinadas reglas de juego social... consiste en aprovechar ciertas reglas de juego formales o informales que la sociedad y el Estado han adoptado e instituido para infiltrar el núcleo de un Estado... alguno tipos... Captura Instrumental de la Academia... de los Medios... de la Sociedad Civil... de Partidos Políticos... (este último) el más común de Cll observado en las redes criminales" (Garay, 2012, p. 37), colombianas y mexicanas. 
Cuando evolucionan situaciones de CdE y de RCdE se presenta la figura de la corrupción sistémica, funcionales a las redes trasnacionales del narcotráfico, las cuales necesitan "coordinación de intereses y acciones, individuales y grupales, y en este sentido... el crimen organizado... envuelve la cooperación de diferentes personas o grupos, para su ejecución exitosa (Lindesmith 1941, p. 119)... la Convención de las Naciones Unidas contra la Delincuencia Organizada considera al crimen organizado como un grupo estructurado de tres o más personas que exista durante cierto tiempo y que actúe concertadamente con el propósito de cometer uno o más delitos graves o delitos tipificados" (Garay, 2012, p. 39).

Por ejemplo, el caso de la parapolítica en Colombia demuestra claramente cómo los grupos ESol narcoviolentos generaron la denominada Paradoja del Estado Cooptado en territorio colombiano, cuando infiltraron "la rama legislativa (llevando) a una situación paradójica y problemática para la consolidación democrática... La legitimidad de ciertas leyes puede incluso ponerse en duda, porque su cumplimiento puede llegar a favorecer intereses excluyentes e incluso criminales, en detrimento del interés común que exige el Estado de derecho" (Garay, 2012, p. 38). Como es el caso de la Ley de Justicia y Paz y de la Ley de Víctimas y de Restitución de Tierras.

Así la ESol narcoviolenta colombiana con red cimentada en la costa atlántica, representa claramente un "caso extremo de avance hacia la ( $\mathrm{RCdE}$ ), con una elevada concentración de funcionarios públicos a cargo de actividades legislativas y candidatos a cargos de elección popular en los niveles local, regional y nacional de la administración pública... la relación más importante es la de acuerdos políticos... relaciones establecidas desde dentro... hacia afuera del Estado, con el fin de aprovechar el poder territorial, la capacidad de intimidación y el ejercicio de la violencia por parte de agentes y grupos ilegales como narcotraficantes, paramilitares y guerrillas... una de las consecuencias en términos del daño institucional es la alta participación de funcionarios públicos pertenecientes a la rama legislativa en los planos regional y nacional. Es estas condiciones, es muy probable que los Estados hubieran sufrido las consecuencias de la situación... Paradoja de Estado Cooptado" (Garay, 2012, p. 282-283).

En cuanto al caso mexicano, en el "análisis de la red de La Familia Michoacana... Ilama la atención la cantidad de relaciones sociales establecidas con funcionarios públicos de alto perfil y candidatos a cargo de responsabilidad pública... la presente red fue elaborada en dos etapas... en la primera... 
se modelaron hechos acontecidos hasta 2005.... Según la información consultada, se daba cuenta de la participación del Tísico, o el Negro, como líder del cártel. Para ese entonces también se observaba la intervención de la Tuta como... relevante para el desarrollo de las acciones de La Familia, sobre todo cuando estaba articulada con el cártel del Golfo... no se registraba una alta concentración de funcionarios públicos en la red... del nivel local... orientada a sobornar agentes encargados de la seguridad... Durante la segunda etapa, que comprende información de hechos sucedidos hasta 2009, comienza a observarse una mayor participación de funcionarios públicos en la red... La Familia michoacana se encarga principalmente de sobornar a funcionarios públicos de las municipalidades para facilitar el movimiento de drogas ilícitas en el interior del estado de Michoacán. Usualmente, en la información proporcionada por los testigos, se señala que esa droga luego se moviliza para ser enviada a EEUU.... Se menciona el uso de automóviles de agencias de seguridad local o... del Estado. Este proceso de infiltración por parte del narcotráfico en las fuerzas policiales del estado de Michoacán coincide con información reciente suministrada por la Secretaria de Seguridad Pública Federal de México (El Universal, junio, 2011): “con infraestructura de la policía estatal establecieron rutas y seguridad para los comandos... vale la pena resaltar que, aunque se observa el establecimiento de acuerdos de colaboración política o de colaboración mutua, la participación de este tipo de relaciones es aún baja en comparación con la de las relaciones sociales establecidas a través del sobornos o la intimidación" (Garay, 2012, p. 223-225).

La Tuta es quien arbitra la mayor cantidad de información lo que puede explicar como configuró "una fracción autónoma de La Familia, actualmente conocida como los Caballeros Templarios, la que rápidamente se ha convertido en prioridad militar para el Estado mexicano (Oter, 2011b)... aunque la captura del Chango Méndez y la muerte del Chayo han sido interpretadas en algunos espacios de opinión como el desmantelamiento de La Familia (Milenio, 2011), el surgimiento de los Caballeros Templarios genera dudas con respecto a cuál era, en los últimos años, la verdadera estructura de la Familia. Aunque la Secretaría de Seguridad Pública identificaba al Doctor y al Chango Méndez como los principales líderes de La Familia (El universal, 2010). Quienes actuaban como líderes en términos de su capacidad para establecer relaciones sociales directas y para arbitrar información eran el Tío y La Tuta" (Garay, 2012, p. 226).

Tal dimensión como la parapolítica colombiana se encuentra en la infiltración de La Familia Michoacana en la administración mexicana en todos sus niveles. Por ejemplo, "el michoacazo, 
operación policiaca en que 35 presidentes municipales fueron capturados por supuestos vínculos con La Familia.... Ejemplifica aquella estructura de relaciones con candidatos a cargos de elección populares y funcionarios públicos... a la fecha, todos los detenidos fueron exonerados y liberados... La ausencia de fallos condenatorios al respecto podría explicarse, en estricto sentido, 1. Por una cooptación avanzada del sistema judicial local...2. Problemas en el proceso pericial de recolección de pruebas; 3 . Aprovechamiento de procedimientos formales como las instancias de apelación, o; 4. La simple inexistencia de dichos vínculos" (Garay, 2012, p. 228-229).

En consecuencia la red de la Familia de Michoacán consolida un tipo de "Captura Avanzada del Estado (CAdE) en el plano local y en menor proporción en el estatal, alrededor de la rama de la seguridad y de la judicial. Adicionalmente, se observa cierta afectación en la Rama Ejecutiva del nivel local (municipal), con algunos avances hacia la RCdE, principalmente, en el nivel local" (Garay, 2012, p. 274-275).

En mayo de 2014 fue capturado en México el sobrino del Chapo alias Rafael Gutiérrez, donde se develó una red de la ESol narco-violenta colombo-mexicana conformada por miembros del cartel de Sinaloa y las FARC, ejecutada a través de transporte aéreo. Al igual que una reciente red ESol narcoviolenta en España con los Urabeños.

Pudiendo afirmar que en los Estados Superados de Colombia y México por Guerras Promiscuas "los procesos hacia la CdE y la RCdE tienden a desarrollarse frecuentemente en el esquema de abajo hacía arriba (bottom-up), ante el interés de redes criminales por aprovechar la descentralización político administrativa y las consecuentes transferencias de poder y recursos públicos a unidades políticas locales que se caractericen por presentar rasgos distintivos de Estados débiles y precarios, con democracias frágiles y serias fallas estructurales (favoreciendo) la reproducción de la Paradoja del Estado Cooptado... No obstante, debe también tomarse en cuenta el caso de Guatemala, en el que el proceso de RCdE se desarrolló mediante un esquema de arriba hacia abajo (top-down)" (Garay, 2012, p. 289). Sin embargo, "en todos los casos analizados, el carácter trasnacional aparece como relevante" (Garay, 2012, p. 291).

“¿Quién ata a quién? La experiencia internacional demuestra que los actores que tradicionalmente definen las ataduras que dan paso a la paz son victimarios y los representantes de la organización 
política que negocia con ellos (en el caso de transiciones negociadas) o los actores victoriosos (en el caso de conflictos resueltos militarmente)" (Arcia en Bagley, 2011, p. 269). 


\section{CAPÍTULO XII: DESCONTEXTUALIZACIÓN NARCOVIOLENTA: LA NECESDIAD DE LA DESTEORIZACIÓN CLÁSICA}

\subsection{NARCOVIOLENCIA: UN DIAGNOSTICO DESCONTEXTUALIZADO}

EEUU presiona sin descanso a las administraciones para hacer del conflicto doméstico un tema internacional.

A su vez, el Interés Nacional de EEUU fundamentado en la primacía de la variable de la Seguridad Nacional, resulta más valioso, que el Interés Nacional de Colombia y México, que si bien apuntan en la misma dirección de la Seguridad, ejercen unas soberanías condicionadas o de papel, que se le ha otorgado a los Estados débiles de la periferia desde el Siglo XIX.

El narcotráfico conectó la agenda norteamericana con la de $A L$ andina. Una unión negativa que revela una constante política de presión al enemigo durante y después de la GF y que desde la década del 70 bajo la administración Nixon, quien inició la guerra contra el flagelo narcótico que terminó confirmando la narcotización internacional de la agenda doméstica y externa de los Estados Superados por Guerras Promiscuas.

Las políticas antinarcóticas represivas generan "el desplazamiento de plantaciones, cambios en la estructura de las organizaciones de traficantes y la adaptación de sistemas de tráfico. Las organizaciones traficantes han reforzado sus vínculos con la clase política en muchas regiones y con organizaciones subversivas y contrasubversivas" (Thoumi en Bagley, 2011, p. 316).

Ahora bien, como vimos en los capítulos referidos a la narcoviolencia en Colombia y México, los fenómenos del narcotráfico y de la insurgencia constituyen un proceso de origen y de lógicas de acción diferentes, cuestión que ha sido negada por EEUU. Lo que imposibilita la solución del conflicto porque no se puede resolver lo que no se conoce y el hacer uno, dos fenómenos que se tocan pero que a su vez chocan, genera teorías interesantes pero que no encuentran eco en la realidad. Es decir, se generan mecanismos para exterminar un fenómeno teórico que en la práctica son dos fenómenos distintos y en disputa. Propiciando el status quo de la violencia. 


\subsection{NARCOGLOBALIZACION - NARCOGLOCALIZACION: REPRESIÓN VIOLENTA LEGÍTIMA O LEGALIZACIÓN}

Las ESol narcoviolentas se expanden "hacía el otro lado de la frontera... se están afincando en todo el hemisferio occidental y a orillas del Atlántico.... Han crecido con la misma ampliación lógica que otras entidades del capitalismo... se están abriendo paso en los débiles estados centroamericanos, así como en Perú y Argentina. También circulan informes sobre su poder adquisitivo en los frágiles estados africanos, sus negociaciones con la mafia rusa, incluso su papel en el abastecimiento de droga a los traficantes de Inglaterra... Mientras que en 2010 había más de tres mil asesinatos en Juárez, que está a un tiro de piedra de El Paso, en esta ciudad sólo hubo cinco homicidios" (Grillo, 2012, p. 379-381).

El gran porcentaje de la narcoviolencia en Norteamérica ocurre mediante "peleas territoriales por controlar las esquinas de esas calles... los asesinatos se comenten en Baltimore, en Chicago, Detroit, Nueva Orleans, Los ángeles y otras ciudades... la pesadilla sería que el narcotráfico interviniera en la guerra de pandillas de EEUU... (lo que) está empezando a materializarse en Texas, que limita con la frontera mexicana. El desbordamiento tiene dos frentes: el pasillo central de El Paso-Juárez, y 1500 kilómetros al este, junto al golfo de México. En El Paso, los vínculos entre las calles estadounidenses y los señores mexicanos de la droga se han reforzado con el crecimiento de la banda Barrio Azteca. A diferencia de otras bandas chicanas, ésta ha establecido una sólida relación con los cárteles y se ha convertido en una auténtica organización transfronteriza" (Grillo, 2012, p. 392).

Las pandillas de EEUU pueden aprender tácticas de carteles mexicanos como estos aprendieron de los colombianos. La alianza multinacional pierde extenderse e incrementar utilidades. Entonces en 2014, “Colombia, al igual que México... se enfrenta en una... insurgencia criminal, no a una insurgencia ideológica" (Grillo, 2012, p. 368).

En 2014, "una vez llega a EEUU, la droga se mueve por una complicada red de rutas que abarca todo el país... los traficantes ya no se preocupan por quien más la vende. El conflicto monopolista y toda la violencia se quedan en el lado mexicano de la frontera... una excepción podría ser 
Phoenix, donde... se han producido secuestros relacionados con la droga... en México corren rumores de que el cartel de Sinaloa ha reclamado Phoenix como propiedad exclusiva. La ciudad está a 250 Kilómetros de Sonora, que el Estado fronterizo que controla la mafia sinaloense" (Grillo, 2012, p. 382-383).

Contradictoriamente con la violencia que despliegan los EEUU trasnacionalmente en ropajes de cooperación militar, no es coherente en cuanto a la situación del uso de drogas al interior de los EEUU. Así, “quien recorra un kilómetro cuadrado de los ángeles verá una veintena de tiendas de marihuana médica... y nadie resulta tiroteado por sicarios con pasamontañas y fusiles de asalto... la hierba de la planta en EEUU, se fuma legalmente en EEUU y paga impuestos en EEUU" (Grillo, 2012, p. 428). Desde 1914 "la cocaína era legal en EEUU... Carter presentó un proyecto de ley para despenalizar el consumo, pero en ese momento solo 30\% lo apoyó"(Aguilar, 2012, p. 123-124).

Las fases de la legalización norteamericana de las drogas comenzaron en la década del 70 bajo la presidencia de Jimmy Carter, despenalizó la "marihuana, y la cocaína se veía en los medios como una droga recreativa para alegrar las fiestas... en los años ochenta EEUU cargó contra las drogas con auténtica saña, y en los noventa la guerra contra los estupefacientes se recrudeció" (Grillo, 2012, p. 428-429). La misma actitud represiva se mantiene en 2014.

A favor de la legalización encontramos diversos partidarios: desde los "rastafaris que fuman maría hasta los fundamentalistas de libre mercado, pasando por todos los que caben entre estos dos extremos. Hay socialistas que piensan que la guerra de la droga perjudica a los pobres, capitalistas que ven una oportunidad económica, liberales que defienden el derecho a elegir, y conservadores en asuntos económicos que se quejan de que EEUU gaste 40.000 millones de dólares al año en la guerra contra las drogas en vez de ingresar unos cuantos miles de millones de dólares gravándolas con impuestos (Miron, 2010). El movimiento esta de acuerdo que la actual política no funciona... sus miembros discuten si las drogas legalizadas deberían estar controladas por el Estado, por empresas, por pequeños comerciantes o por agricultores independientes; y tampoco saben si deberían anunciarse públicamente, gravarse con impuestos o entregarse gratis a los adictos en cajitas blancas... (pero) fuera de EEUU también hay voces que se suman al campo antidroga. Los tratados de las Naciones Unidas piden que todos los firmantes mantengan políticas prohibicionistas y aquí es difícil que haya cambios" (Grillo, 2012, p. 432-434). 
Holanda "ha tenido leyes liberales...y... el consumo es allí inferior al del Reino Unido, cuyas leyes son más estrictas. Portugal, cuya legislación era estricta, tenía uno de los índices de consumo más bajos de Europa, y ha seguido descendiendo a pesar de la despenalización de todas las drogas que se decretó en 2001. El principal logro de este cambio fue ahorrar dinero y reducir contagios del sida" (Grillo, 2012, p. 434).

EEUU lidera el sistema internacional occidental con su política prohibicionista extrema contra las drogas "continúa teniendo uno de los niveles de consumo más altos del mundo... sin embargo, con el paso del tiempo han cambiado las drogas que se consumen. La cocaína en polvo estuvo de moda en los años setenta, el crack hizo irrupción en los ochenta, el éxtasis adquirió protagonismo en los noventa, y los cristales de metanfetamina tuvieron temporada de fama con el advenimiento del nuevo milenio... el consumo de América Latina, México incluido, es muy inferior al de EEUU, aunque se ha elevado mucho en los últimos veinte años"143. A lo descrito, podemos identificarle como los efectos trasnacionales del narco-calentamiento global. 


\section{CONCLUSION}

Podemos afirmar que efectivamente las soberanías de Colombia y México están condicionadas por las pautas de la política estatal norteamericana sobre la lucha contra las ESol narco-violentas. Las pautas fueron dilucidadas a través de la imperatividad de las políticas estatales de EEUU sobre las posiciones sumisas asumidas por los Estados de Colombia y México al respecto.

Desde la década del 90 México y Colombia experimentaron las estrategias militares provenientes de Norteamérica para enfrentar el flagelo narcótico, que en fondo y forma minan la capacidad de respuesta soberana al fenómeno narco-violento.

El análisis de la vinculación entre las RRII de las ESol en México y Colombia ha demostrado el mantenimiento e incremento de las consecuencias de la narcoviolencia por las directrices de la política norteamericana con respecto a ambos Estados.

Lo que posibilita describir a la ESol narcoviolenta de matriz colombo-mexicana en 2014 como un red cuya condición primaria es la trasnacionalización mediante la expansión de redes ESol narcoviolentas que se estructuran en la ruta con punto de origen sudamericano, con escala en Centroamérica y destino final EEUU, principal agente comprador o sujeto destinatario de narcóticos y surtidor de armas a dichos grupos, de manera directa o indirecta, utilizando las narcoincoterms, como reglas subterráneas que sin estar tipificadas son respetadas en el mundo criminal.

La regla general de la relación observada es que las economías, legal internacional y legal doméstica, se encuentran permeadas por los rendimientos de las actividades desarrolladas por las trasnacionales ESol narcoviolentas con matriz colombo-mexicana.

Así mismo, mientras que EEUU tercamente impone medidas represivas fuera de sus territorios y en ocasiones atentatorias del derecho internacional, produce la mayor cantidad de marihuana en el mundo y la reparte medicinalmente mientras que continúa liderando la estrategia 
estatocéntrica unilateral desde su política exterior y multilateral como líder de la institucionalidad internacional contra la producción y distribución de narcóticos. Así mismo, en agosto de 2014, el reelecto Presidente de Colombia, Santos Calderón, le dio un empujón político a la legalización de la marihuana para usos terapéuticos.

La falta de institucionalidad (valor) afecta las políticas globales antinarcóticas, marco que encuentra en la corrupción de los sistemas colombianos y mexicanos, Estados Superados y abiertos a la negociación clandestina.

Precisamente uno de los aportes teóricos a la disciplina de las RRII se traduce en la creación de conceptos como: Estados Superados, Estados Superadores, Guerras Bastardas o Huérfanas, Estados Educados y Maleducados, Link Narcoviolento, Región Superada, ESol narcoviolenta, Narco-calentamiento Global; Narco-iconterms; entre los principales así como sus respectivas características de composición y descripción de las actividades de funcionamientos e inserción política trasnacional. Todos los conceptos son posibles gracias a la debilidad de los Estados y la corrupción de las esferas legales endógenas y exógenas, los cuales nos permitiremos sintetizar más adelante.

Ahora bien, es definitiva la inaplicabilidad del paradigma realista y neorrealista por la ignorancia de la presencia que hacen los actores no estatales dentro del sistema internacional y de su marcada trasnacionalidad y multidimensionalidad del fenómeno de las ESol narco-violentas. Adicionalmente aquellos que se consideran más pacíficos y desarrollados, resultan bajo este tipo de enfoques ortodoxos, siendo los más violentos.

La cooperación internacional ofrecida en ámbitos de seguridad contra el fenómeno narcoviolento es en realidad un condicionamiento unilateral proveniente de los EEUU. Es preciso concebir a una verdadera política regional que adapte cada uno de los particularismos que caracterizan las ESol narco-violentas de Colombia y México, pues conlleva un fenómeno global.

Consideramos entonces, que una de las referencias teóricas que facilita el estudio del fenómeno de las ESol narcoviolentas en las RRII debe cimentarse a partir de la interdependencia. Sin embargo, ante la asimetría de los sujetos, no es posible conceptuar una interdependencia estatal 
sino de otro tipo de sujetos y actores, que la interdependencia original no contempla, como otros campos no exclusivamente económicos, por ejemplo, los escenarios interculturales. Por lo que adecuamos nuestro estudio a la teoría del linkage al linkage narcoviolento.

Siguiendo con la construcción teórica para el estudio del fenómeno de las ESol narcoviolentas en el marco de las RRII, se privilegió la variable de los DDHH sobre la variable de la seguridad, lo que propició el uso del enfoque pluralista de Boaventura de Sousa Santos, articulado con un fundamento paradigmático constructivista.

Dicha concepción teórica planteó la coexistencia de dos o más ordenamientos jurídicos en un mismo ámbito de tiempo y espacio, como alternativa jurídica. El pluralismo desde su enfoque socio-jurídico potencializará la creación de nuevos marcos normativos menos represivos y más coherentes con las realidades culturales narcóticas.

En consecuencia y junto al proceso globalizador, la agenda internacional de tipo vertical comenzó a horizontalizarse mediante el reconocimiento de nuevas variables, sin descartar a la seguridad, pero mediante un tratamiento menos mono-causal.

Es por lo anteriormente descrito que consideramos que el mejor camino paradigmático se cimentó en la amalgama de la línea del postbehaviorismo o pluralismo paradigmático que enfrenta las realidades que no resuelven los tradicionales paradigmas de las RRII pese a ser aplicados con sangrienta crueldad a las narco-comunidades.

Estas consideraciones críticas y pos-estructurales permiten describir a un objeto que persigue como finalidad la construcción de una paz emancipatoria y polifacética, de mente más amplia y analítica que ortodoxa y represiva, que considere un concepto de justicia menos estrecho y de más de 11 barrotes del eminentemente clásico y que permita contribuir a la reconciliación entre la diversidad factorial, impidiendo el mantenimiento de la imposición de los asuntos de las minorías centrales sobre mayorías periféricas.

EEUU condiciona como factor exógeno principal las soberanías de Colombia y México, ocansionando inputs y outputs soberanos. Un input de un Estado Superador reporta al Estado 
Superado una ventaja o valor agregado a su condición soberana, por ejemplo: alianzas políticas, gobernabilidad sin presión, seguridad y prerrogativas jurídicas para las élites político-económicas de los Estados Superados. Por su parte, un output en el mismo escenario, representaría la balanza negativa de la relación, cuando el Estado Superado representa un papel desobediente en alguno de los deseos caprichosos del Superador, que decide reprenderlo, porque sabe que lo domina, siendo su Superador Hegemónico.

Los Estados Superados parcialmente por factores endógenos y casi completamente por factores exógenos, varían conforme lo dictan sus superadores, los marcos que regulan las actividades narcoviolentas. Tal superficialidad jurídica es otro símbolo del precario sistema estatal superado por sus realidades sociales y que prefiere ignorarlas mediante la represión que alimenta las frustraciones sociales que desencadenan fenómenos rellenos de violencia y odio, que a la vez, parecen impulsar a las respuestas realistas.

No hablemos entonces de narco estados sino de narco naciones. Pues se trata ya de un asunto cultural y no solo de salud pública. Este ha arraigado y se enfrenta a la violencia legal e ilegal así como también se incorpora en las instituciones más representativas de los Estados Superados.

La adaptabilidad como principio de las ESol narcoviolentas las hace permanentes en los Estados Superados y Superadores. Tal flexibilización estructural les permite acomodarse antes de ser exterminadas y si son machacadas finalmente, nuevas organizaciones se enfrentarán para cooptar los narco-territorios. Tal como ocurrían las guerras legítimas de independencia.

Adicionalmente, la variable cultural se adapta a los postulados de la teoría de la interdependencia, debido a la imposición de patrones culturales. Culturas con estructuras político-sociales más fuertes terminan imponiendo sus patrones, así como se impone la tradicional cultura de occidente sobre la de oriente a niveles macro-culturales. Sin embargo, la narco-cultura representa patrones micro-culturales que chocan entre sí, dentro y fuera, de los territorios soberanos superados.

La variable cultural anti-narcótica resulta predominante sobre la de las narco-identificados. No obstante, la elevada represión cimienta los lazos de las narco-comunidades en la construcción de una nación de alcances trasnacionales. 
Resultando que los Estados Superados por Guerras promiscuas son Estados Obedientes o Educados que responden a las necesidades o intereses de sus superiores políticos. América Central podrá convertirse en una Región Superada por Guerras Promiscuas.

Las Guerras Promiscuas agrupan enfrentamientos internos donde la autoridad del Estado es parcialmente cuestionada por el remplazo del proveedor de medios de supervivencia o la simple neutralización de grupos sociales mediante el uso de la narco-amenaza o el empleo de la narcoviolencia. Utilizan cualquier herramienta en la consecución de sus diversos objetivos personalismos pero planificados en red como lo exige el Sistema Internacional.

Los Estados Superados se asemejan en aceptar las solicitudes del hegemón modernizando con su ayuda a sus Ejércitos mediante la cooperación militar, lo cual no reviste mayor gravedad, por el contrario, revitaliza los estándares de Seguridad y Defensa nacionales cuando no se extralimitan ni se omiten las funciones de ley. Pero la realidad muestra como las CMP son financiadas para labores concretas a través de dinero provenientes de los planes armados norteamericanos. La unidireccionalidad de tratamiento al complejo fenómeno que requiere una Guerra Promiscua trasnacional y millonaria, la hace permanente.

Igualmente las ESol narco-violentas superan sus Estados al ejercer poder político en ciertos territorios, al imponer reglas de juego para que sean protegidos frente a otros grupos armados ilegales como las guerrillas y grupos ESol narco-violentos, las cuales realizan el mismo procedimiento generando muchas veces que los pobladores sean amenazados desde diversos grupos, quedando a merced de la suerte y la casualidad.

También la permeabilidad del sistema financiero legal por parte de las finanzas narco-violentas es un resultado de la inserción de dichos actores como dirigentes de un desorden mundial, o incluso, trasnacional.

Entre tanto, el diagnóstico hegemónico errado y tercamente impuesto enciende los focos de las Guerras Promiscuas y retiñe la impronta de Estados Superados, lo cual resulta conveniente a los gobiernos de los mismos y al Hegemón, en cuanto al mantenimiento de las relaciones cordiales 
entre las partes negociantes. En dicho contexto Colombia y México adoptan una legislación antinarcótica.

En 2014, la alternativa sigue siendo la legalización de la producción, distribución y consumo de drogas. México atraviesa por un escenario narco-violento que corre el riesgo de entrar en metástasis por el alto índice de niveles de corrupción en sus Instituciones y Fuerzas Armadas. Las armas norteamericanas se utilizan no solamente para operaciones violentas ilegales sino como moneda de cambio por la droga recibida de carteles de Colombia, México y de intermediarios centro-americanos.

Entonces los Estados Superados nutren sus ejércitos para combatir actores ilegales, que con armas no convencionales montan pie de fuerza a cualquier tipo de estrategia o inteligencia militar. Fomentando la multiplicación de ESol que evolucionan en guerras bastardas o huérfanas, es decir, sin padres reconocidos y donde se asientan los enfrentamientos indirectos en remplazo de choques interestatales.

Ahora bien, los Estados que decidan no obedecer los diagnósticos de los EEUU y a cimentarse en tal moral politizada, deberán asumirse dentro de los postulados de la irrelevancia de la racionalidad de EEUU. Es decir, puede que un Estado Superado sea realmente irrelevante para los intereses norteamericanos, pero al no seguir los lineamientos del hegemón puede ser atacado no porque represente una verdadera amenaza sino para amedrentarlo y obligarlo a seguir sus postulados. Si la narco-amenaza representara un riesgo latente para los intereses vitales de EEUU no serían confrontados directamente porque allí sí estaría en riesgo el interés vital del hegemón. Algo similar sucede dentro de los Estados Superados con sus propios actores superadores. Si son realmente violentos podrán más fácil acceder al poder público, de lo contrario, estarán marginalizados del proceso de toma de decisiones estatales.

Un hegemón que no necesita ni de México ni de Colombia en cuanto a intereses nacionales se refiere. No obstante, si necesitan de los productos narcóticos para satisfacer las necesidades de los consumidores norteamericanos, los cuales al adquirir la droga realizan un blanqueo automático e imperceptible de dineros ilícitos que se insertan en la economía legal estadounidense y mundial. 
La lucha internacional contra las drogas liderada por EE.UU se ha focalizado erróneamente en Colombia, México y otros países ligados a la ESol narco-violenta mexicana, "cuando es posible que suponga el primer conflicto global" (Ramírez, 2011, p. 22).

Narcotizando las agendas externas de los Estados Superados mediante la utilización de guerras promiscuas que se valen de cualquier método e ideología para hacer respetar su ley.

Los narcotraficantes se copiaron de las estrategias de las guerrillas para ascender en la escalera política mediante la violencia comprable

El Estado Superado en la esfera internacional acepta con prioridad las obligaciones internacionales a que se acogen condicionados por la existencia de sus Guerras Promiscuas, que a la vez, legitima sus discursos políticos y su manteamiento en los poderes domésticos.

En consecuencia, la narco-economía es trasnacional; la narco-cultura es meramente nacional o inclusive regional.

Aclarando que la mayoría del control territorial de dichos Estados Superados es monopolizado por las FFAA de Colombia y México. Lo que los diferencia de ser Estados Fallidos. Aunque el nivel de corrupción de la fuerza legal en México es desmesurada.

El negocio trasnacional del narco y su posicionamiento trasnacional se debe a la prohibición, es decir, a trascurrir en escenarios supuestos de ilegalidad. Podemos afirmar que los narcos son el producto final de la ilegalidad pues dicho contexto eleva los precios de los objetos ilícitos comercializados.

El mantenimiento del fenómeno de la narcoviolencia durante décadas demuestra que el fenómeno no afecta los intereses vitales de los EEUU. Los Estados Superadores como EEUU no intervendrían Estados Pares sino intervienen a Estados Superados pues los mismos no le representarían un pie de lucha. Se omite la intervención en Estados que responderían la violación de los estándares soberanos con el uso de la fuerza y el deseo de posicionarse sobre el hegemón. 
Los Estados Superados que no obedecen a su hegemón o Estado Superador en cuanto a la lucha específica del conflictos intermésticos (de interés nacional e internacional) generados por actores ilegales que igualmente los superan realizando algunos de los fines del Estado democrático, tiende a salir perdiendo. Es decir, les va peor estar peleados que dominados o condicionados en el mejor de los casos.

Lo que traduce que en los tiempos actuales, la política exterior más adecuada para llevar avante este tipo de incidencias, es adoptar un bajo perfil y no necesariamente definirse en términos geoestratégicos. Los Estados Superados necesitan al Hegemón así éste no los necesite. Por ello, siempre resulta menos traumático obedecer o estar de acuerdo con el Hegemón que ir en su contra.

Las realidades narcoviolentas en Colombia y México no deben ser calificados como Estados Fallidos, han sido superados por grupos narcotraficantes, autónomos, que sacian falencias estatales mediante los cuantiosos recursos que le significa su actividad ESol narco-violenta, lo que les permite asumir las funciones no desarrolladas por los aparatos jurídico-políticos estatales, en ciertos lugares del territorio soberano. Resaltando que el territorio de los Estados Superados sigue siendo soberano.

Los Estados Superados por actores ilegales para-estatales o no estatales (dependiendo de cada grupo ESol narco-violento), como son los diversos grupos narcotraficantes, generan un nuevo desorden mundial que puede fácilmente extenderse a los Señores de la Guerra y a los actores de las Nuevas Amenazas, que en realidad no son tan nuevas.

Las ESol narcoviolentas actúan como narco-compañías armadas privadas que superar funciones estatales como la seguridad, empleo y satisfacción de necesidades básicas. Un remplazo por brindar narco-oportunidades que eliminan la frustración de ciertas comunidades.

Es por lo anteriormente expuesto que nos permitimos caracterizar a las ESol narcoviolentas en los siguientes escenarios trasnacionales: 
1. Los Estados superados por Guerras promiscuas son Estados Educados, los cuales obedecen y atienden las necesidades de sus directores políticos o Estados/sujetos Superadores para evitar trastornos políticos, económicos o jurídicos. Lo cual hace pensar que un Estado Superado que actúa en forma beligerante, o en simple uso de su soberanía, frente a los condicionamientos externos de los Estados Potencia, serían clasificados como Estados Maleducados que no obedecen a los postulados o casi imposiciones externas, en cuanto a las medidas a adoptar, como en la lucha contra el narcotráfico y sus daños colaterales, se refiere.

2. Los Estados Superados también son sobrepasados o remplazados por actores superadores endógenos y exógenos.

3. Las Guerras Promiscuas agrupan enfrentamientos internos donde la autoridad del Estado es parcialmente cuestionada por el remplazo del proveedor de medios de supervivencia o la simple neutralización de grupos sociales mediante el uso de la narco-amenaza o el empleo de la narco-violencia.

4. La población ubicada en narco-territorios está supeditada al empleo ilegal, a la marginalidad o a la vulneración de sus DDHH por los deseos o intereses de las ESol Narco-violentas.

5. Igualmente las poblaciones más adineradas de los Estados Superados y los Estados Superadores, encuentran en las ESol narcoviolentas, una economía rentable para invertir, dineros legales e ilegales.

6. Las ESol narcoviolentas no requieren una estructura ni vertical ni horizontal sino trasnacional. Solo persiguen sus intereses así deban usar la violencia y enfrentarse con sus Estados, aunque no sea su prioridad en 2014, como lo fue en la década de los 80s en Colombia y del Nuevo Milenio en México.

7. Es inconcebible pensar un Estado sin ejército. Los Estados superados tienden a poseer fuertes ejércitos a través de la figura de la cooperación militar. Ese no es el problema, 
el problema es la unidireccionalidad de tratamiento al complejo fenómeno que requiere una guerra promiscua trasnacional y millonaria.

8. Ejércitos poderosos y modernos que son funcionales al status quo narco-violento por determinación política exógena que moldea la endógena convirtiéndola en interméstica, al menos en la teoría, pues en la práctica internacional continúa siendo estadounidense. Está bien que un Ejército se vuelva más capaz con ayuda internacional pero no obedece a la necesidad de alivio del resto de los daños colaterales que genera la ESol narco-violenta.

9. Las guerras de democratización se trasforman en guerras de ocupación en la medida que no pueda resolver el conflicto. Una situación peor es la no victoria. Un ejército gigante que no puede resolver, como el norteamericano y sus armados discípulos.

10. El diagnóstico hegemónico errado y tercamente impuesto enciende los focos de las Guerras Promiscuas y retiñe la impronta de Estados Superados, lo cual resulta conveniente, a los gobiernos de los mismos y al hegemón, en cuanto al mantenimiento de las relaciones cordiales entre las partes negociantes.

11. Los narco actores en Colombia y México superan sus Estados al servir a cierta parte de la comunidad, brindándole modos de sobrevivir y protección frente a otros grupos narco-violentos, lo que se podría denominar como una especie de narco-prosperidad; también estos Estados Superados observan como los grupos ESol narco-violentos impiden el mantenimiento de la integridad territorial en Colombia y México bajo la implementación de un tipo de desorden justo, es decir, si se siguen las reglas impuestas por los actores narco no se generan riesgos y se cumplen las narcogarantías.

12. También son hallazgos de Estados Superados las numerosas condenas de actores legales que aprovecharon su posición de funcionarios políticos y de las FFAA para realizar negocios meramente con fines económicos y de construcción y mantenimiento de poder, con millonarios actores narco-violentos. Así mismo, la 
permeabilidad del sistema financiero legal por parte de las finanzas narcoviolentas es un resultado de la inserción de dichos actores como dirigentes de un desorden mundial, o incluso, trasnacional.

13. Lo paradójico es que cuando los residentes no son violentos el Estado sistemáticamente incumple con la garantía de los derechos constitucionales, pero omite aplicar su imperio coercitivo, cuando ha sido superado por amenazas y ataques provenientes de los narco-violentos, muchas veces mejor armados y menos restringidos por el temor a la penalización por incumplimiento de normatividades internacionales relativas a la guerra o al conflicto.

14. Colombia el 26 de junio de 2013 firmó el primer acuerdo como país latinoamericano de cooperación especial e intercambio de información con la OTAN, una posible puerta de ingreso militar a Suramérica de potencias internacionales como los EEUU. Si bien, Colombia no es socia de la OTAN, es la primera piedra de la edificación del área de seguridad actual de EEUU.

15. México atraviesa por un escenario narcoviolento que corre el riesgo de entrar en metástasis por el alto índice de niveles de corrupción en sus instituciones y FFAA.

16. Las armas norteamericanas se utilizan no solamente para operaciones violentas ilegales sino como moneda de cambio por la droga recibida de carteles de Colombia, México y de intermediarios centro-americanos. Así como también oficialmente nutre a los ejércitos y los moderniza para que se enfrenten con aquellos actores ilegales, que con armas no convencionales, montan pie de fuerza a cualquier tipo de estrategia o inteligencia militar.

17. En regiones del sur de Colombia no existe el peso colombiano y la moneda de cambio es la pasta de coca. Así lo ratificó el programa Los Informantes de Caracol el 13 de julio de 2014, manifestando que en las veredas aledañas del Caguán el abandono del Estado es tan inhóspito, que el remplazo de las FARC y su narco-economía, ha sustituido por completo al Estado colombiano. Situación calcada en el Triángulo 
Dorado mexicano. Inclusive comunidades indígenas se insertan en la economía de la droga, donde muchos beneficiarios indirectos acreditan narco-ganancias.

18. Lo anterior fomenta la multiplicación de ESol que evolucionan en guerras bastardas, es decir, sin padres reconocidos. Prevalecen las características de las guerras indirectas, en las cuales no hay choques clásicos ente Estados. La estrategia en el Siglo XXI es la perturbación, causada por la incertidumbre política que enfatiza en soluciones militares que provocan círculos viciosos narco-violentos.

19. Uno de los ejemplos más claros de lo que puede consolidar la figura del Estado Superado lo refleja el Líbano al ser remplazado en muchos aspectos por el Hizbollah. En Colombia y México, la superación sucede incluso en ámbitos legales que son funcionales a los narco-intereses.

20. Se incrementa la injerencia de EEUU en la vida política de Colombia y México a través de la figura de la cooperación en la lucha contra los narcotraficantes y sus aliados que incrementan la perturbación en los Estados Superados mediante el uso de Guerras Promiscuas. Los acuerdos con Ejércitos de la región, la instalación de bases militares, las operaciones de la DEA y los Tratados de Libre Comercio, pueden generar problemas en la vida interna de los países.

21. Resurgiendo asistemáticamente de la represión de Estados que contratan CMP y grupos para-estatales, como una forma de vida paralela también subterránea y que maneja sus propios códigos, actores como los Caballeros Templarios en México y los Urabeños o la Oficina de Envigado en Colombia.

22. La clasificación de los grupos narco-violentos por los Estados de Colombia y México sostienen que la mayoría son agentes no estatales y de eminente estructura de crimen organizado, pero la realidad demuestra que la mayoría de éstos poseen vínculos estatales en diferentes grados, e inclusive, que son varios los que obedecen a la mera funcionalidad de los gobiernos de Colombia y México e incluso de los EEUU. 
Concluyendo con la enumeración de las características de las ESol narco-violentas que engendran las Guerras Promiscuas en los Estados Superados que enfrentan para vivir conforme a sus propias reglas que surgen en buena medida desde el abandono y atropellos de estructuras estatales, presentándose las siguientes narco-tendencias trasnacionales:

1. Diversificación de productos narcóticos: adecúa su mercado dependiendo de la solicitud de sus clientes, principalmente norteamericanos y europeos.

2. Narco-subversión: cambios teleológicos en grupos guerrilleros tradicionales, como los grupos de la sierra de Guerrero en México, las FARC en Colombia, que se insertan a la cadena comercial de la narco-violencia.

3. Generador de Narco-empleo: sub-sistema narco-violento que impregna a la población marginal. Un vínculo laboral que no se caracteriza por la subordinación sino por la obediencia que ejerce la intimidación de estructuras narco-violentas.

4. Transnacionalización del lavado de activos: Empresas nacionales y transnacionales legales dedicadas a tales fines.

5. Subasta del sistema político: Las agencias de seguridad y las dependencias del poder ejecutivo, el poder legislativo y judicial están impregnados de corrupción y co-gobiernan con los narco-violentos, en especial, en Colombia y México.

6. Narco-cultura: un estilo de vida narcotraficante reflejado en todo aspecto: ropa, música, lenguaje, creencias, cercanía al sentimiento de la muerte como inevitable en la lucha de la fuerzas en situaciones anárquicas.

7. Narco-guerras: EE.UU las diagnostica como problema de Seguridad Nacional e interviene en los Estados nicho narco-violentos en su lucha pero provee armas a los narcotraficantes en su territorio legalmente. Un tipo de represión preventiva que agrava las condiciones de violencia y de vulneración sistemática de DDHH. Potenciando la implementación de un tipo de desorden trasnacional. 
8. Narco-legitimidad - Narco-poder: Algunos gobiernos de la región buscan legitimarse a través de encabezar los procesos represivos contra los narcotraficantes. Es el caso de Colombia, Perú y México, que ante su fragilidad estatal o débil legitimidad, lo adopta como lema de campaña y/o estrategia de mantenimiento de poder, respectivamente.

Durante el período comprendido entre el inicio de la posguerra fría hasta los atentados terroristas del $11 S$, el concepto de seguridad se tornó en el eje fundamental de la política exterior. La política exterior estadounidense no acepta grises, no conoce niveles intermedios. Su discurso conlleva emblemas como el bien y el mal y con nosotros o contra nosotros, enfrentando a los sujetos y actores internacionales desarrollados y subdesarrollados, que interactúan en el rin donde se enfrentan la dominación y la soberanía. Siendo así, la estabilidad, una consecuencia, de la influencia.

En cuanto a la preminencia de los factores exógenos al mantenimiento de las actividades de las ESol narcoviolentas trasnacionales podemos sintetizar lo siguiente:

1. El diagnóstico de seguridad internacional contemporáneo debe provenir de marcos multilaterales y multidimensional, para no eternizar las consecuencias catastróficas y para nada efectivas desplegadas por los ideólogos norteamericanos y ejecutados por sus aliados políticos colombianos y mexicanos. De preferencia, con enfoques regionales y culturales, para perseguir el objetivo del mantenimiento de la paz y seguridad internacionales de todos los Estados, no sólo de los intereses centrales. Colombia y México, deberán insertarse decididamente dentro del proceso de integración latinoamericano, en especial, para mitigar las asimetrías del sistema mundo.

2. La dependencia política internacional de la política norteamericana se convierte en una amenaza de intervención armada para cualquiera que no piense lo mismo. Todo diagnóstico en RRII posterior a 2008 debe partir de una concepción de multipolaridad. 
3. La política exterior amigo-enemigo es insostenible en el sistema mundo de 2014. El condicionamiento norteamericano a través del diagnóstico del conflicto incrementó de la violencia doméstica colombiana y mexicana, al militarizar la lucha interna, como única respuesta a la narcoviolencia, en sus diversas modalidades.

4. La dominación territorial de actores no estatales, con el visto bueno de las autoridades nacionales, y el concurso de la FFAA desborda la clasificación de Estados Fallidos y da paso a la concepción propia denominada Estados Superados por Guerras Promiscuas gestadas por actores ilegales para-estatales o no estatales como son los paramilitares u otro tipo de ESol Narcoviolentas como los Caballeros Templarios.

5. Lo anterior genera el status quo de los narco-círculos viciosos, configurando la sistematización del uso de la violencia, que usada en diferentes escalas, permitirá que los mismos grupos asciendan en el sistema político o desciendan para evitar los riesgos de penalización. Es decir, por ejemplo, cuando nuevamente las BACRIM enciendan su maquinaria de guerra, seguramente el Estado, les abrirá un espacio político, y posteriormente las reinsertará, volviendo a considerar sus remanentes como grupos de crimen organizado. Un grupo terrorista que se proclama antiterrorista y se convierte en actor político, evidencia la ambigüedad conceptual reflejada en definiciones meramente políticas, por ende coyunturales.

6. En Colombia, México y a lo largo y ancho del Sistema Mundo, se es claramente actor político mediante el uso sistemático de la violencia.

En cuanto a las actividades anti-narcóticas estatales y controversiales encontramos a EEUU con sus planes militares y sus penas excesivas a los peldaños más pequeños de la cadena narco-económica así como la desproporción de condenas por factores raciales; México, Centro América y Colombia con índices elevadísimos de narco-violencia; en Canadá, EE.UU. y Rusia, el miedo a medidas represivas desalienta a usuarios de drogas a acceder a servicios de salud necesarios; en Afganistán y Colombia, la producción de narcóticos ha fortalecido a grupos armados que se oponen o son afines al gobierno; en India, Ucrania y Senegal, pacientes con cáncer sufren dolores severos debido a las estrictas regulaciones de control de drogas que hacen que la morfina sea prácticamente 
inaccesible; y en China, Vietnam y Camboya, existen centros de rehabilitación para drogodependientes, donde las personas son sometidas a la tortura, el trabajo forzado y el abuso sexual $^{144}$. China, Singapur y Malasia contemplan la pena de muerte e Irán siempre la ejecuta en temas relacionados a drogas.

Dichas experiencias de despenalización de los narcóticos demuestran que conllevan a una reducción significativa de la violencia y no a un incremento desmedido de consumo.

Adicionalmente se han reducido los costos de las drogas según datos aportados por el JIFE y UNDOC. Pudiendo estar presentándose en el terreno trasnacional de las ESol narcoviolentas una narco-enfermedad holandesa. No obstante que los precios finales se mantengan no quiere decir que el precio de la materia prima no se modifique durante su recorrido, al ser revendida cada vez que atraviesa una narco-frontera, endógena o exógena.

Entonces, contra las amenazas globales, podríamos describir la tendencia a una guerra funcional a los intereses de EEUU en su nuevo proyecto hegemónico para el S. XXI, si observamos la dinámica del sistema internacional.

El tiempo es el detonante de los conflictos. Al igual que las arbitrariedades o unilateralismos ilegales. Una periferia con soberanía de papel que no puede retener sus riquezas en suelo propio, mediante el juego político que se plantea desde los países del Primer Mundo. En otras palabras, la periferia existe en el capitalismo en función del mismo.

Conllevando a la casi total narcotización de las agendas externas de los Estados Superados por ESol narcoviolentas trasnacionales que ejecutan en sus territorios Guerras Promiscuas.

Así, la incidencia y participación de Estados Unidos en el proceso de toma de decisiones antinarcóticas de los Estados Superados ha sido determinante para transferir a los Estados Superados por Guerras Promiscuas, la lógica estéril pero altisonante de la lucha antinarcóticos.

144 INFORME MUNDIAL HUMAN RIGHT WATCH 2014. http://www.hrw.org/sites/default/files/reports/wr2014sp_web.pdf. Cómo la criminalización de las drogas destruye vidas, fomenta abusos y subvierte la justicia Por María McFarland Sánchez-Moreno. Consultado el 16-2-2014. 
Convirtiéndose el Estado en uno de tipo superado por las ESol narcoviolentas que ejecutan las Guerras Promiscuas en sectores parciales del territorio de Colombia y México, y de muchos otros Estados trasplantados.

En cuanto a la opción de la legalización de los narcóticos como estrategia para terminar con la violencia que genera ese tipo de economía dentro de los Estados Superados y que amenaza con invadir a los Estados Superadores, podemos manifestar que:

1. Recientemente Portugal y Uruguay realizaron procedimientos de despenalización con resultados muy positivos en cuanto el consumo.

2. En días pasados se solicitó a la sociedad internacional cesar las aspersiones con glifosato en Colombia así como que se respeten los tratados ratificados que se violan mediante las fumigaciones: Por ejemplo, la Convención sobre Diversidad Biológica, el Protocolo de Bioseguridad de Cartagena, la Declaración de Estocolmo de 1972 y Declaración de Río de 1992 sobre el Medio Ambiente Humano y Desarrollo Sostenible.

3. EEUU solo se preocupa en 2014 para que el glifosato que se use sea norteamericano y no el genérico producido en China. Y aunque EEUU sostiene que el glifosato es inocuo, los científicos indican que "el uso agrícola del glifosato puede generar daños crónicos a la salud y defectos genéticos cuando se administra en altas dosis y por periodos prolongados. En Colombia, donde el mismo campo puede ser fumigado hasta cuatro veces, y tras el vertimiento de millones de litros de glifosato, el riesgo de que esto suceda es extremadamente alto" ${ }^{145}$. Adicionalmente surte armas a las diferentes partes en conflicto.

4. La aspersión aérea es una de las primeras causas del crimen del desplazamiento interno forzado de los territorios que los sufren y genera un daño trasnacional ambiental. Ni los cocaleros andinos, ni los amapoleros afganos, ni los junkies de Londres o Nueva York tienen la culpa, solo necesidades que son narco-saciadas. Si procede la legalización se parará la contaminación ambiental que podrá considerarse como un genocidio si se hace 
un estudio juicioso de las consecuencias. Sin embargo, y sin importar los impactos sociales y ambientales descritos, EEUU ha certificado a Colombia y México como Estados que cumplen las garantías para consolidar el respeto de los DDHH.

5. De nada sirve envenenar el medio ambiente como pretexto de erradicar cultivos ilícitos para desfinanciar la guerra pues inmediatamente se produce la resiembra para satisfacer las necesidades o demandas de los consumidores norteamericanos principalmente. Como lo demuestra el desplazamiento de los cultivos ilícitos en 2014 a Perú por las presiones en tierras colombianos y por ende la posibilidad de la tragedia ambiental en expansión. Que Perú lidere la producción no es sinónimo de disminución significativa de producción colombiana, la cual se mantiene estable a lo largo de las narco-décadas. Es urgente un cambio de políticas antinarcóticas.

6. Lo que hace contradictoria la estrategia de combate norteamericana por años en territorio colombiano donde no cesa el conflicto ni sus daños colaterales por la lucha antinarcótica, pero que en la actualidad, el Estado Superado por terroristas es presentado en la página web, sitito oficial, del Departamento de Estado de los EEUU, es enmarcado como un Estado capacitador en cuanto a la resolución de situaciones terroristas y narcóticas se refiere.

Los movimientos ilícitos escapan a las reglas impuestas por los sistemas. Esto es lo que acentúa considerablemente la ventaja económica, cuando se logran evadir las gravosas y variadas barreras impositivas y arancelarias que ordenan la lógica de la estructura centro-periferia. Estados Superados que con garantías para aquellos quienes quebrantan la Ley y la moldean a través de sus Guerras Promiscuas.

En los Estados Superados las ESol narcoviolentas han aprovechado la plataforma que propicia el conflicto, que cuenta con una propia estructura económica y un nivel de población poca ilustrada.

Los conocedores de la narcoviolencia mexicana coinciden con los colombianos en cuanto a la mutación y adaptabilidad repentina a las que se someten sin más miramientos los grupos del crimen organizado para sobrevivir a las estrategias oficiales que adelantan las fuerzas armadas 
minadas por agentes corruptibles y que se encuentran igualmente dentro de la nómina de alguno de los famosos carteles, ocasionando el efecto narco-global de desplazamiento de plantaciones, transnacionalización de matrices narcoviolentas, mutación en las narco-estructuras administrativas y operativas e inmersión en la economía legal mundial así como las alianzas con los sectores políticos y organizaciones subversivas y contrasubversivas.

Las lecciones que deja Colombia para México no han sido asimiladas e insiste el gobierno en la militarización contra el narco. No en vano Peña Nieto vinculó a su estrategia al Gr. Naranjo y expone el caso colombiano como el ejemplo a seguir en la lucha contra el narcotráfico, ocultando los aberrantes escenarios de violación de DDHH y DIH.

La corrupción no solamente se encuentra presente e inserta en Estados débiles ni mucho menos como elemento exclusivo y factor decisivo de fenómenos globales como el narcotráfico, sino por el contrario se halla en casi todas las cuestiones que se encuentran inmersas en el juego de poderes.

Pese a la multimillonaria inyección monetaria y en especie aplicada a los Estados Superados, las ESol narcoviolentos, han generado un desorden internacional mediante la captura de Estados Superados que han sido reconfigurados y cooptados por los grupos narcoviolentos y su narcoeconomía, avalada por los Estados Superadores como prevalentes políticos y sus aliados socioeconómicos, amorales y a-éticos. Una verdadera Narco-Soberanía económica donde priman los intereses particulares sobre la vida misma.

Desarticular uno u otro cartel no ha conllevado a la disminución de las actividades de las ESol narcoviolentas que se re acomodan a las nuevas necesidades impuestas por sus Estados Superados y por sus aliados Superadores. Y que en la clandestinidad son sus narco-socios como lo ejemplificamos a lo largo de esta investigación. El matar a un gran capo no se termina la narcoviolencia sino por el contrario se incrementa tras la lucha de los demás capos o narco-líderes para apoderarse de los territorios en luto.

Estos grupos decididos a morir por su libre elección, consideran si es mejor morir pobre o rico. ¿Qué será mejor?. Indiscutiblemente de las comodidades, la muerte parece ser el destino que 
determina a sujetos y actores internacionales a amainarse en la plataforma que representan las ESol narcoviolentas. 


\section{REFERENCIAS}

ADAMS, David. Capítulo: Vínculos entre paramilitares y drogas: antes y después de la desmovilización. Bagley, Bruce; Restrepo, Elvira. (2011). La desmovilización de los paramilitares en Colombia. Entre el escepticismo y la esperanza. Universidad de Miami - Universidad de los Andes Colombia

AGUILAR, Rubén; CASTAÑEDA. Jorge. (2012). Los saldos del narco: el fracaso de una guerra. Punto de Lectura. México, pp. 33Tostado Félix. En Hernández, Anabel. (2012).Los señores del narco. Random House Mondadori, México.

AGUILAR, Rubén; CASTAÑEDA, Jorge. (2009). El narco: la guerra fallida, Santillana, México. En BENITEZ MANAUT, Raúl; RODRIGUEZ LUNA, Armando. (2010). México: el combate al narcotráfico, la violencia y las debilidades de la seguridad nacional. Ibídem, Anuario 2010. MATHIEU, Hans y; NIÑO GUARNIZO, Catalina. (Editores).

ALBAR, Germán; CANCADO TRINDADE, Antonio. (1998). Reflexiones sobre el futuro del sistema interamericano de derechos humanos, en El futuro del sistema interamericano de protección de los derechos humanos. Cox Editores. Costa Rica.

ÁLVAREZ ZÁRATE, José Manuel. (1999). Cambio de Jurisprudencia de la Corte Constitucional en materia internacional. La sentencia C-400 de 1998. En Homo luris. Ensayos de Derecho Contemporáneo. Universidad Externado de Colombia. Bogotá, Colombia.

ÁNGEL, M. (2012). Manual Básico de Doctrina y Protección Cruz Roja Colombiana. Dirección General de Doctrina y Protección. Colombia.

AMIN, Samir (1997). Los desafíos de la mundialización. México: Siglo XXI: 95-107 y 109-240.

ARANGO, Carlos; y, otros. (2004). Economía Subterránea en Colombia 1976 - 2003: Una medición a partir de la demanda de efectivo. Banco de la República, Bogotá - Colombia. Pg. 2.

ARCHILA NEIRA, Mauricio (2005). "Desafíos y perspectivas de los movimientos sociales en Colombia". En CARDENAS RIVERA, Miguel Eduardo (coordinador). La reforma política del Estado en Colombia: una salida integral a la crisis. Bogotá, Friederich Ebert Stiftung en Colombia FESCOL- Fondo Editorial CEREC. Primer edición.

ARCIA, Carla; CASAS, Andrés. Capítulo: Atando víctimas: reflexiones sobre la ley de justicia y paz, pp. 267. BAGLEY, Bruce; Restrepo, Elvira. (2011). La desmovilización de los paramilitares en Colombia. Entre el escepticismo y la esperanza. Universidad de Miami - Universidad de los Andes Colombia.

ARENAL, Celestino Del. (2010). Introducción a las Relaciones Internacionales. Ed. Tecnos. Cuarta Edición - Reimpresión. Septiembre. Madrid, España. 
ARIAS, Gerson; Guáqueta, Alexandra. Capítulo: Impactos de los programas de desmovilización y reinserción, pp. 508. Bagley, Bruce; Restrepo, Elvira. (2011). La desmovilización de los paramilitares en Colombia. Entre el escepticismo y la esperanza. Universidad de Miami Universidad de los Andes Colombia.

ARIAS HENAO, Diana Patricia. (2014). Investigación Comparativa Transcontextual en Relaciones Internacionales narcoviolentas. Revista De Relaciones Internacionales, Estrategia y Seguridad de la Universidad Militar Nueva Granda. Bogotá. 2014. Vol. 9.2.

ARIAS HENAO, Diana Patricia. (2013). Observatorio en estudios de Seguridad y Defensa Nacionales del Centro de Estudios Estratégicos en Seguridad y Defensa Nacionales. Escuela Superior de Guerra de Colombia. Publicada el 13.8.2013.

ARIAS HENAO, Diana Patricia. (2013). Marco Jurídico Para la Paz. Bogotá, Colombia. CEESEDEN.

ARIAS HENAO, Diana Patricia. (2008). Sistema Político Colombiano: el desarrollo de la violencia y la incidencia del condicionante externo. Universidad Nacional de La Plata, Argentina. Instituto de Relaciones Internacionales IRI. Tesis de maestría en RRII.

ARIAS HENAO, Diana Patricia; CIEZA, Daniel. (2010). Conferencia en el II Congreso Internacional de Derecho Constitucional de la Universidad Libre de Colombia-13-15 de Octubre. Violencia y Políticas de Derechos Humanos: Reflexiones a partir del caso argentino. Bogotá, Colombia.

ARNSON, Cynthia. (2001). "La degradación de un plan". Foreign Affairs, mayo.

ARQUILLA, John y RONFELDT; David (2001), Swarming and the future of conflict, Santa Mónica, Rand Corporation.

ARCHILA, Mauricio. (2008)“Vida, pasión y... de los movimientos sociales en Colombia”. Bogotá, Colombia.

ARRIETA, Carlos Gustavo (1995). "La Política Criminal: sus planteamientos, normas, prácticas y críticas. Perspectiva socio-jurídica". En TOKATLIAN, Juan Gabriel, y otros. Narcotráfico en Colombia. Dimensiones políticas, económicas, jurídicas e internacionales. Bogotá, TM Editores. Universidad de los Andes, ediciones Uniandes.

ARNSON, C; ZARTMAN, W. (2006) Economías de guerra: la intersecciónde necesidad, credo y codicia. En Mesa y González. M. Poder y democracia. Los retos del multilateralismo: Anuario CIP 2006. Icaria, Centro de Investigación para la Paz, Barcelona.

ASTORGA, Luis. (2005). El Siglo de las Drogas: el narcotráfico, del porfiritaro al nuevo milenio, Plaza y Janés, Ciudad de México.

ÁVILA MARTínEZ, Ariel Fernando. Injerencia política de los grupos armados ilegales. López, Hernández, Claudia. (2010). Y refundaron la patria... de cómo mafiosos y políticos reconfiguraron el Estado colombiano. Debate, Rando House Mondadori, Bogotá. 
AYALA DIAGO, César Augusto (2003). "Un Decreto de Estado de Sitio dejo a los congresistas en la calle". El cierre del congreso de 1949. Bogotá; Revista Credencial Historia, edición 162.

AZZELINI. (2005). En La privatización de las Guerra\$ Paramilitares, "señores de la guerra" y ejércitos privados. Versión para el Cono Sur de América Latina De Das Unternehmen Krieg, Assoziation A, Berlin 2003 Edición boliviana, Febrero.

BAGLEY, Bruce. "Colombia y la guerra contra las drogas”. Foreign Affairs en Español, Enero-Marzo 2008.

BASE DE DATOS.(2010). Secretaría de Seguridad Pública de México.

BENITEZ MANAUT, Raúl, y otros. (2010). La Seguridad de América Latina en la Encrucijada: entre la geopolítica, la ideología y las amenazas emergentes. En Seguridad Regional en América Latina y el Caribe Anuario 2010. MATHIEU, Hans y; NIÑO GUARNIZO, Catalina. (Editores). Programa de Cooperación en Seguridad Regional. Friedrich Ebert Stiftung.

BENITEZ MANAUT, Raúl; RODRIGUEZ LUNA, Armando. (2010). México: el combate al narcotráfico, la violencia y las debilidades de la seguridad nacional. Ibídem, Anuario 2010. MATHIEU, Hans y; NIÑO GUARNIZO, Catalina. (Editores).

BECK, Urilch. 1998. La sociedad del riesgo. Ed, Paidós, Barcelona, 1998.

BECK, Urilch. Estructuras legales y unas formas de democracia y legitimación insuficientes. BECK, Urilch. Poder y contrapoder en la era global.

BOBBIO, Norberto (1985). El futuro de la democracia. Madrid. Plaza y Janés.

BORDA GUZMAN, Sandra (2007). “La internacionalización del conflicto armado después del 11 de septiembre: ¿La ejecución de una estrategia diplomática hábil o la simple ocurrencia de lo inevitable?". Bogotá, Colombia Internacional, No. 65. enero-junio. Universidad de los Andes.

BORGES, Tomas. (2008). “Maquiavelo para narcos”. Planeta, México.

BROOKS, Rosa Ehrenreich (2005), "Failed States, or the State as Failure?", The University of Chicago Law Review, 4(27), Autumn.

BOUTHOUL, Gastón. Tratado de Polemología. Ediciones Ejército. Madrid, 1984 .En TELLO, Ángel Pablo. (2010). La teoría de las Relaciones Internacionales desde un punto de vista político-polemológico.

BUZAN, BARRY; WAEVER, Ole. (2003). Regions and Powers. The Structure of International Secuirity. Ed, Cambridge University Press, Reino Unido.

CABRERA, Carlos; FUNG, Thalía (2002). “Ciencia política: nuevas dimensiones y perspectivas". La Habana, edición Editorial Félix Varela.

CHAILAND, Gerard (2005). Terrorismo et guérrillas. En CUBIDES, Fernando. Burocracias Armadas. El Problema de la Organización en el Entramado de las Violencias Colombianas. Bogotá; Grupo editorial Norma.

CALVO, Hernando (2004). "Los Negocios de las SMP, Colombia, como el de Irak, un conflicto privatizado". Le Monde Diplomatique. Noviembre. 
CALVO OSPINA, Hernando. (2005). Colombia Como en Irak. Guerra privada en Colombia. Le Monde Diplomatique.

CÁMARA DE DIPUTADOS DE MÉXICO. 7.9.2010.

CAMPA, Homero; TÉLLEZ, Édgar. Las redes se extienden. Rodríguez Castañeda, Rafael. (2012). El Imperio del Chapo. Ed, Planeta Mexicana. México.

CANTORI, Louis; SPIEGEL, Steven. (1970). The International Politics of Regions: A comparative Approach, Englewwood Cliffs, N.J.

CARDENAS RIVERA, Miguel Eduardo (coordinador) (2005). La reforma política del Estado en Colombia: una salida integral a la crisis. Bogotá, Friederich Ebert Stiftung en Colombia - FESCOL- Fondo Editorial CEREC. Primer edición.

CARDENAS RIVERA, Miguel Eduardo; RODRÍGUEZ WILCHES, Andrés. Estudio introductorio (2005). "Reinterpretando la noción de Estado o crítica de la retórica liberal". En CARDENAS RIVERA, Miguel Eduardo (coordinador). La reforma política del Estado en Colombia: una salida integral a la crisis. Bogotá, Friederich Ebert Stiftung en Colombia - FESCOL- Fondo Editorial CEREC. Primer edición.

CARRASCO, Jorge. Al amparo del panismo. Rodríguez Castañeda, Rafael. (2012). El Imperio del Chapo. Ed, Planeta Mexicana. México.

CARRASCO, Jorge; Esquivel, Jesús. En Guatemala, bajo protección. Rodríguez Castañeda, Rafael. (2012). El Imperio del Chapo. Ed, Planeta Mexicana. México.

CARRILLO, J. A. (2001). Soberanía de los estados y Derechos Humanos en el Derecho Internacional Contemporáneo. 2a ed. Madrid, España: Tecnos.

CARVAJAL, Leonardo (2004). Violencia, Paz y Política Exterior en Colombia. Bogotá. Universidad Externado de Colombia.

CASTAÑO, Carlos. Mi Confesión (2005). En CUBIDES, Fernando. Burocracias Armadas. El Problema de la Organización en el Entramado de las Violencias Colombianas. Bogotá; Grupo editorial Norma.

CASTRO, Jaime (2004). Juicio a la Reelección, Bogotá, Planeta.

CASTRO, Gustavo. (1998). Centro de Derechos Humanos Fray Bartolomé de Las Casas: Ni Paz Ni Justicia, 1996, P. 94; Castro Gustavo: Boletín Chiapas al Día 140, CIEPAC, Dic. 1998. 15 Proceso No. 1105.

CERVANTES, Jesusa. Argentina, nuevo dominio. Rodríguez Castañeda, Rafael. (2012). El Imperio del Chapo. Ed, Planeta Mexicana. México.

CHOMSKY, Noam (2008), Estados fallidos, México, ediciones B.

CHUA, Ami L (2003). World on fire:how exporting free market democracy breeds ethnic hatred and global instability, Doubleday.

CICR. Derecho Internacional Humanitario. Preguntas y respuestas. Ginebra: CICR. 
CIEZA, Daniel; BEYREUTHE, Verónica. Economía subterránea, control social y violencia. Socialización y Violencia. En Asociación Latinoamericana de Sociología (ALAS) XXVII Congreso, Buenos Aires, Argentina, 31 Agosto-4 septiembre. Grupo de Trabajo 28.

CIEZA, Daniel. (2014). La caída del Chapo Guzmán. Antecedentes e interrogantes. Nota compartida por el autor.

CINEP, MINGA, Codhes, (2006). GONZALEZ, Fernán y otros. Violencia Política en Colombia. De la Nación fragmentada a la construcción del Estado. Bogotá, Centro de Investigación y Educación Popular - CINEP.

CLAUSEWITZ, Carl Von. (1995). De la Guerre. Les editios de minuit, Paris.

CODHES (2005). "Plan Colombia: fracaso anunciado". Bogotá, Consultoría para los Derechos Humanos y el Desplazamiento.

COMISIÓN NACIONAL DE LOS DDHH. (CNDH) de México. Página oficial el 20.2.2014.

CONAGUA. Núm. De concesión 03SIN116508/10ABGR02. HERNÁNDEZ, Anabel. (2012).Los señores del narco. Random House Mondadori, México.

CONFERENCIA SEMINARIO: "Los Resultados de la Cumbre de Brasilia y la Construcción de la Unión Sudamericana", titulada "La Construcción de la Unión Sudamericana" el 5 de octubre en el Centro Cultural Borges, Buenos Aires, Organizado por el Foro del Sur de las Americas (FOCOSUR). Archivos del Presente.

CONSANI, Norberto (2006). Material de estudio de la maestría en Relaciones Internacionales en el Instituto de Relaciones Internacionales (IRI), correspondiente a la clase de Derecho Internacional Contemporáneo. Facultad de Ciencias Sociales y Jurídicas. Universidad Nacional de la Plata- Argentina.

CSIS Report. Back from the Brink. Evaluating Progress in Colombia, 1999-2007. A report of the Americas Program Center for Strategic AND International studies. November 2007, Washington.

CONDORELLI, Luigi. (2001). Les attentats du 11 septembre et leurs suites: où va le Droit international?. RGDIP 105, 4.

CONSANI, Norberto; SURASKY, Javier. ¿la lucha contra la pobreza en las Cumbres de las Américas ¿hechos o palabras?. Argentina.

CONSTITUCIÓN POLÍTICA DE COLOMBIA. (1991). Constitución Política de Colombia. Bogotá, Colombia: Editorial Legis. Art.93

CONVENCIÓN DE VIENA. (1969).

CONVENIO DE GINEBRA. (1864).

CONVENIO DE GINEBRA. (1906).

CONVENIO DE GINEBRA. (1929).

CONVENIO DE GINEBRA. (1949).

CONSEJO DE ESTADO DE LA REPÚBLICA DE COLOMBIA. (2009). Sala de lo Contencioso Administrativo. Sección 3ra. Sentencia 1.28.2009. 30340 (R-20030015801). 
CORTE INTERAMERICANA DE DERECHOS HUMANIOS. (1997). Caso Suárez Rosero Vs. Ecuador, Sentencia de 12.11.1997, Serie C No. 35, párrafo. 98.

CORTE INTERAMERICANA DE DERECHOS HUMANOS. (1999). Caso Castillo Petruzzi y otros Vs. Perú. Sentencia de 30.5.1999, Serie C No. 52.

CORTE INTERAMERICANA DE DERECHOS HUMANOS. (2013). Voto razonado del Juez Sergio García. Caso Myrna Mack Chang Vs. Guatemala, Sentencia de 25.11.2003, Serie C No. 101.

CORTE INTERAMERICANA DE DERECHOS HUMANOS. (2007). Caso de la masacre La Rochela contra Colombia. Sentencia 11.5.2007. Serie C No. 163, párrafo. 197.

CORTE INTERAMERICANA DE DERECHOS HUMANOS. Corte IDH, Caso Tibi. voto concurrente razonado del Juez Sergio García Ramírez, pár. 3.

Cort.IDH, (2004). Caso de la "Masacre de Mapiripán". Excepciones Preliminares y Reconocimiento de Responsabilidad. Sentencia de 7 de marzo de 2004. Serie C No. 122. Un paso hacia el cumplimiento de sus obligaciones internacionales.

CUBIDES, Fernando (2005). Burocracias Armadas. El Problema de la Organización en el Entramado de las Violencias Colombianas. Bogotá, Grupo editorial Norma.

DALLANEGRA PEDRAZA, Luís. (2003) “El Sistema Político Latinoamericano”, Reflexión Política, 10. IEP-UNAB Colombia.

DAVID, Stuart. (2004). Dangerous Garden: The Quest for Plants to Change Our Lives. Frances Lincon Limited, Londres.

DÁVILA, Patricia. Entre Duelos y Guerras. Rodríguez Castañeda, Rafael. (2012). El Imperio del Chapo. Ed, Planeta Mexicana. México.

DELGADO RAMOS, Gian Carlos; ROMANO, Silvina. (2011). Plan Colombia e Iniciativa Mérida: negocio y seguridad interna. El Cotidiano, núm. 170. Universidad Autónoma Metropolitana Azcapotzalco. México.

DREKONJA, Gerard (1983). Retos De la política exterior colombiana. Bogotá, Cerec/CEI.

DE LA CORTE IBAÑEZ, Luis; GIMÉNEZ-SALINAFRAMIS, Andrea. (2010). Crimen.org. Evolución y claves de la delincuencia organizada. Ariel, Barcelona - España.

DE LA MAISONNEUVE, Eric (1998). La Metamorfosis de la violencia. Ensayo sobre la guerra moderna. Los conflictos contemporáneos- Capítulo VII, Buenos Aires: Gel.

DOLLARD, John; y otros. (1930). Frustation and Agression. Yale University Press. New Haven.

DUHALDE, Eduardo. (1999). El Estado Terrorista argentino. Eudeba, Buenos Aires, Argentina.

DUNCAN, Gustavo (2005). “Narcotraficantes, mafiosos y guerreros. Historia de una subordinación”. En RANGEL, Alfredo. (2005). Narcotráfico en Colombia. Economía y Violencia. Ensayos de Seguridad y Democracia. Bogotá, Fundación Seguridad y Democracia. 
ECHANDIA, Camilo (2004). "Dimensiones territoriales del conflicto armado colombiano". En CARVAJAL, Leonardo; LONDOÑO, Patti. (compiladores). Violencia, Paz y Política Exterior en Colombia. Bogotá, Universidad Externado de Colombia, Facultad de Finanzas, Gobierno y Relaciones Internacionales.

ECHANDÍA CASTILLA, Camilo, y, otros. (2010). Colombia: Estado del Conflicto Armado al final de la administración de Álvaro Uribe. Anuario 2010. MATHIEU, Hans y; NIÑO GUARNIZO, Catalina. (Editores).

EFECTO NAÍM. Embajador de México en EEUU. Trasmisión del 11.12.12

EGío, Víctor. (2005). cerca del Imperio cosmopolita de Ulrich Beck: una discusión sobre las tareas contemporáneas de la historia imperial comparada Universidad de Murcia. Becario FPI-Fundación Séneca.

EISTEIN, Albert. Citado por Jacques Cosner en Psychologie des émotions et des sentiments. Retz. Paris.

EISTEIN. En Richmond, Oliver P. (2012). La paz en las Relaciones Internacionales". Ed, Bellaterra. Barcelona, España.

EI ESTADO DEL MUNDO (2012). Anuario económico geopolítico mundial 2012. El Estado de las Relaciones Internacionales. El Estado de la economía mundial. El balance del año de 214 países del mundo.

El Espectador, 28 de octubre de 2011. Consultado el 17.7.2012.

El Tiempo, 17 de agosto de 1989, p. 11C.

El Tiempo, 19 de agosto de 1989, p. última A.

El Tiempo 30/10/2002. Consultado el 23.10.2012.

El Tiempo 30/10/2002. Consultado el 5.9.2013.

El Tiempo. "Los apellidos de Uribe" (2004). PARDO, Rodrigo; Carvajal, Leonardo. "Relaciones Internacionales, conflicto Domestico y Procesos de Paz en Colombia". En CARVAJAL, Leonardo; LONDONO, Patti. (compiladores) "Violencia, Paz y Política Exterior en Colombia". Bogotá, Universidad Externado de Colombia - Facultad de Finanzas, Gobierno y Relaciones Internacionales.

ENFERMAN, Stanly y SOKOLOFF, Kenneth (2005). Factor Endowments, Institutions and Differential Gorwth Rates among New World Economies. Stephen (ed.). How Latin America Fell venid. Stanford University Press..

Entrevista con Rodrigo Pardo. Programa trasmitido el 8.8.2013.

ESCUDÉ, Carlos; SOUTO, Mariana. Hipótesis de conflicto. El cono sur frente al eje Chávez-FARC. Mayo de 2001 Universidad Torcuato Di Tella.

ESTRADA VILLA, Armando (2005). El impacto institucional de la reelección. En CARDENAS RIVERA, Miguel Eduardo (coordinador). La reforma política del Estado en Colombia: una salida integral a la crisis. Bogotá, Friederich Ebert Stiftung en Colombia - FESCOL- Fondo Editorial CEREC. Primer edición.

ESTY, D. C., Goldstone, J. A., Gurr, T. R., Surko, P. T., y Unger, A. N. (1995), State Failure Task Force Report, Central Intelligence Agency.

EVANSE-PITCHARD, Ambrose. (1997). Evans-Pitchard, The Secrte Life of Bill Clinton, Washington, Regnery Publishing. 
FERNÁNDEZ STEINKO, Armando. (2008). Las falsas pistas del crimen organizado. Finanzas paralelas y orden internacional. Catarata, Madrid, España.

FERRO, Juan Guillermo; URIBE, Graciela (2006). El orden de la guerra. Las FARC-EP: entre la organización y la política. En GONZALEZ, Fernán y otros. Violencia Política en Colombia. De la Nación fragmentada a la construcción del Estado. Bogotá, Centro de Investigación y Educación Popular - CINEP.

FONSECA, Roberto. La ruta nicaragüense. Rodríguez Castañeda, Rafael. (2012). El Imperio del Chapo. Ed, Planeta Mexicana. México.

FOREING AFFAIRS. The End of the Bush Revolution". July/August 2006.

FOUCAULT, M. (1991). Truth and Power, pp. 63. En Richmond, Oliver P. (2012). La paz en las Relaciones Internacionales". Ed, Bellaterra. Barcelona, España.

GALINDO HERNANDEZ, Carolina (2007). "Neopopulismo en Colombia: el caso del gobierno de Álvaro Uribe Vélez". Bogotá, Revista de Ciencias Sociales, No. 27. Universidad del Rosario.

GALLON GIRALDO, G. Política de Defensa y Seguridad Democrática (borrador), Capítulo VII sobre el Plan de Seguridad Democrática, Punto 5 sobre la Promoción de la cooperación ciudadana, Bogotá, mimeo.

GALLÓN GIRALDO, Gustavo (2005). "Los riesgos de una desenfocada política antiterrorista en Colombia. Directos de la Comisión Colombiana de Juristas". En CARDENAS RIVERA, Miguel Eduardo (coordinador). La reforma política del Estado en Colombia: una salida integral a la crisis. Bogotá, Friederich Ebert Stiftung en Colombia - FESCOL- Fondo Editorial CEREC. Primer edición.

GALTUN, Johan (2003). Paz por medios pacíficos. Paz y conflicto, desarrollo y civilización, Bilbao, Bakeaz/Gernica Gogoratuz, pp. 62 y 96-. En Heyck Puyana, Caterina. (2011). Derecho internacional; acuerdo humanitario y resolución pacífica del secuestro. Universidad del Rosario. Bogotá - Colombia.

GARAY SALAMACA, Luis Jorge; SALCEDO ALBARÁN, Eduardo. (2012). Narcotráfico, corrupción y Estados. Cómo las redes ilícitas han reconfigurado las instituciones en Colombia, Guatemala y México. Debate, Colombia.

GARCIA, Eloy (2000). Cuadernos civitas, Madrid, España.

GARCíA, José Francisco, VERDUGO, Sergio. Libertad y Desarrollo, Radiografía Política al Sistema Interamericano de DD.HH.".

GARCÍA, Mauricio; ESPINOSA, José. Crimen, conflicto armado y Estado en Colombia, México y Guatemala. De Justicia. No. 7. Documentos de Discusión.

GARCÍA MÁRQUEZ, Gabriel (1996). El otoño del patriarca, Bogotá, Grupo Editorial Norma.

GARCÍA PICASO, Paloma. (2000). ¿Qué es esa cosa llamada relaciones internacionales? Ed. Marcial Pons. Madrid, España.

GARCÍA PICASO, Paloma (2010). Teoría Breve de las Relaciones Internacionales. Ed. Tecnos Tercera Edición Reimpresión. Septiembre. Madrid, España. 
GARCÍA RAMÍREZ, Sergio. (2011). Revista IUS ISSN 1870-2147 vol.5 no.28 Puebla 12.2011 control judicial interno de convencionalidad Sergio García UNAM, México.

GARCIA VILLEGAS, Mauricio (2005). “Democracia y Estado Social de Derecho”. En CARDENAS RIVERA, Miguel Eduardo (coordinador). La reforma política del Estado en Colombia: una salida integral a la crisis. Bogotá, Friederich Ebert Stiftung en Colombia - FESCOL- Fondo Editorial CEREC. Primer edición.

GIDDENS. (2003). La constitución de la sociedad; COHEN (1996). En RIVAS, José Antonio. "El neoinstitucionalismo y la revalorización de las instituciones". Colombia, Reflexión Política IEP - UNAB; No.9.

GIRALDO, Fernando; LÓPEZ, José Daniel (2006). “El Comportamiento electoral y de partidos en los comicios para Cámara de Representantes de 2002 y 2006": Un estudio comparado desde la Reforma Política. Bogotá, Colombia Internacional, Universidad de los Andes; 64.

GEERTZ, Cliford. (1994) Conocimiento Local, capítulo 6: “Centros, reyes y carisma: una reflexión sobre el simbolismo del poder. Paidós, Buenos Aires, Argentina.

GOLDMAN, Robert (2005). Protección de los Derechos Humanos y las libertades fundamentales en la lucha contra el terrorismo. Comisión Interamericana de Derechos Humanos. Organización de los Estados Americanos. No. E/CN.4/2005/103. GALLÓN GIRALDO, Gustavo. "Los riesgos de una desenfocada política antiterrorista en Colombia. Directos de la Comisión Colombiana de Juristas". En CARDENAS RIVERA, Miguel Eduardo (coordinador). La reforma política del Estado en Colombia: una salida integral a la crisis. Bogotá, Friederich Ebert Stiftung en Colombia - FESCOL- Fondo Editorial CEREC. Primer edición.

GÓMEZ, Augusto (2005). "Los pájaros, los sicarios y los paramilitares: los grupos de justicia privada o la privatización de la violencia oficial". Universitas Humanística, Revista de la Universidad Javeriana. En CUBIDES, Fernando. Burocracias Armadas. El Problema de la Organización en el Entramado de las Violencias Colombianas. Bogotá; Grupo editorial Norma.

GOMEZ, Juan Carlos, y otros (2006). "La personalización en la política, una práctica a prueba de reformas". Bogotá, Palabra Clave, Universidad de la Sabana; 2.

GONZÁLEZ CUERVO, Mauricio. Capítulo: Control constitucional y justicia transicional en Colombia. Bagley, Bruce; Restrepo, Elvira. (2011). La desmovilización de los paramilitares en Colombia. Entre el escepticismo y la esperanza. Universidad de Miami - Universidad de los Andes Colombia.

GONZÁLEZ, Fernán (2006). “Clientelismo y administración pública”. En GONZÁLEZ, Fernán y otros. Violencia Política en Colombia. De la Nación fragmentada a la construcción del Estado. Bogotá, Centro de Investigación y Educación Popular - CINEP.

GONZÁLEZ, Fernán y otros (2006). Violencia Política en Colombia. De la Nación fragmentada a la construcción del Estado. Bogotá, Centro de Investigación y Educación Popular - CINEP.

Gutiérrez Sanín, Francisco. López, Hernández, Claudia. (2010). Y refundaron la patria... de cómo mafiosos y políticos reconfiguraron el Estado colombiano. Debate, Rando House Mondadori, Bogota, pp.21.

GORDON, Philip. "The End of the Bush Revolution". Foreign Affairs, July/August 2006.

GOTT, Richard (2006)). Las guerrillas en América Latina. Santiago de Chile, Editorial Universitaria. 
GRILLO, Ioan. (2012). El Narco: en el corazón de la insurgencia criminal mexicana. Editorial Urano, S.A., Barcelona - España.

GRUNEWALD, F. (1995). Antes, durante y después de la urgencia. La experiencia del CICR en perspectiva. RCICR, (129).

Grupo Académico Binacional (1999). “Colombia- Venezuela. Análisis de la agenda el siglo XXI”. En Análisis Político, Edición Especial.

GUAQUETA, Alexandra (2007). “Change and Comunity in US and Colombian relations and the war against drugs". Journal of drugs issuses. En BORDA GUZMAN, Sandra. "La internacionalización del conflicto armado después del 11 de septiembre: ¿La ejecución de una estrategia diplomática hábil o la simple ocurrencia de lo inevitable?".Bogotá, Colombia Internacional, Universidad de los Andes; 65

GUTIERREZ SANíN, Francisco (2004). “Ilegalidad y Sistema Político en Colombia: la agenda de URIBE VÉLEZ”, Nueva Sociedad; 192.

GUTIERREZ SANÍN, Francisco. López; HERNÁNDEZ, Claudia. (2010). Y refundaron la patria... de cómo mafiosos y políticos reconfiguraron el Estado colombiano. Debate, Rando House Mondadori, Bogotá.

GUTIERREZ, F; JARAMILlO, A. Pactos paradoxis, en de Souza Santos, B (ed), Reconhecer para Libertar: Os caminos do cosmopolitismo multicultural, Civilizacao Brasilera, Rio de Janeiro, 2003.

HALLIDAY, Fred. (2000). Las relaciones Internacionales en un mundo en transformación. Editorial Catarata. Traducción de Mónica Salomón.

HARDINGHAUS, Nicolás. (1989). Droga y crecimiento económico: el narcotráfico de las cuentas nacionales. Nueva Sociedad No. 102. Pg. 94.

HERNÁNDEZ, Anabel. (2012).Los señores del narco. Random House Mondadori, Mexico.

HEYCK PUYANA, Caterina. (2011). Derecho internacional; acuerdo humanitario y resolución pacífica del secuestro. Universidad del Rosario. Bogotá - Colombia.

HITTERS, Juan. (2007). Responsabilidad del Estado por violación de Tratados Internacionales, La Ley 2007-C.

HITTERS, Juan. (2008). ¿Son vinculantes los pronunciamientos de la Comisión y de la Corte Interamericana de Derechos Humanos?. La Ley 2008-E.

HITTERS, Juan. (2009). Control de Constitucionalidad y control de convencionalidad. Comparación. Estudios constitucionales. 10.4067/S0718-52002009000200005. Año 7, N².

HOFFMAN, Stanley. (1961) Théorie et Relations Internationales. Reveu Francaise de Science Politique, vol. II. HOFFMAN, Frank. (2007). Conlfict in the 21th Century: the rise of Hybrid Wars. Potomac Institute for Police Studies. Arlington.

HOFFMANN, Stanley (1991) Liberalismo y Asuntos Internacionales Jano y Minerva Ensayos sobre la Guerra y la Paz. "Liberalismo y Asuntos Internacionales".; Bueno Aires; Gel.

HOPENHAYN, Martín. (2002). Droga y Violencia: fantasmas de la nueva metrópoli latinoamericana. Polis, Revista de la Universidad Bolivariana, Vol. 1, No. 003. Santiago, Chile. 
HOWARD, L. (1987). The Law of non-international armed conflict: Protocol II to the 1949 Geneva convention. Ginebra, Suiza: Martinus Nijhoff Publishers.

HOWLAND, Todd. Representante en Colombia de la Oficina de la Alta Comisionada de las ONU para los DDHH. DIH en las nuevas guerras. El Tiempo, 6 de febrero de 2012. Consultado el 21 de octubre de 2012. www.asuntosdelsur.org/opiniones/opinion/221.

HUMAN RIGTHS WATCH. Informe Mundial 2012. Capítulos de la Región de las Américas.

HURREL, Andrew. Political Regimes and Foreign Policies: An Introduction. s/d/edición.

INFANTE VILLAREAL, Arturo (1995). En TOKATLIAN, Juan Gabriel, y otros. Narcotráfico en Colombia. Dimensiones políticas, económicas, jurídicas e internacionales. Bogotá, TM Editores. Universidad de los Andes, ediciones uniandes.

INFORME DE INTERNATIONAL NARCOTICS CONTROL BOARD. Precursors and Chemicals frequently used in the illicit manufacture of narcotic drugs and psychotropic substances. 19.2.2009.

INFORME FBI. Trends in Resource Utilization on Major Cases. Desclasificado en septiembre de 2003. Hernández, Anabel. (2012).Los señores del narco. Random House Mondadori, México.

INFORME FBI. Criminal Inbvestigative Division \& San Antonio Field Intelligence Group, 15.7.2005.

INFORME HUMAN RIGTH WATCH. En CUBIDES, Fernando (2005). Burocracias Armadas. El Problema de la Organización en el Entramado de las Violencias Colombianas. Bogotá, Grupo editorial Norma.

INTERNATIONAL CRISIS GROUP. (2002), "Colombia: perspectivas de paz con el ELN", Bogotá/Bruselas, Reporte de América Latina, No. 2, 4 de octubre.

JAGUARIBE, Helio (1979). “Autonomía periférica y hegemonía céntrica”. Santiago de Chile, Estudios Internacionales; 46.

JARAMILLO CARO, Sergio. International Review or the red Cross. Diciembre de 2008, No. 872 . En KALSHOVEN, Frits; ZEGVELD, Liesbeth. Restricciones en la Conducción de la Guerra.

JIFE. ORGANIZACIÓN DE NACIODES UNIDAS. (2011). Informe Junta Internacional de Fiscalización de Estupefacientes 2011. Pg. 1.

JIMÉNEZ BAUTISTA, Francisco; Muñoz, Francisco. (2004)- Violencia cultural en López Martínez, Mario. (Dir.). Enciclopedia de paz y conflictos, Granada, Editorial Universidad de Granada y Junta de Andalucía, pp. 1161 y 1162. En HEYCK PUYANA, Caterina. (2011). Derecho internacional; acuerdo humanitario y resolución pacífica del secuestro. Universidad del Rosario. Bogotá - Colombia.

JIMÉNEZ, C. (1998). La calificación y regulación jurídica internacional de las situaciones de violencia interna. Ponencia para el Instituto Hispano-Luso-Americano de Derecho Internacional. XX Congreso 7-12 de septiembre de 1998. Manila, Filipinas.

JUZAGADO 56 PENAL DEL CIRCUITO DE BOGOTÁ. Sentencia condenatoria 1.29.2009. No. 1100131040562008-00016-00 NI 2008-00016.

KAISER, Karl. Trasnational Relations as a Threat to the Democratic Process. En R.O. Keohanes, J. Nye. 
KALDOR, M. (1999). New and Old Wars: Organized Violence in a Global Era, Stanford Univ. Press, Stanford.

KALULAMBI PONGO, Martín. (2003). Perspectivas comparadas de mercados de violencia, Universidad Nacional de Colombia.

KAHN, Paul. (2012). Teología política: cuatro nuevos capítulos sobre el concepto de soberanía. Siglo del hombre editores Universidad de los Andes - Pontificia Universidad Javeriana - Instituto Pensar. Nuevo Pensamiento Jurídico. Bogotá, Colombia.

KALDOR, y otros. En La privatización de las Guerra\$ Paramilitares, "señores de la guerra" y ejércitos privados. Versión para el Cono Sur de América Latina De Das Unternehmen Krieg, Assoziation A, Berlin 2003 Edición boliviana, Febrero 2005.

KALMANOVITZ, Salomón (2004). "Recesión y recuperación de la economía colombiana". Nueva Sociedad; 192.

KALSHOVEN, F. \& ZEGVELD, L. (N.D.). Restricciones en la Conducción de la Guerra.

KAPLAN, Morton. System and process in International politycs. Ithaca, New York, 1957. Citado en Celestino del Arenal. Introducción a las Relaciones Internacionales.

KEOHANE, Robert; NYE, Joseph (1988). "La interdependencia en la política mundial. Poder e Interdependencia”. Buenos Aires, Grupo Editor Latinoamericano.

KLINE, Harvey. Sowing Teeth to the Dragons. Henderson, James. (2012). Víctima de la globalización. La historia de cómo el narcotráfico destruyó la paz en Colombia. Panamericana. Bogotá - Colombia.

KRASNER, Stephen. (1983). International Regimens. Ithaca, N.Y. Morse, Edward. Modernization and the Transformation of international Relations, Nueva York, 1076.

KRASNER, Stephen. (1999). Sovereignty: Organized Hypocrisy. Princenton University Press.

LAIR, Eric (2004). "Colombia una guerra contra los civiles", Revista Colombia Internacional, Centro de Estudios Internacionales de la Universidad de los Andes; 49-50. En CARVAJAL, Leonardo. Violencia, Paz y Política Exterior en Colombia. Bogotá, Universidad Externado de Colombia.

LASAGNA, Marcelo (1995). "Las determinantes internas de la política exterior, un tema descuidado en la teoría política exterior". Chile, Estudios Internacionales - Centro de Redacción.

LEAL BUITRAGO, Francisco. Capítulo: Militares y Paramilitares en Colombia. En Bagley, Bruce; Restrepo, Elvira. (2011). La desmovilización de los paramilitares en Colombia. Entre el escepticismo y la esperanza. Universidad de Miami - Universidad de los Andes Colombia

LEMOINE, Maurice. (2009). Oú intervener et pourquoi?. Le Monde Diplomatique.

LEOGRANDE, William; SHARPE, Kenneth (2004). "Cómo nos va a ir con Bush", Cambio; 194. PARDO, Rodrigo; CARVAJAL, Leonardo. "Relaciones Internacionales, conflicto Domestico y Procesos de Paz en Colombia". En CARVAJAL, Leonardo; LONDOÑO, Patti. (compiladores) Violencia, Paz y Política Exterior en Colombia. Bogotá, Universidad Externado de Colombia - Facultad de Finanzas, Gobierno y Relaciones Internacionales. 
LIJPHART (1971:70). Consultado en PIOVANI, JUAN IGNACIO (b). Relaciones Internacionales, Año 10, N. 20. Pg. 2.

LIZÁRRAGA, Daniel. Contacto en Colombia. Rodríguez Castañeda, Rafael. (2012). El Imperio del Chapo. Ed, Planeta Mexicana. México.

LOOTSTEEN, Yair. (2000). The concept of belligerancy in International Law. Military Law Review, Minessota, LLMM.vol.166, pp. 123,133-141. En Heyck Puyana, Caterina. (2011). Derecho internacional; acuerdo humanitario y resolución pacífica del secuestro. Universidad del Rosario. Bogotá - Colombia.

LOPEZ HERNANDEZ, Claudia. (2011). Conflicto, crimen organizado y procesos de construcción de Estado en Colombia.

LÓPEZ RESTREPO, Andrés (2005). “Conflicto interno y narcotráfico entre 1970 y 2005”. En RANGEL, Alfredo. Narcotráfico en Colombia. Economía y Violencia. Bogotá, Ensayos de Seguridad y Democracia. Fundación Seguridad y Democracia.

LÓPEZ STERUP, Henrik; ÁNGEL, Natalia y otros. (2013). Trasnformaciones en el espacio de la soberanía. Universidad de los Andes, Bogotá - Colombia, pp. 14.

LORENZ, Konrad. (1967). On Agression. N.Y. Bantham.

LOS PARAMILITARES: El fantasma de una nueva guerra asoma sobre México. Consultado el 20.2.2014. S.D.E.

LO-SHU FU, A. (1996). Documnetary Chronicle of Sino - Western Relations, The Association for Asian Studies, Teh University or Arizona Press, Tucson, Vol I.

LOZANO en Bartolozzi, Pedro. (1987). Estructura y Dinámica de las Relaciones Internacionales, Mitre, Barcelona.

LUHMANN, Niklas. (2007). La sociedad de la sociedad. México Herder- Universidad Iberoamericana.

MAHATMA, Gandhi. S.d.e.

MAGHROORI, Ray. (1982). Introduction: Major Debates.

MANGAS, A. (1990). CIJ, Recueil, 1970, citado en: Conflictos armados internos y Derecho Internacional Humanitario. Salamanca, España: Universidad de Salamanca.

MANSILLA. (2008). Academia de Ciencias de Bolivia. Drogas, valores sociales y neoliberalismo: El debate en el área andina a partir de 1990. Universidad Complutense de Madrid. España. Pg. Revista Crítica de Ciencia Sociales.

MATHIEU, Hans; NIÑO GUARNIZO, Catalina. (Editores). Programa de Cooperación en Seguridad Regional. Friedrich Ebert Stiftung. Pg. XXVI.

MARTINEZ ORTIZ, manuela. (2007). Donde nace la violencia. Artículo publicado en la Revista PS, Diario El País, Madrid, España.

McCHESNEY. The global Media. The New Missionaries of Corporate Capitalism Londres/Washington D.C., Casell, 1997 y Our Media, not theirs: The Democratic Struggle Against Corporate Media. New York, Seven Stories Press, 2002. En Ferreira, Leonardo. Capítulo: Se busca: Investigación sobre noticias y violencia en América Latina. Bagley, Bruce; Restrepo, Elvira. (2011). La desmovilización de los paramilitares en Colombia. Entre el escepticismo y la esperanza. Universidad de Miami - Universidad de los Andes Colombia. 
MCDERMOTT,. (2008). Revealed: The secrets of colombia's murderous Castaño Brothers. Daily Telegraph, noviembre 8, 2008. Adams, David. Capítulo: Vínculos entre paramilitares y drogas: antes y después de la desmovilización, pp. 70 . Bagley, Bruce; Restrepo, Elvira. (2011). La desmovilización de los paramilitares en Colombia. Entre el escepticismo y la esperanza. Universidad de Miami - Universidad de los Andes Colombia.

MAQUIVELO, Nicolás. Discurso sobre la Primera Década de Tito Livio.

MEDELLÍN TORRES, Pedro (2005). “De la crisis de la representación a la representación de la crisis en Colombia. Análisis de las alternativas de salida ofrecidas por el Acto Legislativo No. 1 de 2003 y la Ley de Bancadas de 2005". En CARDENAS RIVERA, Miguel Eduardo (coordinador). La reforma política del Estado en Colombia: una salida integral a la crisis. Bogotá, Friederich Ebert Stiftung en Colombia - FESCOL- Fondo Editorial CEREC. Primer edición.

MELO GONZÁLEZ, Jorge Orlando (2002). "Instituciones de Colombia: una historia inconclusa. Revista Credencial Historia". Bogotá, Edición 145; Edición en la biblioteca virtual del Banco de la República de Colombia.

MESA DE CONVERSACIONES (2013). Página oficial Diálogos con las FARC y gobierno Juan Manuel Santos Calderon.

MIGDAL, Joel S. (2011), Estados débiles, Estados fuertes, México, FCE.

MONCAYO, Víctor Manuel (2004). “El Leviatán derrotado. Reflexiones sobre la teoría del Estado y el caso colombiano". ARCHILA NEIRA, Mauricio. Desafíos y perspectivas de los movimientos sociales en Colombia. En CARDENAS RIVERA, Miguel Eduardo (coordinador). La reforma política del Estado en Colombia: una salida integral a la crisis. Bogotá, Friederich Ebert Stiftung en Colombia - FESCOL- Fondo Editorial CEREC. Primer edición.

MURILLO CASTAÑO, Gabriel y otros (1995). “Narcotráfico y Política en la década de los ochenta: entre la represión y el diálogo". En TOKATLIAN, Juan Gabriel, y otros. Narcotráfico en Colombia. Dimensiones políticas, económicas, jurídicas e internacionales. Bogotá, TM Editores. Universidad de los Andes, ediciones uniandes.

MEDELLín TORRES, Pedro (2005). “De la crisis de la representación a la representación de la crisis en Colombia. Análisis de las alternativas de salida ofrecidas por el Acto Legislativo No. 1 de 2003 y la Ley de Bancadas de 2005". En CARDENAS RIVERA, Miguel Eduardo (coordinador). La reforma política del Estado en Colombia: una salida integral a la crisis. Bogotá, Friederich Ebert Stiftung en Colombia - FESCOL- Fondo Editorial CEREC. Primer edición.

MELO GONZÁLEZ, Jorge Orlando (2002). "Instituciones de Colombia: una historia inconclusa. Revista Credencial Historia". Bogotá, Edición 145; Edición en la biblioteca virtual del Banco de la República de Colombia.

MESA DE CONVERSACIONES (2013). Página oficial Diálogos con las FARC y gobierno Juan Manuel Santos Calderon.

MIRON, Jeffrey; Waldock, Katherine. (2010). The Budgeraty Impact of Ending Drug Prohibition. Cato Institute, Washington, D.C. 
MONCAYO, Víctor Manuel (2004). “El Leviatán derrotado. Reflexiones sobre la teoría del Estado y el caso colombiano". ARCHILA NEIRA, Mauricio. Desafíos y perspectivas de los movimientos sociales en Colombia. En CARDENAS RIVERA, Miguel Eduardo (coordinador). La reforma política del Estado en Colombia: una salida integral a la crisis. Bogotá, Friederich Ebert Stiftung en Colombia - FESCOL- Fondo Editorial CEREC. Primer edición.

MONDRAGÓN, Héctor. Plan Colombia: gasolina al fuego. REVISTA ABACO No. 32/33. Un mosaico imperfecto.

MOREANO, Urigüen Hernán (2009). “Frontera Ecuador-Colombia: desarrollo, securitización y vulnerabilidades". En JARAMILLO, Grace (Comp.), Construyendo puentes entre Ecuador y Colombia, OEAFLACSO-PNUD-QUITO.

MUNKLER, Herfried. (2002). Entrevista con Eberhard Sens, Lettre International 14.

MÜNKLER, H. Viejas y nuevas guerras: asimetría y privatización de la violencia, Siglo XXI, Madrid, España.

MUÑOZ ROJAS, Daniel; FRÉSARD, Jean- Jacques. CICREL. Origen del Comportamiento en la Guerra. Comprender y prevenir las violaciones del DIH. Comité Internacional de la Cruz Roja. Los grupos armados no estatales.

MURILLO CASTAÑO, Gabriel y otros (1995). "Narcotráfico y Política en la década de los ochenta: entre la represión y el diálogo". En TOKATLIAN, Juan Gabriel, y otros. Narcotráfico en Colombia. Dimensiones políticas, económicas, jurídicas e internacionales. Bogotá, TM Editores. Universidad de los Andes, ediciones uniandes.

NATIONAL DEFENSE UNIVERITY. Strategic Assesment, 1999. Washington DC, 2000. En Tello

NICHOLSON, Michel. Análisis del conflicto. En ARENAL, Celestino Del. (2010). Introducción a las Relaciones Internacionales. Ed. Tecnos. Cuarta Edición. Septiembre. Madrid, España.

NIÑO GUARNIZO, Catalina. (2011). La seguridad de América Latina: respuestas fragmentadas a desafíos trasnacionales. En Seguridad Regional en América Latina y el Caribe ANUARIO 2011.

NOCHE Y NIEBLA. (2006). Revista Banco de Datos Derechos Humanos, CINEP y Justicia Y Paz, No. 11. En GONZALEZ, Fernán y otros. Violencia Política en Colombia. De la Nación fragmentada a la construcción del Estado. Bogotá, Centro de Investigación y Educación Popular - CINEP.

NIXON, Richard Nixon. Orden Ejecutiva11727, Cumplimiento de la Ley sobre los Estupefacientes, 6 de julio de 1973. GRILLO, loan. (2012). El Narco: en el corazón de la insurgencia criminal mexicana. Editorial Urano, S.A., Barcelona - España.

NOZICK, Robert. (1998). Anarquía, Estado y Utopía, (Trad. Rolando Tamayo), Fondo de Cultura Económica, México, D.F. Anarchy, State and Utopia 74, Basic Books, Inc., Nueva York, EEUU.

OEA (2007). Comunicado de Prensa; “Ecuador presenta en la OEA reclamo a Colombia por fumigaciones de herbicidas en la frontera"; 9 de Enero.

OLAVARRIETA, Sergio. Aspectos metodológicos en la investigación cross-cultural. Escuela de negocios, Universidad de Chile. 
OROZCO, Iván. Capítulo: Derechos humanos, justicia transicional y bandas emergentes. BAGLEY, Bruce; Restrepo, Elvira. (2011). La desmovilización de los paramilitares en Colombia. Entre el escepticismo y la esperanza. Universidad de Miami - Universidad de los Andes Colombia.

PANORAMA ACTUAL DEL PARAMILLO Y SU ENTORNO. Observatorio del Programa Presidencial de Derechos Humanos y DIH, (2005). En CUBIDES, Fernando. Burocracias Armadas. El Problema de la Organización en el Entramado de las Violencias Colombianas. Bogotá; Grupo editorial Norma.

PALACIO SARMIENTO, Eduardo y otros (1995). “Economía del Narcotráfico”. En TOKATLIAN, Juan Gabriel, y otros. Narcotráfico en Colombia. Dimensiones políticas, económicas, jurídicas e internacionales. Bogotá, TM Editores. Universidad de los Andes, ediciones Uniandes.

PALACIOS, Marco (2006). De populistas, mandarines y violencias. Luchas por el poder. Editorial Planeta, Bogotá. GONZÁLEZ, Fernán y otros. Violencia Política en Colombia. De la Nación fragmentada a la construcción del Estado. Bogotá, Centro de Investigación y Educación Popular - CINEP.

PALOMARES LERMA, Gustavo. (2009). Relaciones Internacionales en el Siglo XXI. Ed. Tecnos. Segunda Edición revisada y ampliada. Madrid, España.

PARDO, Rodrigo; CARVAJAL, Leonardo (2004). "Relaciones Internacionales, conflicto Domestico y Procesos de Paz en Colombia”. CARVAJAL, Leonardo; LONDOÑO, Patti. (compiladores) Violencia, Paz y Política Exterior en Colombia. Bogotá, Universidad Externado de Colombia - Facultad de Finanzas, Gobierno y Relaciones Internacionales.

PARDO, Rodrigo; TICKNER, Arlene (2003). “Estados Unidos, Colombia y sus vecinos: los desafíos de la seguridad democrática”. Foreign Affairs en Español.

PEARCE, J. (2005). Policu Failure and Petroleum Depredation: The Economics of civil war Debate Viewed From The Wae Zone, en govermente and opposition: An international journal of comparative politics, No. 2.

PEÑAS, Francisco Javier (1997). “Liberalismo y relaciones internacionales: la tesis de la paz democrática y sus críticos". Universidad Autónoma de Madrid. ISEGORIA/16; 119-140.

PEREIRA, Juan Carlos. (2009). Historia de las relaciones internacionales contemporáneas. Ed. Ariel. Barcelona, España.

PETERS, Ralph. Citado en Kaplan. El Retorno de la Ambigüedad.

PIZARRO LEONGOMEZ, Eduardo (1996) (c). "Insurgencia sin revolución”. La guerrilla en Colombia en una perspectiva comparada, Bogotá, Tercer Mundo Editores - IEPRI.

PIZARRO LEONGOMEZ, Eduardo (2004) (b). “Una luz al final del túnel. Balance estratégico del conflicto armado en Colombia", Nueva Sociedad, 192.

PICTET, J. (1983). Développement et principes du droit international humanitaire. Ginebra, Suiza/París, Francia: Instituto Henry Dunant/Pédone.

PICTET, J. (1958). Geneva Conventions of 12 August 1949. Ginebra, Suiza: Commentary, CICR - Plaza \& Janés Editores Colombia S. A. 
PIOVANI, Luis Ignacio (a). Los Estudios Comparativos: estrategias de investigación empírica en relaciones internacionales. Publicado en RRII, X, 20:97-108. ISSN 1515-3371. Argentina.

PIOVANI, JUAN IGNACIO (b). Acerca del status de la comparación en la Ciencia Política. Esta ponencia se basó parcialmente en el artículo "los estudios comparativos: estrategias de investigación empírica en relaciones internacionales. Relaciones Internacionales, Año 10, N. 20. Argentina.

PIZARRO LEONGOMEZ, Eduardo (a) (2006). Una Democracia Asediada. Balance y Perspectivas del Conflicto Armado. Bogotá, Grupo editorial Norma.

POSSO GONZÁLEZ, Darío. (2002). Armas químicas y biológicas. En Jairo Estrada. El Plan Colombia y la intensificación de la guerra. Universidad Nacional de Colombia. En Henderson, James. (2012). Víctima de la globalización. La historia de cómo el narcotráfico destruyó la paz en Colombia. Panamericana. Bogotá Colombia.

PROTOCOLO ADICIONAL I. (1977).

PROTOCOLO ADICIONAL II. (1977).

PROTOCOLO ADICIONAL III. (2005).

QUINBAYO, Germán. Transnational Institute (TNI). Cultivos de uso ilícito y ecocidio.

QUINCHE RAMÍREZ, Manuel Fernando. (2009). El control de convencionalidad y el sistema colombiano. Revista Iberoamericana de Derecho Procesal Constitucional. 163 núm. 12, julio-diciembre.

RAE, 22a ed., 2001. GRILLO, loan. (2012). El Narco: en el corazón de la insurgencia criminal mexicana. Editorial Urano, S.A., Barcelona - España.

RAMÍREZ VUELVAS, Carlos. (2011). Mexican Drugs. Cultura popular y narcotráfico. Ediciones Lengua de Trapo SL, Madrid - España.

RANGEL, Alfredo (2005). Narcotráfico en Colombia. Economía y Violencia. Bogotá, Ensayos de Seguridad y Democracia. Fundación Seguridad y Democracia.

RANGEL, Alfredo (2006), "Parasites and Predators. Guerrillas and the Insurrection Economy of Colombia", Journal of International Affairs, Vol. 53, No. 2. En PIZARRO LEONGOMEZ, Eduardo (a). Una Democracia Asediada. Balance y Perspectivas del Conflicto Armado. Bogotá, Grupo editorial Norma. Colombia.

RAPOPORT, Anatol. En Buckeley, W. Modern System Research for the behavioral Scientists, Chicago, 1968, p. XVII. En ARENAL

RAVELO, Ricardo. El ganón. Rodríguez Castañeda, Rafael. (2012). El Imperio del Chapo. Ed, Planeta Mexicana. México.

RESTREPO, Luís Alberto (2004). “La difícil recomposición de Colombia”, Nueva Sociedad, 192.

REVISTA JUSTICIA Y PAZ. (2006), vol. 8, N. 3. En GONZÁLEZ, Fernán y otros. Violencia Política en Colombia. De la Nación fragmentada a la construcción del Estado. Bogotá, Centro de Investigación y Educación Popular - CINEP. 
REY CANTOR, Ernesto. (2008). Control de Convencionalidad de las Leyes y Derechos Humanos. México, Editorial Porrúa.

REYES, Gerardo (2002). "Washington impaciente con el proceso de paz", en El Nuevo Herald, Miami. En Revista Cambio; 17. En PIZARRO LEONGOMEZ, Eduardo (a). Una Democracia Asediada. Balance y Perspectivas del Conflicto Armado. Bogotá, Grupo editorial Norma.

RICHMOND, Oliver P. (2012). La paz en las Relaciones Internacionales”. Ed, Bellaterra. Barcelona, España.

RISSE, Thomas (1995). "Avances en el estudio de las Relaciones Transnacionales y la Política Mundial". Revisión y ampliación de "Bringing Transnational Relations Back in: Introduction" y "Structures of Governance and Transnational Relations: What Have We Learned?”. En Risse (comp.), Bringing Transnational Relations Back in: Non-State Actors, Domestic Structures and International Institutions, Cambridge.

RIVAS, José Antonio. (2003) “El neoinstitucionalismo y la revalorización de las instituciones". Bogotá, Reflexión Política IEP - UNAB; 9.

ROCHA GARCIA, Ricardo (2005). “Sobre las magnitudes del Narcotráfico".En RANGEL, Alfredo. Bogotá, Narcotráfico en Colombia. Economía y Violencia. Ensayos de Seguridad y Democracia. Fundación Seguridad y Democracia.

RODGERS, Dennis. International Review of the red Cross. Junio de 2010, No. 878.

RODHES (2003). En RIVAS, José Antonio. "El neoinstitucionalismo y la revalorización de las instituciones". Bogotá, Reflexión Política IEP - UNAB; 9.

RODRÍGUEZ CASTAÑEDA, Rafael. (2012). El Imperio del Chapo. Ed, Planeta Mexicana. México.

RODRIGUEZ, Roberto A (1985). “¿Qué fue la operación Marquetalia-Día D, mayo 28 de 1964?”. En: ACORE. Órgano de Divulgación de la Asociación Colombiana de Oficiales en Retiro de las FFMM., No. 333.

ROJAS, Diana Marcela (2007). “Plan Colombia II: ¿Más de lo mismo?”. Bogotá, Colombia Internacional, No 065. Universidad de los Andes.

ROJAS ARAVENA, Francisco. (2010). América Latina y el Caribe: avances retóricos sin acuerdos vinculantes. Atlas Comparativo de la Defensa en América Latina y Caribe. Edición 2010. RESDAL.

ROMERO VILDAL, Mauricio. (2011). La economía de los paramilitares: redes de corrupción, negocios y política. Debate, Bogotá - Colombiana.

ROMERO, (2006). “Identidades políticas, intervención estatal y paramilitares: el caso del Departamento de Córdoba”. En GONZÁLEZ, Fernán y otros. Violencia Política en Colombia. De la Nación fragmentada a la construcción del Estado. Bogotá, Centro de Investigación y Educación Popular - CINEP.

ROSSI, Adriana. (2009). Radiografía del narcotráfico. Le Monde Diplomatique Nro. 118, Buenos Aires, Argentina.

ROUSSEAU, C. (1969). Derecho Internacional Público. Barcelona, España: Ariel. 
ROSENAU, James. The Scientific Study of Foreing Policy, Nueva York, 1971. P. 325. En ARENAL, Celestino Del. (2010). Introducción a las Relaciones Internacionales. Ed. Tecnos. Cuarta Edición. Septiembre. Madrid, España.

ROVIRA KALTWASSER, Cristóbal (2005). Nuevas y viejas guerras: asimetría y privatización de la violencia”. Herfried Münkler. Madrid: Siglo XXI Editores.

ROZENTAL, Manuel. El despojo y la defensa de la vida, desde México hasta Colombia. s.d.e.

SAMBANIS, Nicholas. (2004). Usign Case Studies to expand economic models of civil war, en Perspectives on Politics, Vol. 2. No. 2, junio, pp. 250-279. Romero Vidal, Mauricio. (2011). La economía de los paramilitares: redes de corrupción, negocios y política. Debate, Bogotá - Colombia.

SANCHEZ, Gonzalo (2006). "Violencia, guerrillas y estructuras agrarias" y "La Violencia: de Rojas al Frente Nacional", en: Nueva Historia de Colombia, Ed. Planeta Colombiana, Bogotá. Y "Raíces históricas de la amnistía o las etapas de la guerra en Colombia", Ensayos de historia social y política del siglo XX, el Ancora Editores, Bogotá. En GONZÁLEZ, Fernán y otros. Violencia Política en Colombia. De la Nación fragmentada a la construcción del Estado. Bogotá, Centro de Investigación y Educación Popular - CINEP.

SANDERS, James (2007). "Pertenecer a la gran familia granadina. Lucha Partidista y construcción de la identidad indígena. Política en el Cauca, Colombia 1849-1890”. Bogotá, Revista de Estudios sociales; 26. Traducido por Claudia Leal y Sandra Caicedo.

SAIN, Marcelo Fabián. (2010). Tendencias del crimen organizado en América Latina y el Caribe. Ibídem, Anuario 2010. MATHIEU, Hans y; NIÑO GUARNIZO, Catalina. (Editores).

SALAZAR, Ana María. (2002). Seguridad Nacional hoy. El reto de las democracias. Ed, Aguilar - Nuevo Siglo. México. En ZERAOUI, Zidane. (2011). Los Procesos mundiales contemporáneos: un mundo transformado. Ed, Trillas. México. Reimpresión.

SANTOS, Boaventura de Sousa. (1998). La globalización del derecho. Los nuevos caminos de la regulación y la emancipación. Bogotá: Universidad Nacional de Colombia e Instituto Latinoamericano de Servicios Legales Alternativos-ILSA.

SCELLE. Desdoblamiento funcional. (2006). Reflexión que surge luego de la revisión del material de estudio de la maestría en Relaciones Internacionales en el Instituto de Relaciones Internacionales (IRI) - Universidad Nacional de la Plata. Apuntes del Dr. Profesor CONSANI, Norberto.

SCHULTZE-KRAFT, Markus. (2010). Actualización y ampliación de los mapeos sobre el crimen organizado en Colombia y la región andina. En Seguridad Regional en América Latina y el Caribe Anuario 2010. MATHIEU, Hans y; NIÑO GUARNIZO, Catalina. (Editores). Programa de Cooperación en Seguridad Regional. Friedrich Ebert Stiftung.

SCHULZ, William. En ZERAOUI, ZERAOUI, Zidane. (2011). Los Procesos mundiales contemporáneos: un mundo transformado. Ed, Trillas. México. Reimpresión.

SENTENCIA. C-1064 de 2001, MM.PP. Manuel José Cepeda Espinosa y Jaime Córdoba Triviño (S.V., Magistrados Jaime Araujo Rentería, Alfredo Beltrán Sierra, Rodrigo Escobar Gil y Clara Inés Vargas).

SERRANO, Alfredo. (2010). La multinacional del crimen. La tenebrosa Oficina de Envigado. Debate, Random House Mondadori. Bogotá - Colombia. 
SILVA MICHELENA, JOSE A. (1987). Política y bloques de poder. Crisis en el sistema mundial, 7ạ.ed., Sglo XXI, México. ZERAOUI, Zidane. (2011). La Guerra Fría y los bloques de poder. Los Procesos mundiales contemporáneos: un mundo transformado. Ed, Trillas. México. Reimpresión.

SINGER, Peter. (2007). La Privatización de la Guerra. Archivos del Presente, No. 38. Buenos Aires.

SMITH, Anthony. (1976). Las Teorías del nacionalismo. Ed, Península. Barcelona.

SPOERRI, Philip. Los Convenios de Ginebra de 1949: orígenes y pertinencia actual. Artículo 3 Soft o Hard Law; lus Cogens o Pacta Sunt Servanda.

SWINARSKI, C. (1984). Introducción al Derecho Internacional Humanitario. CICR.

SOSSAI, Mirko (2007). "The international conflict in Colombia and the fight against terrorism".

SUENDORF (2001), DUYNE/LEVI (2005). FERNANDEZ STENKO, Armando. (2008). Las falsas pistas del crimen organizado. Finanzas paralelas y orden internacional. Catarata, Madrid, España.

TÉLLEZ, E; LESMES, J. (2006). Pacto en la sombra. Los tratos secretos de Estados Unidos con el narcotráfico, Bogotá. Planeta. Thoumi, Francisco. Capítulo: Paramilitares, crimen organizado y tráfico de drogas, pp. 308. Bagley, Bruce; Restrepo, Elvira. (2011). La desmovilización de los paramilitares en Colombia. Entre el escepticismo y la esperanza. Universidad de Miami - Universidad de los Andes Colombia.

TELLO, Ángel. (2004). Conferencia "La globalización y la seguridad internacional” Círculo de Legisladores de la Nación Argentina 29.07.2004.

TELLO, Ángel Pablo. (2010). La teoría de las Relaciones Internacionales desde un punto de vista políticopolemológico.

THE ECONOMIST. (1995). Democracy and War. Londres.

THE END OF THE BUSH REVOLUTION. (2006). Foreign Affairs, July/August. Colombia.

THE NEW YORK TIMES (2004). “Plan, but No Clear Objective. General Powell to Secretary Powell: We Need to Talk Colombia". PARDO, Rodrigo; CARVAJAL, Leonardo. "Relaciones Internacionales, conflicto Domestico y Procesos de Paz en Colombia". En CARVAJAL, Leonardo; LONDOÑO, Patti. (compiladores) Violencia, Paz y Política Exterior en Colombia. Bogotá, Universidad Externado de Colombia - Facultad de Finanzas, Gobierno y Relaciones Internacionales. Colección Pre Textos Bogotá.

THE USA AND COLOMBIA: The Journey form Ambiguity to strategic Clarity, Strategic Studies Institute, Carlisle (2003). En PIZARRO LEONGOMEZ, Eduardo (s). Una Democracia Asediada. Balance y Perspectivas del Conflicto Armado. Bogotá, Grupo editorial Norma.

THENON, Eduardo. Teoría de la Ciencia y Formación Universitaria. (14).

TICKNER, Arlene. "Intervención por invitación. Claves de la Política Exterior Colombiana y de sus debilidades principales”. Bogotá, Colombia Internacional, enero-junio, No. 065. Universidad de los Andes.

TOKATLIAN Juan Gabriel (1995). “La Política Exterior de Colombia hacia Estados Unidos 1978-1990: el asunto de las drogas y su lugar en las relaciones entre Bogotá y Washington”. En TOKATLIAN, Juan Gabriel, y otros. 
Narcotráfico en Colombia. Dimensiones políticas, económicas, jurídicas e internacionales. Bogotá, TM Editores. Universidad de los Andes, ediciones Uniandes.

TOKATLIAN, Juan Gabriel, y otros (1995). Narcotráfico en Colombia. Dimensiones políticas, económicas, jurídicas e internacionales. Bogotá, TM Editores. Universidad de los Andes, ediciones Uniandes.

THOUMI, Francisco. Capítulo: Paramilitares, crimen organizado y tráfico de drogas. Bagley, Bruce; Restrepo, Elvira. (2011). La desmovilización de los paramilitares en Colombia. Entre el escepticismo y la esperanza. Universidad de Miami - Universidad de los Andes Colombia.

THÜRER, D. (1999). The Failed State and International Law. RICR, 81(836).

TOMUSCHAT, C. (2003). Human Rights between Idealism and Realism. Oxford: Academy of European Law of the European Universityg Institute / Oxford University Press. Extraído de Salomon, Elizabeth.

TORRALBA, Silvia (2006). Redacción (07/02). s/d/e.

TRATADO DE LA UNIÓN EUROPEA. 1992.

TRIBUNAL SUPERIOR DE BOGOTÁ. Sala de Justicia y Paz. Sentencia 3.19.2009. No. 11001600253200680526.

TRUYOL, Antonio. (1973). La Teoría de las relaciones internacionales como sociología. 2a. Ed. Revisada y aumentada, reimpresión con una bibliografía adicional. Madrid.

UNDOC. (2012). Transnational Organized Crime -The Globalized Illegal Economy

UNGAR, Elizabeth; CARDONA, Juan Felipe. (2006). En LEAL BUITRAGO, Francisco. En la Encrucijada. Colombia en el siglo XXI. Bogotá: CESO, Grupo Editorial Norma.

US. Congress Office of Technology Assessment, 1990, Report Num. OTA 4-4 418. Consultado el 20.2.2014.

UESSELER, Rolf. (2007). La Guerra como Negocio. Norma, Bogotá, 2007.

VARGAS MEZA, Ricardo (2004). "Drogas, conflicto armado y seguridad global en Colombia", Nueva Sociedad, 192.

VARGAS MEZA, Ricardo (2005). “Cultivos Ilícitos en Colombia: elementos para un balance”. RANGEL, Alfredo. Narcotráfico en Colombia. Economía y Violencia. Bogotá, Ensayos de Seguridad y Democracia. Fundación Seguridad y Democracia.

VARGAS VELÁSQUEZ, Alejo (2004). “El gobierno de Álvaro Uribe: proyecto y resultado. Políticas, estrategias y doctrinas", Nueva Sociedad, 192.

VARGAS VELÁSQUEZ, Alejo (2005). En CARDENAS RIVERA, Miguel Eduardo (coordinador). La reforma política del Estado en Colombia: una salida integral a la crisis. Bogotá, Friederich Ebert Stiftung en Colombia FESCOL- Fondo Editorial CEREC. Primer edición.

VARGAS VELÁSQUEZ, Alejo (2005). “¿Qué tan profunda es la reforma del régimen político colombiano?”. En CARDENAS RIVERA, Miguel Eduardo (coordinador). La reforma política del Estado en Colombia: una salida integral a la crisis. Bogotá, Friederich Ebert Stiftung en Colombia - FESCOL- Fondo Editorial CEREC. Primer edición. 
VELEZ, María Alejandra (2006). "FARC-ELN. Evolución y expansión territorial”, Tesis de Pregrado en Economía. Universidad de los Andes, Bogotá. PIZARRO LEONGOMEZ, Eduardo (a). Una Democracia Asediada. Balance y Perspectivas del Conflicto Armado. Grupo editorial Norma.

VERRY, P. (1998). Diccionario de Derecho Internacional de los conflictos armados. Bogotá, Colombia: Tercer Mundo Editores.

VIGNAL, Renaud; PARDO, Rodrigo; CARVAJAL, Leonardo. (2004) "Relaciones Internacionales, conflicto Domestico y Procesos de Paz en Colombia". En CARVAJAL, Leonardo; LONDOÑO, Patti. (compiladores) Violencia, Paz y Política Exterior en Colombia. Bogotá, Universidad Externado de Colombia - Facultad de Finanzas, Gobierno y Relaciones Internacionales.

WALTZ, Kenneth. (1979). Theory of International Politics. Random House. New York, Estados Unidos.

WOLA. Washington Office On Latin America. Sistemas Sobrecargados. Leyes de Drogas y Cárceles en América Latina. Trasnational Institute.

WOLFGANG, Ernst. (2000). Estudios sobre Estado de Derecho y democracia, Ed. Trotta, Madrid, España.

YOUNGERS, Coletta y ROCIN, Eileen. (2005) Drugs and Democracy in Latin America: The Impact of U.S. Policy. Boulder: Lynne Rienner Publishers.

ZELIK, Raul. (1999) Ursachen der Gewalt, in: Zelik, R. / Azzellini, D.: Kolumbien- Große Geschäfte, staatlicher Terror und Aufstandsbewegung.

ZERAOUI, Zidane. (2011). Los Procesos mundiales contemporáneos: un mundo transformado. Ed, Trillas. México. Reimpresión.

\section{REFERENCIAS ELECTRÓNICAS}

conventions/overview-geneva-conventions.htm

www.elheraldo.co/judicial/policia-anuncia-14-capturas-por-narcotrafico-en-el-caribe-156322. Consultado el 22.6.2014.

www.granma.cu/mundo/2014-04-15/el-caribe-en-el-mar-del-narcotrafico. Habana. Consultado el 22.6.2014

www.laopinion.com/noticiaslatinoamerica/article/20131105/Aumenta-el-narcotrafico-en-el-Caribe.

Consultado el 22.6.2014.

www.elcoloquiodelosperros.com/coloqterror/terrorintrod.htm.

derechoshumanos-unab.blogspot.com/2012/05/el-control-de-convencionalidad-derecho.html.

www.oas.org/es/cidh/mandato/Basicos/intro.asp.

www.elespectador.com/noticias/judicial/articulo-321684. 18.1.2012.

http://cejil.org/amicus-curiae.

http://www.corteidh.or.cr/docs/casos/Artículos/seriec_134_esp.doc

http://m.eltiempo.com/justicia/fiscalia-denuncia-falsos-muertos-en-masacre-demapiripan/10636224/1/home.

www.restauracionacional.org/?cat $=282$

www.colectivodeabogados.org/CCAJAR-Comunicado-a-la-opinion 1.11. 2011.

www.semana.com/nacion/mapiripan-dudas-certezas-masacre/174190-3.aspx

www.semana.com/nacion/mapiripan-ahora-victimas-debemos-estado-culpables-masacre/167978-3.aspx

www.uscateguiesinocente.com

http://www.geocities.com/cajaeditora/News/Hobsbawn_01.txt.

www.ambitojuridico.com/BancoConocimiento/N/noti11112105

http://lema.rae.es. Consultado el 11.8.2013. 


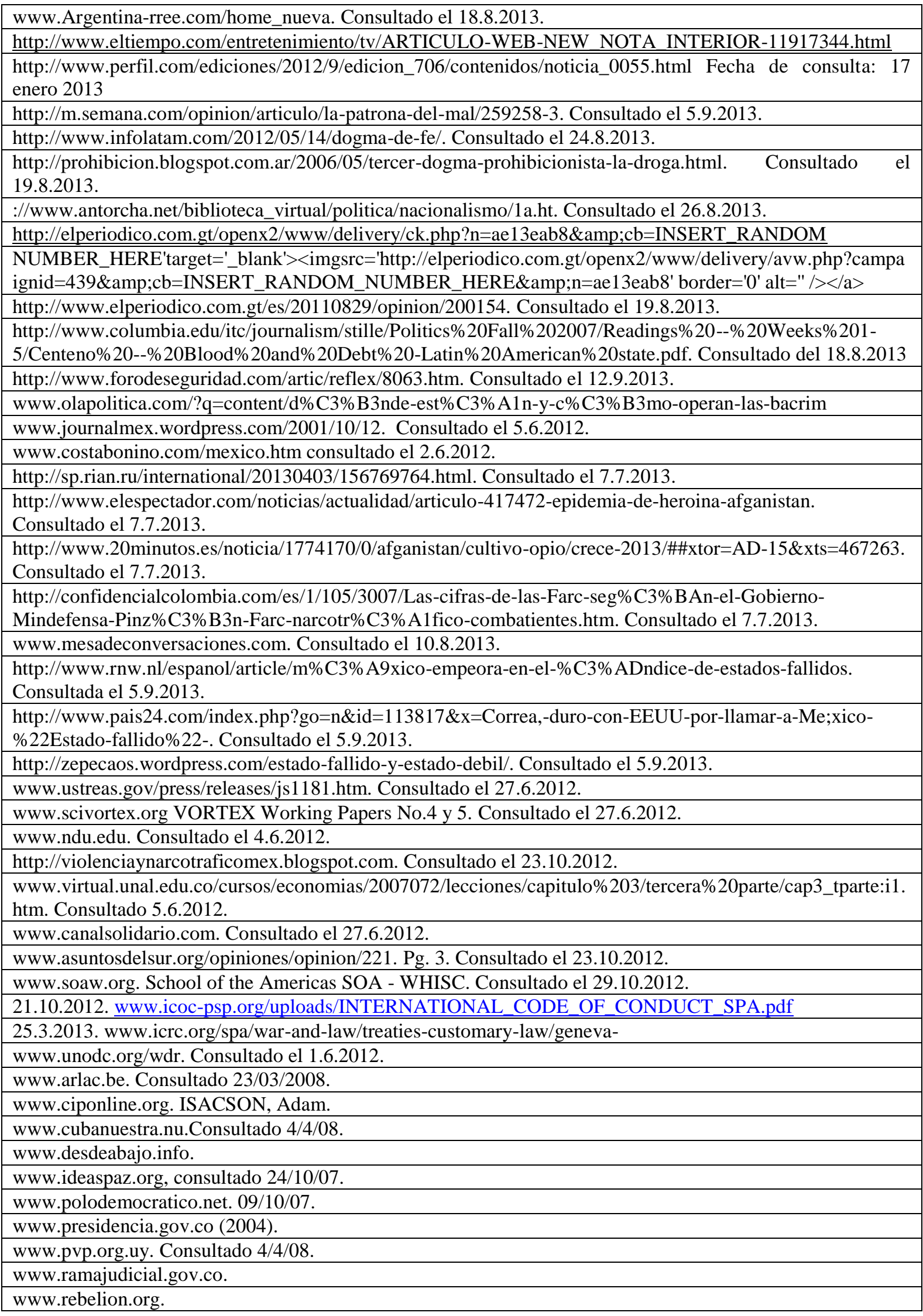


www.revista-abaco.com. MONDRAGÓN, Héctor. Plan Colombia: gasolina al fuego. REVISTA ABACO No. 32/33. Un mosaico imperfecto.

www.revistaquorum.es. CELI, Pablo. El área andina: entre la geopolítica regional y las vicisitudes nacionales. www.usinfo.state.gov. Consultado 4/4/08.

www.visionesalternativas.com. Consultado 11/11/07.

http://colombiadrogas.wordpress.com/2008/05/27/\%c2\%bfla-responsabilidad-de-quien/\#more-58. Consultado 9.2.2014.

http://www.biodiversidadla.org/Principal/Secciones/Noticias/Suspension_de_fondos_a_la_Iniciativa_Merida_ salvara_vidas. Consultado el 20.2.2014.

http://desinformemonos.org/2013/10/el-despojo-y-la-defensa-de-la-vida-desde-mexico-hasta-colombia/.

Consultado el 20.2.2014.

http://www6.rel-uita.org/old/home/plan\%20colombia/inconsistencias.htm. Consultado el 20.2.2014.

http://prensarural.org/spip/spip.php?article10116. Consultado el 20.2.2014.

www.google.com.mx/url?sa=t\&rct=j\&q=\&esrc=s\&source=web\&cd=9\&ved=0CFYQFjAI\&url=http $\% 3 \mathrm{~A} \% 2$

F\%2Fclasarchive.berkeley.edu $\% 2 \mathrm{FEvents} \% 2 \mathrm{Fconferences} \% 2 \mathrm{FColombia} \% 2 \mathrm{Fworkingpapers} \% 2 \mathrm{Fworking}$ _pa per_tokatlian.doc\&ei=HG4GUeH8jc2QWgqoDoBA\&usg=AFQjCNEQmGWbw2z0oGr5Sb1Sw_bUECWXj

g. Consultado el 20.2.2014.

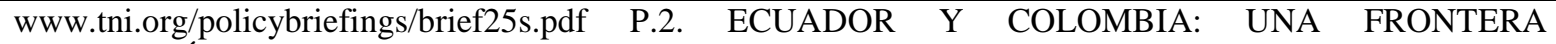
PROBLEMÁTICA. Consultado el 20.2.2014.

www.caata.org/impactos_en_el_aire_por_plaguicidas.html. Consultado el 20.2.2014.

www.lanacion.com.ar/1656676-el-fantasma-de-una-nueva-guerra-asoma-sobre-mexico.14.2.2014

www.mmrree.gov.ec. Consultado el 20.2.2014.

www.ecuadorinmediato.com/noticias/100437. Consultado el 20.2.2014.

www.elnuevoherald.com/2014/01/23/1662928/eeuu-debe-apoyar-un-plan-colombia.html\#storylink=cpy.

Consultado el 18.2.104.

www.hrw.org/sites/default/files/reports/wr2014sp_web.pdf. Consultado el 16-2-2014.

www.comminit.com Consultado el 4 de febrero de 2010.

lmagin «lCommunilits.\&jkctionstheOriginPublicadoporVERSO,LondresyNuevaYorkISBN0860915468cultura LibreD.R.e1993,FONDODECULTURAECONÓMICA,S.A.V.CarreteraPicachoAjusco227;14200México,D.F .ISBN968-16-3867-0ImpresoenMéxico

www.usergioarboleda.edu.co/civilizar. Londres, 9 de mayo de 1998. Consultado el 5.9.2013.

conventions/overview-geneva-conventions.htm

www.Argentina-rree.com/home_nueva. Consultado el 18.8.2013.

http://www.eltiempo.com/entretenimiento/tv/ARTICULO-WEB-NEW_NOTA_INTERIOR-11917344.htm

http://www.perfil.com/ediciones/2012/9/edicion_706/contenidos/noticia_0055.html Fecha de consulta: 17 enero http://www.infolatam.com/2012/05/14/dogma-de-fe/

http://elperiodico.com.gt/openx2/www/delivery/ck.php?n=ae13eab8\&amp;cb=INSERT_RANDOM_NUMB

ER_HERE'target='_blank'><imgsrc='http://elperiodico.com.gt/openx2/www/delivery/avw.php?campaignid=4 39\&amp;cb=INSERT_RANDOM_NUMBER_HERE\&amp;n=ae13eab8' border='0' alt=" / $></ \mathrm{a}\rangle$

http://www.elperiodico.com.gt/es/20110829/opinion/200154. Consultado el 19.8.2013.

http://prohibicion.blogspot.com.ar/2006/05/tercer-dogma-prohibicionista-la-droga.html. Consultado el 19.8.2013.

http://www.letraslibres.com/revista/convivio/identidad-politica-y-politica-de-identidades. Consultado el 25.8.2013.Índice de Nacionalismo y cultura de Rudolf Rocker

http://www.antorcha.net/biblioteca_virtual/politica/nacionalismo/1a.ht. Consultado el 26.8.2013.

http://www.elheraldo.co/judicial/policia-anuncia-14-capturas-por-narcotrafico-en-el-caribe-156322.

Consultado el 22.6.2014.

http://www.granma.cu/mundo/2014-04-15/el-caribe-en-el-mar-del-narcotrafico. Habana. Consultado el 22.6.2014

http://www.laopinion.com/noticiaslatinoamerica/article/20131105/Aumenta-el-narcotrafico-en-el-Caribe.

Consultado el 22.6.2014

http://www.columbia.edu/itc/journalism/stille/Politics\%20Fall\%202007/Readings\%20--\%20Weeks\%201-

5/Centeno\%20--\%20Blood\%20and\%20Debt\%20-Latin\%20American\%20state.pdf. Consultado del 18.8.2013

www.unodc.org/wdr. Consultado el 1.6.2012.Pg 57 y 58. 
http://www.elespectador.com/noticias/actualidad/articulo-417472-epidemia-de-heroina-afganistan.

Consultado del 7.7.2013.

http://www.20minutos.es/noticia/1774170/0/afganistan/cultivo-opio/crece-2013/\#\#xtor=AD-15\&xts=467263.

Consultado el 7.7.2013.

Noticias RCN Internacional Colombia. 6.12.2012.

www.mesadeconversaciones.com

http://confidencialcolombia.com/es/1/105/3007/Las-cifras-de-las-Farc-seg\%C3\%BAn-el-Gobierno-

Mindefensa-Pinz\%C3\%B3n-Farc-narcotr\%C3\%A1fico-combatientes.htm

http://www.youtube.com/watch?v=HnT12T9RsA0

http://www.olapolitica.com/?q=content/d\%C3\%B3nde-est\%C3\%A1n-y-c\%C3\%B3. Consulato el 12.12.12.

www.costabonino.com/mexico.htm consultado el 2.6.2012.

www.journalmex.wordpress.com/2001/10/12. Consultado el 5.6.2012.

http://zepecaos.wordpress.com/estado-fallido-y-estado-debil/.

http://www.pais24.com/index.php?go=n\&id=113817\&x=Correa,-duro-con-EEUU-por-llamar-a-

Me;xico-\%22Estado-fallido\%22-|. Consultado el 5.9.2013.

http://www.rnw.nl/espanol/article/m\%C3\%A9xico-empeora-en-el-\%C3\%ADndice-de-estados-fallidos.

Consultada el 5.9.2013.

http://www.caata.org/impactos_en_el_aire_por_plaguicidas.html. Consultado el 20.2.2014.

http://www.elespectador.com/noticias/judicial/condenan-30-anos-de-carcel-alias-rasguno-articulo-461829.

Consultado el 10.6.2014.

www.mmrree.gov.ec. Consultado el 20.2.2014

www.uam.es.

www.revistaquorum.es

http://www.hrw.org/sites/default/files/reports/wr2014sp_web.pdf. Consultado el 16-2-2014.

www.worldbank.org/research/conflict/index, abril, 1999, p. 15.

www.colombiainternacional.uniandes.edu.co/view.php/202/view.php.

http://www.hrw.org/sites/default/files/reports/wr2014sp_web.pdf. Consultado el 16-2-2014.

www.corteidh.or.cr/tablas/r25212.pdf 